\title{
AS OPINIÕES, INTERESSES E ATITUDES DOS JOVENS BRASILEIROS FRENTE À CIÊNCIA: UMA AVALIAÇÃO EM ÂMBITO NACIONAL
}

\author{
Tese apresentada a Faculdade de Educação da \\ Universidade de São Paulo para obtenção do título \\ de Doutora em Educação
}

Área de concentração: Ensino de Ciências e Matemática

Orientador: Prof. Dr. Nelio Marco Vincenzo Bizzo

Versão Revisada

São Paulo

2013 
Autorizo a reprodução e divulgação total ou parcial deste trabalho, por qualquer meio convencional ou eletrônico, para fins de estudo e pesquisa, desde que citada a fonte.

Catalogação na Publicação

Serviço de Biblioteca e Documentação

Faculdade de Educação da Universidade de São Paulo

373.2 Santos Gouw, Ana Maria

S237o As opiniões, interesses e atitudes dos jovens brasileiros frente à ciência : uma avaliação em âmbito nacional / Ana Maria Santos Gouw ; orientação Nélio Marco Vincenzo Bizzo. São Paulo : s.n., 2013.

242 p. : il., grafs. tabs

Tese (Doutorado - Programa de Pós-Graduação em Educação. Área de Concentração : Ensino de Ciência e Matemática) - Faculdade de Educação da Universidade de São Paulo)

1. Ciências - Estudo e ensino 2. Pesquisa educacional 3. Jovens Percepção - Educação 4. Avaliação da educação I. Bizzo,Nélio Marco Vincenzo Bizzo, orient. 


\section{FOLHA DE APROVAÇÃO}

Nome: SANTOS GOUW, Ana Maria.

Título: As opiniões, interesses e atitudes dos jovens brasileiros frente à ciência: uma avaliação em âmbito nacional

Tese apresentada a Faculdade de Educação da Universidade de São Paulo para obtenção do título de Doutora em Educação

Área de concentração: Ensino de Ciências e Matemática

Aprovada em:

\section{Banca Examinadora}

Prof. Dr.

Instituição: Assinatura:

Prof. Dr.

Instituição: Assinatura:

Prof. Dr.

Instituição: Assinatura:

Prof. Dr.

Instituição: Assinatura:

Prof. Dr.

Instituição: Assinatura: 

Para Andre que tem compartilhado comigo todos os desafios e para Theo nossa maior recompensa 



\section{AGRADECIMENTOS}

Ao prof. Dr. Nelio Marco Vincenzo Bizzo, por ter me apoiado e orientado nesta grande empreitada. Obrigada pela oportunidade e constante apoio em todos os momentos desta pesquisa, se fazendo presente mesmo a milhares de quilômetros de distância. Obrigada acima de tudo por ter me acolhido no momento mais importante, a maternidade. Muito obrigada.

A colega Helenadja Mota Rios Pereira, parceira na pesquisa, que esteve ao meu lado durante todos os momentos, vibrando a cada pequena conquista e procurando soluções para os impasses que surgiram ao longo do percurso. Obrigada por oferecer apoio incondicional em todas as fases do trabalho.

A profa. Dra. Maria Elice Brzezinski Prestes e profa. Dra. Valéria Arantes Amorim, pelas valiosas contribuições oferecidas durante o exame de qualificação e pela sinalização de caminhos possíveis.

Ao prof. Dr. Svein Sjøberg, da Universidade de Oslo (Department of Teacher Education and School Development), coordenador geral do projeto ROSE, pelo apoio na aplicação do projeto ROSE no Brasil.

Ao colega prof. Dr. Luiz Caldeira Brant de Tolentino Neto, pioneiro na aplicação do projeto ROSE no Brasil, por ter oferecido apoio e diversos materiais necessários para a realização desta pesquisa.

A Mariana Antonieta Barreto do Prado, Pedro Henrique de Mattos Kurtz, Felipe Simões e Carolina Canton Maciel, então alunos de iniciação científica, que auxiliaram na coleta de dados e no contato com as escolas. Muito obrigada.

Aos colegas participantes do GONB, em especial Paulo Henrique Nico Monteiro, Paulo Sérgio Garcia, Fernanda Franzolin, Flávio Rocca, Acácio Pagan, Graciela S. Oliveira e Jaqueline Pinafo, pelo constante apoio e pelas diversas contribuições dadas nos momentos de discussão do trabalho.

A Faculdade de Educação da Universidade de São Paulo (FEUSP), por ter oferecido apoio financeiro e institucional para a execução da pesquisa, nas pessoas das então diretoras da instituição, Ilma. Sra. Profa. Dra. Sonia Teresinha de Sousa Penin e Ilma. Sra. Profa. Dra. Lisete Regina Gomes Arelaro.

Aos funcionários da Faculdade de Educação da Universidade de São Paulo, em especial 
do Departamento de Metodologia de Ensino, Edmilson Sousa Santos, Leonardo Pudelko e Marcela Gladys Rodriguez, que muito auxiliaram na execução da pesquisa.

Aos também funcionários da Faculdade de Educação da Universidade de São Paulo, Almir Silva Dias, responsável pela seção de protocolo, que muito auxiliou no envio e recepção das remessas de questionários para as escolas pesquisadas e Léia Mota Tácito, pela ajuda oferecida em diversos momentos da pesquisa.

A Sheyla Carvalho Lira, gerente do Programa Internacional de Avaliação de Alunos (PISA) no Brasil - Instituto Nacional de Estudos e Pesquisas Educacionais "Anísio Teixeira" (INEP), Diretoria de Avaliação para Certificação de Competências (DACC), por ter fornecido informações acerca da implementação do PISA no Brasil.

A todos os professores, funcionários, coordenadores e diretores das escolas participantes da pesquisa. Muito obrigada.

A PICSIS Informática, empresa responsável pela impressão e leitura dos questionários, nas pessoas de Ricardo Sabbag, Marcelo Yamaguishi, Leandro Leoratti e Sebastião Soares.

A Patrícia Vianna da Silva, estatística que auxiliou na primeira fase da pesquisa, na discussão das questões referentes ao planejamento da coleta de dados, e na fase final, tirando dúvidas sobre alguns resultados.

A Cecília Goi Porto Alves, estatística que nos auxiliou no estudo da amostragem, fornecendo valiosas contribuições para que a pesquisa pudesse ser representativa do Brasil.

A empresa Estanislao Consultoria em Estatística e Treinamento, nas pessoas de Marcus Vinicius Estanislao e Lucas Fahham, pelas valiosas contribuições oferecidas para a discussão dos resultados.

A meu irmão Daniel Pereira dos Santos, por ter tornado a tese mais bonita, através da realização da diagramação e da produção gráfica. Muito obrigada.

A Profa. Dra. Maria Elena Infante-Malachias, pelo apoio sempre presente, pela introdução ao universo da Biologia do Conhecimento de Humberto Maturana e pela contribuição na tradução de textos de Maturana. Muito obrigada.

A Profa. Dra. Marcela Elena Fejes, pelo apoio que sempre demonstrou ao longo de todo o percurso do doutorado, muito obrigada.

A querida Monique Sian Gouw, pela ajuda oferecida em diversos momentos da pesquisa, em especial pela leitura atenta dos primeiros manuscritos e a Rafael Machado Brilha, por ter me 
socorrido em diversos momentos ao longo do trabalho.

A profa. Dra. Rosangela Calado da Costa, pelo apoio oferecido durante todos os momentos da pesquisa.

A minha família, em especial minha mãe Juraci, meu pai Eduardo, meus irmãos Daniel, Eduardo, Claudio e Renato, e minhas tias Meire e Fia, que sempre apoiaram, desde a graduação, minha incursão pela carreira acadêmica.

A meu marido Andre Gouw, pelo apoio incondicional, pela paciente tolerância nos meus momentos de ausência, por ter assumido minhas funções inúmeras vezes para que eu pudesse me dedicar à pesquisa. Muito obrigada.

A Coordenação de Aperfeiçoamento de Pessoal de Nível Superior (CAPES), pela concessão da bolsa de doutorado.

Ao Conselho Nacional de Desenvolvimento Científico e Tecnológico (CNPq), pela concessão do financiamento necessário à execução desta pesquisa. 



\section{RESUMO}

SANTOS GOUW, Ana Maria. As opiniões, interesses e atitudes dos jovens brasileiros frente à ciência: uma avaliação em âmbito nacional. 2013. 242f. Tese (Doutorado em Educação) Faculdade de Educação, Universidade de São Paulo, São Paulo, 2013.

O desencanto dos estudantes pela ciência escolar e pela carreira científica tem provocado um movimento na área acadêmica em prol de se ouvir o que os alunos têm a dizer das suas aulas de ciências, de seus temas científicos de maior interesse e de sua posição frente a diversas questões relacionadas à ciência e à tecnologia. Um desses movimentos é o projeto The Relevance of Science Education (ROSE), sediado na Universidade de Oslo, Noruega, e implementado em mais de 40 países. No Brasil, o ROSE foi aplicado pela primeira vez em 2007, envolvendo 625 estudantes de dois municípios dos estados de São Paulo e Mato Grosso. Diante das primeiras observações junto ao ROSE, verificou-se a necessidade de se conhecer quais são os interesses, atitudes e preferências dos jovens em relação à ciência e à tecnologia em âmbito nacional. Assim, a pesquisa aqui descrita teve como objetivo implementar o projeto ROSE no Brasil em uma amostra de representatividade nacional, consolidando o perfil dos jovens brasileiros em relação à ciência e tecnologia e, a partir desses dados, discutir de que forma conhecer a relevância que o conhecimento científico tem para os jovens pode influenciar no ensino de ciências que hoje é apresentado nas escolas. A pesquisa, de natureza essencialmente quantitativa, encontra-se dentro do campo da avaliação educacional, e utilizou como instrumento de coleta de dados um questionário fechado com 245 itens cujas respostas são expressas em uma escala de Likert de 4 pontos. $O$ estudo amostral foi desenhado através de uma amostragem estratificada pelos 26 estados e o Distrito Federal com alocação proporcional, tendo como universo amostral a amostra do Programa Internacional de Avaliação de Estudantes (PISA) no Brasil no ano de 2009. Ao todo, 2365 estudantes participaram da pesquisa, oriundos de 84 escolas localizadas em todos os estados brasileiros. Os dados obtidos revelam que o brasileiro, de modo geral, possui grande interesse pelos temas científicos abordados na escola. Dentre esses, os que mais despertam seu interesse são os relacionados ao corpo humano. Em relação à posição dos jovens frente aos desafios ambientais, consideramos que os brasileiros apresentam atitudes preditoras de comportamento ambiental positivo. Por exemplo, nossos jovens possuem uma visão otimista quanto ao futuro, especialmente as meninas, e consideram fortemente que podemos encontrar soluções para os problemas ambientais. Em relação à ciência escolar, os jovens brasileiros consideram a disciplina interessante, apesar de não terem preferência por ela em relação a outras disciplinas. Há uma atitude positiva geral em relação à disciplina, tanto no que se refere à sua importância como à sua utilidade. Apesar de demonstrarem interesse pela ciência escolar, tanto meninas como meninos tem pouco interesse em ingressar na carreira científica.Verificamos também que os jovens brasileiros têm uma atitude geral otimista em relação à ciência e à tecnologia. Diante dos dados aqui obtidos, de maneira a legitimar as considerações manifestas por esses estudantes, cabe uma reflexão sobre as eventuais ações que podem ser tomadas a fim de que suas opiniões dialoguem com professores, currículos, livros didáticos e outros.

Palavras-chave: relevância do ensino de ciências, interesses dos jovens pela ciência, avaliação educacional. 



\begin{abstract}
SANTOS GOUW, Ana Maria. Opinions, interests and attitudes of young Brazilian in face of science: an evaluation in nationwide. 2013. 242f. Tese (Doutorado em Educação) - Faculdade de Educação, Universidade de São Paulo, São Paulo, 2013.

The disenchantment of students in science education and career in science has led to a movement in the academic field in favor of listening to what students have to say about their science classes, their scientific topics of greatest interest and its position against several issues related to science and technology. One of these movements is the project The Relevance of Science Education (ROSE), based at the University of Oslo, Norway, and implemented in more than 40 countries. In Brazil, ROSE was first applied in 2007, involving 625 students from two municipalities in the states of São Paulo and Mato Grosso. From the first observations with the ROSE, there was the need to know what are the interests, preferences and attitudes of young people towards science and technology nationwide. Thus, the research described here aimed to implement the ROSE project in Brazil in a nationally representative sample, consolidating the profile of Brazilian youth in relation to science and technology and, from these data, discuss how the comprehension about the relevance of Scientific knowledge for young people can influence the teaching of science being presented nowadays in schools. The research, which is essentially quantitative, lies within the field of educational assessment and used as tool for data collection a closed questionnaire with 245 items whose answers are expressed in a Likert scale of 4 points. The study sample was drawn through a stratified sampling by 26 states and the Federal District with proportional allocation, having as sampling universe the sample of the Programme for International Student Assessment (PISA) in Brazil in 2009. In all, 2365 students participated in the survey, coming from 84 schools located in all Brazilian states. The data reveal that the Brazilian, in general, has great interest in the scientific topics covered in school. Among these, the ones that arouse their interest are those related to the human body. Regarding the position of young people with environmental challenges, we consider that the Brazilians have predictive attitudes of positive environmental behavior. For example, our youngsters have an optimistic view about the future, especially girls, and feel strongly that we can find solutions to environmental problems. In relation to science school, the young Brazilians consider discipline interesting, although not having preference for it over other disciplines. There is a positive relation to the general subject, both with respect to its importance as to its usefulness. Although they showed interest in science education, both boys and girls have low interest in joining a scientific career. We also observed that young Brazilians have a generally optimistic attitude towards science and technology. From the data obtained here, in order to legitimize the obvious considerations from these students, it is worth reflecting on the possible actions that can be taken in order that their opinions dialogue with teachers, curricula, textbooks and other.
\end{abstract}

Keywords: relevance of science education, interests of youngsters in science, educational evaluation 



\section{LISTA DE FIGURAS}

Figura 3.1 - Recorte da Seção A do questionário ROSE

aplicado no Brasil.

Figura 3.2 - Reprodução de parte da primeira página do

questionário ROSE Brasil, onde está presente o código de barras.

Figura 4.1 - Distribuição da amostra nos estados brasileiros.

Figura 4.2 - Distribuição da amostra nas regiões brasileiras.

Figura 4.3 - Gráfico representando a quantidade de livros presente

nos domicílios dos alunos amostrados.

Figura 4.4 - Gráfico representando porcentagem relativa

ao número de banheiros presentes nos domicílios dos alunos

participantes da pesquisa.

Figura 4.5 - Frequência relativa das idades dos

alunos brasileiros participantes da pesquisa.

Figura 5.1 - Média obtida pelos países participantes do ROSE

nas 108 questões das seções ACE. Figura adaptada de Sjøberg

e Schreiner (2010).

Figura 5.2 - Linha de regressão obtida a partir dos valores de IDH (eixo

horizontal) e a pontuação média global nos itens ACE (eixo vertical) para

países participantes do ROSE. Fonte: Sjøberg e Schreiner (2005).

Figura 5.3 - Linha de regressão obtida a partir dos valores

de IDH e a pontuação média geral em todos os itens das questões

ACE para países participantes do ROSE incluindo o Brasil.

Figura 5.4 - Linha de regressão obtida a partir dos valores de IDH

dos municípios brasileiros participantes da pesquisa ROSE Brasil e a

pontuação média geral em todos os itens das questões ACE.

Figura 5.5 - Respostas dos alunos sobre interesse por "Cientistas famosos e

suas vidas" - Questão E37. Adaptado de Matthews (2007).

Figura 6.1 - Representação esquemática das variáveis da teoria VBN segundo STERN (2000, p. 412) 
Figura 6.2 - Gráfico que apresenta diferenças de gênero dos

jovens brasileiros quanto as visões de futuro,

Figura 6.3 - Gráfico que apresenta diferenças de gênero dos

jovens brasileiros quanto à motivação para a ação.

Figura 6.4 - Distribuição das respostas médias de meninos e

meninas na questão D1, adaptado de Matthews (2007)

Figura 6.5 - Distribuição das respostas médias de meninos e

meninas na questão D4, adaptado de Matthews (2007).

Figura 6.6 - Distribuição das respostas médias de meninos e

meninas na questão D14, adaptado de Matthews (2007).

Figura 7.1 - $\mathrm{O}$ interesse de meninos e meninos pelas

carreiras científicas e tecnológicas.

Figura 7.2 - Distribuição das respostas médias de meninos e

meninas na questão F1, adaptado de Matthews (2007).

Figura 7.3 - Distribuição das respostas médias de meninos e

meninas na questão F2, adaptado de Matthews (2007).

Figura 7.4 - Distribuição das respostas médias de meninos e

meninas na questão F14, adaptado de Matthews (2007).

Figura 7.5 - Distribuição das respostas médias de meninos e

meninas na questão F16, adaptado de Matthews (2007).

Figura 8.1 - Distribuição das respostas médias de meninos e

meninas na questão G01, adaptado de Matthews (2007).

Figura 8.2 - Distribuição das respostas médias de meninos e

meninas na questão G08, adaptado de Matthews (2007).

Figura 8.3 - Distribuição das respostas médias de meninos e

meninas na questão G14, adaptado de Matthews (2007).

Figura 9.1 - Imagem com o modelo de declaração enviado

aos aplicadores do questionário nas escolas.

Figura 9.2 - Aplicação do questionário ROSE em uma

escola do município de Limoeiro - PE. 


\section{LISTA DE QUADROS}

Quadro 3.1 - Temas abordados nas questões das seções ACE

(proposta por Schreiner, 2006).

Quadro 3.2 - Categorias de temas proposta por Tolentino Neto (2008)

para as seções ACE.

Quadro 3.3 - Categorias da Seção D "Eu e os desafios ambientais"

(proposta por Schreiner, 2006).

Quadro 3.4 - Categorias da Seção F “As minhas aulas de ciências”

(elaboradas pela autora).

Quadro 3.5 - Categorias da Seção H "Minhas experiências fora da escola" (elaboradas pela autora).

Quadro 5.1 - Grupos de questões envolvendo preponderantemente conteúdo e questões contextualizadas da área de Biologia.

Quadro 5.2 - Grupos de questões envolvendo preponderantemente conteúdo e questões contextualizadas das áreas da Física, Química, Geociência e Astrofísica 



\section{LISTA DE TABELAS}

Tabela 3.1 - Distribuição das escolas no PISA (2009) e na amostra do estudo

ROSE-Brasil por Unidade da Federação .............................................................................

Tabela 3.2 - Tamanhos de amostras segundo erros de amostragem ................................... 77

Tabela 3.3 - Número de escolas sorteadas e questionários

previstos por região.

Tabela 3.4 - Número de envios realizados para as escolas por estado.

Tabela 3.5 - Número de questionários enviados e reenviados para

escolas por região.

Tabela 3.6 - Número de questionários recebidos por região.

Tabela 4.1 - Distribuição das escolas participantes nos estados

e municípios brasileiros.

Tabela 4.2 - Localização das escolas participantes da pesquisa.

Tabela 4.3 - Dependência administrativa das escolas participantes

da pesquisa. 88

Tabela 4.4 - Distribuição da amostra em relação ao gênero.

Tabela 4.5 - Distribuição da amostra em relação à posse de livros.

Tabela 4.6 - Distribuição da amostra em relação à posse de livros

dos alunos nas regiões brasileiras.

Tabela 4.7 - Comparação entre os dados obtidos junto à pesquisa

ROSE e PISA 2006 no que se refere à posse de livros.

Tabela 4.8 - Distribuição da amostra em relação ao número de banheiros.

Tabela 4.9 - Distribuição da amostra em relação ao número de banheiros,

por região.

Tabela 4.10 - Distribuição da amostra em relação à idade.

Tabela 4.11 - Média e desvio padrão da amostra para a idade.

Tabela 4.12 - Média de idade dos alunos amostrados por região brasileira.

Tabela 5.1 - Itens das seções ACE com maior pontuação entre os

jovens brasileiros

Tabela 5.2 - Itens das seções ACE com menor pontuação entre os jovens brasileiros. 
Tabela 5.3 - Médias (geral, de meninos e meninas) agrupadas por assunto.

Tabela 5.4 - Comparação entre ROSE e PISA 2006 sobre o interesse

por temas da ciência.

Tabela 5.5 - Médias obtidas nos grupos de questões contextualizadas e

questões envolvendo preponderantemente conteúdo.

Tabela 5.6 - Médias de interesse (média geral) por assuntos entre

as regiões brasileiras.

Tabela 5.7 - Itens com as dez maiores médias em questões das seções ACE,

distribuídos pelas regiões brasileiras.

Tabela 5.8 - Médias obtidas junto às regiões brasileiras para a questão A10.

Tabela 5.9 - Resultados do Teste de Tukey para questões A09, E13, E23, A37,

E05 e E32

Tabela 5.10 - Médias nas regiões para temas não científicos

ou "alternativos".

Tabela 5.11 - Médias das regiões brasileiras para as questões relacionadas

à agricultura.

Tabela 5.12 - Teste de Tukey para observação de diferenças entre regiões

nas questões E17, E19 e E33.

Tabela 5.13 - Médias verificadas nas regiões brasileiras para questões

relacionadas ao meio ambiente.

Tabela 6.1 - Médias e testes de Mann-Whitney para diferença em relação

ao gênero dos estudantes para o grupo de questões D.

Tabela 6.2 - Médias por região da seção "Eu e os desafios ambientais".

Tabela 6.3 - Diferenças existentes entre as regiões (teste Tukey) para a seção D.

Tabela 6.4 - Fatores (e questões) obtidos a partir da Análise por Componentes

Principais da seção D

Tabela 6.5 - Os valores de correlação existentes entre as questões originais e os fatores obtidos.

Tabela 6.6 - Média geral, por meninos e meninas, obtidas em cada fator.

Tabela 7.1 - Médias e testes de Mann-Whitney para diferença em relação ao gênero dos estudantes para o grupo de questões $\mathrm{F}$.

Tabela 7.2 - Médias de meninas, meninos e geral para categorias da seção F 
Tabela 7.3 - Comparação de médias obtidas junto ao ROSE e PISA 2006

referente as questões relacionadas ao interesse pela ciência escolar

Tabela 7.4 - Médias por região da seção “As minhas aulas de ciências”.

Tabela 7.5 - Diferenças existentes entre duas regiões para as questões F5 e F16

Tabela 7.6 - Diferenças existentes entre duas regiões para as questões F2 e F7.

Tabela 7.7 - Valores obtidos para o teste de correlação entre IDH e média das questões F14 e F16.

Tabela 7.8 - Resultados obtidos da associação entre as respostas das questões F14 e F16 e número de livros e número de banheiros.

Tabela 7.9 - Médias por região das questões F14 e F16

Tabela 7.10 - Fatores (e questões) obtidos a partir da Análise Fatorial da seção F

Tabela 7.11 - Os valores de correlação existentes entre as questões originais

e os fatores obtidos

Tabela 7.12 - Medidas e testes de Mann-Whitney para diferença em relação ao

gênero dos estudantes para os fatores do grupo de questões $F$.

Tabela 8.1 - Médias e testes de Mann-Whitney para diferenças em relação ao gênero dos estudantes para o grupo de questões $\mathrm{G}$.

Tabela 8.2 - Comparação entre algumas questões da pesquisa ROSE, FAPESP (2005 e 2010) e MCT 2010

Tabela 8.3 - Comparação entre ROSE e PISA 2006 sobre questões que

abordam o papel da C\&T na sociedade.

Tabela 8.4 - Médias por região da seção G.

Tabela 8.5 - Diferenças existentes entre duas regiões (teste Tukey)

para a seção "As minhas opiniões sobre ciência e tecnologia".

Tabela 8.6 - Variância explicada pelos fatores com autovalores maiores

que 1 para o grupo de questões $\mathrm{G}$.

Tabela 8.7 - Os valores de correlação existentes entre as questões

originais e os fatores obtidos.

Tabela 8.8 - Medidas e testes de Mann-Whitney para diferença em relação ao gênero dos estudantes para os fatores do grupo de questões $G$

Tabela 9.1 - Dados amostrais de alguns países participantes do ROSE. 



\section{SUMÁRIO}

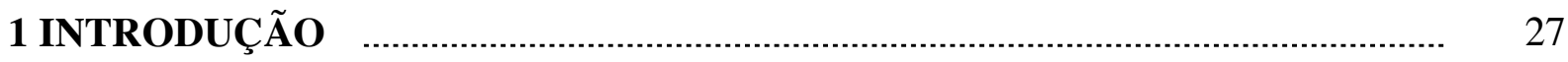

O contexto da pesquisa .................................................................................... 27

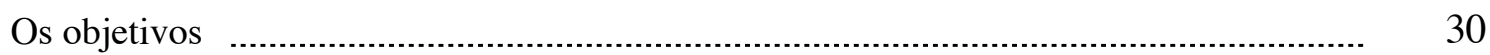

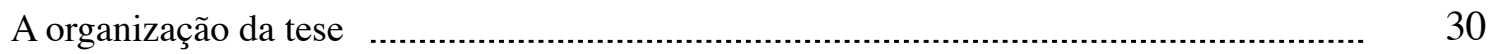

2 REFERENCIAIS TEÓRICOS GERAIS ......................................................... 32

2.1 A RELEVÂNCIA DA CIÊNCIA NA ESCOLA ............................................... 32

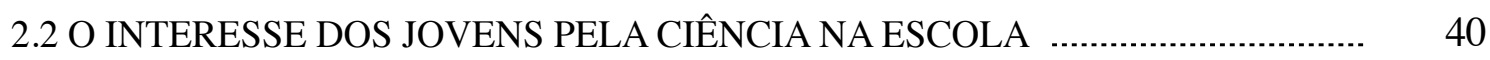

2.3 ESCUTAR A VOZ DO ALUNO PARA RESSIGNIFICAR A RELEVÂNCIA

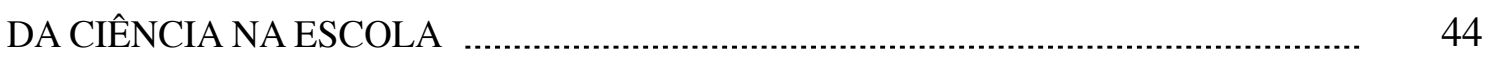

2.4 INTERESSES E ATITUDES: A DIMENSÃO AFETIVA DA

APRENDIZAGEM DA CIÊNCIA ........................................................................ 48

2.5 PESQUISAS SOBRE PERCEPÇÕES, OPINIÕES, ATITUDES E VISÕES ACERCA DA CIÊNCIA …............................................................................. 51

2.6 O PROJETO INTERNACIONAL “THE RELEVANCE OF SCIENCE

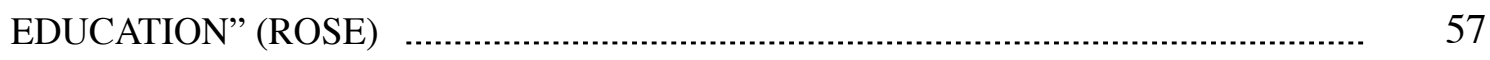

3 METODOLOGIA DE PESQUISA ................................................................. 64

3.1 UMA AVALIAÇÃO DE NATUREZA QUANTITATIVA .................................... 64

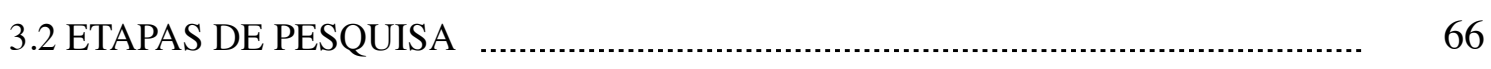

3.3 O INSTRUMENTO DE COLETA DE DADOS .................................................. 67

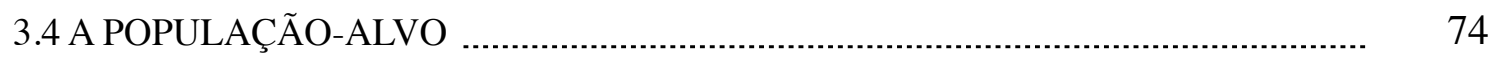

3.5 DETERMINAÇÃO DO TAMANHO DA AMOSTRA ....................................... 75

3.5.1 Processo de seleção da amostra .......................................................... 78

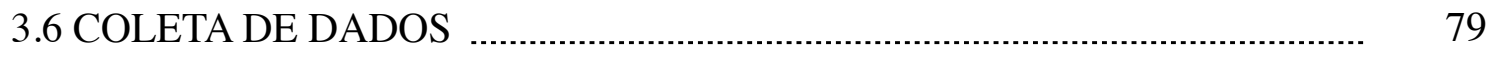

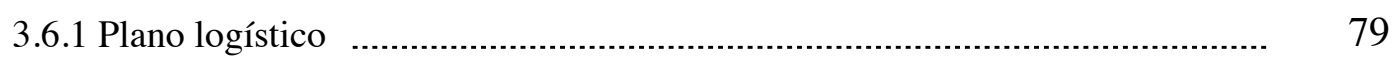

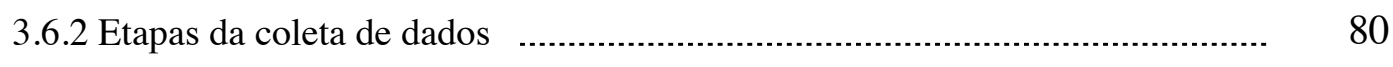

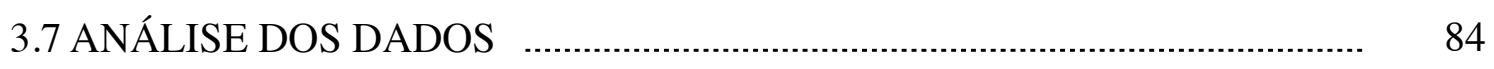

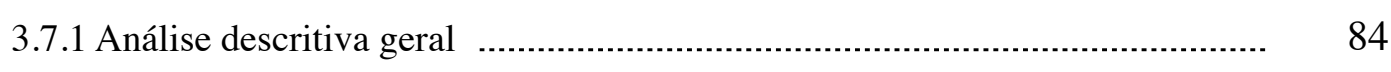

3.7.2 Análises Multivariadas .................................................................. 85

3.7.3 Análise Comparativa entre ROSE-Brasil e PISA 2006 .............................. 86 
4.1 AS ESCOLAS PARTICIPANTES DA PESQUISA $\quad$........................................... 87

4.2 OS JOVENS PARTICIPANTES DA PESQUISA …………………………….... 89

\section{O INTERESSE DOS JOVENS BRASILEIROS PELAS CIÊNCIAS}

NA ESCOLA .......................................................................................................... 100

5.1 O QUE OS JOVENS BRASILEIROS MAIS (E MENOS) SE INTERESSAM

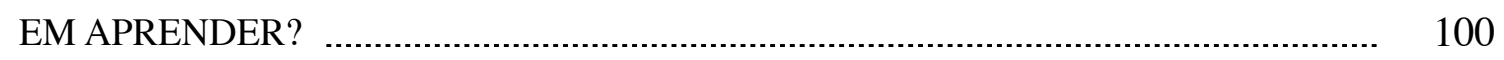

5.2 AS DISCIPLINAS E ASSUNTOS DA CIÊNCIA QUE MAIS (E MENOS)

INTERESSAM OS JOVENS BRASILEIROS ................................................................ 106

5.3 A CIÊNCIA APRESENTADA NA ESCOLA: DIFERENÇAS OBSERVADAS

EM RELAÇÃO A CONTEÚDOS E CONTEXTOS ..................................................... 111

5.4 OS INTERESSES DOS JOVENS BRASILEIROS: ASPECTOS REGIONAIS $\ldots \ldots \ldots . . .116$

5.5 O JOVEM BRASILEIRO NO CENÁRIO INTERNACIONAL - ALGUMAS

QUESTÕES DE INTERESSE ............................................................................... 123

\section{OS JOVENS BRASILEIROS FRENTE AOS}

DESAFIOS AMBIENTAIS

6.1 OS JOVENS BRASILEIROS FRENTE AOS PROBLEMAS AMBIENTAIS:

UM PANORAMA GERAL

6.2 OS JOVENS BRASILEIROS FRENTE AOS PROBLEMAS AMBIENTAIS:

UM PANORAMA POR REGIÃO

6.3 TIPOS DE POSICIONAMENTO DOS JOVENS BRASILEIROS FACE AOS

PROBLEMAS AMBIENTAIS

6.4 A POSIÇÃO DOS JOVENS BRASILEIROS EM RELAÇÃO AO MEIO

AMBIENTE NO CENÁRIO INTERNACIONAL

7 O QUE OS JOVENS BRASILEIROS PENSAM DAS SUAS AULAS

DE CIÊNCIAS?

7.1 O QUE PENSAM OS JOVENS BRASILEIROS SOBRE SUAS AULAS DE

CIÊNCIAS: UM PANORAMA GERAL

7.2 OS JOVENS BRASILEIROS E SUAS AULAS DE CIÊNCIAS: UM

PANORAMA POR REGIÃO

7.3 O INTERESSE DO JOVEM BRASILEIRO PELA CARREIRA CIENTÍFICA

7.4 TIPOS DE POSICIONAMENTO DOS JOVENS BRASILEIROS EM

RELAÇÃO ÀS AULAS DE CIÊNCIAS

7.5 A POSIÇÃO DOS JOVENS BRASILEIROS EM RELAÇÃO À CIÊNCIA ESCOLAR NO CENÁRIO INTERNACIONAL 


\section{OPINIÕES DOS JOVENS BRASILEIROS FRENTE À}

CIÊNCIA E À TECNOLOGIA

8.1 OPINIÕES DOS JOVENS BRASILEIROS FRENTE À CIÊNCIA E À

TECNOLOGIA: UM PANORAMA GERAL

8.2 OPINIÕES DOS JOVENS BRASILEIROS FRENTE À CIÊNCIA E À

TECNOLOGIA: UM PANORAMA POR REGIÃO

8.3 POSICIONAMENTOS DOS JOVENS BRASILEIROS FRENTE À CIÊNCIA

E À TECNOLOGIA

8.4 A POSIÇÃO DOS JOVENS BRASILEIROS EM RELAÇÃO À CIÊNCIA E

TECNOLOGIA NO CENÁRIO INTERNACIONAL

\section{COMENTÁRIOS SOBRE A APLICAÇÃO DO PROJETO}

ROSE NO BRASIL

9.1 RECURSOS HUMANOS E FINANCEIROS

9.2 SOBRE A AMOSTRA E A LOGÍSTICA DE COLETA DE DADOS 188

9.3 A LEITURA ÓPTICA

9.4. FORMATO DO QUESTIONÁRIO

9.5 TAMANHO DO QUESTIONÁRIO

9.6 OPINIÕES DOS ALUNOS E PROFESSORES SOBRE O

QUESTIONÁRIO ROSE

10 CONSIDERAÇÕES FINAIS

ANEXO A

Questionário ROSE Brasil completo.

APÊNDICE A

Resultados obtidos junto às seções ACE “O que quero aprender” (completo).

APÊNDICE B

Resultados obtidos junto à seção B "Meu futuro emprego".

APÊNDICE C

Resultados obtidos junto à seção H “As minhas experiências fora da escola”.

APÊNDICE D

Carta de instruções para as escolas participantes do projeto ROSE.

APÊNDICE E

Carta de apresentação do projeto ROSE enviada às escolas.

APÊNDICE F

Termo de Consentimento Livre e Esclarecido enviado para as escolas participantes da pesquisa. 



\section{INTRODUÇÃO}

\section{$O$ contexto da pesquisa}

Um grave problema na área de ensino tem preocupado professores, acadêmicos e elaboradores de políticas públicas nos últimos anos: o desencanto dos jovens pela ciência. Diversos artigos, relatórios e avaliações em larga escala tem verificado que os jovens não têm interesse pela ciência escolar e tampouco pela carreira científica (AIKENHEAD, 2004; BARAM-TSABARI; YARDEN, 2005; BARAM-TSABARI et al., 2009; EUROPEAN COMMISSION, 2004, EUROPEAN COMMISSION, 2007; FENSHAM, 2004a; FENSHAM, 2004b; JENKINS, 2000; JENKINS, 2006a; JENKINS; NELSON, 2005; JENKINS; PELL, 2006; KENNEDY, 2008; LAVONEN et al., 2005; MATTHEWS, 2007; OSBORNE; SIMON; COLLINS, 2003; OSBORNE, 2006; OSBORNE; DILLON, 2008; SHAMOS; HOWES, 1996; TOMEI, 2008; SCHREINER; SJØBERG, 2004; SJØBERG, 2001; SJØBERG, 2002; VÁZQUEZ ALONSO; MANASSERO MAS, 2008).

Anthony Tomei (2008) comenta, sobre este aspecto, que há deficiências observadas na pedagogia, no currículo e nas avaliações, mas o problema mais profundo reside no fato da ciência escolar nunca ter fornecido uma educação satisfatória para a maioria, o que tem gerado implicações adversas para a formação de futuros cientistas.

A educação científica está, de fato, diante de um desafio: ajustar-se ao mundo moderno, atendendo às necessidades de todos os alunos, quer os que irão seguir as carreiras científicas, quer não. Desse modo, convém iniciar esta reflexão com as palavras do biólogo chileno Humberto Maturana e sua colaboradora Ximena Yáñez

O educando se transforma na convivência com o educador. O educador dos tempos pós-modernos é aquele que adota a tarefa de criar um espaço de convivência, onde os outros (educandos) se transformam reflexivamente junto com ele (o educador). Para que isto ocorra, o educando e o educador devem conviver em um espaço no qual se aceitem mutuamente como legítimos outros na convivência. Isto é, o educador deve se transformar em um educador social (YÁÑEZ; MATURANA, 2009, p. 144). 
Ressalto aqui a frase "se aceitem mutuamente como legítimos outros na convivência". Quem são os legítimos outros nas instituições escolares, nas pesquisas acadêmicas e nas políticas públicas? Quem são os legitimamente consultados nas reformas educacionais? Quem são os legitimamente ouvidos?

Sobre isso, Cook-Sather (2002, p. 3) comenta: "há algo fundamentalmente equivocado ao se estruturar e reestruturar todo um sistema educacional sem consultar, em um único ponto, aqueles a quem o sistema se destina".

Se há problemas na educação científica, como a baixa proficiência observada entre os jovens brasileiros e o pouco interesse, o que os próprios estudantes têm a dizer sobre isso? Esta pesquisa ouviu 2365 jovens oriundos de todos os estados brasileiros, com o intuito de conhecer suas preferências, seus temas científicos de maior interesse, suas posições frente aos desafios ambientais, o que pensam de suas aulas de ciências e do papel da ciência e tecnologia na sociedade.

Para isso, foi implementado o projeto internacional The Relevance of Science Education (ROSE), elaborado por pesquisadores da Universidade de Oslo, que visa averiguar a relevância do conhecimento científico e tecnológico para os jovens que estão finalizando os estudos compulsórios (com cerca de 15 anos de idade). O projeto tem sido adaptado de forma colaborativa por diversos pesquisadores ao redor do mundo e seu instrumento de coleta de dados um questionário fechado com 245 itens - já foi aplicado em mais de 40 países (SCHREINER; SJØBERG, 2004).

No Brasil, o ROSE foi aplicado pela primeira vez em 2007, envolvendo 625 estudantes de dois municípios dos estados de São Paulo e Mato Grosso: São Caetano do Sul - SP, caracterizado como pós-industrial, com um alto Índice de Desenvolvimento Humano (IDH) e Tangará da Serra - MT, afastado dos grandes centros e com vocação ao agronegócio.

Essa primeira aplicação culminou em uma tese de doutorado, defendida por Luiz Caldeira Brant de Tolentino Neto (TOLENTINO NETO, 2008). Tal aplicação também contemplou a inclusão de seções adicionais - denominadas “Questões Nacionais Rose Brasil”, que procurou compreender aspectos envolvendo a aceitação/rejeição da evolução biológica. A análise desta parte gerou a dissertação de mestrado de Graciela da Silva Oliveira (OLIVEIRA, 2009).

Dentre os resultados obtidos através da primeira aplicação do ROSE no Brasil, Tolentino Neto (2008) destaca que houve uma valorização da ciência no município de Tangará da Serra, 
fato não observado entre os alunos de São Caetano do Sul. Esses dados corroboram a tendência dos alunos de países com alto IDH terem menor interesse pelas ciências do que os alunos de países com baixo IDH (SCHREINER; SJØBERG, 2005, SCHREINER; SJØBERG, 2007, SJØBERG; SCHREINER, 2005). O autor exemplifica, para isso, a aplicação do projeto ROSE na Irlanda, onde os estudantes foram classificados como tendo uma "tendência à aversão em ser cientista".

Diante das primeiras observações junto ao ROSE, verificou-se a necessidade de se conhecer quais são os interesses, atitudes e preferências dos jovens em relação à ciência e à tecnologia em âmbito nacional, a fim de se averiguar, inclusive, a relação entre interesse pela carreira científica e aspectos econômicos. Assim, esta pesquisa procurou verificar tais questões mediante a aplicação do projeto ROSE em uma amostra de representatividade nacional, consolidando o perfil dos jovens brasileiros em relação à ciência e tecnologia.

Esses dados, apresentados ao longo da tese, trarão subsídios para discussões relacionadas ao ensino de ciências, à estruturação dos currículos, livros didáticos e atividades pedagógicas, bem como para o debate da relevância e importância da ciência na sociedade e na escola.

Os pesquisadores envolvidos no projeto ROSE concordam com o fato de que o currículo de ciências deve contemplar as necessidades dos estudantes, considerar o que eles consideram relevante, de forma que a voz e a visão do aluno devem influenciar os elaboradores de currículos e sua implementação nas escolas (ANDERSON, 2006; CAVAS et al., 2009; JENKINS, 2006; JIDESJÖ, OSCARSSON; KARLSSON, 2009; MATTHEWS, 2007; SCHREINER; SJØBERG, 2004; VÁZQUEZ ALONSO; MANASSERO MAS, 2008).

Esta é, sem dúvida, uma das maneiras de contemplar o fato de que "todo aluno tem o direito de ser consultado e ter sua voz ouvida. Toda criança é um ser humano com integridade, personalidade e habilidade para participar livremente da sociedade" (MCINTYRE; PEDDER; RUDDUCK, 2005, p. 150). 


\section{Os objetivos}

Conhecer o interesse que os jovens têm pela ciência e tecnologia, através da aplicação do projeto ROSE, em uma amostra representativa do âmbito nacional brasileiro, é o principal objetivo deste trabalho, que procura ainda, a partir desses dados, discutir de que forma conhecer a relevância que o conhecimento científico tem para os jovens pode influenciar no ensino de ciências que hoje é apresentado nas escolas.

Procuramos, através do desenvolvimento desta pesquisa, responder algumas questões:

- Quais são os temas das ciências pelos quais os jovens brasileiros se interessam?

- Os jovens brasileiros consideram suas aulas de ciências interessantes e importantes para sua formação pessoal?

- Qual a posição dos jovens brasileiros frente aos desafios ambientais?

- Qual a importância que os jovens brasileiros atribuem à ciência e à tecnologia na sociedade?

- Os jovens brasileiros têm interesse na carreira científica?

Tais questões poderão subsidiar discussões no que se refere ao currículo de ciências, à diversidade cultural brasileira e sua relação com a ciência, às aulas de ciências, às percepções dos estudantes em relação à ciência e tecnologia e às diferenças de gênero.

\section{A organização da tese}

O projeto ROSE possui como instrumento de coleta de dados um questionário constituído por 245 itens fechados dispostos em 8 seções. As seções, identificadas com letras consecutivas, são: A, C e E - “O que eu quero aprender", B - “O meu futuro emprego", D - "Eu e os desafios ambientais", F - "As minhas aulas de ciências", G - "As minhas opiniões sobre a ciência e a tecnologia” e H - “As minhas experiências fora da escola”. 
Conforme pode ser observado, os conteúdos abordados ao longo do questionário são bastante abrangentes e diferentes entre si, o que levou à necessidade de selecionar algumas seções para análise e discussão, a saber, A, C, E, D, F e G. Assim, os resultados estão organizados em capítulos que contemplam cada uma dessas seções individualmente, com exceção das seções $\mathrm{A}, \mathrm{C}$ e $\mathrm{E}$, que constituem um único bloco denominado $\mathrm{ACE}$.

Cada capítulo de resultado possui um contexto teórico específico, que permite o diálogo dos dados de forma mais próxima e uma discussão mais sistemática. O capítulo 2, denominado Referenciais Teóricos Gerais, traz elementos comuns a todos os dados, o que permite o diálogo da tese como um todo.

Desta forma, a tese foi organizada em 10 capítulos: o capítulo 1 - Introdução - procura dar um breve panorama da pesquisa aqui abordada, o capítulo 2 apresenta os referenciais teóricos gerais que subsidiaram a pesquisa, o capítulo 3 descreve os procedimentos metodológicos envolvidos na organização, coleta e análise de dados, o capítulo 4 descreve a amostra obtida, os capítulos 5, 6, 7 e 8 apresentam e discutem os resultados obtidos, apresentando para isso, alguns referenciais teóricos específicos do assunto abordado, o capítulo 9 comenta aspectos da aplicação da pesquisa ROSE no Brasil e por fim, no capítulo 10 apontam-se algumas considerações finais. 


\section{REFERENCIAIS TEÓRICOS GERAIS}

\subsection{A RELEVÂNCIA DA CIÊNCIA NA ESCOLA}

É indiscutível, na sociedade moderna, a importância das mudanças determinadas pelos avanços da ciência e tecnologia. Aparelhos domésticos, meios de comunicação e informação, meios de transporte e até mesmo os alimentos que ingerimos, fazem a sociedade atual única em termos de dependência dos produtos científicos e tecnológicos.

Uma das implicações desse movimento é o papel do conhecimento científico na sociedade. Dentro da perspectiva cultural, a ciência, por possuir um sistema próprio de significados e símbolos compartilhados por pessoas socialmente, pode ser considerada como uma sub-cultura da sociedade ocidental, o que implica a necessidade dos cidadãos em conhecê-la (AIKENHEAD, 1996).

A ciência possui normas, valores, crenças, expectativas e ações convencionais que são compartilhadas de diversas maneiras pelas comunidades científicas, por isso, ela satisfaz a definição de cultura de Phelan et al. (1991), que conceitua cultura como o conjunto desses elementos em um determinado grupo.

Peter Broks (2003) considera que ao final do século XIX a ciência passou a adquirir um prestígio sem precedentes na história da humanidade, a ponto de ser objeto de fé e confiança, muitas vezes ocupando o papel da própria religião. O autor considera que (2003, p. 76)

em muitos aspectos, ciência é o que significa ser moderno, e no século XXI a ciência estaria inextricavelmente enredada com todas as esperanças e medos da modernidade [...]. Quanto à ciência, o seu status cultural nunca foi tão privilegiado ou aberto a desafios.

A relevância da ciência na sociedade atual foi sintetizada por Vogt (FAPESP, 2005) quando ele descreveu os impactos da ciência e tecnologia no mundo atual: na economia, na política, na comunidade (em termos de sociedade civil), nos domínios institucionais especializados 
(saúde, educação, leis, bem-estar e seguridade social, etc.), na cultura e nos valores - indústria cultural, crenças, normas e comportamento.

Inserido neste contexto de modernidade, importância, impacto social e relevância, o ensino da ciência tem assumido uma posição de destaque na sala de aula, uma vez que é através dele que os jovens podem compreender os processos de produção científica, os produtos da ciência, sua forma de ver o mundo, seus valores e mesmo sua linguagem específica.

A discussão sobre a importância de se ensinar ciência nas escolas é, entretanto, bastante antiga. Já na década de 20, um relatório elaborado pela National Education Association (NEA) dos Estados Unidos indicava a importância "da aplicação do conhecimento científico para as atividades da vida, em termos da demanda de assuntos como uma ciência logicamente organizada" (NEA ${ }^{1}, 1918$, p. 8 apud DEBOER, 2000, p. 584).

Foi a partir da década de 60 que o ensino de ciências passou a ser, de fato, objeto de interesse político. Com os avanços tecnológicos impulsionados pela Guerra Fria, tendo como ponto de partida o lançamento do satélite soviético Sputnik em 1957, o ensino de ciências passou a ser visto como uma maneira de produzir cidadãos com compreensão e simpatia pelas ciências (DEBOER, 2000).

No Brasil, o grande marco em direção a uma reformulação do ensino de ciências foi a criação, em 1946, do Instituto Brasileiro de Educação, Ciência e Cultura (IBECC). Num estudo onde 24 pesquisadores da área de ensino de ciências foram entrevistados, todos apontaram a criação do IBECC como um marco para o ensino de ciências no Brasil, tanto no que se refere aos programas educativos como para a conformação de uma área específica de pesquisa voltada para o ensino de ciências (NARDI, 2005).

No país, a partir da década de 50, com a criação do IBECC, passa-se a observar diversas mudanças na disciplina escolar ciências, principalmente no que se refere aos conteúdos a serem ensinados e aos métodos de ensino privilegiados. Krasilchik (2000, p. 85) reforça esta tendência ao destacar que

Tomando como marco inicial a década de 50, é possível reconhecer nestes últimos 50 anos movimentos que refletem diferentes objetivos da educação modificados evolutivamente em função de transformações no âmbito da política e economia, tanto nacional como internacional.

\footnotetext{
${ }^{1}$ NATIONAL EDUCATION ASSOCIATION (NEA). Cardinal principles of secondary education: A report of the commission on the reorganization of secondary education. (U.S. Bureau of Education Bulletin No. 35). Washington, D.C.: 
Até meados desse período, o modelo de transmissão de conhecimento marcou o ensino de ciências no Brasil, onde aulas teóricas reforçavam uma ciência neutra, com características positivistas e apresentavam o conhecimento científico como um produto final, ou seja, uma verdade já pronta e absoluta. Até este período, o ensino de ciências estava centrado na figura do professor, onde preponderavam aulas expositivas, a verbalização do conhecimento e demonstrações de fenômenos científicos (KRASILCHIK, 1987; KRASILCHIK, 2000; DELIZOICOV; ANGOTTI; PERNAMBUCO, 2002).

Durante este período, os Estados Unidos se viram desafiados a incrementar seu desenvolvimento científico e tecnológico, o que culminou, nos anos 60, em

\begin{abstract}
investimentos de recursos humanos e financeiros sem paralelo na história da educação, para produzir os hoje chamados projetos de $1^{\mathrm{a}}$ geração do ensino de Física, Química, Biologia e Matemática para o ensino médio. A justificativa desse empreendimento baseava-se na ideia de que a formação de uma elite que garantisse a hegemonia norte-americana na conquista do espaço dependia, em boa parte, de uma escola secundária em que os cursos das Ciências identificassem e incentivassem jovens talentos a seguir carreiras científicas (KRASILCHIK, 2000, p. 85)
\end{abstract}

O cerne de tais investimentos foi a criação, nos Estados Unidos, dos grandes projetos curriculares científicos: o Biological Science Curriculum Study (BSCS); Physical Science Study Commitee (PSSC); Chemical Study Group (CHEM); Chemical Bond Aproach (CBA), Project Harvard Physics, Chem Study e Chemical Bond Approach (CBA), Science Mathematics Study Group (SMSG) entre outros (KRASILCHIK, 1992; KRASILCHIK, 2000; VILLANI; ALMEIDA PACCA; FREITAS, 2009).

Na Inglaterra, este movimento deu origem ao projeto Nuffield, financiado pela fundação de mesmo nome, que exerceram grande influência na Europa (GOODSON, 1995; VILLANI, ALMEIDA PACCA; FREITAS, 2009). Os ingleses, entretanto, decidiram "produzir seus próprios projetos consonantes com a organização escolar de forma a preservar a influência acadêmica e científica de instituições inglesas" (KRASILCHIK, 2000, p. 86).

No Brasil, "a necessidade de preparação dos alunos mais aptos era defendida em nome da demanda de investigadores para impulsionar o progresso da ciência e tecnologia nacionais" (KRASILCHIK, 2000, p. 86). Bizzo (2009, p. 99) corrobora esta questão ao afirmar que 
Estimulava-se a ideia de que as crianças desenvolviam pesquisas "reais", incentivando-as a adotar uma postura de "pequeno cientista" (...). Não há como negar que esta proposta estivesse ligada ao espírito da época, que via no ensino de ciências uma maneira de localizar talentos precocemente, que seriam rapidamente direcionados para as carreiras científicas.

Nesta época passou-se a utilizar o termo alfabetização científica, usado por Paul DeHart Hurd já em 1958, como significado do provimento de uma ampla compreensão da ciência e do empreendimento científico para aqueles que quisessem ou não se tornar cientistas (DEBOER, 2000, p. 586).

Durante os anos 70 e 80, a alfabetização científica se tornou fortemente associada ao contexto social, culminando no movimento curricular intitulado Ciência, Tecnologia e Sociedade (CTS), que foi promovido primariamente pelo National Science Teachers Association (NSTA) dos Estados Unidos. O objetivo do currículo CTS era dar aos estudantes conhecimento acerca da interface ciência/sociedade e habilidades para tomar decisões em relação a temas relacionados (RAMSEY², 1989 apud DEBOER 2000).

Ainda sobre a inserção da ciência dentro do contexto social, é interessante observar os argumentos apresentados por Laugksch (2000) para se ensinar ciências na educação básica. O autor descreve dois contextos onde o ensino de ciências se faz necessário: o contexto macro escala e o contexto micro escala. No macro escala estão elencados: 1) a relação entre a alfabetização científica e o bem estar econômico da nação, uma vez que a presença de cientistas e engenheiros são fatores determinantes para o sucesso econômico. $\mathrm{O}$ autor considera também que pessoas alfabetizadas cientificamente participam mais inteligentemente do setor produtivo da economia; 2) níveis mais elevados de alfabetização científica entre a população podem ser traduzidos em um maior apoio à ciência em si, e que o apoio público para a ciência depende de um nível mínimo de conhecimento sobre o que os cientistas fazem; 3) expectativas das pessoas em relação à ciência, uma vez que ela influencia muitos aspectos da vida pública e privada e 4) relação entre ciência e cultura.

Laugksch (2000), dentro do contexto micro escala, aponta a necessidade do ensino de ciências por que: 1) uma melhor compreensão da ciência e da tecnologia é vantajosa para qualquer um na sociedade atual; 2) proporciona novas oportunidades de emprego e 3) por uma questão estética, onde a ciência também tem papel central, ao lado da literatura, música e arte.

Bizzo (2012, p. 154) ao discutir sobre a importância de se ensinar ciências na escola, destaca

\footnotetext{
${ }^{2}$ RAMSEY, J. Curricular framework for community-based STS issue instruction. In: J. Penick (Ed.). Education and urban society: Issues-Based education, 1, 40-53, 1989.
} 
Um cidadão que não compreenda o modo de produzir ciência na modernidade será certamente uma pessoa com sérios problemas de ajuste no mundo. (...) Um país com a maioria de seus cidadãos sem essa compreensão não terá condições de participar do desenvolvimento econômico e enfrentará sérios problemas sociais, políticos e ambientais.

Fensham (2004a) declara que, durante a década de 80, havia dois pressupostos para se ensinar ciências durante a escolaridade compulsória: 1) o pressuposto pragmático, que versava sobre a necessidade dos cidadãos conhecerem a ciência, já que a sociedade está em constante contato com as ideias e produtos da ciência e tecnologia e 2) o pressuposto democrático, que declarava que uma educação em ciências de qualidade permite aos cidadãos uma participação significativa nas decisões políticas e sociais de sua comunidade, em especial nas que remetem a questões sócio-científicas e sócio-tecnológicas.

A mudança de papel que o ensino de ciências passou desde o início do século XX, bem como dos "slogans" a ela associados, que Aikenhead (2003) enumera abaixo, ocorreram em virtude de mudanças na realidade social. Assim, o ensino de ciências passou a ser conhecido também como alfabetização científica e a ele se associaram "Ciência-Tecnologia-Sociedade", "Ciência-Tecnologia-Sociedade-Ambiente", "Ciência-Tecnologia-Cidadania", "Ciência para Todos", "Ciência para a Compreensão Pública", "Ciência Cidadã”, "Alfabetização Funcional Científica" e muitos outros.

Com as mudanças ou a necessidade delas, críticas passaram a conviver com os documentos da área. Fensham (2004a, p. 10) declara, por exemplo, não haver referência nos documentos CTS, ao fato da "ciência ser um campo de investigação humana fascinante, que pode interessar tanto alunos quanto adultos”, e mais ainda, que a mídia há muito tem percebido isso, e tem oferecido uma série de produtos de entretenimento com esse objetivo.

Segundo Fensham (2004a) tanto o pressuposto pragmático como o democrático passaram a receber várias críticas: o pragmático passou a ser criticado pelo simples fato de que a necessidade de se conhecer a ciência não tem o mesmo peso da necessidade de se conhecer a língua materna, por exemplo. E a necessidade de se conhecer a ciência não é essencial para se exercer a cidadania responsável. Ainda, muitos líderes possuem assumidamente fraco conhecimento científico e o reconhecem sem constrangimento. Já o pressuposto democrático foi criticado por que mesmo que tenhamos um grande conhecimento científico, ele não nos habilita para a 
discussão aprofundada das questões científicas.

Assim, alguns autores são categóricos em afirmar que a alfabetização científica não conseguiu alcançar seus objetivos iniciais, e tampouco os pressupostos acima expostos, apontando a necessidade de uma reforma no ensino de ciências. Tal reforma foi respondida através da proposta Ciência para Todos, da Associação Americana para o Avanço da Ciência (AAAS) (DEBOER, 2000; FENSHAM, 2004a; FENSHAM, 2004b).

Tal proposta tinha como objetivo a necessidade de uma alfabetização científica atingível por todos os alunos. Ela foi fortemente criticada por Morris Shamos (1996), que argumentava que a alfabetização científica universal é um objetivo inútil, não tangível e tampouco desejável, por que além de não poder ser alcançado, a vasta maioria dos alunos sai das aulas de ciências sem nenhuma compreensão intelectual ou apreciação pragmática da ciência.

Shamos (1996) sugeriu a apreciação da ciência como um empreendimento cultural, e que a alfabetização científica deveria significar ter consciência do impacto tecnológico na saúde, na segurança, e a necessidade de usar habilidades sabiamente para resolver problemas científicos e sociais. O autor ainda declara ser romântico pensar que todos devem aprender conteúdos da ciência, mesmo aqueles que não irão seguir carreiras científicas. Mais ainda, insistir que a compreensão pública da ciência envolve alguns temas básicos da ciência mais que a tecnologia, que é algo mais palatável para o público em geral. Conhecer os produtos da ciência e seus pontos positivos e negativos para a sociedade não implica o conhecimento dos fundamentos científicos.

Ainda sobre o uso do termo alfabetização científica para o ensino de ciências, Fensham (2004b, p. 3) também tece críticas

\footnotetext{
Se o uso do termo foi dar à ciência uma nova importância e status, principalmente nas séries iniciais, quando a alfabetização da leitura e escrita e a alfabetização matemática possuem posições pré-eminentes, isso não teve sucesso. A aprendizagem da leitura, escrita e matemática sempre foram peças centrais do currículo, independentemente de quantos anos de escolaridade elementar as crianças tenham. [...] A Ciência, por outro lado, não teve lugar historicamente estabelecido no currículo primário.
}

Uma solução para o dilema do ensino de ciências é apontada por Deboer (2000): a necessidade de se decidir o que ensinar e como ensinar com base no interesse dos alunos, na 
experiência dos professores, e nos contextos locais. O objetivo não dever ser propiciar aos alunos notas altas em testes internacionais, mas sim alunos que consideram a ciência interessante e importante, com aplicação direta em suas próprias vidas e aptos a participar das conversas sobre ciência que ocorrem na sociedade.

Cossons (1993) neste respeito declara que se a ciência e a tecnologia é o fator determinante principal da nossa cultura, o papel da educação científica deve ser o de decodificar a cultura da ciência. Se a questão for assim percebida, então devemos conciliar o ensino de ciência com atitudes para com a ciência e tecnologia: é necessário saber sobre a ciência para o desenvolvimento de atitudes adequadas a ela.

Kolstø (2001) aponta a relevância da ciência para a vida cotidiana dos alunos. A alfabetização científica, segundo o autor, deve se preocupar, sobretudo, em contribuir para a solução de problemas que serão enfrentados na vida adulta, ao invés de estar relacionada a uma longa lista de tópicos científicos.

Chassot (2006, p. 96) corrobora esta visão ao afirmar que não ensinamos ciências para formar cientistas, mas para ensinar "uma linguagem que facilite o entendimento do mundo pelos alunos e alunas".

No que se refere à relevância da ciência escolar, Vazquez Alonso e Manassero Mas (2009a, p.34) apontam para a importância da discussão de diversas questões:

Que é relevante? - questões mais motivadoras do currículo;

Para quem é relevante? - alunos, professores, pais, políticos, cientistas, engenheiros, empresários etc.;

Para que é relevante? - para a vida cotidiana, exercer a cidadania, prosseguir os estudos, conseguir um emprego, ser cientista ou engenheiro etc.;

Quem decide o que é relevante? - alunos, professores, pais, políticos, cientistas, engenheiros, empresários etc.;

A resposta para tais questões não é única, uma vez que envolve uma combinação de todas as respostas, e que leva para diversas categorias de ciência escolar, desde uma ciência propedêutica, que possui relevância para aqueles que querem prosseguir seus estudos e que preparam currículos tradicionais, uma ciência social, relevante para aqueles que consideram o diálogo da ciência com a sociedade importante até uma ciência doméstica, relevante para aque- 
les que querem uma aplicação direta e prática da ciência em suas vidas (VÁZQUEZ ALONSO; MANASSERO MAS, 2009a).

Aikenhead (2004, p. 4) traz uma interessante abordagem sobre a relevância da ciência na escola. Ele sistematiza sete categorias de relevância e as relaciona a "quem decide o que é relevante":

1- Ciência que é desejável que conheçam: cientistas acadêmicos, educadores oficiais e alguns professores de ciências.

2- Ciência necessária que conheçam: O público em geral que enfrenta e resolve problemas da vida real relacionados com a ciência e tecnologia.

3- Ciência funcional: Pessoas que ocupam cargos na área científica.

4- Ciência atrativa para se conhecer: A mídia e sites na Internet.

5- Ciência que tem um motivo para ser conhecida: Experts que interagem com o público em geral a respeito de questões da vida cotidiana.

6- Ciência de curiosidade pessoal: Estudantes.

7- Ciência como cultura: Intérpretes da cultura que podem determinar quais aspectos da ciência estão presentes na cultura local, nacional e global.

A respeito da categoria "6- Ciência como curiosidade pessoal", o autor esclarece que é aquela onde os próprios alunos decidem os tópicos de interesse da ciência na escola. Sobre isso, o autor ainda comenta que "a educação científica tradicional tem desempenhado um papel insignificante na vida da maioria dos alunos", e que a ciência escolar só irá envolver os alunos quando o currículo tiver valor pessoal para os estudantes (AIKENHEAD, 2004, p. 6).

Assim, observa-se que o ensino de ciências é considerado relevante sob diversos aspectos, mesmo que não seja consenso entre os pesquisadores. Enquanto muitos apontam que o ensino é necessário para várias questões da vida cotidiana (AIKENHEAD, 2003; BIZZO, 2012; CHASSOT, 2006; COSSONS, 1993; DEBOER, 2000; KOLSTØ, 2001; LAUGKSCH, 2000), outros possuem uma visão mais simplificada, apontando como necessária apenas algumas noções básicas da ciência (FENSHAM, 2004a; FENSHAM, 2004b; SHAMOS, 1996). O que a maioria dos pesquisadores acima concorda, entretanto, é que a despeito da relevância, em diversos países tem se observado a falta de interesse dos jovens pela ciência. 


\subsection{O INTERESSE DOS JOVENS PELA CIÊNCIA NA ESCOLA}

Mesmo com tantas razões que justifiquem a relevância do ensino de ciências durante a educação básica, um grande problema contemporâneo a ser enfrentado pela comunidade científica é a falta de engajamento dos estudantes junto às ciências.

Investigações a respeito das atitudes dos estudantes frente às ciências têm aumentado significativamente, e ao mesmo tempo há evidências do declínio do interesse dos jovens em seguir as carreiras científicas. Mesmo reconhecendo-se a disseminada ignorância da população em geral sobre a ciência, há reconhecimento da importância econômica e cultural do conhecimento científico. Por isso, o aumento de atitudes negativas para com a ciência escolar tem sido motivo de preocupação (OSBORNE; SIMON; COLLINS, 2003).

Fensham (2004b, p. 2) comenta que a falta de interesse pela ciência tem sido evidenciada em muitos países e destaca a necessidade de um currículo mais significativo para os estudantes. Ao comentar pesquisas ligadas ao ensino de ciências, ele aponta para três pontos que fazem com que a ciência escolar seja desinteressante para os alunos: "1) transmissão de conhecimentos de respostas certas; 2) conteúdo irrelevante e chato e 3) dificuldade, em comparação à outras disciplinas".

Shamos (1996) corrobora este quadro ao apontar que a dificuldade dos alunos na maioria das disciplinas científicas leva a uma taxa de abandono substancial, tanto na educação básica como no ensino superior. O autor declara ainda que enquanto muitos estudantes expressam um vago interesse em ciência, não há evidências de que melhorar a instrução científica leve a um aumento do número de cidadãos competentes capazes de decidir sobre as questões científicas que permeiam a sociedade.

Fourez (2003, p. 110) aponta que a crise no ensino de ciências, refletida no baixo ingresso dos alunos nas carreiras científicas, deve-se em grande parte a uma ciência escolar que não promove o interesse dos alunos

Os alunos teriam a impressão de que se quer obrigá-los a ver o mundo com os olhos de cientistas. Enquanto o que teria sentido para eles seria um ensino de ciências que ajudasse a compreender o mundo deles. [...] Ou seja, os jovens prefeririam cursos de ciências que não sejam centrados sobre os interesses de outros (quer seja a comunidade de cientistas ou o mundo industrial), mas sobre os deles próprios. 
Uma interessante reflexão sobre este assunto foi realizada por Anthony Tomei, no prefácio do relatório Science Education in Europe: Critical Reflections. A Report to The Nuffield Foundation

[...] a compreensão de algumas práticas e processos da ciência é essencial para se envolver em certas questões confrontadas pela sociedade contemporânea. No entanto, nos últimos tempos, cada vez menos jovens parecem estar interessados em disciplinas científicas e técnicas. Por quê? Será que o problema reside em amplas mudanças socioculturais, nas formas em que os jovens nos países desenvolvidos agora vivem e desejam moldar suas vidas? Ou será que é devido a deficiências no ensino de ciências em si? (TOMEI, 2008, p. 5)

Tal relatório apresenta dados que evidenciam a diminuição do número de alunos que escolhem prosseguir o estudo das ciências físicas, engenharia e matemática na universidade em muitos países europeus. De 1993-2003 a porcentagem de graduados em ciência e tecnologia caiu na Polônia, Portugal, França, Alemanha e Países Baixos. Também diminuiu o número de alunos que seguem a carreira acadêmica (doutorado), o que tem como consequência a diminuição de cientistas (OSBORNE; DILLON, 2008).

Esta situação foi apresentada em detalhes no relatório Europe Needs More Scientists (EUROPEAN COMMISSION, 2004). No documento se destaca a preocupação com o fato de que dentre os 25 países membros da União Europeia, apenas na Grécia e na Bélgica (parte Flamenca) não se observa uma diminuição no número de jovens que escolhem estudar ciências nas escolas. No Reino Unido e Irlanda, por exemplo, a escolha pela Física e Química tem diminuído, já pela Biologia os números tem se mantido estáveis. O problema tem se apresentado também na França, Países Baixos, Noruega, Dinamarca e Itália.

Um dos tópicos abordado pelo relatório no enfrentamento deste problema é a ciência escolar. Segundo o documento, é apenas na escola que os jovens são expostos à ciência de forma sistemática, organizada e explícita. E muito provavelmente os primeiros encontros com o pensamento científico trarão impressões duradouras em sua percepção sobre a natureza da ciência e sobre as suas atitudes em relação a ela. O relatório ainda comenta que o ensino e aprendizagem da ciência na escola deveria proporcionar o aumento do interesse dos jovens pela ciência e estudos correlatos, incluindo carreiras e empregos futuros (EUROPEAN COMMISSION, 2004).

Outro relatório, organizado pela OECD, denominado Evolution of Student Interest in 
Science and Technology Studies (OECD, 2006), apresentou que nos países da OECD, nos últimos 15 anos, houve aumento do número de alunos no ensino superior, porém a proporção de alunos que se matricularam nas áreas de ciência e tecnologia caiu acentuadamente, em especial na área de ciências físicas e matemática.

Osborne, Simon e Collins (2003) comentam que uma possível interpretação para esta questão é que este é um fenômeno profundamente cultural e que o problema está além do âmbito do ensino de ciências. Tendo em conta que a aprendizagem das ciências é exigente, requer disciplina e aplicação, valores que a cultura contemporânea tem negligenciado, algum fator repousa sobre a questão do ensino. Porém, os autores comentam que a relevância imediata da ciência na sociedade parece não ser evidente para os alunos.

Os autores ainda declararam que a condição básica para a apreciação pública da ciência é o envolvimento do público com a ciência - algo que é produto de atitudes positivas geradas através da educação científica formal, ou no mínimo, atitudes neutras. As atitudes, uma vez formadas, são duradouras e difíceis de mudar (OSBORNE; SIMON; COLLINS, 2003).

Osborne, Simon e Collins (2003) relatam haver uma diminuição do interesse pela ciência com o passar dos anos escolares, principalmente a partir do ensino médio. As crianças nas séries iniciais apresentam maior interesse pela ciência do que os jovens que finalizam a educação básica. Tal fato também é evidenciado em Israel (TRUMPER, 2006), onde se tem observado que o interesse pela ciência, principalmente pela física, tem diminuído durante a escolaridade.

O relatório Science Education Now: a renewed pedagogy for the future of Europe comenta neste respeito:

O ensino de ciências na escola primária tem um impacto de longo tempo. A escola primária corresponde ao tempo de construção da motivação intrínseca, associada a efeitos de longa duração, é o tempo em que as crianças têm um forte senso de curiosidade natural, e é o tempo certo para se enfrentar padrões de preconceito. (EUROPEAN COMMISSION, 2007, p.11)

Vázquez Alonso e Manassero Mas (2008) apontam para estudos que consideram que os estudantes passam a perder o interesse pela ciência durante a adolescência, na mudança do ensino primário para o secundário. Os autores comentam que durante este período, a curiosidade natural e o interesse da criança pela ciência começam a se transformar em tédio e desinteresse 
e as experiências escolares com a disciplina passam a se tornar fracassadas, o que culmina no abandono dos jovens nas carreiras científicas.

Shamos (1996, p. 1102) também aborda esta questão ao declarar

\begin{abstract}
Por que nas séries elementares, onde os professores geralmente tem pouca formação em ensino de ciências, as crianças pequenas são deslumbradas pela magia e mistérios da ciência, e depois os jovens do Ensino Médio, que possuem professores mais bem preparados, passam a ter pouco interesse pela ciência e pela carreira científica?
\end{abstract}

Baram-Tsabari et al. (2009) comentam que as decisões dos jovens sobre os rumos de sua formação acadêmica são influenciadas em alto grau pelo interesse a temas desenvolvidos nos anos anteriores. E comentam que a habilidade em aprender também afeta a escolha da futura carreira.

Entretanto, há um consenso voltado ao fato de que todo ensino deve ser construído com base nos interesses e experiências da criança. Para que os conteúdos de ensino sejam significativos para o aluno, é necessário que tenham algum tipo de relevância, e que se encaixem no contexto pessoal e social do estudante (SJØBERG, 2000).

Jenkins (2006a) aponta, como hipótese ainda não testada, que quanto mais se sabe sobre os interesses, entusiasmos, crenças e atitudes dos estudantes, mais exequível será desenvolver um currículo escolar na área das ciências que engaje os estudantes e os ajude a diminuir as diferenças existentes no que se refere às suas escolhas acadêmicas.

Osborne (2006, p. 2) ao comentar a onda de pânico sobre a falta de interesse dos jovens no estudo da ciência, cita o comentário de um jovem sueco: "O problema com a ciência escolar é que ela fornece respostas a perguntas desinteressantes que nós nunca fizemos".

Osborne (2006) destaca a pesquisa The Relevance of Science Education (ROSE) liderada por Svein Sjøberg (Noruega) cujos resultados permitem relacionar o interesse pela ciência ao desenvolvimento econômico, através do Índice de Desenvolvimento Humano (IDH). Segundo os autores, Schreiner e Sjøberg (2005), quanto maior o valor do IDH de um país, menor é o interesse dos jovens pela ciência. E o inverso também é verdadeiro, quanto menor o IDH, maior é o interesse dos jovens pela ciência.

Baram-Tsabari e Yarden (2005,p. 803) destacam a relevância das pesquisas que visam o 
interesse do estudante: elas "permitem tornar a ciência escolar mais atrativa para o estudante e verificam como as atitudes e interesses afetam o aprendizado do conhecimento científico", uma vez que o interesse é o fator determinante que irá preparar o estudante para gastar esforços no aprendizado e na compreensão de conceitos científicos.

Diante de um quadro tão complexo, Osborne (2006) declara que não há uma resposta simples e tampouco única para a questão. A saúde do ensino de ciências depende da nossa capacidade como comunidade de ajudar a definir e informar o debate sobre que tipo de educação científica deve ser oferecida aos jovens, e em que contextos.

Assim, no que se refere à educação voltada para a ciência, a necessidade de se ouvir o estudante se torna imperativa quando nos deparamos com o fato dos jovens estarem cada vez menos interessados na ciência escolar formal. Baram-Tsabari e Yarden (2005) apontam para a importância de se ouvir a voz do aluno na construção do currículo ou nas reformas dos cursos de ciências, de maneira que se tornem mais interessantes e atrativos para os alunos.

\subsection{ESCUTAR A VOZ DO ALUNO PARA RESSIGNIFICAR A RELEVÂNCIA DA CIÊNCIA NA ESCOLA}

Para se conhecer o interesse dos estudantes pelos assuntos relacionados à ciência e suas aulas de ciências, há necessidade de se ouvir o que eles têm a dizer. Tal fato não é, de forma alguma, contemplado pelos educadores e tampouco pelos idealizadores das políticas públicas educacionais.

Sobre isso, Cook-Sather (2002, pág. 3) comenta: "há algo fundamentalmente equivocado em se estruturar e reestruturar todo um sistema educacional sem consultar, em um único ponto, aqueles a quem o sistema se destina". A autora salienta que está mais do que na hora de se ouvir e autorizar a participação dos estudantes nas críticas e reformas educacionais.

A voz do aluno, ou o termo em inglês "student voice", vem surgindo como significado de uma série de pesquisas e diretrizes tomadas pelos pesquisadores da área de educação para se referir a algo básico e ao mesmo tempo profundo: o ouvir. Tais pesquisas apontam para um reposicionamento dos estudantes nas discussões e reformas educacionais (COOK-SATHER, 2006).

Tal reposicionamento, segundo a autora, assegura aos alunos um lugar legítimo no âmbito 
educacional; permite não só estar presente, mas fazer parte, o que significa ter um papel ativo nas decisões acerca da implementação das políticas e práticas educacionais. Assim, o movimento em prol da "voz do estudante", em sua forma mais radical, exige uma mudança cultural voltada para dar "poder" aos estudantes (COOK-SATHER, 2006).

Um dos precursores deste movimento foi o programa inglês Consulting pupils about teaching and learning (2000-2003), ligado ao Economic \& Social Research Council (ESRC) ${ }^{3}$. O programa tinha como premissas:

1) Todo aluno tem o direito de ser consultado e ter sua voz ouvida. Toda criança é um ser humano com integridade, personalidade e habilidade para participar livremente da sociedade; [...] 2) É uma importante maneira dos alunos melhorarem a si mesmos. A escolarização tem como principal objetivo beneficiar os alunos, e a visão dos próprios alunos sobre tais benefícios pode melhorar sua performance na escola; [...] 3) Eles se tornam mais sensíveis a mudanças após a consulta (MCINTYRE; PEDDER; RUDDUCK, 2005, p. 150).

Os pesquisadores do programa apontam que há mais do que reconhecer que os estudantes podem ter coisas a dizer sobre como melhorar as suas experiências na escola. Através dos projetos do programa Consulting pupils observou-se uma maior apreciação da capacidade dos jovens e um reconhecimento da importância do seu desenvolvimento pessoal e social (RUDDUCK; FIELDING, 2006).

Robinson e Taylor (2007) comentam que a "voz do aluno" não significa simplesmente palavras faladas pelos alunos, mas as muitas maneiras em que os alunos expressam seus sentimentos ou pontos de vista sobre qualquer aspecto de sua vida escolar.

O valor das percepções de estudantes nos contextos contemporâneos "consiste em grande parte em sua capacidade de alertar as escolas para deficiências de seu desempenho atual e as possíveis formas de abordar essas deficiências" (FIELDING, 2001, p. 123).

A dificuldade de expressar-se num ambiente tão tradicional como o escolar, onde as opiniões pessoais não vêm facilmente à tona, foi apontada por Ranson (2000). Porém, ele declara que ouvir a voz do aluno oferece uma oportunidade dos jovens descobrirem e afirmarem suas perspectivas pessoais, além de aprenderem a cooperar, dialogar e negociar.

A sociedade atual está em constante mudança, principalmente em virtude das mídias digitais e da globalização, e os jovens, neste contexto, são informados de forma diferente, o

\footnotetext{
${ }^{3}$ ESRC Network Project: Consulting Pupils about Teaching and Learning. Disponível em <http://www.consultingpupils. co.uk/>. Acesso em 23.nov. 2012.
} 
que tem gerado implicações profundas nas relações escolares. Dada a sua experiência pessoal, os alunos devem assumir um papel diferente na educação e nas reformas educacionais (COOK-SATHER, 2002).

Jenkins (2006a, p. 4) comenta que ouvir os alunos é uma forma de reduzir sua própria alienação pela escolaridade, introduzi-los às complexidades e limitações do processo democrático, preparando-os para o exercício da cidadania. "Desta perspectiva, ouvir a voz do estudante torna-se um meio de transformar a escolaridade, uma vez que torna o currículo mais relevante para as necessidades e interesses dos alunos".

Rudduck e Flutter (2000) consideram que as crianças têm pouco a dizer sobre o currículo em si, por não possuírem parâmetro de comparação, não conhecerem currículos anteriores, e tampouco conhecerem todo o currículo. Porém, elas podem falar de pequenas partes do currículo e sobre o processo de ensino-aprendizagem.

Em relação às mudanças curriculares, Rudduck e Flutter (2000) apontam que o conteúdo curricular é pautado no conceito de relevância. Porém, tal conceito é reflexo do que é relevante para os adultos, e não do que é significativo para os jovens. Eles concluem que o currículo deve ser subsidiado por um conceito transformador de conhecimento, que enfatiza os alunos sobre como eles podem agir na sociedade atual. E ainda, dar destaque a conteúdos que possuem relevância para seus problemas cotidianos.

É claro que o processo de ouvir alunos envolve uma série de cautelas. Cook-Sather (2006) destaca algumas delas: manter a voz do estudante passiva, audível apenas como produto de desempenho do passado; fazer uma simplificação do assunto discutido, visando uma prática de manipulação; ter uma visão romântica das crianças, privilegiando-as nas reformas; ouvir coisas que não se quer ouvir; resistir à tentação de glamourizar a voz do estudante; colocar alunos e professores uns contra os outros e ainda, criticar professores.

Os alunos podem ser ouvidos de diversas formas. Segundo Fielding (2001) os alunos podem ser fonte de dados, respondentes ativos, co-pesquisadores e pesquisadores. Dentro desta tipologia, Fielding esclarece que qualquer um dos papéis é válido, desde que adequado ao objetivo proposto pela pesquisa ou reforma.

A despeito da vasta literatura existente sobre o "ouvir estudantes", Jenkins (2006a) declarou que ela tem tido pouco impacto no ensino de ciências. Ele aponta que poucas pesquisas têm sido realizadas sobre a opinião dos alunos em relação à relevância de conteúdos em testes 
internacionais ou mesmo sobre o interesse em si, que comumente é tratado como um atributo pessoal do estudante, e não como um resultado da educação científica.

O autor ainda comenta que pesquisas sobre "a voz do estudante" revelam que uma queixa frequente dos alunos é que o currículo de ciências na escola está sobrecarregado com o conteúdo, queixa muitas vezes repetida pelos professores. Ele ainda salienta o fato dos alunos não apreciarem atividades com apresentações repetitivas de tópicos científicos ou ditado/cópia. Eles de fato gostariam que suas aulas de ciências fossem mais significativas para sua vida diária, incluindo mais atividades práticas, mais atenção a temas científicos contemporâneos e atividades geradoras de discussão e participação (JENKINS, 2006a).

Jenkins e Nelson (2005) apontam que, no que se refere ao ensino de ciências, os pesquisadores tem dificuldade em acomodar a voz do aluno num currículo que enfatiza a ciência como um corpo estabelecido de conhecimento a ser aprendido. Uma hipótese é de que eles consideram que os alunos não estão em condições de fazer julgamentos sobre o que deve ser ensinado em seus cursos de ciências na escola.

Sjøberg (2002) aponta que há uma preocupação generalizada para tentar fazer o currículo de ciências mais significativo, relevante e adaptado a diferentes grupos e diferentes culturas. Ele conclui discutindo a questão da relevância para o aluno, através do conhecimento de suas visões, experiências e perspectivas.

Jenkins (2006a, p. 23) finaliza seu artigo com a seguinte consideração

\footnotetext{
Finalmente, o que as pesquisas sobre a voz do estudante podem dizer especificamente sobre o ensino de ciências nas escolas? Há evidências que sugerem que consultar os estudantes acerca de suas percepções sobre a ciência e sobre o ensino de ciências na escola podem melhorar sua motivação e contribuir para o desenvolvimento de uma ampla gama de estratégias de ensino e, assim, elevar os níveis de sucesso dos alunos em ciências.
}

Assim, escutar o que os alunos têm a dizer sobre os temas de ciências que consideram interessantes, suas aulas de ciências e suas posições acerca da importância da ciência na vida cotidiana podem trazer contribuições significativas para o ensino de ciências em si, tornando o currículo mais relevante também para aqueles que irão cursá-lo, e não somente para os professores e pesquisadores. 


\subsection{INTERESSES E ATITUDES: A DIMENSÃO AFETIVA DA APRENDIZAGEM DA CIÊNCIA}

Um dos pontos que permeia as discussões aqui apresentadas é referente às atitudes para com a ciência. Atitudes, entusiasmo e interesse constituem o que se denomina dimensão afetiva da aprendizagem. Simpson et al. (1993) esclarecem que o domínio afetivo do aprendizado envolve uma série de construtos: atitudes, valores, crenças, opiniões, interesses e motivação. Durante o processo de aprendizagem, todos esses elementos se relacionam, de forma que

os aspectos afetivos e cognitivos presentes na mente humana não se constituem em universos opostos, pelo contrário, estão indissociados em nossos pensamentos e nossas ações (ARANTES, 2003, p. 109).

O interesse por temas apresentados na escola está vinculado ao afeto, tanto aquele demonstrado ao se executar atividades pedagógicas, como o relacionado aos riscos pessoais envolvidos durante o aprender. $\mathrm{O}$ afeto envolve evitar situações consideradas chatas, onde o trabalho do aluno é penoso e muitas vezes repetitivo, e valorizar situações que promovam entusiasmo, alegria, quando o estudante é tomado pela vontade de aprender (ALSOP; WATTS, 2003).

Conhecer as atitudes dos alunos para com a aprendizagem é necessário por que, conforme relatam Pell e Jarvis (2001), crianças com atitudes positivas são mais suscetíveis em manter a aprendizagem e querer dar continuidade ao estudo dos assuntos que gostam. Schreiner e Sjøberg (2004, p. 19) consideram que

A aprendizagem a longo prazo só é possível se as escolas estimularem interesse duradouro e atitudes positivas para a aprendizagem. Investir em atitudes é investir no futuro.

Especificamente dentro do campo do ensino de ciências, podemos distinguir dois tipos de atitudes: atitudes científicas e atitudes para com a ciência. Simpson et al. (1993) apontam as atitudes científicas como modos de pensamento, uma vez que envolvem as maneiras pelas quais os cientistas creem e conduzem seu trabalho: a busca por respostas, o questionamento, a coleta de dados e seu significado, a verificação de hipóteses etc. 
Sobre as atitudes para com a ciência, Simpson et al. (1993) argumentam que se referem a positivas ou negativas respostas pessoais ao empreendimento científico. Os autores apresentam uma série de itens que auxiliam na compreensão das atitudes dos alunos para com a ciência: 1) Gostar/não gostar da ciência (ex.: Eu realmente gosto de ciência; Eu gostaria de ser cientista); 2) Motivação para obtenção de resultados em ciência; 3) Ansiedade relacionada à ciência (ex.: As provas de ciências me deixam nervoso); 4) Atitudes relacionadas ao professor de ciências e 5) Atitudes relacionadas ao currículo de ciências.

Uma pesquisa realizada por Siegel e Ranney (2003, p. 758) a respeito das atitudes dos alunos para com a ciência revela que "conhecer as atitudes dos alunos é uma maneira de aumentar o interesse, a performance e a persistência dos alunos na ciência”. Os autores também verificaram que as atitudes dos estudantes em relação à relevância da ciência podem ser mudadas através de atividades pedagógicas orientadas especificamente para este fim. Eles ainda ressaltam que as atitudes em relação à ciência são determinantes sobre seu futuro envolvimento e desempenho nas aulas e carreiras científicas.

Em relação à motivação, Koballa Jr. e Glynn (2006) esclarecem seu papel no aprendizado da ciência: atitudes influenciam a motivação, que por sua vez influenciam o aprendizado e o comportamento. A motivação é considerada intrínseca quando derivada da excitação, interesse e curiosidade pessoal. Um aluno com motivação intrínseca em aprender o faz com deleite, sem se preocupar com recompensas. Motivações de ordem externa à pessoal, como incentivos, são consideradas extrínsecas.

Nesta perspectiva, alinhado à motivação, o interesse também constitui importante elemento no aprendizado da ciência. Wade (2001) esclarece que o interesse está relacionado às interações do indivíduo com o ambiente: há interesses derivados especificamente das características do meio - conhecido como interesse situacional - e derivados de disposições inerentes ao indivíduo - conhecido como interesse individual ou pessoal.

Sobre o interesse individual ou pessoal, Wade (2001, p. 245) considera que

O interesse individual (...) se desenvolve por longo tempo, é relativamente estável e está associado ao significado pessoal, a emoções positivas, de alto valor, e aumento de conhecimento.

A autora ainda discute que há pesquisadores que igualam o interesse individual com a 
motivação intrínseca, sugerindo que quando as pessoas estão intrinsecamente motivadas, elas estão livremente fazendo o que lhes interessa, porém outros os consideram diferentes, uma vez que o interesse está relacionado especificamente a determinado tema ou pessoa, enquanto que a motivação ao comportamento humano. De fato, o interesse individual pode ser considerado como provendo contexto para o desenvolvimento da motivação intrínseca (WADE, 2001).

O interesse individual se desenvolve ao longo do tempo, através do conhecimento de determinado assunto, perguntas instigantes sobre ele e desafios. Ele fornece a base para o aprofundamento do conhecimento e sentimentos de competência. Desta forma, o interesse individual possui componentes que evoluem ao longo do tempo, contemplando tanto o prazer em descobrir algo como o compromisso em trabalhar com ele (WADE, 2001).

Dada a importância que o interesse possui na vida do aluno, tanto no que se refere ao envolvimento com a ciência escolar, como às suas escolhas futuras - acadêmicas, de trabalho e de ordem pessoal - é essencial que os pesquisadores da área de ensino de ciências se debrucem sobre este tema, procurando compreender tantos os assuntos que os interessam como as razões para o desenvolvimento do interesse.

Para Simpson et al. (1993), as atitudes podem ser indicadores da condição do ensino de ciências, uma vez que há comportamentos desejáveis que os alunos desenvolvam ao longo da escolaridade. Conhecer as relações envolvidas neste processo permite estabelecer nexos de casualidade que possuem implicações no aprendizado do aluno e nas atitudes que eles desenvolvem para com a ciência. Por exemplo, os autores citam atitudes como: o reconhecimento de que o aprendizado da ciência é útil, o uso dos métodos e ferramentas científicas para resolver problemas, o apoio às atitudes científicas que visam à solução de problemas ambientais e ao trabalho no campo da ciência ou do seu ensino.

Alsop e Watts (2003, p. 1046) defendem que

o afeto está relacionado com a cognição, as crianças não irão aprender se não estiverem confortáveis e alegres, independente de quão bem delineadas forem as práticas pedagógicas.

O aprendizado da ciência deve ser divertido e significativo para o aluno, de forma a favorecer atitudes positivas que os motivem em prol da aquisição de conhecimento e melhoras na sua performance (KOBALLA JR.; GLYNN, 2006). 
$\mathrm{Ng}$ et al. (2012, p. 234) relatam que emoções relacionadas à competência, à autoconfiança, ao medo e à frustração desempenham um importante papel no modo como o aluno aprende, uma vez que o afeto é um sentimento que possui consequências ativas no modo como os estudantes se relacionam com a escola. Por isso, "os educadores de ciências e matemática têm que reconhecer que os alunos vêm para a sala de aula com emoções e predisposições, especialmente no contato com assuntos mais difíceis, como ciência e matemática".

Schreiner e Sjøberg (2004) consideram que a apreciação da natureza em si e o empreendimento científico são importantes questões da dimensão afetiva da aprendizagem da ciência. Valorizar a natureza e o conhecimento que o homem construiu sobre ela permite que os alunos, futuros cidadãos, tenham uma postura mais consciente em relação aos desafios enfrentados pela humanidade. Os autores também apontam o empowerment (palavra com tradução limitada para o português, como capacitar, habilitar, autorizar) derivado da aprendizagem da ciência como outra questão que merece importância na escola: o sentimento de que você tem condições de mudar, de fazer diferença, tanto na vida pessoal como na do outro, nas esferas local, nacional e até mesmo global, permite que os jovens se tornem participantes ativos da sociedade em prol de um mundo melhor.

\subsection{PESQUISAS SOBRE PERCEPÇÕES, OPINIÕES, ATITUDES E VISÕES ACERCA DA CIÊNCIA}

O papel da ciência na sociedade atual passou a adquirir, no final do século XX, um status diferenciado, associado à sua relevância, impacto, e as necessidades dos cidadãos em compreenderem e discutirem seus desdobramentos na vida diária. Assim, assumindo as palavras de Vogt (FAPESP, 2005, p. 4)

\footnotetext{
$\mathrm{Na}$ tentativa de compreender a dinâmica das relações entre ciência, tecnologia e sociedade, colocou-se a necessidade de se desenvolver uma geração de indicadores que permitam avaliar o modo pelo qual evoluem a percepção pública, a participação dos cidadãos e a cultura científica, de modo geral.
}

Dessa tentativa surgiu, na década de 80, um importante movimento: a Compreensão Pública da Ciência. Segundo Turner (2008, p. 55) 
esse movimento consistiu em novos esforços para promover o conhecimento público da ciência e incutir confiança e apoio ao empreendimento científico. Como efeito associado, o movimento estimulou o crescimento de um novo campo de pesquisa organizado em torno de medidas sobre a Compreensão Pública da Ciência e análises dos fatores que lhe dão forma.

Vogt (FAPESP, 2005) aponta que esta nova área de conhecimento está organizada sobre três indicadores básicos: o interesse, o conhecimento e as atitudes. Através do indicador interesse a sociedade atribui importância à atividade científica; o indicador conhecimento permite estabelecer relações entre a sociedade e a compreensão de tópicos científicos e os indicadores de atitudes permitem conhecer algumas posturas da sociedade, como por exemplo, confiança na comunidade científica, percepção dos benefícios e riscos da atividade científica e outros.

Turner (2008) considera que os resultados do movimento Compreensão Pública da Ciência têm influenciado os debates educacionais, porém há necessidade de uma maior interação entre ele e a educação científica escolar. Isso por que, os educadores de ciências ainda não estão familiarizados com o movimento como um campo de pesquisa, o que tem levado os estudiosos da área a concentrar seus esforços em adultos e jovens fora do ambiente escolar.

No âmbito educacional, uma pesquisa pioneira na investigação da visão do aluno acerca da ciência e de seu papel na sociedade foi a Views on Science, Technology and Society (VOSTS) liderada pelos pesquisadores Glen Aikenhead e Alan Ryan, da Universidade de Saskatchewan, no Canadá. A pesquisa, datada de fins da década de 80 e início de 90, possui como instrumento um questionário de 114 itens com afirmações e uma série de posições dos alunos acerca de cada uma dessas afirmações (AIKENHEAD; RYAN; FEMING, 1989, AIKENHEAD; RYAN, 1992, AIKENHEAD, 1997).

Esta pesquisa teve uma série de desdobramentos, e influenciou muitos pesquisadores, inclusive no Brasil, sendo direcionada tanto a professores como a alunos. Uma razão para a utilização do instrumento VOSTS nas pesquisas é a estrutura do questionário, que possui diversos tipos de posicionamento dos respondentes (classificados como adequado, plausível e ingênuo) e o fato dele ter sido desenvolvido a partir das respostas escritas dos estudantes e de sequências de entrevistas, e, sobretudo por que ele visava conhecer as ideias dos es- 
tudantes (MANASSERO MAS; VÁZQUEZ ALONSO, 2001; AULER; DELIZOICOV, 1999; GUIOMAR; TOMAZELLO, 2004).

Assim, desde a década de 80, pesquisas relacionadas à percepção pública da ciência ou compreensão pública da ciência e ao movimento "Ciência, tecnologia e Sociedade" (CTS) passaram a ser desenvolvidas em diversos países, com o intuito de conhecer e discutir a importância da ciência tanto para os estudantes como para o público em geral (TURNER, 2008).

Algumas pesquisas sobre a percepção pública da ciência no Brasil, que trazem pontos de diálogo com a pesquisa apresentada nesta tese, merecem ser discutidas: uma pesquisa piloto realizada no município de Campinas, dentro de um contexto internacional envolvendo a Rede IberoAmericana de Indicadores de Ciência e Tecnologia (RYCT) e a Organização dos Estados IberoAmericanos (OEI) (VOGT; POLINO, 2003), outra promovida pela FAPESP, também dentro do contexto RYCT, nos anos 2004 e 2010 (FAPESP, 2005; FAPESP, 2011) e outra, de caráter nacional, realizada pelo Ministério da Ciência e Tecnologia (MCT, 2007). O Ministério da Ciência e Tecnologia fez uma $2^{\mathrm{a}}$ edição da pesquisa em 2010 (MCT, 2010; MOUTINHO, 2011).

A pesquisa realizada pelo MCT (2007) consistiu num estudo quantitativo, realizado através de 2004 entrevistas domiciliares e pessoais, com questionário estruturado, realizadas entre os dias 25 de novembro e 09 de dezembro de 2006. Nesse estudo, os estratos principais foram as regiões brasileiras, de forma que nem todos os estados foram contemplados na amostra. Dentre as questões realizadas, algumas estavam relacionadas diretamente com a ciência e tecnologia: $41 \%$ dos entrevistados declararam ter muito interesse pelo tema e $46 \%$ declararam que a ciência e a tecnologia trazem mais benefícios que malefícios para a humanidade. Outras questões relacionadas à credibilidade das informações, a visitação em espaços de divulgação científica, às instituições científicas e os cientistas também foram abordadas (MCT, 2007).

$\mathrm{Na}$ edição da pesquisa realizada em 2010, 65\% dos entrevistados declararam possuir interesse pela ciência de modo geral, $83 \%$ afirmaram ter interesse por temas relacionados ao meio ambiente e $81 \%$ por temas relacionados à medicina (MOUTINHO, 2011).

O estudo piloto sobre a percepção pública da ciência promovido pelo RICYT e OEI envolveu o Brasil, Argentina, Uruguai e Espanha, e trouxe uma discussão interessante sobre a importância da percepção pública da ciência, tanto como indicador de valor estratégico como para a definição e consecução de políticas públicas na área: 
o interesse pela cultura científica e tecnológica da sociedade pode ser a base de tentativas de democratização na seleção de tecnologias e prioridades de conhecimento mais adequadas às demandas da sociedade e aos 'interesses objetivos' das maiorias sociais (VOGT; POLINO, 2003, p. 33).

Sobre a importância de o público geral ter conhecimento da ciência, os autores listam quatro argumentos: 1. Argumento pragmático: para saberem como atuar na vida cotidiana; 2. Argumento democrático (cívico): para relacionarem-se com os complexos temas científicos que se confrontam os cidadãos; 3 . Argumento cultural: a ciência é necessária para a compreensão da cultura, uma vez que constitui parte da herança cultural da humanidade e propõe explicações sobre diversos objetos e fenômenos e 4. Argumento econômico: cidadãos com suficiente cultura científica consolidam a economia da maioria dos países (VOGT; POLINO, 2003).

A amostra brasileira envolveu 162 pessoas de diversas faixas etárias. A maioria dos entrevistados, nos quatro países, "concorda que o desenvolvimento da ciência e da tecnologia é o principal motivo da melhoria da qualidade de vida da sociedade" (VOGT; POLINO, 2003, p. 81). Porém, a visão de que a ciência e tecnologia podem resolver todos os problemas não é compartilhada por nenhum dos países pesquisados.

Sobre a relação entre ciência e emprego, $61,7 \%$ dos entrevistados brasileiros concordam que a aplicação da ciência e tecnologia aumentará as oportunidades de trabalho. Ainda, 64,8\% concordam com a afirmação "Se descuidarmos da ciência, nossa sociedade será cada vez mais irracional" e 75,9\% indicaram concordar que os benefícios da ciência e da tecnologia são maiores que seus efeitos negativos (VOGT; POLINO, 2003).

Ao citarem um estudo realizado pela americana National Science Foundation (NSF) publicado em 2000, os autores declararam que o interesse pela ciência aumenta à medida que os indivíduos têm maior nível de formação e posição elevada na escala socioeconômica, porém pessoas com atitudes altamente positivas possuem baixa compreensão dos conteúdos científicos (VOGT; POLINO, 2003).

Estes dados, apesar de não estarem relacionados diretamente com o público escolar e sim com o público geral, oferecem elementos para a discussão de alguns dados interessantes já obtidos pelo projeto ROSE citados anteriormente: jovens de países em desenvolvimento têm mais interesse pela ciência escolar que os jovens de países desenvolvidos (SCHREINER; SJØBERG, 2005, SCHREINER; SJØBERG, 2007, SJØBERG; SCHREINER, 2005). 
A pesquisa publicada pela FAPESP em 2005 também aborda esta questão ao mencionar estudos que afirmam que "níveis maiores de conhecimento científico e status socioeconômico podem também ser relacionados à atitude mais crítica diante de aplicações tecnológicas e sobre (...) o impacto social da pesquisa científica” (FAPESP, 2005, p. 7).

A amostra da FAPESP em 2005 envolveu 1063 entrevistados das mais diversas faixas etárias. $78 \%$ dos entrevistados concordaram com a frase "a causa principal da melhoria da qualidade de vida humana é o avanço da ciência e da tecnologia". Apesar da visão positiva da ciência, ela não é vista no superlativo, como capaz de resolver todos os problemas da sociedade, já que apenas 19\% assinalaram esta opinião. Em relação a empregos, $67 \%$ dos entrevistados concordaram que a aplicação da ciência e da tecnologia tem o potencial de aumentar os postos de trabalho (FAPESP, 2005).

Sobre a imagem da ciência como fonte de risco, $72 \%$ consideraram que ela traz mais benefícios que prejuízos, porém a visão dos entrevistados não é tão otimista, uma vez que $45 \%$ dos entrevistados apontaram que o desenvolvimento da ciência traz problemas para a humanidade. Por fim, a pesquisa aponta que há um alto nível de interesse médio declarado pelos cidadãos em relação à ciência e tecnologia e um reconhecimento alto do valor e da importância da pesquisa científica de base para todas as sociedades (FAPESP, 2005).

A pesquisa publicada pela FAPESP em 2010 também está dentro do contexto iberoamericano, envolvendo desta vez mais países: Colômbia, Argentina, Venezuela, Espanha, Panamá, Chile e Brasil. Foram entrevistadas 1076 pessoas na cidade de São Paulo e 749 no interior e litoral, totalizando 1825 entrevistados em 35 municípios. Vale ressaltar que nesta edição da pesquisa, o questionário foi modificado de forma que os entrevistados, em algumas questões, indicavam o nível de interesse numa escala de Likert com quatro pontos (muito interessado a nada interessado) (FAPESP, 2011).

Os resultados obtidos revelam que no Estado de São Paulo o interesse que as pessoas declaram ter por assuntos de caráter científico ou tecnológico é bastante elevado. Os temas que receberam maior declaração de interesse foram Alimentação e consumo, Medicina e Saúde, Meio ambiente e ecologia. Interessante notar também que foi observado que "as classes econômicas mais altas tendem a apontar mais benefícios futuros da ciência e da tecnologia", fato não observado nas classes mais baixas, que parecem mais céticas, "muito provavelmente porque acreditam que o usufruto desses benefícios envolve um poder econômico que elas não possuem" (FAPESP, 2011, p. 48). 
Observa-se que as pesquisas sobre percepção pública da ciência no Brasil trazem dados extremamente significativos sobre o interesse da população pela ciência. É possível e necessário estabelecer um diálogo entre a percepção do público em geral e a percepção pelos jovens escolares, já que se observa que enquanto o interesse dos jovens pela ciência vem diminuindo, o interesse pela ciência não-formal - revistas, livros, programas de rádio e televisão, visitas a centros e museus - do público em geral vem aumentando (SCHREINER; SJØBERG, 2007). Assim, procuraremos, ao discutir os resultados obtidos junto ao ROSE Brasil, trazer à tona algumas comparações com as pesquisas aqui apresentadas, não só como um parâmetro, mas também como meio de se verificar se os jovens, no que se refere ao interesse pela ciência, diferem ou não do público em geral.

Uma pesquisa sobre interesse especificamente dos jovens pela ciência foi realizada pelo Programa Internacional de Avaliação de Estudantes (PISA) da Organização para Cooperação Econômica (OECD) no ano de 2006. O PISA é uma avaliação internacional desenvolvida pelos países-membros da OECD, de habilidades e conhecimentos de jovens de 15 anos, que visa aferir até que ponto os alunos que estão finalizando a educação obrigatória adquiriram conhecimentos e habilidades essenciais para a participação efetiva na sociedade, focado nos domínios da leitura, matemática e ciências (INEP, 2001).

A aplicação do PISA em 2006 foi focada na área de ciências e teve como instrumento, além do caderno de testes que visa avaliar a proficiência do aluno, o instrumento "Questionário do Aluno" que buscava obter informações socioeconômicas e culturais, hábitos de estudo dos alunos, seus interesses e motivações (INEP, 2008).

Através dos questionários foi possível conhecer o interesse dos estudantes pelas ciências e suas aulas de ciências, incluindo "questões relacionadas a ciências, seu desejo de adquirir habilidades e conhecimentos científicos, e sua avaliação quanto a carreiras relacionadas a ciências". Também se obteve dados sobre "a percepção e as atitudes dos estudantes com relação a questões ambientais" (OECD, 2007).

Alguns resultados obtidos sobre interesse junto ao PISA 2006 são bastante interessantes: os estudantes relataram gostar de ciências em geral e apoiar a investigação científica. Entre os países da OECD, 93\% concordaram que o estudo de ciências é importante para compreender o mundo natural e $92 \%$ concordaram que os avanços em ciência e tecnologia usualmente melhoram as condições de vida das pessoas (OECD, 2007). 
Os dados obtidos ainda apontam que $75 \%$ concordaram que as ciências ajudam a compreender as coisas ao seu redor, mas apenas $57 \%$ concordaram que o estudo de ciências é relevante em termos pessoais. Os estudantes relataram ainda ter interesse em estudar ciências, mas apenas uma minoria se vê utilizando ciências no futuro (OECD, 2007).

Conforme observado acima, os resultados da pesquisa do PISA 2006 sobre interesse apresentados nos relatórios referem-se aos dados de modo geral e não são específicos sobre o Brasil. Apenas nos quadros comparativos entre países há algumas informações sobre o país (OECD, 2007). Assim, foi realizada uma análise do próprio banco de dados do PISA $2006^{4}$ no que se refere ao interesse dos alunos pela ciência, a fim de comparar com os dados obtidos junto ao ROSE Brasil. Tais informações serão apresentadas mais adiante nos capítulos referentes à Metodologia (capítulo 3) e Resultados (capítulos 5, 67 e 8).

\subsection{O PROJETO INTERNACIONAL "THE RELEVANCE OF SCIENCE EDUCATION”(ROSE)}

O projeto The Relevance of Science Education (ROSE) surgiu como uma tentativa em responder aos diversos dilemas enfrentados pelos pesquisadores da área de ensino de ciências e pela própria sociedade: a diminuição do interesse dos jovens em seguir carreiras científicas, a diminuição do interesse pela ciência ao longo da escolaridade básica, a necessidade de se ouvir os estudantes nas propostas educacionais e a posição da educação científica face à diversidade cultural existente na sociedade.

Para isso, ele busca coletar dados de natureza atitudinal e emocional dos estudantes, abordando aspectos que podem ser importantes para o engajamento tanto na ciência escolar como na vida em geral. As experiências que o estudante tem, os tipos de interesse relacionados a conteúdos da ciência e tecnologia $(C \& T)$ e suas visões e atitudes em relação à $C \& T$ na sociedade são contemplados através do instrumento de coleta de dados (SCHREINER; SJØBERG, 2004).

O projeto ROSE teve como precursor o projeto Science and Scientists (SAS-study), sediado na Universidade de Oslo, que tinha como objetivo obter padrões de referência sobre o papel e função do currículo de ciências. Para isso, um questionário voltado a crianças de

\footnotetext{
${ }^{4}$ O banco de dados do PISA 2006 referente ao Questionário do Aluno foi obtido através da Coordenação Nacional do PISA no Brasil (INEP/MEC).
} 
13 anos de idade foi desenvolvido em colaboração com pesquisadores da Uganda e Índia. O questionário abordava questões relacionadas às experiências dos alunos fora da escola, seus interesses em aprender diferentes tópicos da ciência, suas percepções sobre a ciência, a imagem dos cientistas e suas prioridades para o futuro (SJØBERG, 2002; SCHREINER, 2006).

O ROSE começou a ser discutido institucionalmente em 2001, quando um workshop internacional foi realizado em Oslo (Noruega). Pesquisadores provenientes de mais de 30 países declararam interesse em participar do projeto e os dados começaram a ser coletados no ano de 2002 (SJØBERG, 2002).

O projeto ROSE foi desenvolvido e coordenado pelo professor Svein Sjøberg e teve como pesquisadora principal Camilla Schreiner, que sistematizou grande parte do projeto em sua tese de doutoramento (SCHREINER, 2006). O projeto busca conhecer o que os alunos consideram relevante, por quais temas eles se interessam, o que pensam da ciência escolar e que fatores podem influenciar suas escolhas em relação ao futuro. Dentre os objetivos do projeto, destaca-se

\footnotetext{
- Desenvolver perspectivas teóricas sensíveis à diversidade de cenários (culturais, sociais, etc.) dos alunos para discussões de prioridades relacionadas à C\&T;

- Desenvolver um instrumento para coletar dados de alunos (com idades próximas aos 15 anos) relacionado a suas experiências, interesses, prioridades, imagens e percepções do que são relevantes para seu aprendizado das C\&T e suas atitudes frente ao assunto;

- Coletar, analisar e discutir dados vindos de um abrangente número de países e de contextos culturais, utilizando o instrumento citado acima;

- Desenvolver recomendações políticas para a melhoria do currículo, de livros e demais materiais didáticos e de atividades em sala de aula baseadas nas descobertas citadas acima;

- Levantar questões relacionadas à relevância e importância da ciência nos debates públicos e nos fóruns científicos e educacionais (SCHREINER; SJØBERG, 2004, p.6).
}

Relevância é a palavra chave para o desenvolvimento do projeto. Por isso, Schreiner (2006, p. 70) apresenta algumas questões que merecem reflexão quando o assunto é a relevância do ensino de ciências 
Relevante para quem? Relevante para o quê? Relevante para os estudantes que têm como objetivo prosseguir seus estudos e carreira em ciência e tecnologia? Relevante para promover o crescimento econômico? Relevante para qualificar cidadãos no exercício da cidadania? Relevante para obtenção de altos scores em testes como o TIMSS $\%$ PISA? Relevante para aulas de ciências mais apreciadas pelos alunos? Relevante para o desenvolvimento sustentável?

Para os idealizadores do projeto ROSE, a "falta de relevância no currículo de C\&T é provavelmente uma das grandes barreiras para a compreensão do tema, bem como para o maior interesse no assunto". Por isso, o projeto pode trazer perspectivas teóricas e empíricas para discussões mais fundamentadas sobre como melhorar o currículo e aumentar o interesse dos alunos em relação à ciência e tecnologia (SCHREINER; SJØBERG, 2004, p.6).

Schreiner (2006) afirma que o projeto ROSE assume a perspectiva do que é relevante sob o ponto de vista do aluno e o que eles expressam ser de interesse para suas vidas. Assim, o projeto procura conhecer uma série de aspectos relacionados aos interesses, percepções, preocupações, esperanças, valores, experiências e atitudes, no que tange à ciência e tecnologia, e seus planos e prioridades para o futuro.

Para Schreiner e Sjøberg (2007), a investigação dos interesses dos estudantes se faz necessária por que suas escolhas em relação ao futuro, a carreira no ensino superior ou a profissão, estão vinculadas a quanto elas serão interessantes, importantes ou significativas, e a quanto elas se harmonizam com a identidade e desenvolvimento pessoal dos jovens.

Os autores argumentam que a maior parte do conteúdo abordado nas aulas de ciência é esquecida pelo aluno ao longo da vida. Porém, questões escolares relacionadas às atitudes possuem um efeito mais duradouro. Estudantes que desenvolveram um interesse pela ciência na escola provavelmente continuarão tendo interesse ao longo da vida. Da mesma forma, os alunos que aprenderam a odiar a ciência e matemática na escola são propensos a evitar estes assuntos. Assim, os fatores afetivos são determinantes para a escolha de opções de futuro dos estudantes (SCHREINER; SJØBERG, 2004).

Estudos envolvendo a aplicação do projeto ROSE em diversos países buscaram compreender os fatores, dentro do domínio afetivo e das atitudes, que interferem no interesse dos jovens em relação à ciência e tecnologia, tanto no que se refere às suas escolhas acadêmicas como também em relação à futura profissão.

\footnotetext{
${ }^{5}$ Trends in International Mathematics and Science Study" (TIMSS) é uma avaliação norte-americana de proficiência realizada desde 1995 quadrienalmente. Em 2011 participaram mais de 60 países. Informações em <http://nces.ed.gov/ timss/>. Acesso em 06.dez.2012.
} 
Anderson (2006), que implementou o projeto ROSE em Gana, discutiu a diferença entre as atitudes em relação à ciência e atitudes científicas. A primeira se refere de modo geral a sentimentos positivos ou negativos sobre a ciência, muitas vezes relacionada a comportamentos e crenças sobre a ciência. Já as atitudes científicas implicam determinadas maneiras de pensar e certos modos de abordar problemas, e costuma ser um resultado do ensino de ciências na escola. No que se refere às atitudes em relação à ciência, que é o foco do projeto ROSE, o autor comenta o papel decisivo dos professores, dos métodos de ensino e do ambiente de sala de aula.

Anderson ainda considera que qualquer tipo de atitude que os alunos desenvolvem nas aulas de ciência influencia na utilização de seus conhecimentos, competências e habilidades, tanto para a escolha da futura profissão, como para a participação democrática no debate sobre questões científicas (ANDERSON, 2006).

Trumper (2006), ao relatar sobre a aplicação do ROSE em Israel, argumenta sobre o domínio afetivo do aprendizado, que está relacionado com o interesse individual, os temas de interesse e o clima da sala de aula, que podem levar a atitudes positivas e/ou negativas em relação ao interesse pela ciência.

Assim, o projeto ROSE parte do pressuposto de que o ensino de ciências está estreitamente conectado a outros tipos de conhecimento, derivados das referências culturais dos estudantes, de seus valores, interesses e atitudes (NERESINI; CROVATO; SARACINO, 2010).

Na Finlândia, um dos países cujos alunos possuem maior proficiência em ciência na avaliação do PISA, os pesquisadores do ROSE abordaram questões envolvendo a diferença entre o interesse pessoal - aquele mais profundo e permanente, e o interesse situacional - aquele que é momentâneo, gerado por determinadas circunstâncias, bem como os fatores que influenciam o interesse. Os autores argumentaram que a exploração do interesse situacional dos alunos na ciência escolar pode levar ao desenvolvimento do interesse pessoal, o que implica a discussão de métodos de ensino adequados (LAVONEN et al., 2005).

O interesse situacional pode variar dependendo das abordagens pedagógicas que o professor contempla em suas aulas. Já o interesse pessoal é mais específico e persistente, e pode ser subdividido em "interesse latente" e "interesse motivacional". O interesse pessoal latente é aquele que guia os alunos através do engajamento cognitivo, quando ele aprecia aprender determinados temas e fenômenos, experimenta e resolve problemas. Já o interesse motivacional é guiado por situações de motivação, ou seja, pelo interesse situacional (LAVONEN et al., 2008). 
Por isso, o ensino ocupa papel central no desenvolvimento do interesse pessoal dos estudantes.

Chang, Yeung e Cheng (2009) apontam que estudos sobre as atitudes dos alunos em relação à ciência ou à aprendizagem da ciência têm se tornado um componente chave para a área de ensino de ciências na atualidade, e deve ser considerado como um indicador da qualidade do ensino. A aplicação do projeto ROSE em Taiwan (China) mostrou que é necessário investigar mais profundamente as relações existentes entre as experiências de vida (em relação à ciência e tecnologia) dos alunos e o interesse pela ciência e a aprendizagem. Eles consideram que atividades práticas nas aulas de ciências, mais informais, onde as experiências dos alunos vêm a tona, podem aumentar o interesse pela disciplina e seu posterior aprendizado.

A discussão do projeto ROSE na Inglaterra foi pautada na importância de se ouvir a voz do estudante, tão negligenciada nos estudos em educação. Os pesquisadores apontaram que os estudantes sempre foram considerados objetos de estudo, e não parceiros do processo educativo, por isso, estudos que consideram a visão dos estudantes são de extrema relevância para o ensino de ciências (JENKINS, 2006b; JENKINS; NELSON, 2005; JENKINS; PELL, 2006).

Jidesjö et al. (2009), que implementaram o projeto na Suécia, consideram fundamental investigações que priorizam a dimensão afetiva do aprendizado, uma vez que se tem observado que a percepção dos estudantes em relação à relevância da ciência escolar é suscetível a diferenças de idade, gênero, experiências fora da escola e do próprio ensino. Desta forma, os autores consideram que investigações centradas nas percepções dos próprios estudantes podem trazer apontamentos significativos, sintonizados com as necessidades dos alunos em relação à ciência escolar.

Stefánsson (2006), que implementou o projeto na Islândia, apontou a importância de se medir a percepção dos estudantes para a melhoria da educação científica, o que inclui o conhecimento de suas crenças e atitudes, o meio cultural, a memória e as reações afetivas dos estudantes, bem como suas expectativas em relação ao engajamento na carreira científica.

Sarjou et al. (2012), do Irã, comentam que o ensino de ciências desempenha um importante papel no desenvolvimento da curiosidade dos estudantes, em sua apreciação da natureza e na promoção de atitudes críticas e céticas em relação aos temas científicos, por isso, conhecer suas opiniões e interesses sobre os diversos temas científicos é um importante instrumento para melhoria do ensino de ciências nas escolas.

Schreiner e Sjøberg (2007) discutiram a aplicação do ROSE tendo como base a relação entre o interesse e a construção da identidade do jovem. Quando os jovens se deparam com 
escolhas, os interesses têm maior peso que as habilidades e talentos, por isso, os interesses dos alunos devem ser levados em conta na estrutura curricular da ciência escolar.

Fato é que o interesse pelos estudos científicos está vinculado ao quanto eles são significativos para os estudantes, e o que é significativo depende da cultura e das condições materiais do país em que vivem. As escolhas de futuro estão vinculadas a identidade e ao apelo que elas têm para o estudante, tanto no que se refere à satisfação pessoal como na possibilidade de desenvolver suas próprias habilidades (SCHREINER; SJØBERG, 2007).

Lavonen et al. (2005) declaram ainda que conhecer os interesses dos estudantes tem muitas implicações relevantes para o processo de ensino-aprendizagem. É somente quando o aluno se interessa por determinado assunto que ele se dedica a um estudo mais aprofundado e mobiliza habilidades e conhecimentos em situações novas. O professor, conhecendo os interesses de seus alunos, pode estimular seu interesse no início dos trabalhos escolares e ainda, pode influenciar o interesse dos estudantes através de métodos diferenciados de ensino.

Ao lado do currículo de ciências tradicional há um currículo tácito, onde aspectos relacionados ao trabalho dos cientistas, ao papel da ciência na sociedade, a natureza do conhecimento científico e sua influência na vida cotidiana são abordados de forma implícita e possuem a mesma importância que o conteúdo formal. Estes aspectos, entretanto, são os que de alguma forma influenciam as atitudes dos alunos em relação a ciências, e passam a ter significado pessoal e relevância em suas vidas, principalmente no que se refere às escolhas futuras, tanto acadêmicas como as de profissão (SJØBERG, 2007).

Vázquez Alonso e Manassero Mas (2009b), que implementaram o projeto ROSE na Espanha, consideram que o engajamento na carreira científica e tecnológica depende significativamente da educação científica e dos conteúdos curriculares escolares, uma vez que estes podem levar ao desenvolvimento do interesse, curiosidade e paixão pela ciência, ou, inversamente, ao tédio, dificuldade e fracasso, a indiferença e rejeição pelo tema.

Assim, conhecer a relevância que o conhecimento científico e tecnológico tem para os jovens brasileiros pode trazer subsídios para a compreensão de sua visão em relação ao futuro, de suas escolhas acadêmicas e profissionais e trazer elementos para a discussão de um currículo científico mais significativo para o estudante.

Até o presente momento, participaram do projeto ROSE pesquisadores da África do Sul, Alemanha, Austrália, Áustria, Bangladesh, Botswana, Brasil, Brunei Darussalam, Camarões, 
China (Taiwan), Dinamarca, Eslováquia, Eslovênia, Espanha, Estônia, Egito, Filipinas, Finlândia, França, Gana, Grécia, Índia, Inglaterra, Irã, Irlanda, Irlanda do Norte, Islândia, Israel, Itália, Japão, Latvia, Lesoto, Lituânia, Malásia, Malawi, Malta, Noruega, Polônia, Portugal, República Tcheca, Rússia, Suazilândia, Suécia, Suíça, Tanzânia, Trinidad e Tobago, Turquia, Uganda e Zimbábue (ROSE, 2012). 


\section{METODOLOGIA DE PESQUISA}

\subsection{UMA AVALIAÇÃO DE NATUREZA QUANTITATIVA}

A pesquisa aqui descrita está situada dentro do campo da avaliação educacional. A avaliação educacional, ao contrário do que muitos pensam, não se restringe à aplicação de testes e provas, visando a averiguação da proficiência do aluno em determinado assunto. Segundo Vianna (1992, p. 100), a avaliação centrada no aluno pode estar focada tanto nos aspectos cognitivos (formativo e somativo) quanto nos não cognitivos, como as "atitudes, interesses e aptidões".

Buriasco (2000, p. 156) também destaca a diversidade de objetivos da avaliação educacional atual, tais como "subsidiar o processo de ensino e aprendizagem, fornecer informações sobre os alunos, professores e escolas, atuar como respaldo da certificação e da seleção e orientar na elaboração de políticas educacionais".

Segundo Gusso (1992, p. 73) a avaliação é "uma aferição de qualidade que visa informar à sociedade para que ela aceite, recuse ou se coloque indiferente frente aos fatos educacionais". Isto não implica certezas ou julgamentos, mas compreensões acerca dos fenômenos educativos e suas possíveis interpretações.

A avaliação educacional no Brasil passou a ganhar impulso na década de 50, com a criação do Instituto Nacional de Estudos Pedagógicos Anísio Teixeira (INEP), que tinha como objetivo medir a eficiência dos sistemas de ensino. Desde então, pesquisas regionais e nacionais passaram a ser realizadas no Brasil, com a cooperação de especialistas estrangeiros. Foi a partir da década de 90, entretanto, que se intensificaram "as recomendações internacionais em decorrência da aceleração do processo de internacionalização do capitalismo, no bojo do qual se verificou o alargamento da internacionalização do processo decisório" (FREITAS, 2005, p. 90).

Desde então, avaliações em larga escala passaram a ser realizadas no Brasil: "o sistema de avaliação da educação básica (SAEB), a instituição de exames (ENEM e ENCCEJA), a modernização das estatísticas educacionais, a criação de um sistema integrado de informações educacionais (SIEd)" ", e a participação em iniciativas internacionais de avaliação educacional, como o Programa Internacional de Avaliação de Alunos (PISA) promovido pela Organização para a Cooperação Econômica (OECD) (FREITAS, 2005, p. 95).

\footnotetext{
${ }^{6}$ As siglas referem-se ao Exame Nacional do Ensino Médio (ENEM), Exame Nacional para Certificação de Competências de Jovens e Adultos (ENCCEJA) e Sistema Integrado de Informações da Educação Superior (SIEd). 
Dentre estas iniciativas, apenas o PISA possui em seu escopo, além de avaliar a proficiência do aluno em leitura, ciências e matemática, avaliar o interesse dos alunos sobre assuntos abordados na escola e sobre a própria escolaridade. A aplicação do PISA em 2006 avaliou o interesse dos estudantes especificamente sobre as ciências, suas aulas de ciências e seus hábitos de estudo (INEP, 2008).

Metodologias de avaliação educacional em âmbito nacional implicam abordagens de natureza quantitativa. Sobre elas, é interessante ressaltar a escassa literatura existente no país. Gatti (2004, p. 13) declara que

Há mais de duas décadas que na formação de educadores e de mestres e doutores em educação não se contemplam estudos disciplinares sobre esses métodos. No entanto, há problemas educacionais que para sua contextualização e compreensão necessitam ser qualificados através de dados quantitativos.

A autora considera que estudos quantitativos contextualizados por perspectivas teóricas trazem subsídios para que os fenômenos educacionais sejam tratados além dos casuímos e "achômetros" construídos a partir do senso comum, trazendo elementos concretos para o enfrentamento de políticas, planejamento e orientação de ações pedagógicas (GATTI, 2004, p. 26).

Sabe-se que, atualmente, a maioria das pesquisas na área de educação envolve estudos qualitativos realizados em microescalas sociais. Segundo Alves-Mazzotti (2001, p. 48), o grande desafio com que os pesquisadores da área se defrontam é conseguir aliar "a riqueza proporcionada pelo estudo em profundidade de fenômenos microssociais, (...) à possibilidade de transferência de conhecimentos (...) para o estudo de outros contextos semelhantes".

Minayo e Sanches (1993, p. 247), ao descreverem alguns aspectos da pesquisa qualitativa e quantitativa, comentam que ambas não devem assumir papéis em oposição, mas sim de complementaridade, já que possuem naturezas diferentes. A pesquisa quantitativa "deve ser utilizada para abarcar, do ponto de vista social, grandes aglomerados de dados, de conjuntos demográficos, por exemplo, classificando-os e tornando-os inteligíveis através de variáveis".

Vianna (1992, p. 102) também comenta esta aparente controvérsia ao declarar que "o problema do qualitativo e do quantitativo em avaliação educacional costuma ser recorrente, mas, na verdade, são aspectos que se equilibram (...). A interação de ambas as abordagens é uma necessidade imperativa". 
No caso da presente pesquisa, não se pretende apresentar dados de natureza quantitativa em detrimento de dados qualitativos, dando a impressão de que um é mais relevante que o outro. O que se apresenta são dados oriundos de métodos quantitativos que permitiram contemplar os objetivos do projeto e chegar a resultados que contemplassem uma melhor compreensão do fenômeno estudado (GÜNTHER, 2006).

O objetivo principal deste projeto é conhecer e avaliar o interesse dos estudantes brasileiros em relação à ciência e à tecnologia e às suas aulas de ciências. Para isso, é necessária uma abordagem que meça atitudes frente à ciência escolar. Osborne, Simon e Collins (2003) citam algumas estratégias para isso: perguntando aos alunos sobre as disciplinas e temas que eles gostam, utilizando questionários com escalas do tipo Likert, fazendo inventários de interesse e através de métodos qualitativos.

Esta pesquisa optou por aplicar o instrumento ROSE, um questionário com questões fechadas que utiliza afirmações acerca da ciência, onde o aluno é convidado a assinalar seu interesse em uma escala tipo Likert. Mais informações sobre o instrumento ROSE estão descritas na seção 3 deste capítulo.

Assim, serão abordadas a seguir as etapas de pesquisa, o instrumento de coleta de dados (questionário ROSE), o estudo amostral, o plano logístico para a coleta de dados e as análises realizadas durante a pesquisa.

\subsection{ETAPAS DE PESQUISA}

Esta pesquisa foi organizada através das seguintes etapas de trabalho:

1. Etapa preparatória e diagnóstica, que consistiu em: 1.1 Busca e captação de recursos de financiamento ${ }^{7}$, através da submissão do projeto a agências financiadoras de pesquisa; 1.2. Estudo amostral e logístico da aplicação do questionário ROSE no âmbito brasileiro e 1.3. Análise da primeira aplicação do projeto ROSE no Brasil e da aplicação do projeto ROSE em outros países.

2. Etapa de aplicação do ROSE e organização dos resultados, que consistiu em: 2.1. Envio dos questionários às escolas selecionadas; 2.2. Recepção e organização dos questionários

\footnotetext{
${ }^{7}$ Os recursos financeiros foram obtidos no ano de 2009 junto ao CNPq, através do Edital Universal 14/2009. Assim, as despesas de custeio, que envolvem o estudo amostral, as análises estatísticas, a impressão do instrumento (questionário ROSE) e a captura digital dos dados foram realizadas através de recursos do CNPq. As despesas com serviços de correio foram realizadas com recursos da Faculdade de Educação da USP.
} 
preenchidos pelos alunos participantes; 2.3. Leitura e consolidação dos dados obtidos; 2.4. Estudo comparativo dos resultados em relação ao gênero e nas diferentes regiões brasileiras.

3. Etapa analítica e discussão, que consistiu em: 3.1. Análise das respostas quanto ao interesse dos alunos por temas da ciência e tecnologia; 3.2. Análise das respostas quanto ao interesse pelas aulas de ciências; 3.3. Análise das respostas quanto à posição dos jovens brasileiros frente aos problemas ambientais; 3.4 Análise das respostas quanto à posição do jovem frente à ciência e à tecnologia; 3.5. Análise comparativa entre os resultados brasileiros e os resultados obtidos por outros países participantes do Projeto ROSE e 3.6 Análise da aplicação do projeto ROSE no Brasil.

\subsection{O INSTRUMENTO DE COLETA DE DADOS}

Os dados foram coletados mediante a utilização do questionário ROSE, desenvolvido pelos organizadores do projeto na Noruega (SCHREINER; SJØBERG, 2004), e adequado ao contexto brasileiro por Tolentino Neto durante seu doutoramento (TOLENTINO NETO, 2008). O questionário ROSE convida o aluno a assinalar qual é o seu nível de interesse sobre diversos temas da ciência, suas aulas de ciências, sua posição em relação aos desafios ambientais, suas opiniões sobre ciência e tecnologia, suas experiências fora da escola e seu futuro emprego através de uma lista de 245 itens.

A figura 3.1 apresenta um recorte da primeira seção do questionário, que é destinada a conhecer o interesse do aluno sobre temas da ciência. O questionário ROSE Brasil completo encontra-se no Anexo A.

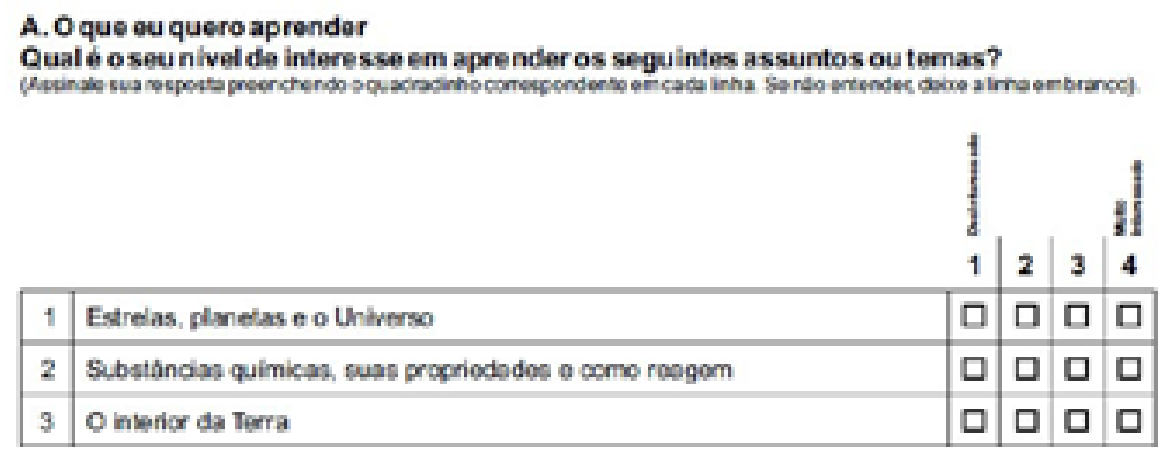

Figura 3.1 - Recorte da Seção A do questionário ROSE aplicado no Brasil. 
Com o intuito de possibilitar que o ROSE fosse utilizado em comparações internacionais, o instrumento aplicado no Brasil seguiu a mesma formatação de fonte, parágrafo, tamanho, papel e quebra de páginas que o questionário original, mantendo o padrão já aplicado e estruturado em outros países (TOLENTINO NETO, 2008).

Os 245 itens do questionário de interesse estão organizados em 8 seções identificadas por letras $(\mathrm{A}$ a H) e as respostas são expressas em uma escala tipo Likert de quatro pontos: opção um - Desinteressado/Nada Importante/Não Concordo/Nunca, à opção quatro - Muito interessado/Muito importante/Concordo/Muitas vezes, com dois níveis intermediários.

A versão brasileira do questionário ROSE possui ainda 23 questões acrescentadas como "Questões Nacionais"» rou estabelecer relações entre a opção religiosa do aluno e o ensino de evolução. A análise das “Questões Nacionais" do ROSE Brasil não será contemplada nesta pesquisa, mas sim no doutoramento da colega Helenadja Mota Rios Pereira, também aluna da FEUSP.

A opção por uma escala com quatro pontos, e não com cinco como são as escalas de Likert clássicas, está relacionada ao fato de que a opção neutra geralmente traz erros de interpretação: pode indicar um ponto central entre extremos, mas também falta de conhecimento ou entendimento da questão, indiferença ou mesmo falta de motivação. Assim, no caso do questionário ROSE, o aluno é orientado a não responder quando não compreende a questão ou quando não quer responder a questão (SCHREINER; SJØBERG, 2004).

Siegel e Ranney (2003) apontam algumas vantagens do uso de questionários do tipo Likert para mensuração de atitudes: são fáceis de elaborar, podem incluir um grande número de itens, os itens podem ser respondidos rapidamente, pode prover informação precisa sobre o grau de concordância ou discordância do respondente e pode ser de alta confiabilidade. Os autores apontam como desvantagem a existência do ponto neutro, uma vez que pode não representar neutralidade ou sim uma confusão de ideias sobre o tema.

Outra questão referente à escala tipo Likert adotada no projeto ROSE é a existência de legenda apenas nas opções extremas (1 e 4). Esta escolha foi feita a fim de se evitar vieses de significado, simplificar a tradução para outros idiomas e a compreensão da própria escala (SCHREINER; SJØBERG, 2004; SCHREINER, 2006). Nas escalas tradicionais, a legenda deve possuir uma distância simétrica do ponto neutro (UEBERSAX, 2006), o que muitas vezes não é simples de se nomear e traduzir face às nuances de cada idioma.

\footnotetext{
${ }^{8}$ Vale ressaltar que cada país participante do ROSE pode ou não acrescentar questões nacionais ao final do questionário. A versão norueguesa do questionário incluiu questões relacionadas com as percepções dos estudantes sobre como eles veem seu papel na sociedade (SCHREINER, 2006, p. 95).
} 
A opção por questões fechadas se deve ao fato de que o instrumento ROSE foi produzido com o objetivo de ser aplicado em diversos países. Para facilitar a tradução e adequação do projeto em cada país participante optou-se por um questionário de estrutura simplificada, fácil de administrar, codificar e analisar. Cada item do questionário procurou ser desenvolvido visando frases curtas, palavras simples, que não exigem muito conhecimento do aluno, conforme observado na figura 3.1 (SCHREINER; SJØBERG, 2004).

O questionário é precedido por uma folha inicial onde o projeto ROSE é apresentado ao estudante. Logo após iniciam-se as questões censitárias (gênero, idade, município) e socioeconômicas (quantidade de livros e banheiros presentes no domicílio do aluno). Não é solicitada a identificação do aluno no questionário.

As Seções A, C e E (ACE) são denominadas “O que eu quero aprender”. Nessas seções pergunta-se aos alunos: "Qual é o seu nível de interesse em aprender os seguintes assuntos ou temas?", onde 108 tópicos do currículo de ciências são apresentados. A opção por colocar em três seções teve como objetivo minimizar a longa lista de questões que possuem a mesma orientação.

O objetivo das seções ACE é conhecer assuntos que possuem o potencial de engajar e envolver os estudantes nas aulas de ciências, não só através do aumento do entusiasmo, mas também do pensamento criativo e do crescimento individual. Conhecer quais assuntos os jovens mais se interessam possibilita a construção de currículos mais significativos para os alunos (SCHREINER; SJØBERG, 2004).

Resultados obtidos pelo SAS-Study, o precursor do projeto ROSE (SJØBERG, 2000), indicam uma sensível diferença entre o conteúdo (a área da ciência) e o contexto de determinado assunto científico. Por exemplo, os alunos se interessam mais em aprender sobre música (contexto) do que sobre acústica e sons (conteúdos). Da mesma maneira, o interesse em aprender sobre o arco-íris ou o pôr do sol (contextos) é maior do que aprender sobre luz e óptica (conteúdos) (SCHREINER; SJØBERG, 2004).

Partindo deste pressuposto, as questões das seções ACE agrupam uma variedade de temas relacionados às ciências expressos em diversos conteúdos e contextos. Schreiner (2006) elaborou uma codificação dos 108 temas abordados nas seções ACE, de forma a expressar como cada questão está conectada a conteúdos e contextos diversos. O quadro 3.1 sintetiza essa codificação (SCHREINER, 2006, p. 91). No quadro, cada questão está identificada em negrito e as siglas em itálico correspondem aos conteúdos e contextos nela abordados. 


\begin{tabular}{|c|c|c|c|c|c|c|c|c|c|c|c|}
\hline A01: & $U$ & $\mathrm{AO2}=$ & c & A03: & $G$ & A04: & $G$ & A05: & $G$ & AD6: & - \\
\hline A07: & $H$ & A08: & $H$ & $A 09:$ & $H Y$ & A10: & $H Y$ & A11: & $H$ & A12: & $A$ \\
\hline A13: & $A$ & A14: & $A Z$ & A15: & $P$ & A16: & - & A17: & $c$ & A18: & $L H Q$ \\
\hline A19: & $L M$ & A20: & $L A$ & A21: & $s$ & A22: & $U Z$ & A23: & $U Z$ & A24: & $G Z$ \\
\hline A25: & $G Z$ & A26: & HQZ & A27: & $A Z$ & A28: & $P Z$ & A29: & CHZ & A30: & $c Z$ \\
\hline A31: & $C Z$ & A32: & $C H Z$ & A33: & $E H Z$ & A34: & $U M$ & A35: & $U M$ & A $36:$ & $L H$ \\
\hline A37: & $H F$ & A38: & $H F$ & A39: & $\mathrm{CHF}$ & A40: & HF & A41: & HF & A42: & LHF \\
\hline A43: & $S H$ & A44: & $U T$ & A45: & $U T$ & A46: & LHQ & A47: & $C T$ & A48: & $C T$ \\
\hline C01: & $C R$ & CO2: & $L T$ & CO3: & $L T$ & CO4: & $S T$ & C05: & $T$ & COG: & $T$ \\
\hline COF: & $T$ & C08: & UM & Cog: & $U M H$ & C10: & $U M$ & C11: & $H M$ & $\mathrm{Cl}$ : & $\mathrm{HQM}$ \\
\hline C13: & $H M$ & C14: & $M$ & C15: & $H M$ & C16: & $\angle U B$ & C17: & $\angle G B$ & C18: & $G B$ \\
\hline E01: & $P B$ & EOO: & $L G B$ & E03: & $G W$ & E04: & $G W$ & E05: & $G W$ & EO6: & $T W$ \\
\hline E07: & $H Q$ & EOS: & $H Q$ & E09: & HQY & E10: & $H Q$ & E11: & $H Q$ & E12: & $H Y$ \\
\hline E13: & $H Y$ & E14: & $H Y$ & E15: & $H Y$ & E16: & $A W$ & E17: & $P R$ & E18: & PHQ \\
\hline E19: & $P W$ & E20: & $E W$ & E21: & $E W$ & E22: & $C R$ & E23: & $H Y$ & E24: & $A R$ \\
\hline B25: & $P R$ & E26: & $C R$ & E27: & $E R$ & E28: & $T R$ & E29: & $v X$ & E30: & $E X$ \\
\hline B31: & $H Y X$ & E32: & $H Q$ & E33: & $w X$ & E34: & $M X$ & E35: & $R H X$ & E36: & $x$ \\
\hline E37: & $x$ & E38: & $X Z$ & E39: & $M X$ & E40: & $x$ & E41: & $x$ & E42: & $x$ \\
\hline
\end{tabular}

Quadro 3.1 - Temas abordados nas questões das seções ACE (proposta por Schreiner, 2006).

Legenda: Conteúdos: U - Universo/Astrofísica; G - Geociências; A - Animais/Zoologia; P - Plantas/Botânica; C - Química; L - Luz/Cores/Radiação; S - Sons; E - Energia; T - Tecnologia; Contextos: Z - Confusão/Fenômenos espetaculares/horror; H - Biologia Humana; Q Saúde; F - Cuidados com o corpo; Y - Saúde juvenil; M - Mistério/filosofia/crenças orientadas; B - Beleza/estética; W - Proteção Ambiental; R - Relevantes para o dia-a-dia; X - Ciência, Tecnologia e Sociedade e Natureza da Ciência. Itens marcados com um traço não foram contemplados nestas categorias.

Os diferentes conteúdos e contextos observados no quadro 3.1 serão abordados no capítulo 5 dos resultados para discutir tais questões e verificar se o interesse observado por Sjøberg (2000) em relação aos assuntos contextualizados se observa no cenário brasileiro.

Tolentino Neto (2008), em sua tese de doutorado, organizou as questões da seção ACE em áreas e temas da ciência que mais se aproximam da estrutura curricular brasileira. Esta organização não é uma versão simplificada do quadro 3.1, mas uma maneira diversa de categorizar as questões, uma vez que aborda apenas áreas da ciência. Tal categorização também foi utilizada para se verificar as áreas da ciência que os jovens brasileiros mais se interessam. $\mathrm{O}$ quadro 3.2 apresenta as áreas e as questões que compõe cada uma delas. 


\section{Categorias (seções ACE)}

\begin{tabular}{ll}
\hline & A01; A19; A21; A22; A23; A30; A33; A34; \\
1. Física (astronomia, óptica, eletricidade) & A35; A36; A44; A45; A47; A48; C02; C08; \\
& C16; C17; E02; E27; E29 \\
2. Biologia (biologia geral, botânica, & A07; A08; A09; A10; A11; A12; A13; A15; \\
zoologia, evolução e ecologia) & A16; A20; A27; A28; E01; E16; E24; E25 \\
3. Geologia, meteorologia e ciências da terra & A03; A04; A05; A24; A25; E17; E18; E19; E22; \\
& E33 \\
4. Química & A02; A17; A31; E26 \\
& A18; A26; A29; A32; A37; A38; A39; A40; \\
5. Saúde, forma física e beleza & A41; A42; A43; A46; C18; E07; E08; E09; E10; \\
& A30; A47; A48; C01; C03; C04; C05; C06; \\
6. Tecnologia & C07; E28; E30; E40; E41 \\
7. Ciência \& cientistas & E34; E36; E37; E38; E39 \\
8. Proteção ambiental & E03; E04; E05; E06; E16; E20; E21 \\
9. Mistério, horror e fenômenos inexplicáveis & A06; A14; C09; C10; C11; C12; C13; C14; C15; \\
& E42
\end{tabular}

Quadro 3.2 - Categorias de temas proposta por Tolentino Neto (2008) para as seções ACE.

As seções ACE, que correspondem à maioria do questionário, não serão discutidas por completo no capítulo de Resultados. Procuramos selecionar aspectos relevantes observados junto aos jovens brasileiros e focar neles nossa atenção. No entanto, os dados completos obtidos junto a essas seções serão apresentados no Apêndice A.

A Seção B tem como tema "Meu futuro emprego", e sua pergunta inicial é "Qual é a importância das seguintes questões para a sua futura profissão ou emprego?”. O objetivo dessa seção é investigar as expectativas e prioridades para o futuro, sendo este um elemento importante na aproximação do aluno com as ciências. Essa seção possui uma lista de 26 aspectos que podem ser importantes para a escolha de um futuro emprego.

Tendo em vista o volume de dados obtidos junto a esta pesquisa, que resultou em 579.425 itens somente através das 245 questões do questionário ROSE original, foi necessário selecionar seções que mais se aproximassem dos objetivos propostos. Assim, a seção B não foi incluída na discussão dos resultados, porém os dados obtidos junto a ela podem ser consultados no Apêndice B.

A Seção D, denominada "Eu e os desafios ambientais", questiona os alunos: "Até que ponto você concorda com as seguintes afirmações sobre os problemas do ambiente (poluição do 
ar e da água, abuso de recursos naturais, mudanças climáticas globais, etc.)?”. Ela está descrita em 18 itens que procuram explorar o modo como os jovens se relacionam com determinadas questões ambientais e serão discutidas no capítulo 6.

As questões da seção D estão organizadas de forma a contemplar a habilidade/capacidade do aluno em enfrentar problemas ambientais. Para tanto, Schreiner e Sjøberg (2004, p.59) assumiram que o estudante deve

\begin{abstract}
estar motivado para ação em relação aos problemas ambientais; ter esperanças e visões para o futuro; ter a percepção de que pode influenciar o desenvolvimento futuro, estar engajado e interessado nas questões ambientais e considerar que a proteção ambiental é importante para a sociedade.
\end{abstract}

Assim, de acordo com as prerrogativas acima, as questões da seção D foram agrupadas por Schreiner (2006, p. 93-4) nas categorias apresentadas no quadro 3.3.

\begin{tabular}{ll}
\hline Categorias (seção B) & Questões \\
\hline Esperanças e visões para o futuro & D2, D7, D14 \\
Motivação para ação & D1, D5 \\
Alguém pode resolver os problemas ambientais? & D4, D11, D13 \\
Sentimento geral de que podem influenciar o & D6, D12 \\
desenvolvimento & \\
A importância das questões ambientais para a sociedade & D3, D8, D9, D10 \\
Visões religiosas da natureza/proteção da natureza & D15, D16, D17, D18 \\
\hline
\end{tabular}

Quadro 3.3 - Categorias da Seção D “Eu e os desafios ambientais” (proposta por Schreiner, 2006).

A Seção F, “As minhas aulas de ciências”, é composta por 16 perguntas que trazem informações sobre como os alunos se relacionam com as ciências na escola, suas motivações em relação à ciência escolar e quais são suas percepções sobre o ensino e aprendizagem da disciplina. Os resultados desta seção serão abordados no capítulo 7. As questões da seção F foram agrupadas pela autora desta tese em 4 categorias, e podem ser observadas no quadro 3.4.

\begin{tabular}{ll}
\hline Categorias (seção F) & Questões \\
\hline Facilidade/Dificuldade no aprendizado da disciplina & F01; F03 \\
Relação entre a disciplina e a futura carreira & F04, F08, F14, F16 \\
Interesse pessoal pela disciplina & F02, F05, F06, F15 \\
Vantagens diretas da aprendizagem da disciplina & F07, F09, F10, F11, F12, F13 \\
\hline
\end{tabular}

Quadro 3.4 - Categorias da Seção F “As minhas aulas de ciências” (elaboradas pela autora). 
O critério utilizado para o agrupamento foi reunir questões com a mesma orientação. Algumas destas questões foram agrupadas da mesma forma por outros pesquisadores, tais como Ogawa e Shimode (2004), que aplicaram o projeto no Japão, e Jenkins e Nelson (2005), que aplicaram o ROSE na Inglaterra.

A Seção G é intitulada “As minhas opiniões sobre as ciências e a tecnologia”, onde estão distribuídos 16 itens relacionados ao papel e função da ciência e da tecnologia na sociedade. Para isso, foram abordadas questões relacionadas à confiança, à crença/descrença na ciência e nos cientistas, a interesses e ao apoio à atividade científica. Os resultados obtidos junto à seção G serão apresentados e discutidos no capítulo 8.

A Seção H "As minhas experiências fora da escola" traz a pergunta "Quantas vezes você já fez estas experiências fora da escola?”, seguida de uma complementação “Já...”, que introduz 61 itens que podem influenciar o ensino ou a aprendizagem das ciências. As questões da seção $\mathrm{H}$ foram categorizadas pela autora desta tese, conforme o quadro 3.5.

O critério utilizado para as categorias a seguir foi reunir experiências que se assemelham, quer devido ao contexto em que são realizadas (por exemplo, afazeres em fazenda/rurais), quer ao manejo de instrumentos que possuem objetivos semelhantes (ferramentas, mensuração), a utilização de instrumentos tecnológicos (telefone celular, computador etc.), contato com a ciência não-formal, e assim por diante.

\begin{tabular}{ll}
\hline Categorias (seção H) & Questões \\
\hline Tive contato físico com a natureza e os animais & $\mathrm{H} 01, \mathrm{H} 05, \mathrm{H} 06, \mathrm{H} 07, \mathrm{H} 08, \mathrm{H} 10$, \\
& $\mathrm{H} 14, \mathrm{H} 15, \mathrm{H} 16, \mathrm{H} 17$ \\
Utilizei ferramentas e/ou objetos (objetos de medição, & $\mathrm{H} 03, \mathrm{H} 04, \mathrm{H} 30, \mathrm{H} 31, \mathrm{H} 33, \mathrm{H} 34$, \\
localização, etc.) & $\mathrm{H} 36, \mathrm{H} 37, \mathrm{H} 41, \mathrm{H} 42, \mathrm{H} 43, \mathrm{H} 56$, \\
& $\mathrm{H} 44, \mathrm{H} 45, \mathrm{H} 46, \mathrm{H} 47, \mathrm{H} 48, \mathrm{H} 49$, \\
Tive contato com tecnologia de informação & $\mathrm{H} 50, \mathrm{H} 51$ \\
(computadores) e comunicação (Internet e celulares) & $\mathrm{H} 11, \mathrm{H} 18, \mathrm{H} 19, \mathrm{H} 20, \mathrm{H} 32, \mathrm{H} 35$, \\
Fiz materiais, produtos, comidas. & $\mathrm{H} 53, \mathrm{H} 54$ \\
& $\mathrm{H} 21, \mathrm{H} 22, \mathrm{H} 23, \mathrm{H} 55$ \\
Participei ativamente das atividades de acampamentos & $\mathrm{H} 09, \mathrm{H} 12, \mathrm{H} 13$ \\
Busquei conhecimentos sobre a natureza através de & $\mathrm{H} 25, \mathrm{H} 26, \mathrm{H} 27, \mathrm{H} 28, \mathrm{H} 29$ \\
leituras, TV e centros de ciências & $\mathrm{H} 24, \mathrm{H} 38, \mathrm{H} 39, \mathrm{H} 40, \mathrm{H} 52$ H59, \\
Cuidados com saúde & $\mathrm{H} 61$ \\
Fiz tarefas, reparos e consertos domésticos & $\mathrm{H} 02$ \\
\hline
\end{tabular}

Quadro 3.5 - Categorias da Seção H “Minhas experiências fora da escola” (elaboradas pela autora).

\footnotetext{
${ }^{9}$ A seção H não será discutida nos resultados, porém os dados obtidos junto a ela serão apresentados no Apêndice C.
} 


\subsection{A POPULAÇÃO-ALVO}

A população-alvo desta pesquisa são os estudantes que estão completando os estudos compulsórios e iniciando a última etapa da educação básica, onde deverão tomar decisões sobre seu futuro profissional. Convencionou-se que todos os países-participantes do projeto ROSE elegeriam a série escolar onde se esperaria encontrar idealmente os estudantes de 15 anos. No caso brasileiro, esta norma foi traduzida optando pela aplicação a jovens do primeiro ano do Ensino Médio e, assim, as instruções para a escolha da turma na qual seria aplicado o questionário apontavam para a sala de primeiro ano do Ensino Médio onde houvesse mais jovens de 15 anos de idade (As instruções enviadas às escolas encontram-se no Apêndice D).

Para definir uma amostra de representatividade nacional foi utilizada como referência a amostra brasileira do Programa Internacional de Avaliação de Alunos (PISA) realizado no ano de 2009, de forma que foram mantidas as mesmas características e representatividade da amostra original. Assim, o universo amostral deste estudo corresponde à amostra PISA do ano de 2009.

É necessário destacar que tal universo amostral não corresponde à totalidade de escolas participantes do PISA em $2009^{10}$, mas sim a totalidade de escolas participantes do PISA em 2009 que possuía algum tipo de contato (endereço para correspondência, telefone ou e-mail), o que corresponde a 535 escolas. Esta escolha foi necessária para garantir a viabilidade do projeto, uma vez que muitas escolas não possuem telefone, e-mail ou mesmo endereço acessível ao serviço de correios.

A opção por ter como referência a amostra PISA 2009 se deu pelo fato dela ser estatisticamente significativa da população estudantil brasileira. Além disso, há proximidade entre público alvo da pesquisa ROSE e PISA ${ }^{11}$ e as informações das escolas participantes do PISA 2009 podem ser acessadas através do INEP.

Devido ao presente estudo ser realizado em escolas, houve a necessidade de aplicar o questionário junto a turmas de alunos, e não a alunos individualmente. Desta forma, foi selecionada uma turma de $1^{\circ}$ ano de Ensino Médio em cada unidade escolar participante, com tamanho médio estimado de 30 alunos, sendo o critério de escolha a presença de alunos de 15 anos de idade em sua maioria.

\footnotetext{
${ }^{10}$ A amostra PISA 2009 total é caracterizada por 950 escolas.
} 


\subsection{DETERMINAÇÃO DO TAMANHO DA AMOSTRA}

Uma primeira estimativa do tamanho amostral foi feita baseada no estudo amostral do PISA 2006. A amostragem mínima exigida pelos organizadores do PISA era de 4500 alunos distribuídos em 150 escolas (OECD/PISA, 2005). Desta forma, foi realizada uma aproximação para a aplicação do projeto ROSE no Brasil considerando-se 4800 alunos distribuídos em 160 escolas (uma média de 30 alunos por escola).

Assim, foram sorteadas aleatoriamente 160 escolas do universo amostral. As instituições foram selecionadas através de uma amostragem estratificada pelos 26 estados e o Distrito Federal com alocação proporcional (BOLFARINE; BUSSAB, 2005), visando adequar a amostra à situação política e econômica do Brasil. Em cada estrato (unidade da federação) foi selecionado aleatoriamente, utilizando o gerador de números aleatórios do programa Excel (pacote Office 2003), um número de escolas proporcional ao número de escolas participantes do PISA.

Na tabela 3.1 estão indicadas as frequências de escolas no universo amostral (PISA 2009) e na amostra ROSE-Brasil.

\footnotetext{
${ }^{11}$ A aplicação do PISA 2009 foi realizada através de uma amostra representativa de escolas brasileiras que possuíam alunos com cerca de 15 anos de idade (nascidos em 1993), matriculados na 7a ou 8a série do Ensino Fundamental ou em qualquer série do Ensino Médio (BRASIL, 2008).
} 
Tabela 3.1 - Distribuição das escolas no PISA (2009) e na amostra do estudo ROSE-Brasil por Unidade da Federação.

\begin{tabular}{|c|c|c|c|}
\hline Região & $\mathbf{U F}$ & $\begin{array}{l}\text { Escolas Amostra } \\
\text { PISA 2009 }\end{array}$ & $\begin{array}{c}\text { Escolas Amostra } \\
\text { ROSE-Brasil }\end{array}$ \\
\hline \multirow[t]{7}{*}{ Norte } & $\mathrm{AC}$ & 13 & 4 \\
\hline & $\mathrm{AM}$ & 23 & 7 \\
\hline & $\mathrm{AP}$ & 20 & 5 \\
\hline & PA & 18 & 5 \\
\hline & RO & 25 & 8 \\
\hline & RR & 20 & 5 \\
\hline & TO & 23 & 7 \\
\hline \multirow[t]{9}{*}{ Nordeste } & $\mathrm{AL}$ & 11 & 4 \\
\hline & BA & 14 & 4 \\
\hline & $\mathrm{CE}$ & 26 & 8 \\
\hline & MA & 11 & 4 \\
\hline & $\mathrm{PB}$ & 15 & 4 \\
\hline & $\mathrm{PE}$ & 25 & 8 \\
\hline & PI & 13 & 4 \\
\hline & $\mathrm{RN}$ & 15 & 4 \\
\hline & $\mathrm{SE}$ & 20 & 5 \\
\hline \multirow[t]{4}{*}{ Centro-Oeste } & DF & 18 & 5 \\
\hline & GO & 19 & 5 \\
\hline & MS & 21 & 7 \\
\hline & MT & 22 & 7 \\
\hline \multirow[t]{4}{*}{ Sudeste } & ES & 17 & 5 \\
\hline & MG & 19 & 5 \\
\hline & $\mathrm{RJ}$ & 20 & 7 \\
\hline & SP & 35 & 11 \\
\hline \multirow[t]{3}{*}{ Sul } & PR & 25 & 8 \\
\hline & $\mathrm{RS}$ & 23 & 7 \\
\hline & $\mathrm{SC}$ & 24 & 7 \\
\hline \multicolumn{2}{|c|}{ Total } & 535 & 160 \\
\hline
\end{tabular}


Todos os alunos das escolas sorteadas (média de 30 por escola) deveriam ser incluídos na amostra. Considerando uma perda de $20 \%$ das escolas sorteadas e de $10 \%$ de alunos dentro das escolas, deveriam ser pesquisadas 128 escolas e 27 alunos em cada escola, resultando em 3456 questionários preenchidos.

Na tabela 3.2, estão indicados os tamanhos de amostra necessários para que estimativas de proporções sejam calculadas com determinados erros de amostragem. Com base nesses dados, é possível verificar que uma amostra de 3456 alunos levaria à obtenção de estimativas com erro de amostragem entre 3 e 4 pontos percentuais.

Tabela 3.2 - Tamanhos de amostras segundo erros de amostragem.

\begin{tabular}{cc}
\hline $\begin{array}{c}\text { Erro de amostragem } \\
(\%)\end{array}$ & Tamanho de amostra \\
\hline 12 & 240 \\
11 & 285 \\
10 & 356 \\
9 & 427 \\
8 & 540 \\
7 & 706 \\
6 & 961 \\
5 & 1382 \\
4 & 2160 \\
3 & 3841 \\
2 & 8644 \\
\hline
\end{tabular}

Os cálculos de tamanho de amostra acima foram feitos considerando a expressão algébrica referente à estimação de proporções ${ }^{12}$ :

$$
n=\frac{P(1-P)}{(d / t)^{2}} \cdot \operatorname{deff}
$$

sendo $P=0,50$ o parâmetro a ser estimado (proporção de indivíduos), $d$ o erro de amostragem a ser tolerado, $t=1,96$ o valor da curva normal correspondente ao nível de confiança de $95 \%$ e deff $=3,6$ o efeito do desenho correspondente ao sorteio de conglomerados (escolas).

\footnotetext{
${ }^{12}$ Tal expressão algébrica é amplamente utilizada para determinação do tamanho de amostras em estudos relacionados à saúde (Ver COSTA, 2009; ALVES, 2008; SALVADOR et al., 2009; SILVA, 2008).
} 
A estimativa de deff foi obtida por:

$\operatorname{deff}=1+\rho(1-\bar{b})$

sendo $\rho=0,10 \quad$ o grau de correlação intraclasse estimado com base em estudos anteriores e $\bar{b}=27$ o número médio de questionários por escola.

Os tamanhos de amostra a serem alcançados em cada região e os respectivos erros de amostragem estão indicados na tabela 3.3. Esses dados indicam que as estimativas da proporção de alunos com determinado nível de interesse pela ciência serão obtidas com erros de amostragem entre 5 e 8 pontos percentuais.

Tabela 3.3 - Número de escolas sorteadas e questionários previstos por região.

\begin{tabular}{lccc}
\hline Região & Escolas & Questionários & $\begin{array}{c}\text { Erro de } \\
\text { amostragem }\end{array}$ \\
\hline Norte & 41 & 1107 & entre 5 e 6 \\
Nordeste & 45 & 1215 & entre 5 e 6 \\
Centro-Oeste & 24 & 648 & entre 7 e 8 \\
Sudeste & 28 & 756 & entre 6 e 7 \\
Sul & 22 & 594 & entre 7 e 8 \\
\hline
\end{tabular}

\subsubsection{Processo de seleção da amostra}

As instituições escolares foram sorteadas aleatoriamente, utilizando o gerador de números aleatórios do programa Excel, um número de escolas proporcional ao número de escolas constantes do universo amostral, tal como explicitado acima.

O sorteio é comumente utilizado nas pesquisas quantitativas, por que além da simplicidade dos instrumentos para obtenção da amostra, permite que os pesquisadores evitem vieses oriundos de seleções sistemáticas, uma vez que estabelece uma média do público alvo. Além disso, ele constantemente se apresenta bem próximo à população alvo, principalmente se for suficientemente grande (SHANK; BROWN, 2007).

Cates (1985) corrobora esta questão ao afirmar que o sorteio aleatório geralmente rompe padrões que possam existir em outros processos de amostragem e aumenta a confiabilidade de 
que a amostra seja típica da população alvo.

Assim, foram sorteadas inicialmente 160 escolas, sendo que 120 participaram da primeira fase de coleta de dados e outras 40 escolas foram utilizadas como escolas-reserva, estando disponíveis para eventualmente integrar a segunda fase de coleta de dados. Tendo como referência o número de escolas participantes em cada estado, pode-se traçar um plano logístico de aplicação do questionário ROSE, que será explicitado na próxima seção.

\subsection{COLETA DE DADOS}

\subsubsection{Plano logístico}

A fim de facilitar a tabulação e análise de um questionário extenso como o ROSE Brasil, que possui 268 itens dispostos em 13 seções (incluindo as “Questões Nacionais"), optou-se por imprimi-lo em folhas ópticas com personalização a laser das folhas de respostas, o que permitiu a captura digital das respostas ${ }^{13}$.

Este método minimizou o tempo e os erros de digitação oriundos da tabulação manual dos dados, além de identificar cada questionário com um código de barras, independentemente se ele é anônimo ou não. No caso do ROSE, o questionário é anônimo, mas cada um deles pode ser localizado através do código correspondente, tal como observado na figura 3.2, que reproduz parte da página inicial do questionário.

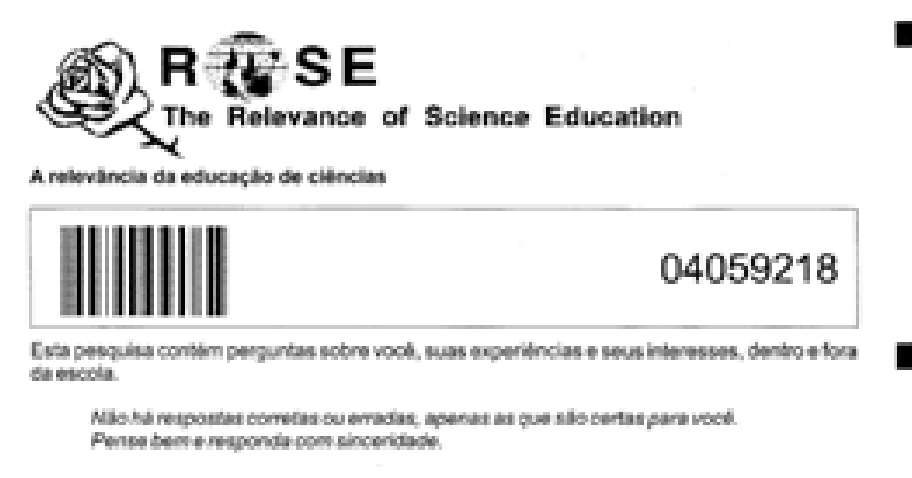

Figura 3.2 - Reprodução de parte da primeira página do questionário ROSE Brasil, onde está presente o código de barras.

\footnotetext{
${ }^{13}$ A impressão do questionário ROSE foi realizada pela empresa PICSIS Informática, cujo website é http://www.picsis .com.br/.
} 
O Brasil foi o primeiro país participante do ROSE a aplicar o questionário utilizando esta tecnologia, que poderá ser usada como modelo em futuras aplicações.

Para minimizar os custos envolvidos com deslocamento de aplicadores, decidiu-se que os questionários seriam enviados por correio às escolas sorteadas, da mesma forma como os questionários PISA têm sido encaminhados às escolas no Brasil (BRASIL, 2008). Para isso, fez-se primeiramente um contato telefônico com as escolas ou com as diretorias de ensino, no caso das escolas que não possuíam telefone próprio. Esse primeiro contato teve como objetivo conhecer o nome do diretor(a) da escola e confirmar o endereço de correspondência, a fim de facilitar contatos posteriores e garantir que os questionários chegassem às mãos da equipe de gestão.

Conhecendo o nome do diretor(a), elaborou-se uma carta de apresentação da pesquisa, que foi enviada a todas as 120 escolas sorteadas para a primeira fase de coleta de dados (Ver Apêndice E). Essa carta foi enviada entre os meses de julho e agosto de 2010. Após o envio dessa primeira carta, muitas escolas enviaram e-mail confirmando a participação ou solicitando maiores esclarecimentos.

Após o envio da carta de apresentação, foram enviados os questionários, acompanhados de uma carta de instruções (Ver Apêndice D), do Termo de Consentimento Livre e Esclarecido (modelo FEUSP - ver Apêndice F) e de envelopes selados para o retorno dos questionários preenchidos.

O Termo de Consentimento Livre e Esclarecido (TCLE) foi enviado conforme as instruções do Comitê de Ética da FEUSP. O modelo utilizado foi o que consta no Anexo I do documento "Padrões Éticos na Pesquisa em Educação: Primeiro Documento"14. Através do TCLE foi solicitada a autorização da direção da escola para a coleta de informações junto aos alunos.

As escolas que retornaram os questionários preenchidos receberam pelo correio uma carta de agradecimento e uma declaração de participação na pesquisa ROSE Brasil.

\subsubsection{Etapas da coleta de dados}

Tendo em vista a dimensão da pesquisa aqui descrita, que previa a aplicação do questionário em 160 escolas oriundas de todos os estados brasileiros, e o andamento inicial da aplicação do questionário, foi necessário organizar a coleta de dados em duas fases distintas:

\footnotetext{
${ }^{14}$ Tal documento foi obtido através do endereço eletrônico <http://www3.fe.usp.br/pgrad/PDF_SWF/Documento_Comite_de_ Etica.pdf>. Acesso em 2010-06-14.
} 


\section{$\underline{1^{a} \text { Fase: Coleta de dados inicial }}$}

Os questionários ROSE foram enviados pelo correio através de 'Aviso de Recebimento' (AR) para as 120 escolas sorteadas no estudo amostral, acompanhados de uma carta de instruções, do Termo de Consentimento Livre e Esclarecido e envelopes selados para a remessa dos questionários preenchidos, durante os meses de agosto e setembro de 2010.

Nesta primeira fase, todas as escolas receberam o material da pesquisa, sendo que a recusa em participar seria realizada após o recebimento, mediante a devolução do material pelo correio.

Até o final do ano letivo de 2010, não obtivemos a devolução de nenhum material, porém menos de 30\% dos questionários foram retornados. Assim, foi estabelecido um prazo - fevereiro de 2011 - de aguardo dos questionários e após este período se iniciou uma segunda fase da coleta de dados.

\section{$2^{\text {a }}$ Fase: Coleta de Dados com Contato}

Tendo em vista o não retorno de cerca de $70 \%$ dos questionários, tivemos que traçar uma nova estratégia de coleta de dados: o envio e/ou reenvio de questionários apenas para as escolas, previamente sorteadas, que aceitassem participar da pesquisa mediante contato telefônico prévio.

Para tanto, assumimos que a disposição da direção/coordenação em participar da pesquisa não influencia as respostas dos alunos, uma vez que o aluno respondente desconhece os meios pelos quais a pesquisa chegou até ele.

Assim, durante o $1^{\circ}$ semestre de 2011 e início do $2^{\circ}$ semestre de 2011 foram realizadas ligações telefônicas para todas as escolas que compunham a amostra inicial e que não tinham retornado os questionários. Muitas delas alegaram extravio do material dentro da própria escola, e solicitaram o reenvio do material. Algumas escolas não foram encontradas e outras ainda recusaram-se a participar, alegando justificativas diversas.

Após esta primeira fase de ligações telefônicas, estabelecemos uma lista prioritária de escolas para contato: 1 - escolas localizadas em estados que não tinham representação nenhuma na pesquisa e 2 - escolas localizadas em estados cuja representação na pesquisa era menor que $50 \%$. 
Para isso, acessamos a lista de escolas reserva, que compunham $20 \%$ da amostra e, posteriormente, a lista do próprio PISA, uma vez que muitas escolas da lista reserva não foram localizadas ou não aceitaram participar. O número de questionários enviados e reenviados por estado pode ser observado na tabela 3.4.

Tabela 3.4 - Número de envios realizados para as escolas por estado.

\begin{tabular}{|c|c|c|c|}
\hline Região & Estados & $\begin{array}{l}N^{0} \text { de envios para } \\
\text { escolas diferentes }\end{array}$ & $\begin{array}{c}\mathbf{N}^{\mathbf{o}} \text { de envios para a } \\
\text { mesma escola } \\
\text { (reenvios) }\end{array}$ \\
\hline \multirow[t]{9}{*}{ Nordeste } & Alagoas & 5 & 1 \\
\hline & Bahia & 8 & 2 \\
\hline & Ceará & 6 & 1 \\
\hline & Maranhão & 3 & 0 \\
\hline & Paraíba & 4 & 0 \\
\hline & Pernambuco & 6 & 0 \\
\hline & Piauí & 7 & 1 \\
\hline & Rio G. do Norte & 3 & 1 \\
\hline & Sergipe & 5 & 1 \\
\hline \multirow[t]{7}{*}{ Norte } & Acre & 3 & 1 \\
\hline & Amapá & 8 & 2 \\
\hline & Amazonas & 5 & 1 \\
\hline & Pará & 6 & 3 \\
\hline & Rondônia & 6 & 0 \\
\hline & Roraima & 5 & 1 \\
\hline & Tocantins & 7 & 0 \\
\hline Centro- & Distrito Federal & 9 & 2 \\
\hline \multirow[t]{3}{*}{ Oeste } & Goiás & 4 & 1 \\
\hline & Mato Grosso & 6 & 1 \\
\hline & Mato Grosso do Sul & 5 & 1 \\
\hline \multirow[t]{4}{*}{ Sudeste } & Espírito Santo & 6 & 1 \\
\hline & Minas Gerais & 6 & 2 \\
\hline & Rio de Janeiro & 7 & 1 \\
\hline & São Paulo & 10 & 1 \\
\hline \multirow[t]{3}{*}{ Sul } & Paraná & 6 & 0 \\
\hline & Rio Grande do Sul & 6 & 0 \\
\hline & Santa Catarina & 5 & 1 \\
\hline Total & & 157 & 26 \\
\hline
\end{tabular}

Desta forma, foram enviados questionários para 157 escolas diferentes, sendo que houve um número maior de envios para escolas localizadas nos estados prioritários. Mesmo assim, 
algumas escolas localizadas nesses estados não puderam ser contatadas devido a diversos problemas, tais como telefones inoperantes e greves dos funcionários da rede pública de ensino ${ }^{15}$. As tabelas 3.5 e 3.6 apresentam o número de questionários enviados e recebidos.

Tabela 3.5 - Número de questionários enviados e reenviados para escolas por região.

\begin{tabular}{lccc}
\hline Região & Escolas & Questionários & $\begin{array}{c}\text { Erro de } \\
\text { amostragem (\%) }\end{array}$ \\
\hline Norte & 48 & 1440 & Entre 4 e 5 \\
Nordeste & 54 & 1530 & Entre 4 e 5 \\
Centro Oeste & 29 & 910 & Entre 6 e 7 \\
Sudeste & 34 & 1020 & Entre 5 e 6 \\
Sul & 18 & 540 & 8 \\
\hline Total & 183 & 5440 & Entre 2 e 3 \\
\hline
\end{tabular}

A coleta de dados se encerrou no final de setembro de 2011, de forma que 84 escolas retornaram os materiais recebidos, totalizando 2365 questionários preenchidos. Este número é considerado satisfatório para a amostragem proposta inicialmente, já que possui uma margem de erro entre 3 e 4 pontos percentuais, a mesma margem de erro do plano amostral inicial. $\mathrm{O}$ número de questionários recebidos por região encontra-se descrito na tabela 3.6.

Tabela 3.6 - Número de questionários recebidos por região.

\begin{tabular}{lccc}
\hline Região & Escolas & Questionários & $\begin{array}{c}\text { Erro de } \\
\text { amostragem (\%) }\end{array}$ \\
\hline Norte & 22 & 661 & Entre 07 e 08 \\
Nordeste & 25 & 634 & Entre 07 e 08 \\
Centro-Oeste & 12 & 332 & Entre 10 e 11 \\
Sudeste & 15 & 471 & Entre 08 e 09 \\
Sul & 10 & 267 & Entre 11 e 12 \\
\hline Total & 84 & 2365 & Entre 03 e 04 \\
\hline
\end{tabular}

Assim, podemos contemplar nos resultados da pesquisa os dados nacionais e regionais, sendo que os dados das regiões Centro-Oeste e Sul possuem uma margem de erro maior que 10 pontos percentuais.

\footnotetext{
${ }^{15}$ No primeiro semestre de 2011 ocorreram greves nos estados de Alagoas, Rio de Janeiro, Santa Catarina e Sergipe. No início do segundo semestre de 2011, algumas escolas técnicas federais também entraram em greve, agravando ainda mais as dificuldades surgidas no percurso da coleta de dados.
} 


\subsection{ANÁLISE DOS DADOS}

\subsubsection{Análise descritiva geral}

Os resultados, em sua grande parte de natureza quantitativa, estão apresentados por análise exploratória e descritivo-comparativa ${ }^{16}$ entre gêneros, por meio de médias, desvio padrão, frequência e percentual, a fim de apresentar as características da amostra e identificar o interesse dos alunos pelos assuntos abordados. Também foram aplicados alguns testes para verificar padrões e/ou diferenças na amostra, onde foi adotado o nível de significância de 0,05 ( $\alpha=5 \%$ ) bicaudados como indicativos de diferença estatística entre os grupos. Os testes aplicados foram:

\section{TESTE DE SHAPIRO-WILK}

Este teste foi utilizado para se detectar a aderência dos dados a uma distribuição normal. Seu resultado é utilizado como insumo para a decisão entre o uso de um teste paramétrico ou não paramétrico para se avaliar respostas quantitativas.

\section{TESTE DE MANN-WHITNEY}

O teste não paramétrico de Mann-Whitney foi usado para a comparação das notas das questões entre meninas e meninos quando não foi detectada normalidade nos dados.

\section{TESTE T DE STUDENT}

Este teste paramétrico foi utilizado para a comparação entre as médias das notas das questões entre meninas e meninos quando detectada a normalidade dos dados.

\section{ANÁLISE DE VARIÂNCIA ANOVA}

Foi utilizada a análise de variância ANOVA para se comparar as médias quando da existência de mais de dois grupos. Por exemplo, a comparação das notas dadas pelos alunos por região do país. O teste indica se há igualdade ou não entre as notas das regiões.

\footnotetext{
${ }^{16}$ As análises foram realizadas utilizando-se o pacote estatístico SPSS (Statistical Package for Social Science), versão 15.0, o programa R, o Microsoft Office Excel e o KNIME.
} 


\section{TESTE DE TUKEY}

O teste de Tukey é um teste post-hoc. É usado após a ANOVA para se descobrir diferenças pontuais entre grupos. Por exemplo, a ANOVA indicou haver uma diferença significativa entre as regiões do país para uma determinada questão. O passo seguinte é descobrir entre quais regiões se encontra essa diferença.

\section{TESTE DE QUI-QUADRADO}

O teste de Qui-quadrado foi usado para se detectar a associação entre variáveis categóricas. Por exemplo, entre as categorias de quantidade de livros dos questionários PISA e ROSE.

\subsubsection{Análises Multivariadas}

Tendo em vista o grande número de questões existente no questionário ROSE, foi necessário recorrer a análises que sistematizassem e reduzissem de forma adequada os dados obtidos. Estas análises foram feitas através da Análise Fatorial e a Análise por Componentes Principais (PCA).

\section{ANÁLISE FATORIAL}

A análise fatorial é utilizada quando se possui um grande número de variáveis e se quer descrever inter-relações entre estas variáveis. Para isso, a análise fatorial reduz as variáveis iniciais (reais) a um número menor de variáveis hipotéticas. Estas variáveis hipotéticas são chamadas de fatores. A análise permite ainda conhecer o quanto cada fator está associado a cada variável original e o quanto o conjunto de fatores explica a variabilidade geral dos dados (ARTES, 1998).

A análise fatorial utiliza o princípio de se maximizar a variância interna das variáveis (variância entre dois conjuntos de respostas e não entre um grupo de respostas e o todo).

\section{ANÁLISE DE COMPONENTES PRINCIPAIS (PCA)}

A Análise por Componentes Principais (PCA) é um tipo de análise multivariada semelhante à análise fatorial, porém se caracteriza metodologicamente diferente da primeira: a PCA 
transforma um conjunto de variáveis em outro conjunto de variáveis menor (os componentes principais), considerando a variância global das respostas (ARTES, 1998).

Nesta pesquisa, foi utilizada a análise de componentes principais para se reduzir a dimensionalidade dos dados e explorar as similaridades entre as respostas das questões dentro de cada seção. A análise de componentes principais pode ser utilizada para se definir, de maneira exploratória, avaliando os auto-valores e variância acumulada, a quantidade de fatores para os quais queremos reduzir os dados e, eventualmente, agrupar variáveis dentro de uma só através da sua correlação individual com o fator.

\subsubsection{Análise Comparativa entre ROSE-Brasil e PISA 2006}

O PISA 2006 foi utilizado como parâmetro de comparação para algumas questões do ROSE, uma vez que ele possui um questionário de interesse pela ciência, denominado "Questionário do Aluno" que possui pontos em comum com a pesquisa aqui apresentada. Este questionário foi aplicado para se conhecer informações sobre a família do aluno, seu interesse em diversos pontos da ciência, tecnologia e meio ambiente, seu tempo de estudo e sobre o ensino e aprendizagem das ciências.

A amostra do PISA 2006 abrangeu 9295 alunos distribuídos em todos os estados brasileiros, sendo que destes $54,2 \%$ eram mulheres e 45,8\% eram homens. A média de idade foi de 15,66 anos, idade semelhante aos alunos participantes do ROSE. 40,87\% dos alunos participantes do PISA 2006 cursavam o $1^{\circ}$ ano do Ensino Médio, sendo que dentre os demais, 26,29\% cursavam o $9^{\circ}$ ano do Ensino Fundamental, 17,75\% o $2^{\circ}$ ano do Ensino Médio, 14,29\% o $8^{\circ}$ ano do Ensino Fundamental e 0,80\% o $3^{\circ}$ ano do Ensino Médio. 


\section{AS ESCOLAS E OS JOVENS DA AMOSTRA ROSE BRASIL}

Neste capítulo serão descritas características da amostra ROSE Brasil. Foram recebidos 2365 questionários oriundos de 84 escolas localizadas em todos os estados brasileiros. Informações sobre essas escolas e seus alunos serão apresentadas a seguir.

\subsection{AS ESCOLAS PARTICIPANTES DA PESQUISA}

As escolas participantes da amostra ROSE Brasil são provenientes de todos os estados brasileiros. Os municípios participantes em cada estado estão apresentados na tabela 4.1. Os números em parênteses indicam o número de escolas participantes, quando este for maior que um.

Tabela 4.1 - Distribuição das escolas participantes nos estados e municípios brasileiros.

\begin{tabular}{|c|c|c|c|}
\hline Região & Estados & $\begin{array}{l}N^{0} \text { de escolas } \\
\text { participantes }\end{array}$ & Municípios \\
\hline \multirow[t]{9}{*}{ Nordeste } & Alagoas & 02 & Maceió, Penedo \\
\hline & Bahia & 04 & Salvador, Catu, Vitória da Conquista, Feira de Santana \\
\hline & Ceará & 05 & Fortaleza, Chaval, Aurora, Maracanaú, Guaraciaba do Norte \\
\hline & Maranhão & 02 & São Luis, Santa Luzia \\
\hline & Paraíba & 01 & Malta \\
\hline & Pernambuco & 04 & Recife, Caruaru, Serra Talhada, Limoeiro \\
\hline & Piauí & 02 & Teresina, Parnaíba \\
\hline & Rio Grande do Norte & 02 & Natal, Marcelino Vieira \\
\hline & Sergipe & 03 & Propriá, Nossa Senhora da Glória, São Cristovão \\
\hline \multirow[t]{7}{*}{ Norte } & Acre & 03 & Rio Branco (2), Feijó \\
\hline & Amapá & 01 & Oiapoque \\
\hline & Amazonas & 03 & Manaus (2), Jutaí \\
\hline & Pará & 03 & Belterra, Cametá, Marituba \\
\hline & Rondônia & 05 & $\begin{array}{l}\text { Rolim de Moura, Jaru, Machadinho d'Oeste, Porto Velho, } \\
\text { Ariquemes }\end{array}$ \\
\hline & Roraima & 03 & Boa Vista (3) \\
\hline & Tocantins & 04 & Itacajá, Miranorte, Araguaina, Wanderlândia \\
\hline \multirow{4}{*}{$\begin{array}{l}\text { Centro- } \\
\text { Oeste }\end{array}$} & Distrito Federal & 03 & Brasília (Taguatinga, Gama, Sobradinho) \\
\hline & Goiás & 03 & Iporá, Aragoiania, Aparecida de Goiânia \\
\hline & Mato Grosso & 03 & Cuiabá, Sinop, Barra do Bugres \\
\hline & Mato Grosso do Sul & 03 & Dourados (2), Jaraguari \\
\hline \multirow[t]{4}{*}{ Sudeste } & Espírito Santo & 02 & Vila Valério, Cachoeiro do Itapemirim \\
\hline & Minas Gerais & 04 & Lagoa da Prata, Ribeirão das Neves, Campo Belo, Ipatinga \\
\hline & Rio de Janeiro & 02 & Campo de Goytacazes, São Gonçalo \\
\hline & São Paulo & 07 & Caçapava, Mogi das Cruzes, Suzano (2), São Paulo (3) \\
\hline \multirow[t]{3}{*}{ Sul } & Paraná & 04 & Arapongas, Maringá, Quedas do Iguaçu, Rio Branco do Ivaí \\
\hline & Rio Grande do Sul & 04 & Pelotas, Montenegro, Parobe, Santa Maria \\
\hline & Santa Catarina & 02 & Joaçaba, Imaruí \\
\hline
\end{tabular}


A distribuição das escolas por localização e dependência administrativa pode ser observada nas tabelas 4.2 e 4.3 .

Tabela 4.2 - Localização das escolas participantes da pesquisa.

\begin{tabular}{lcc}
\hline Localidade & $\mathbf{N}^{\mathbf{0}}$ de escolas & \% \\
\hline Urbana & 81 & 96 \\
Rural & 3 & 4 \\
\hline Total & 84 & 100 \\
\hline
\end{tabular}

Tabela 4.3 - Dependência administrativa das escolas participantes da pesquisa.

\begin{tabular}{lcc}
\hline $\begin{array}{l}\text { Dependência } \\
\text { Administrativa }\end{array}$ & $\mathbf{N}^{\mathbf{o}}$ de escolas & $\%$ \\
\hline Pública Estadual & 74 & 88 \\
Pública Federal & 3 & 4 \\
Pública Municipal & 0 & 0 \\
Privada & 7 & 8 \\
\hline Total & 84 & 100 \\
\hline
\end{tabular}

Observa-se que a amostra possui escolas localizadas na sua maioria no setor urbano, e que pertencem a rede pública estadual de ensino. Os dados são esperados uma vez que o mantenimento de escolas do Ensino Médio é de competência prioritária dos estados (Constituição Federal de 1988, artigo 208, inciso II). 


\subsection{OS JOVENS PARTICIPANTES DA PESQUISA}

Os jovens participantes da pesquisa, 2365 estudantes do $1^{\circ}$ ano do Ensino Médio, estão distribuídos em todos os estados brasileiros, conforme pode ser observado na figura 4.1.

\section{Distribuição da Amostra nos Estados Brasileiros}

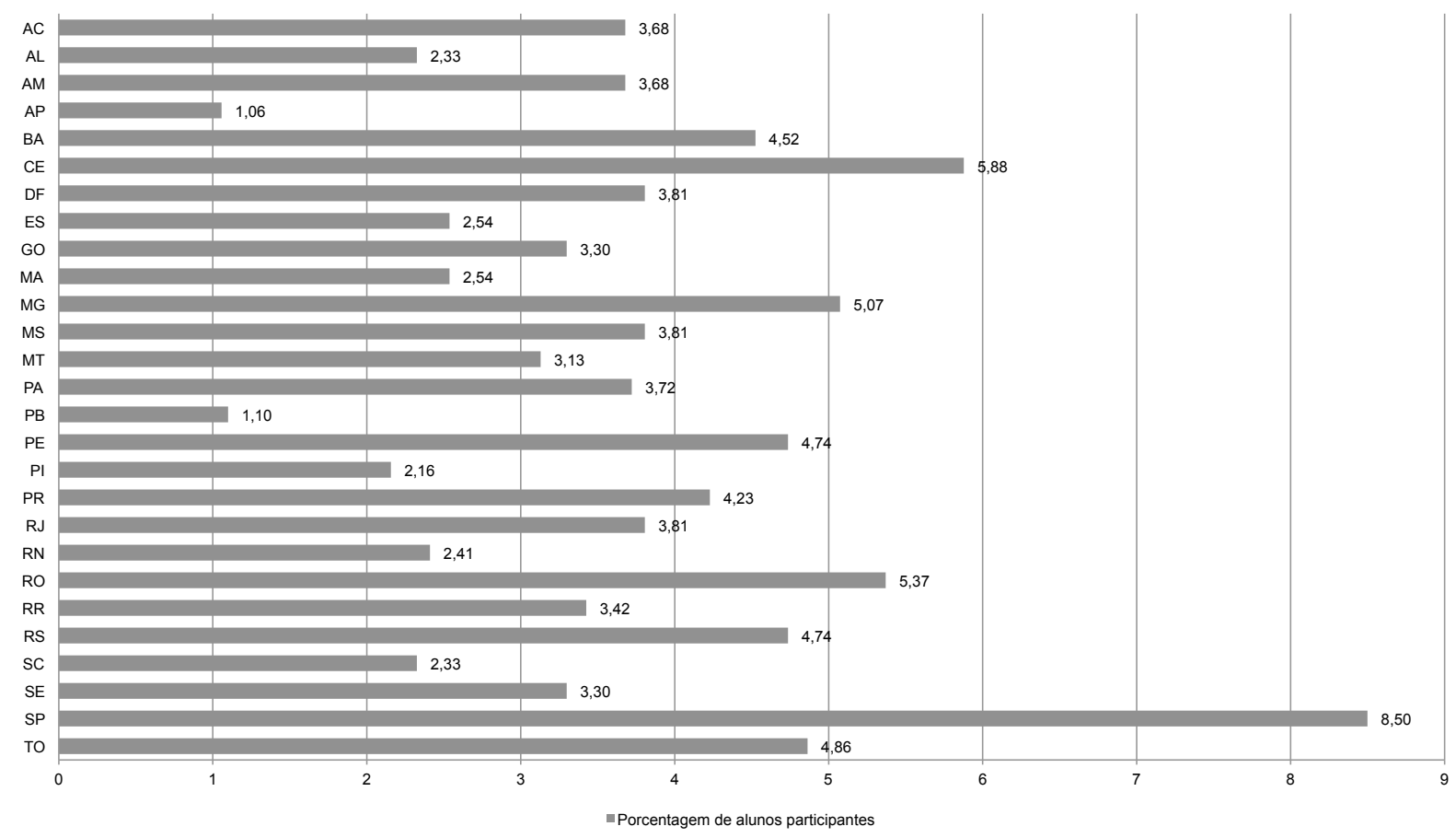

Figura 4.1 - Distribuição da amostra nos estados brasileiros. 
Como grande parte das análises será comparativa entre as regiões brasileiras, apresentamos na figura 4.2 a distribuição da amostra (número de alunos) pelas cinco regiões brasileiras.

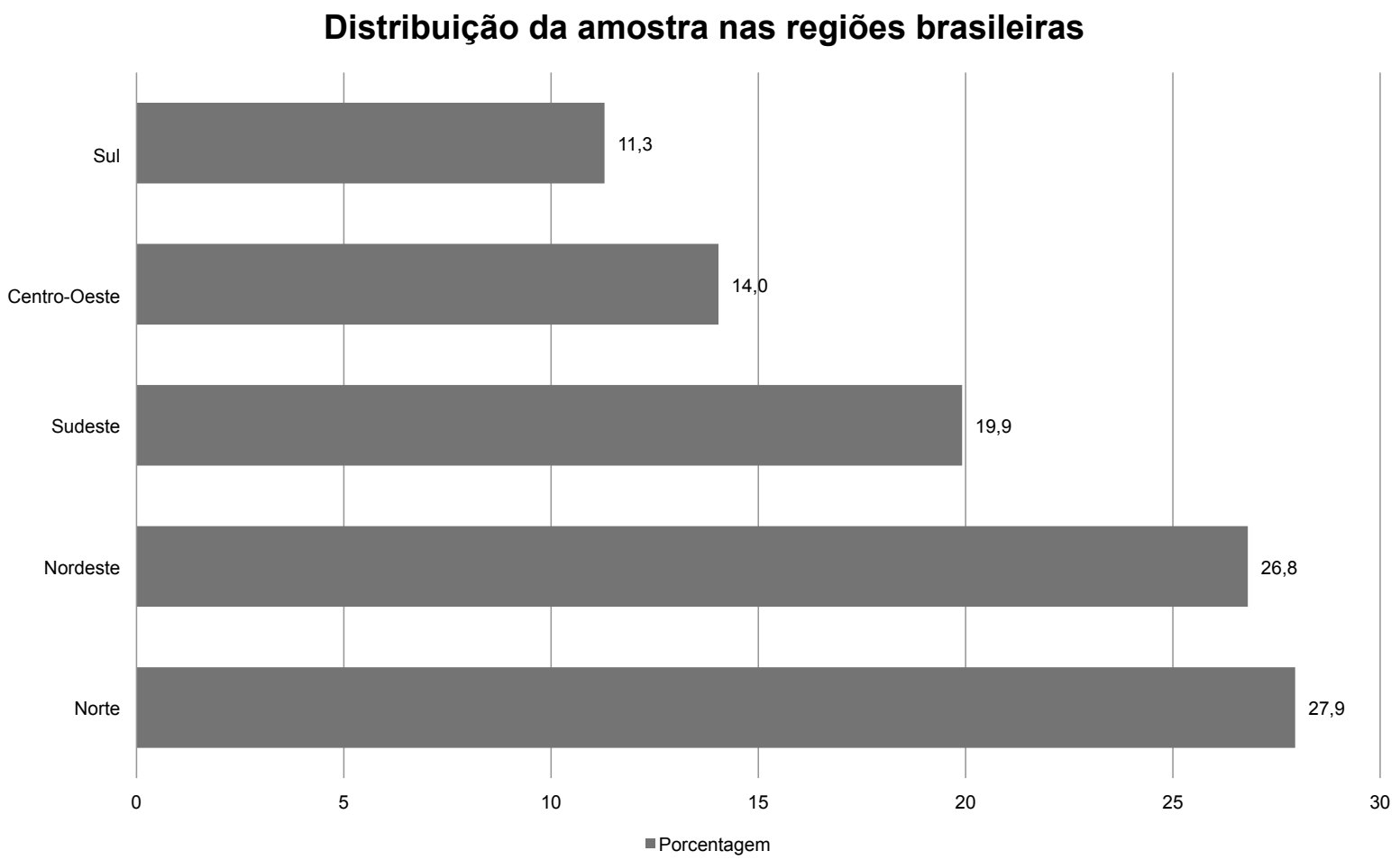

Figura 4.2 - Distribuição da amostra nas regiões brasileiras.

A distribuição da amostra em relação ao gênero pode ser observada na tabela 4.4.

Tabela 4.4 - Distribuição da amostra em relação ao gênero.

\begin{tabular}{lccc}
\hline Gênero & N & $\%$ & $\begin{array}{c}\% \\
\text { (válido) }\end{array}$ \\
\hline Homem & 983 & 41,56 & 42,33 \\
Mulher & 1339 & 56,62 & 57,67 \\
Total válido & 2322 & 98,18 & 100,00 \\
\hline Resposta Inválida & 43 & 1,82 & - \\
Total & 2365 & 100,00 & - \\
\hline
\end{tabular}

Os dados encontrados em relação ao gênero são próximos aos dados obtidos pelo PISA no ano 2006 , onde $54,2 \%$ eram mulheres e $45,8 \%$ eram homens.

Para o conhecimento de informações socioeconômicas, o questionário possuía duas 
questões: uma relacionada à posse de livros e outra relacionada ao número de banheiros presentes na casa do estudante. A questão relativa ao número de livros é, Segundo Schreiner (2006, p. 87), uma “cópia literal de uma das questões do PISA 2000”, que foi mantida em versões posteriores, como a de 2006. A outra questão de caráter socioeconômico, relativa ao número de banheiros presentes no domicílio do aluno, foi incluída pela equipe que organizou a primeira aplicação do ROSE no Brasil (TOLENTINO-NETO, 2008). Esta questão também aparece no questionário PISA 2006 como indicador socioeconômico.

As informações socioeconômicas obtidas encontram-se descritas nas tabelas 4.5 a 4.9 e nas figuras 4.3 e 4.4 .

Tabela 4.5 - Distribuição da amostra em relação à posse de livros.

\begin{tabular}{lccc}
\hline $\begin{array}{l}\text { Quantos livros há na sua } \\
\text { casa? }\end{array}$ & $\mathbf{N}$ & $\%$ & $\begin{array}{c}\% \\
\text { (válido) }\end{array}$ \\
\hline Nenhum & 79 & 3,34 & 3,43 \\
1-10 livros & 736 & 31,12 & 31,99 \\
11-50 livros & 864 & 36,53 & 37,55 \\
51-100 livros & 339 & 14,33 & 14,73 \\
101-250 livros & 175 & 7,40 & 7,61 \\
251-500 livros & 65 & 2,75 & 2,82 \\
Mais que 500 livros & 43 & 1,82 & 1,87 \\
Total Válido & 2301 & 97,29 & 100,00 \\
\hline Resposta Inválida & 64 & 2,71 & - \\
Total & 2365 & 100,00 & - \\
\hline
\end{tabular}

Pode-se observar que no âmbito brasileiro, $71 \%$ dos alunos possuem menos que 50 livros em casa, o que indica acesso restrito a um bem cultural relativamente comum e de ampla distribuição, como o caso dos livros didáticos. A faixa onde se concentrou maior porcentagem $(37 \%)$ foi a de 11 a 50 livros. 


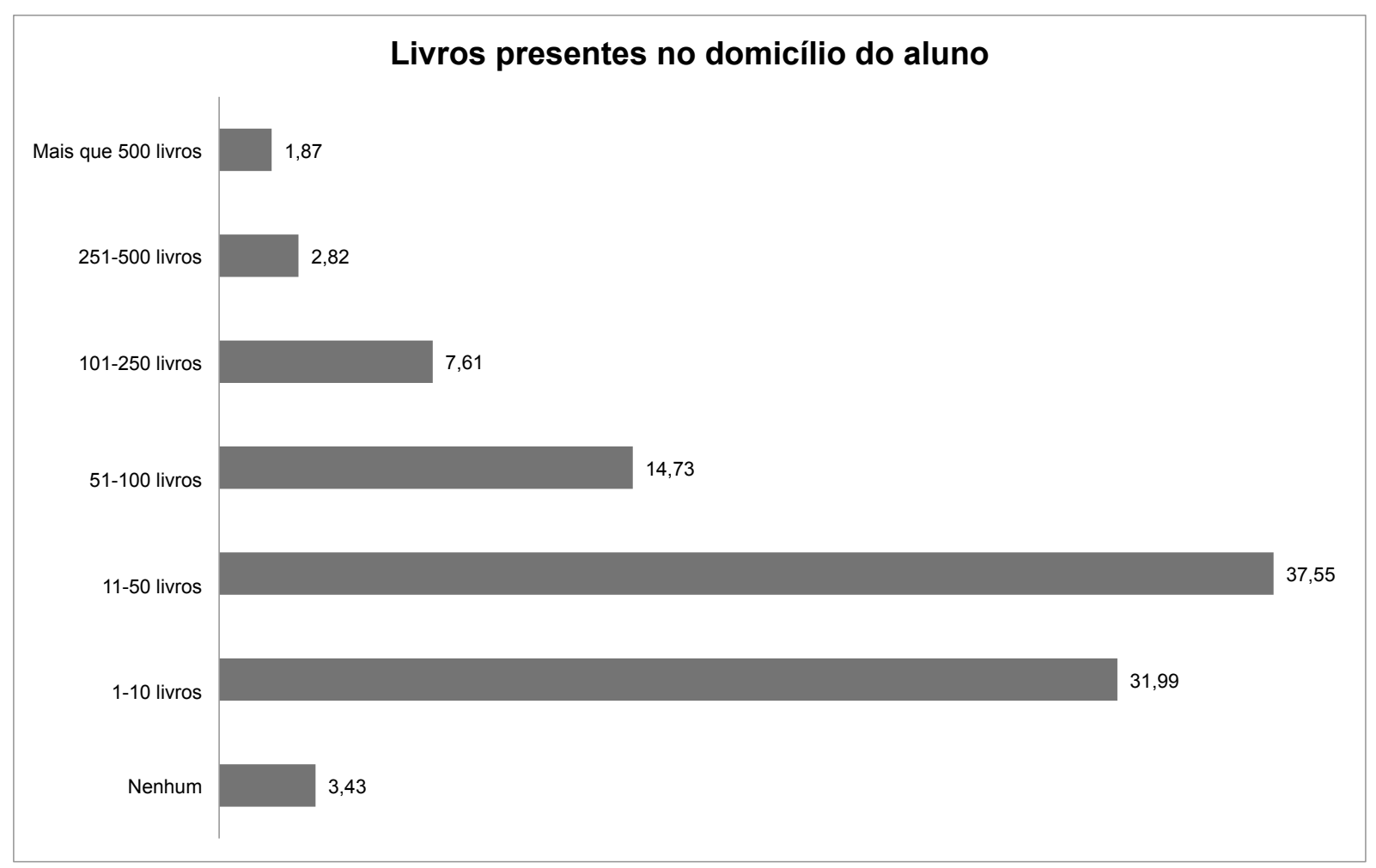

Figura 4.3 - Gráfico representando a quantidade de livros presentes nos domicílios dos alunos amostrados.

A observação da tabela 4.6 permite identificar que a faixa de maior concentração de respostas dentre as regiões brasileiras se manteve em 11 a 50 livros, com exceção das regiões Sul e Centro-Oeste, cuja faixa de maior concentração de respostas foi a de 1 a 10 livros (48\% e $35,91 \%$ respectivamente). 


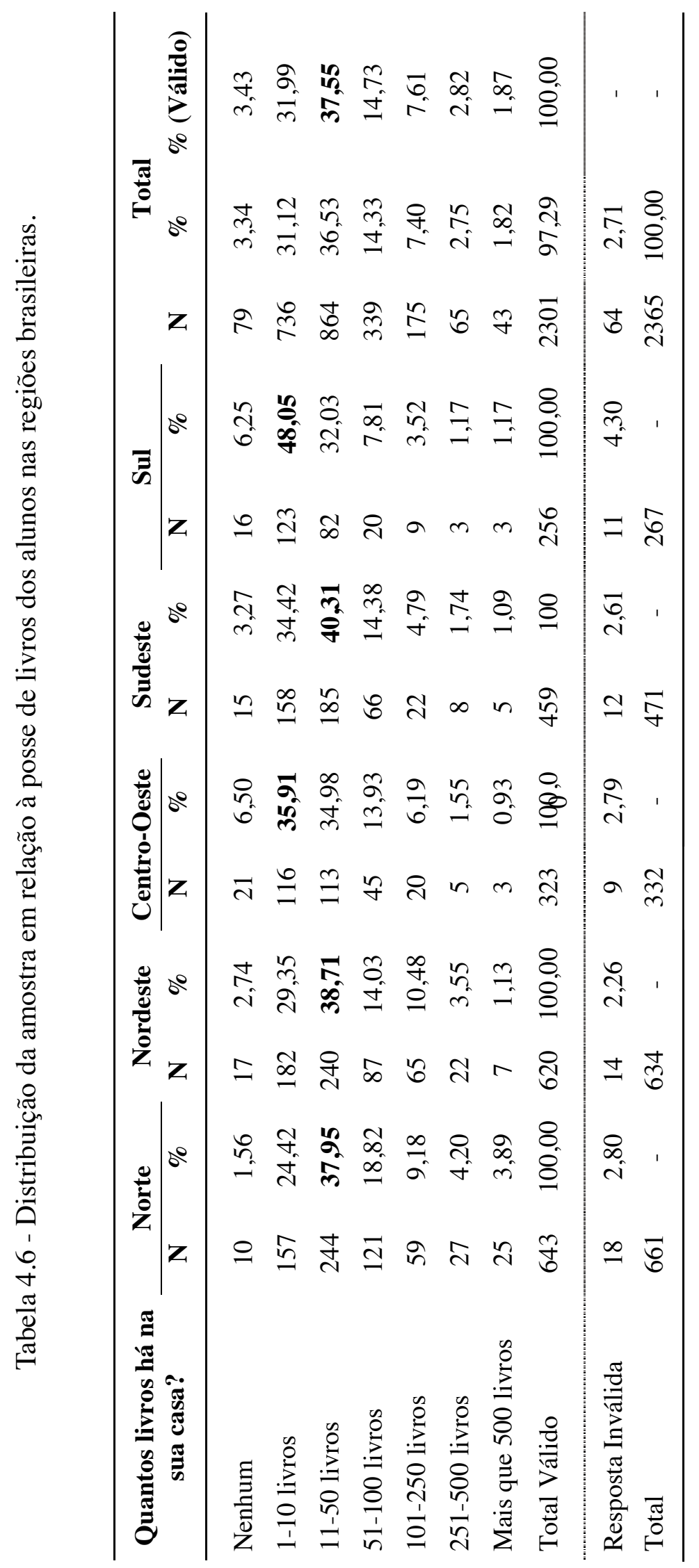


Foi aplicado o teste de Qui-Quadrado para avaliar se há associação entre a quantidade de livros e a região do aluno. A hipótese H0 é de que não há associação entre as variáveis, enquanto a hipótese alternativa, Ha, indica associação. O p-valor obtido, menor que 0,001 , nos faz rejeitar a hipótese $\mathrm{H} 0$, o que indica haver evidências estatísticas fortes da associação entre as variáveis.

Para efeito de comparação entre a amostra ROSE e a amostra PISA 2006, se fez a análise comparativa entre as duas amostras no que se refere ao número de livros, uma vez que ambos os questionários possuem esta questão. Os dados obtidos podem ser observados na tabela 4.7 .

Tabela 4.7 - Comparação entre os dados obtidos junto à pesquisa ROSE e PISA 2006 no que se refere à posse de livros.

\begin{tabular}{lcccc}
\hline & $\begin{array}{c}\text { 0-100 } \\
\text { Livros }\end{array}$ & $\begin{array}{c}\text { 101-500 } \\
\text { Livros }\end{array}$ & $\begin{array}{c}\text { Mais de 500 } \\
\text { Livros }\end{array}$ & P-valor \\
\hline ROSE & $85,33 \%$ & $10,15 \%$ & $1,82 \%$ & 0,025 \\
PISA 2006 & $86,98 \%$ & $8,61 \%$ & $1,44 \%$ & \\
\hline
\end{tabular}

Foi usado o teste de Qui-Quadrado para se avaliar se há associação entre o número de livros reportado pelos alunos que responderam o questionário ROSE e o questionário PISA. A hipótese testada foi H0: as respostas dos questionários são independentes e Ha: as respostas são dependentes. O p-valor obtido para o teste $(\mathrm{p}=0,025)$ nos leva a rejeitar a hipótese H0. Dessa forma, podemos dizer que estatisticamente há associação entre as respostas dos dois questionários, ou seja, as respostas foram similares.

Em relação ao número de banheiros, os dados gerais podem ser observados na tabela 4.8 e figura 4.4 . 
Tabela 4.8 - Distribuição da amostra em relação ao número de banheiros.

\begin{tabular}{lccc}
\hline $\begin{array}{c}\text { Quantos banheiros há na } \\
\text { sua casa? }\end{array}$ & $\mathbf{N}$ & $\mathbf{\%}$ & $\begin{array}{c}\% \\
\text { (válido) }\end{array}$ \\
\cline { 2 - 4 } Nenhum & 6 & 0,25 & 0,26 \\
1 & 1320 & 55,81 & 57,44 \\
2 & 673 & 28,46 & 29,29 \\
3 & 208 & 8,79 & 9,05 \\
4 & 64 & 2,71 & 2,79 \\
5 & 21 & 0,89 & 0,91 \\
Mais de 5 & 6 & 0,25 & 0,26 \\
Total Válido & 2298 & 97,17 & 100,00 \\
\hline Resposta Inválida & 67 & 2,83 & - \\
Total & 2365 & 100,00 & - \\
\hline
\end{tabular}

\section{Banheiros no domicílio do aluno}

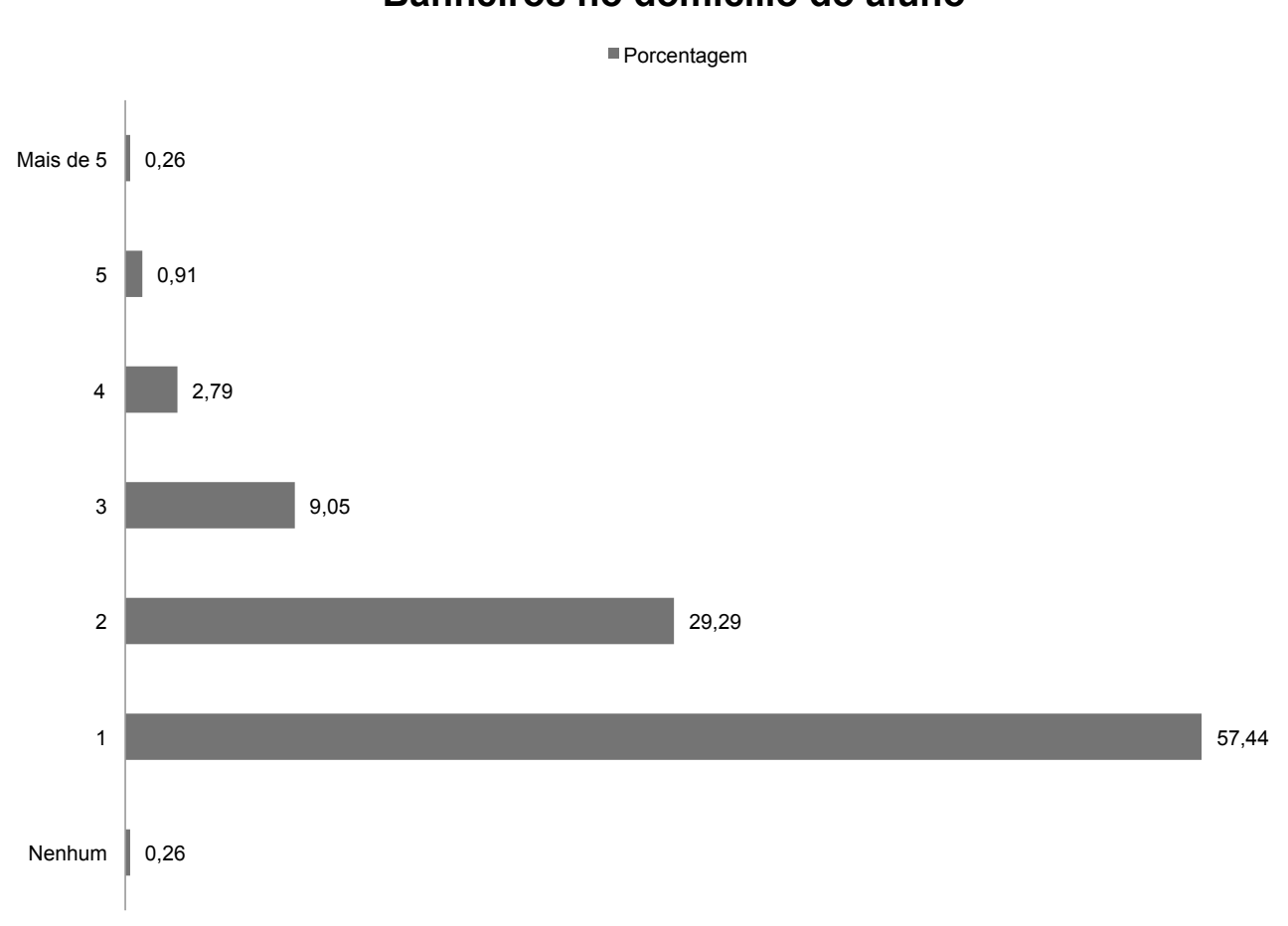

Figura 4.4 - Gráfico representando porcentagem relativa ao número de banheiros presente nos domicílios dos alunos participantes da pesquisa.

A tabela 4.8 e a figura 4.4 apontam que na maioria dos domicílios dos alunos amostrados há um banheiro. A distribuição da variável banheiro nas regiões brasileiras pode ser observada na tabela 4.9 . 


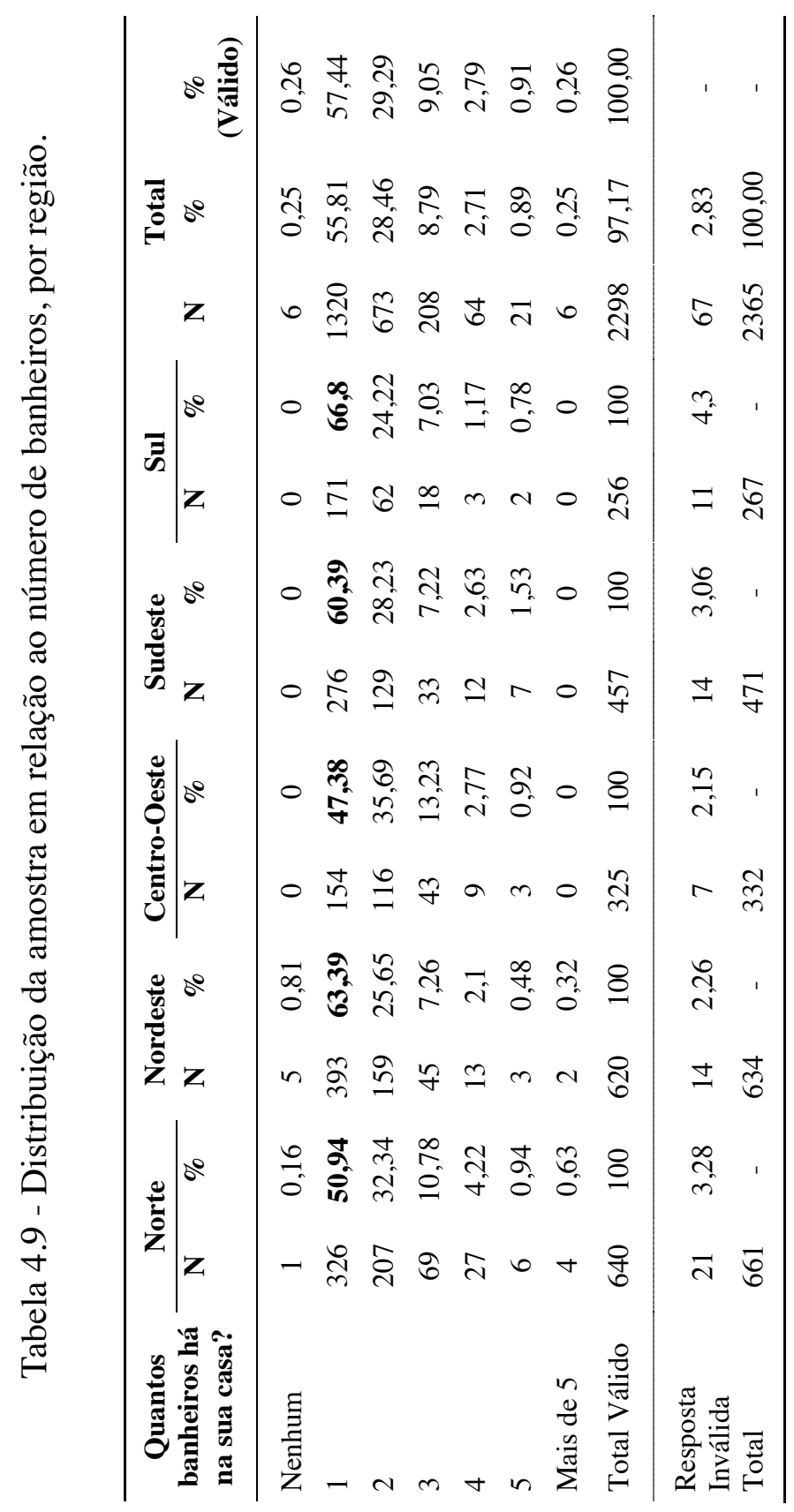

A tabela acima indica que há maior ocorrência de um banheiro nos domicílios dos alunos de todas as regiões brasileiras. Foi aplicado o teste de Qui-Quadrado para se avaliar a associação entre a quantidade de banheiros e a região do aluno. A hipótese H0 é de que não há associação entre as variáveis, enquanto a hipótese alternativa, Ha, indica associação. O pvalor obtido, menor que 0,001 , nos faz rejeitar a hipótese H0, o que indica haver evidências estatísticas fortes da associação entre as variáveis. 
Os jovens participantes da pesquisa eram oriundos de turmas de $1^{\circ}$ ano de Ensino Médio, com idade esperadas de 14-15 anos. Foram encontrados jovens com idade entre 13 e 25 anos de idade, conforme pode ser observada na tabela 4.10 .

Tabela 4.10 - Distribuição da amostra em relação à idade.

\begin{tabular}{lccc}
\hline Idade & $\mathbf{N}$ & $\mathbf{\%}$ & $\mathbf{\%}$ (válido) \\
\hline 13 & 11 & 0,47 & 0,48 \\
14 & 340 & 14,38 & 14,75 \\
15 & 1163 & 49,18 & 50,46 \\
16 & 483 & 20,42 & 20,95 \\
17 & 210 & 8,88 & 9,11 \\
18 & 62 & 2,62 & 2,69 \\
19 & 25 & 1,06 & 1,08 \\
20 & 6 & 0,25 & 0,26 \\
21 & 2 & 0,08 & 0,09 \\
22 & 1 & 0,04 & 0,04 \\
24 & 1 & 0,04 & 0,04 \\
25 & 1 & 0,04 & 0,04 \\
Total Válido & 2305 & 97,46 & 100,00 \\
\hline Resposta Inválida & 60 & 2,54 & - \\
Total & 2365 & 100,00 & - \\
\hline
\end{tabular}

Apesar de haver variabilidade de idade, indicando a existência de defasagem sérieidade, a média de idade obtida na amostra Brasil foi considerada adequada para os objetivos do projeto, uma vez que o esperado era a maior ocorrência de alunos com 15 anos. A frequência relativa das idades dos alunos participantes pode ser observada na figura 4.5. 


\section{Idade dos alunos participantes da pesquisa}

- Frequência Relativa

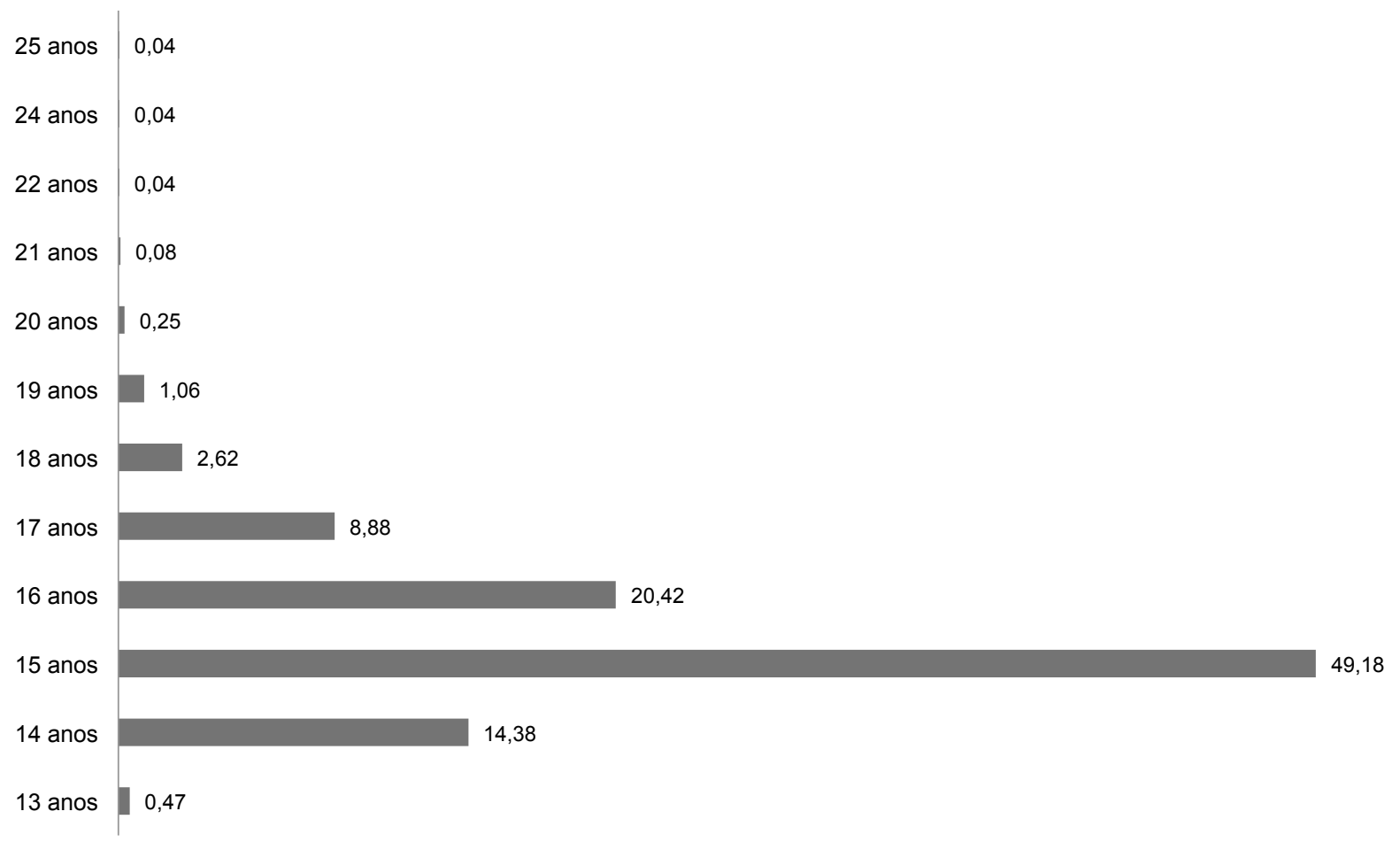

Figura 4.5 - Frequência relativa das idades dos alunos brasileiros participantes da pesquisa.

A tabela 4.11 apresenta a média e desvio padrão da variável idade para a amostra em geral.

Tabela 4.11- Média e desvio padrão da amostra para a idade.

\begin{tabular}{llll}
\hline Idade & $\mathbf{N}$ & Média & DP \\
\hline & 2305 & 15,39 & 1,10 \\
\hline
\end{tabular}

A distribuição da idade pelas regiões brasileiras pode ser observada na tabela 4.12.

Tabela 4.12 - Média de idade dos alunos amostrados por região brasileira.

\begin{tabular}{lccc}
\hline Região & Média & DP & N \\
\hline Centro-Oeste & 15,32 & 1,12 & 324 \\
Nordeste & 15,60 & 1,18 & 621 \\
Norte & 15,36 & 1,11 & 642 \\
Sudeste & 15,25 & 0,90 & 460 \\
Sul & 15,28 & 1,08 & 258 \\
\hline
\end{tabular}


A média entre as regiões permaneceu na idade de 15 anos, apesar de haver diferenças entre cada região. Observa-se que a média de idade brasileira também coincide com a média de idade obtida numa análise realizada entre 25 países participantes do ROSE, que foi de 15,3: Bangladesh, Botswana, Dinamarca, Inglaterra, Estônia, Finlândia, Gana Central, Grécia, Islândia, Índia (Gurajat), Irlanda, Japão, Latvia, Malásia, Irlanda do Norte, Noruega, Filipinas, Polônia, Portugal, Russia (Carélia), Suiça, Suécia, Trinidad e Tobago, Uganda e Zimbábue (SCHREINER, 2006). 


\section{O INTERESSE DOS JOVENS BRASILEIROS PELAS CIÊNCIAS NA ESCOLA}

Neste capítulo serão apresentados os resultados obtidos junto às seções ACE, que questionavam ao aluno: "Qual é o seu nível de interesse em aprender os seguintes assuntos ou temas?”. Conforme declaram Schreiner e Sjøberg (2004), conhecer quais tópicos da ciência os jovens têm interesse em aprender poderá subsidiar questões envolvendo o currículo de ciências atual, de forma que permita o maior engajamento do estudante. Kwiek et al. (2007) afirmam que abordar na escola temas que despertem o interesse dos alunos pode ajudar a aumentar sua motivação e seu aprendizado.

Para tornar mais palatável os resultados obtidos ao longo das 108 questões presentes nas seções $\mathrm{ACE}^{17}$, optou-se por apresentar os dados da seguinte forma: 1) através da exposição dos 20 itens com maior/menor pontuação entre meninos e meninas; 2) através da exposição das disciplinas/assuntos da ciência que mais/menos interessam meninos e meninas; 3) através de análise comparativa entre tópicos de interesse envolvendo conteúdos e contextos; 4) através de uma análise comparativa entre os jovens das diversas regiões brasileiras e 5) posicionando o jovem brasileiro no cenário internacional.

Para a verificação de diferenças entre gênero, foram utilizados testes de Mann-Whitney quando não se observou normalidade dos dados e o teste T Student quando foi detectada normalidade dos dados. Diferenças com valores de $\mathrm{p}<0,05$ foram consideradas significativas. Para a verificação de diferenças entre regiões brasileiras, foram utilizados os testes ANOVA e Tukey, conforme discriminado no capítulo 3.

\subsection{O QUE OS JOVENS BRASILEIROS MAIS (E MENOS) SE INTERESSAM EM APRENDER?}

Optamos por introduzir os resultados com um panorama geral do interesse do jovem brasileiro pela ciência na escola, apresentando as 20 respostas com maior e menor pontuação das seções ACE, discriminando meninos e meninas. Os resultados podem ser observados na tabela 5.1 e 5.2 .

\footnotetext{
${ }^{17}$ Os dados completos, com as médias e testes para diferenças de gênero dos 108 itens presentes nas seções ACE, encontram-se no Apêndice IV. 
Tabela 5.1 - Itens das seções ACE com maior pontuação entre os jovens brasileiros.

\begin{tabular}{|c|c|c|c|}
\hline Meninos & & Meninas & \\
\hline A09 - Sexo e reprodução & 3,18 & E10 - Como prestar primeiros socorros & 3,45 \\
\hline C07 - Como os computadores funcionam & 3,17 & $\begin{array}{l}\text { E08 - O câncer, o que sabemos e como } \\
\text { podemos tratá-lo }\end{array}$ & 3,40 \\
\hline E10 - Como prestar primeiros socorros & 3,17 & $\begin{array}{l}\text { C13 - Porque sonhamos e qual o } \\
\text { significado dos nossos sonhos }\end{array}$ & 3,34 \\
\hline $\begin{array}{l}\text { A } 40 \text { - Como manter o meu corpo forte e em } \\
\text { boa condição física }\end{array}$ & 3,15 & $\begin{array}{l}\text { E09 - As doenças sexualmente } \\
\text { transmissíveis e como se proteger delas }\end{array}$ & 3,33 \\
\hline A30 - Como funciona a bomba atômica & 3,07 & $\begin{array}{l}\text { E11 - O que sabemos sobre HIV/AIDS } \\
\text { e como controlá-la }\end{array}$ & 3,31 \\
\hline $\begin{array}{l}\text { E09 - As doenças sexualmente transmissíveis } \\
\text { e como se proteger delas }\end{array}$ & 3,06 & $\begin{array}{l}\text { A } 40 \text { - Como manter o meu corpo forte e } \\
\text { em boa condição física }\end{array}$ & 3,29 \\
\hline $\begin{array}{l}\text { C08 - A possibilidade de vida fora do planeta } \\
\text { Terra }\end{array}$ & 3,03 & $\begin{array}{l}\text { E13 - Como as diferentes drogas } \\
\text { proibidas podem afetar o nosso corpo }\end{array}$ & 3,19 \\
\hline $\begin{array}{l}\text { E08 - O câncer, o que sabemos e como } \\
\text { podemos tratá-lo }\end{array}$ & 3,01 & $\begin{array}{l}\text { A07 - Como o corpo humano é feito e } \\
\text { como funciona }\end{array}$ & 3,18 \\
\hline $\begin{array}{l}\text { E05 - O que se pode fazer para assegurar ar } \\
\text { limpo e água potável }\end{array}$ & 3,00 & $\begin{array}{l}\text { E07 - Como controlar epidemias e } \\
\text { doenças }\end{array}$ & 3,18 \\
\hline $\begin{array}{l}\text { E11 - O que sabemos sobre HIV/AIDS e } \\
\text { como controlá-la }\end{array}$ & 2,99 & $\begin{array}{l}\text { E23 - Como o meu corpo cresce e se } \\
\text { desenvolve }\end{array}$ & 3,17 \\
\hline $\begin{array}{l}\text { E42 - Fenômenos que os cientistas ainda não } \\
\text { conseguem explicar }\end{array}$ & 2,99 & $\begin{array}{l}\text { A37 - O que comer para nos mantermos } \\
\text { saudáveis e em boa forma física }\end{array}$ & 3,14 \\
\hline $\begin{array}{l}\text { E16 - Como proteger espécies de animais } \\
\text { ameaçados de extinção }\end{array}$ & 2,98 & $\begin{array}{l}\text { E12 - Como o álcool e o tabaco podem } \\
\text { afetar o corpo humano }\end{array}$ & 3,11 \\
\hline $\begin{array}{l}\text { A33 - O efeito dos choques elétricos e dos } \\
\text { relâmpagos no corpo humano }\end{array}$ & 2,95 & $\begin{array}{l}\text { E05 - O que se pode fazer para } \\
\text { assegurar ar limpo e água potável }\end{array}$ & 3,10 \\
\hline $\begin{array}{l}\text { A37 - O que comer para nos mantermos } \\
\text { saudáveis e em boa forma física }\end{array}$ & 2,94 & $\begin{array}{l}\text { A26 - Epidemias e doenças que causam } \\
\text { muitas mortes }\end{array}$ & 3,07 \\
\hline A48 - Como funciona uma usina nuclear & 2,94 & $\begin{array}{l}\text { C07 - Como os computadores } \\
\text { funcionam }\end{array}$ & 3,07 \\
\hline $\begin{array}{l}\text { C13 - Porque sonhamos e qual o significado } \\
\text { dos nossos sonhos }\end{array}$ & 2,93 & A09 - Sexo e reprodução & 3,05 \\
\hline $\begin{array}{l}\text { A } 23 \text { - Como meteoritos, cometas e asteroides } \\
\text { podem causar catástrofes na Terra }\end{array}$ & 2,91 & $\begin{array}{l}\text { C08 - A possibilidade de vida fora do } \\
\text { planeta Terra }\end{array}$ & 3,05 \\
\hline A27 - Animais perigosos e venenosos & 2,88 & C11 - A vida, a morte e a alma humana & 3,05 \\
\hline $\begin{array}{l}\text { E21 - Novos recursos de energia - sol, vento, } \\
\text { marés, ondas, etc. }\end{array}$ & 2,88 & $\begin{array}{l}\text { E31 - Os aspectos biológicos e } \\
\text { humanos do aborto }\end{array}$ & 3,05 \\
\hline $\begin{array}{l}\text { E40 - Invenções e descobrimentos que } \\
\text { transformaram o mundo }\end{array}$ & 2,87 & $\begin{array}{l}\text { E32 - Como a tecnologia genética pode } \\
\text { evitar doenças }\end{array}$ & 3,05 \\
\hline
\end{tabular}


Podemos observar que dos 20 itens expostos acima, dentre os meninos, 9 estão relacionados à Biologia Humana e dentre as meninas, 17 estão relacionados a este tema. Ou seja, num grupo de 20 itens, $45 \%$ dos temas que mais interessam os jovens brasileiros na escola e $85 \%$ dos temas que mais interessam as jovens brasileiras na escola estão relacionados ao seu próprio corpo, tanto no que se refere aos seus cuidados como a questões polêmicas, como significado dos sonhos e alma humana (C11, C13).

Em seguida, os temas que os meninos apontaram como de maior interesse foram: Tecnologia (15\%), Meio Ambiente (15\%), Universo (10\%), Ciência, Tecnologia e Sociedade (10\%) e Zoologia (5\%). Dentre as meninas, os temas seguintes de maior interesse foram: Meio Ambiente (5\%), Tecnologia (5\%) e Universo/Mistério (5\%). Os temas utilizados para categorizar as questões são os expostos no quadro 3.1 (capítulo Metodologia).

Osborne, Simon e Collins (2003) identificaram, dentro da Biologia, a Biologia Humana como conteúdo relevante e pertinente do ponto de vista dos alunos, uma vez que está direcionado ao interesse do estudante pelo seu próprio corpo e a questões relacionadas a doenças e saúde. Os dados obtidos junto ao ROSE no Brasil e em diversos países também caminham nesta direção.

A pesquisa ROSE realizada na Inglaterra apontou os 10 temas que mais interessam os jovens ingleses: o tema Biologia Humana apareceu uma vez (10\%) na lista dos meninos e nove vezes (90\%) na lista das meninas (JENKINS; NELSON, 2005; JENKINS; PELL, 2006). Na Suécia, na lista dos itens mais populares entre os estudantes, 55\% está relacionada a temas da Biologia Humana (JIDESJÖ; OSCARSSON; KARLSSON, 2009). Na Finlândia, Irlanda, Itália, Estônia, Dinamarca e Israel também se observou grande interesse pelos temas da Biologia Humana, especialmente dentre as meninas (LAVONEN et al., 2005; MATTHEWS, 2007; NERESINI; CROVATO; SARACINO, 2010; TEPPO; RANNIKMÄE, 2004; BUSCH, 2005; TRUMPER, 2006). Também se verificou grande interesse pela Biologia Humana entre os jovens de Gana, porém de forma inversa: na lista dos temas de mais interesse dos meninos, $50 \%$ era voltado para Biologia Humana, contra $40 \%$ da lista das meninas (ANDERSON, 2006).

Na primeira aplicação do ROSE no Brasil foi observado que os temas relacionados ao corpo humano ocuparam de 90 a 100\% da lista dos tópicos de mais interesse das meninas (em São Caetano do Sul e Tangará da Serra, respectivamente) e 20\% da lista dos meninos (TOLENTINO NETO, 2008). A aplicação do PISA em 2006 avaliou também o interesse dos alunos pela ciência. Os resultados indicaram que $68 \%$ dos jovens provenientes dos países membros da 
OECD possuem alto ou médio interesse pela Biologia Humana (KENNEDY, 2008).

Os dados obtidos na presente pesquisa evidenciam que o jovem tem grande interesse pelo seu corpo, como ele funciona, as doenças que o afetam e é claro, o sexo. O currículo de ciências não pode passar ao largo deste fato para se tornar significativo para o aluno. $\mathrm{O}$ engajamento dos alunos pela ciência e pelas aulas de ciências poderá ser impulsionado por estratégias que abordem tais temas, de forma que o interesse já existente, que é intrínseco ao jovem, poderá favorecer o despertar de interesse pelos demais conteúdos abordados na escola.

Os tópicos menos populares dentre os jovens brasileiros podem ser observados na tabela 5.2. 
Tabela 5.2 - Itens das seções ACE com menor pontuação entre os jovens brasileiros.

\begin{tabular}{|c|c|c|c|}
\hline Meninos & & Meninas & \\
\hline E01 - Simetrias e padrões em folhas e flores & 1,76 & E01 - Simetrias e padrões em folhas e flores & 1,75 \\
\hline A10 - Controle de natalidade e contracepção & 1,92 & E37 - Cientistas famosos e as suas vidas & 2,01 \\
\hline $\begin{array}{l}\text { A41 - Cirurgias plásticas e tratamentos de } \\
\text { beleza }\end{array}$ & 1,94 & $\begin{array}{l}\text { E26 - Os detergentes e sabões e como } \\
\text { funcionam }\end{array}$ & 2,05 \\
\hline E37 - Cientistas famosos e as suas vidas & 2,07 & $\begin{array}{l}\text { E28 - Como utilizar e consertar } \\
\text { equipamentos elétricos e mecânicos }\end{array}$ & 2,09 \\
\hline $\begin{array}{l}\text { E26 - Os detergentes e sabões e como } \\
\text { funcionam }\end{array}$ & 2,10 & $\begin{array}{l}\text { E33 - Os benefícios e os possíveis perigos } \\
\text { dos métodos modernos da agricultura }\end{array}$ & 2,20 \\
\hline $\begin{array}{l}\text { C14 - Bruxas e fantasmas, e se existem ou } \\
\text { não. }\end{array}$ & 2,13 & A10 - Controle de natalidade e contracepção & 2,22 \\
\hline A17 - Átomos e moléculas & 2,16 & $\begin{array}{l}\text { A47 - Como funcionam os motores a diesel, } \\
\text { a álcool, a gás e a gasolina }\end{array}$ & 2,22 \\
\hline $\begin{array}{l}\text { A39 - A capacidade de loções e cremes } \\
\text { manterem a pele jovem }\end{array}$ & 2,18 & A17 - Átomos e moléculas & 2,24 \\
\hline $\begin{array}{l}\text { A38 - As perturbações alimentares, como } \\
\text { anorexia e bulimia }\end{array}$ & 2,18 & $\begin{array}{l}\text { E17 - Como se melhoram as colheitas em } \\
\text { hortas e roças }\end{array}$ & 2,24 \\
\hline $\begin{array}{l}\text { A08 - Hereditariedade e como os genes } \\
\text { afetam o nosso desenvolvimento }\end{array}$ & 2,19 & E25 - As plantas da minha região & 2,24 \\
\hline $\begin{array}{l}\text { A } 42 \text { - Como a luz solar e a dos bronzeadores } \\
\text { artificiais afetam a pele }\end{array}$ & 2,20 & $\begin{array}{l}\text { E19 - A agricultura orgânica, sem uso de } \\
\text { pesticidas e adubos artificiais }\end{array}$ & 2,25 \\
\hline $\begin{array}{l}\text { C12 - Medicinas alternativas (acupuntura, } \\
\text { homeopatia, ioga, etc.) e a sua eficácia }\end{array}$ & 2,21 & $\begin{array}{l}\text { C14 - Bruxas e fantasmas, e se existem ou } \\
\text { não. }\end{array}$ & 2,26 \\
\hline $\begin{array}{l}\text { A15 - Como as plantas crescem e se } \\
\text { reproduzem }\end{array}$ & 2,23 & $\begin{array}{l}\text { E38 - Erros e fracassos em pesquisas e } \\
\text { invenções }\end{array}$ & 2,31 \\
\hline $\begin{array}{l}\text { C18 - As propriedades das pedras e dos } \\
\text { cristais e como são usados para embelezar }\end{array}$ & 2,25 & $\begin{array}{l}\text { A15 - Como as plantas crescem e se } \\
\text { reproduzem }\end{array}$ & 2,33 \\
\hline A05 - Nuvens, chuva e tempo & 2,25 & $\begin{array}{l}\text { A } 45 \text { - O uso de satélites para comunicação e } \\
\text { outros propósitos }\end{array}$ & 2,34 \\
\hline $\begin{array}{l}\text { C09 - Astrologia e horóscopos e se os } \\
\text { planetas podem influenciar os seres humanos }\end{array}$ & 2,26 & $\begin{array}{l}\text { A04 - Como evoluem e se transformam as } \\
\text { montanhas, rios e oceanos }\end{array}$ & 2,37 \\
\hline $\begin{array}{l}\text { A11 - Como os bebês crescem e se } \\
\text { desenvolvem }\end{array}$ & 2,29 & A03 - O interior da Terra & 2,39 \\
\hline $\begin{array}{l}\text { E19 - A agricultura orgânica, sem uso de } \\
\text { pesticidas e adubos artificiais }\end{array}$ & 2,32 & A05 - Nuvens, chuva e tempo & 2,40 \\
\hline $\begin{array}{l}\text { E33 - Os benefícios e os possíveis perigos dos } \\
\text { métodos modernos da agricultura }\end{array}$ & 2,33 & E24 - Os animais da minha região & 2,41 \\
\hline $\begin{array}{l}\text { E17 - Como se melhoram as colheitas em } \\
\text { hortas e roças }\end{array}$ & 2,35 & $\begin{array}{l}\text { E27 - Eletricidade, sua produção e uso } \\
\text { doméstico }\end{array}$ & 2,41 \\
\hline
\end{tabular}


Ao observarmos a lista dos itens que os meninos brasileiros menos se interessam, verificamos, paradoxalmente, que 8 dentre os 20 tópicos (40\%) referem-se à Biologia Humana. Dentre estes, 5 são relacionados a cuidados com o corpo e estética (A41, A39, A38, A42 e C12), temas tradicionalmente pertencentes ao universo feminino. Porém, 3 desses temas são relacionados à: sexualidade (A10), hereditariedade (A08) e à vida cotidiana (A11). Os outros temas que menos interessam os meninos são Botânica (20\%), Química (10\%) e Geociências (10\%).

O tema que as meninas brasileiras menos se interessam em aprender é Botânica (25\%), seguido pela Química (15\%), Geociências (15\%) e assuntos ligados à Ciência, Tecnologia e Sociedade $(15 \%)$. É interessante verificar que havia na lista das meninas um único tema relacionado à Biologia Humana, também presente na lista dos meninos: Controle da natalidade e contracepção (A10). Assim, daremos destaque a esta questão em particular.

Diversos estudos no contexto brasileiro mostram problemas relacionados ao uso de contraceptivos entre os jovens, principalmente do sexo masculino. Antunes et al. (2002, p. 89) consideram que "as normas culturais presentes na socialização de meninos e meninas para a vida sexual continuam colocando homens e mulheres em situações vulneráveis", uma vez que o conhecimento sobre métodos contraceptivos não implica mudanças de atitudes e práticas (BORGES; SCHOR, 2005).

Villela e Doreto (2006, p. 2471) apontam que "são múltiplos os caminhos que levam um jovem a ter relações sexuais desprotegidas, e os números que vêm à tona sobre a gravidez, DST ou (...) HIV sem dúvida são menores do que os números reais”.

Diante de tais problemas, Tonatto e Sapiro (2002, p. 164) apontam que o ensino de ciências em especial deve "oferecer à instituição escolar formas significativamente contextualizadas de se trabalhar as questões acerca da sexualidade", privilegiando os interesses e as necessidades dos estudantes. Para as autoras, o currículo deve atender às necessidades dos alunos, de forma a favorecer a compreensão da sociedade em que vivem.

Os dados obtidos nesta pesquisa apontam que o sexo desperta o interesse e a curiosidade dos jovens, porém é necessário que a escola estimule o interesse e atitudes positivas em relação aos métodos contraceptivos, tendo em vista os problemas envolvidos acerca da vulnerabilidade ${ }^{18}$ sexual dos jovens. Os dados revelam que a atual abordagem envolvendo controle da natalidade e contracepção não desperta o interesse dos nossos jovens, ao contrário, tem levado esta questão ao topo da lista dos temas indesejados. Cabe aos educadores repensarem a maneira

\footnotetext{
${ }^{18}$ A vulnerabilidade foi definida por Ayres (2003, p. 122) como "o movimento de considerar a chance de exposição das pessoas ao adoecimento como resultante de um conjunto de aspectos, não apenas individuais, mas coletivos, contextuais, que acarretam maior suscetibilidade à infecção e ao adoecimento".
} 
que esta questão é tratada na escola, a fim de que a educação sexual ofereça, de fato, elementos que permitam aos jovens uma vida sexual saudável.

Assim, concordamos com as considerações de Jenkins (2006a, p. 4), quando afirmou que “ouvir o estudante" é uma maneira de transformar a escolaridade, uma vez que "torna o currículo mais relevante para as necessidades e interesses dos alunos”. Segundo o autor, conhecer os temas que interessam os alunos e considerá-los nas práticas educativas pode aumentar sua motivação e contribuir para melhorias no processo de ensino-aprendizagem.

\subsection{AS DISCIPLINAS E ASSUNTOS DA CIÊNCIA QUE MAIS (E MENOS) INTERESSAM OS JOVENS BRASILEIROS}

Os 108 temas presentes nas seções ACE foram agrupados em assuntos da ciência segundo Tolentino Neto (2008), conforme observado no quadro 3.2. Alguns destes assuntos envolvem diretamente as disciplinas científicas Física, Biologia, Geologia e Química. Os dados obtidos podem ser observados na tabela 5.3. Em negrito destacam-se as médias cuja diferença dentre meninos e meninas é significativa.

Durante a primeira aplicação do projeto ROSE no Brasil verificou-se que tanto os meninos de Tangará da Serra (MT) como os de São Caetano do Sul (SP) apontaram como de maior interesse os temas relacionados à Física, Tecnologia e Proteção Ambiental, enquanto que as meninas de ambas as cidades apresentaram interesse por temas relacionados à Saúde, Forma Física e Beleza, Proteção Ambiental e Mistério, Horror e Fenômenos Inexplicáveis (TOLENTINO NETO, 2008). Tais dados também foram observados no contexto brasileiro, conforme mostra a tabela 5.3. 
Tabela 5.3 - Médias (geral, de meninos e meninas) agrupadas por assunto.

\begin{tabular}{|c|c|c|c|c|c|c|}
\hline Assuntos & $\begin{array}{l}\text { Média } \\
\text { Geral }\end{array}$ & $\underset{(\mathrm{H})}{\operatorname{Meninos}}$ & $\begin{array}{l}\text { Meninas } \\
(\mathrm{M})\end{array}$ & $\begin{array}{c}\text { Diferença } \\
(\mathrm{H}-\mathrm{M})\end{array}$ & $\begin{array}{l}\text { IC 95\% } \\
\text { (Diferença) }\end{array}$ & P-valor \\
\hline $\begin{array}{l}\text { 1. Física (astronomia, óptica, } \\
\text { eletricidade, acústica) }\end{array}$ & 2,70 & 2,72 & 2,68 & 0,04 & {$[-0.02 ; 0.09]$} & 0,213 \\
\hline $\begin{array}{l}\text { 2. Biologia (biologia geral, botânica, } \\
\text { zoologia, evolução e ecologia) }\end{array}$ & 2,58 & 2,51 & 2,63 & $-0,12$ & {$[-0.17 ;-0.07]$} & 0,000 \\
\hline $\begin{array}{l}\text { 3. Geologia, meteorologia e ciências } \\
\text { da terra }\end{array}$ & 2,46 & 2,46 & 2,47 & $-0,01$ & {$[-0.07 ; 0.05]$} & 0,781 \\
\hline 4. Química & 2,33 & 2,36 & 2,30 & 0,06 & {$[0.00 ; 0.12]$} & 0,052 \\
\hline 5. Saúde, forma física e beleza & 2,86 & 2,67 & 3,01 & $-0,34$ & {$[-0.40 ;-0.29]$} & 0,000 \\
\hline 6. Tecnologia & 2,70 & 2,84 & 2,60 & 0,24 & {$[0.18 ; 0.30]$} & 0,000 \\
\hline 7. Ciência \& cientistas & 2,40 & 2,39 & 2,42 & $-0,03$ & {$[-0.10 ; 0.04]$} & 0,395 \\
\hline 8. Proteção ambiental & 2,83 & 2,84 & 2,82 & 0,01 & {$[-0.05 ; 0.08]$} & 0,657 \\
\hline $\begin{array}{l}\text { 9. Mistério, horror e fenômenos } \\
\text { inexplicáveis }\end{array}$ & 2,69 & 2,59 & 2,76 & $-0,17$ & {$[-0.23 ;-0.11]$} & 0,000 \\
\hline
\end{tabular}

Através da análise dos dados com diferenças significativas (p-valor menor que 0,05 ), observa-se que os meninos têm maior interesse que as meninas por assuntos da Tecnologia. Já as meninas possuem maior interesse em temas relacionados à Saúde, Forma Física e Beleza, Biologia e Mistério, Horror e Fenômenos Inexplicáveis que os meninos.

Dentre as disciplinas, é interessante destacar que tanto meninos quanto meninas apresentam grande interesse pela Física e Biologia e pouco interesse pela Geologia e Química. Osborne e Collins (2001) em uma pesquisa que averiguou atitudes e interesses dos estudantes acerca da ciência verificaram que, a despeito do fato de que a Física tradicionalmente ser a ciência que os estudantes costumam ter mais antipatia, os alunos mostraram por ela mais interesse que pela Química.

Algumas pesquisas apontam que os meninos costumam ter mais interesse pela Física que as meninas (JONES; HOWE; RUA, 2000; OSBORNE; SIMON; COLLINS, 2003; BARAMTSABARI; YARDEN, 2005), em especial em assuntos relacionados a aviões, carros, computadores, eletricidade, luz, radioatividade e novas fontes de energia. Os dados brasileiros não corroboram esta tendência, uma vez que as diferenças entre meninas e meninos não foram significativas ( $\mathrm{p}$-valor $=0,213)$. 
A aplicação do PISA no ano de 2006 também procurou conhecer os interesses dos estudantes em relação às ciências. Selecionamos aqui os tópicos temáticos propostos pelo PISA (através da questão ST21 do "Questionário do aluno") com os tópicos temáticos do ROSE, discriminados na tabela 5.3 (ver quadro 3.2). Os resultados gerais podem ser observados na tabela 5.4.

Tabela 5.4 - Comparação entre ROSE e PISA 2006 sobre o interesse por temas da ciência.

\begin{tabular}{|c|c|c|c|c|c|c|}
\hline Itens com & parados & & & Diferença & IC 95\% & \\
\hline PISA & ROSE & IISA & KUSE & ROSE) & (Diferença) & $\mathrm{r}$-valou \\
\hline Idade & Idade & 15,66 & 15,39 & 0,27 & {$[0.24 ; 0.30]$} & 0 \\
\hline Gênero (Feminino) & Gênero (Feminino) & $5037(54,2 \%)$ & $1339(57,7 \%)$ & $-3,50 \%$ & {$[-1.24 \% ;-5.76 \%]$} & 0 \\
\hline $\begin{array}{l}\text { Tópicos de Física e } \\
\text { Astronomia }\end{array}$ & Física & 2,68 & 2,7 & $-0,02$ & {$[-0.05 ; 0.02]$} & 0,682 \\
\hline Tópicos de Química & Química & 2,78 & 2,33 & 0,45 & {$[0.42 ; 0.49]$} & 0 \\
\hline Tópicos de Geologia & $\begin{array}{l}\text { Geologia, } \\
\text { meteorologia e } \\
\text { ciências da terra }\end{array}$ & 2,49 & 2,46 & 0,03 & {$[-0.01 ; 0.06]$} & 0,223 \\
\hline
\end{tabular}

A Biologia não foi comparada, por que enquanto que no ROSE se aborda a área de modo geral, o PISA verificou apenas o interesse por Botânica e Biologia Humana.

Conforme observado acima, a média de idade entre os alunos participantes do ROSE e do PISA 2006 é similar e em ambos os casos, a presença feminina é maior que a masculina. Na questão do PISA 2006 que está sendo comparada, ST21, as respostas também eram expressas em uma escala de Likert de quatro pontos, o que facilitou a comparação.

A Biologia (média da área de Biologia das Plantas e Biologia Humana) foi a disciplina com maior média no PISA 2006, com pontuação bem maior que a média obtida junto ao ROSE. Em seguida, a disciplina com mais pontuação foi a Química, depois a Física e Geologia. Entretanto, foram atribuídas médias em Física e Geologia estatisticamente semelhantes na amostra ROSE e PISA 2006. A tendência observada nas médias gerais também foi verificada quando comparados os meninos e meninas participantes do ROSE e PISA 2006.

Em relação à Biologia, os dados obtidos através da aplicação do ROSE (tabela 5.3) corroboram as considerações de Baram-Tsabari et al. (2009), que revelam que a Biologia é uma 
ciência bastante popular especialmente entre as meninas, e dentro do campo da Biologia, a Biologia Humana desperta mais o interesse dos jovens que a Zoologia ou a Botânica. Os dados observados na tabela 5.1 corroboram esta afirmativa.

O estudo da Biologia ${ }^{19}$ no Ensino Médio no Brasil, de fato, engloba os assuntos relacionados à Saúde, Forma Física e Beleza e Proteção Ambiental, porém, desmembrando-os foi possível se ter uma ideia de quais os temas dentro da Biologia despertam o interesse dos jovens: dentre as meninas, a saúde e dentre os meninos os relacionados ao meio ambiente.

A discussão dos temas que devem ser abordados nos currículos de Biologia tem sido realizadas, inclusive pelas secretarias estaduais de educação, mas as razões recaem sobre a análise do tema em si, e não sobre o interesse dos alunos (MARTINS et al., 2007). A proposta curricular de Biologia do estado de São Paulo justifica a escolha dos temas segundo a relevância social dos conteúdos, de forma que questões relacionadas à saúde, entre as quais as que envolvem a sexualidade, são contempladas, o que já se configura uma aproximação em prol dos interesses dos estudantes (SÃO PAULO, 2011).

Moraes (2006, p. 31), ao comentar sobre a organização dos conteúdos curriculares, considera que se deve assumir uma concepção de conteúdo "que vá além dos aspectos cognitivos", ou seja:

(...) incluir nos conteúdos a serem trabalhados aspectos afetivos, atitudinais, éticos e de valores. Significa procurar atingir os sujeitos aprendizes em seu todo, não apenas no sentido de seus conhecimentos.

O autor considera que os currículos, para isso, devem estar sempre em processo, proporcionando uma aproximação entre a escola e a comunidade de forma contextualizada e problematizada (MORAES, 2006). Apesar de o autor enfatizar os conhecimentos prévios dos alunos na construção dos currículos, é necessário também conhecer seus interesses prévios, uma vez que os interesses estão diretamente vinculados com a motivação em aprender.

Krasilchik (2004, p. 46) considera que a seleção dos temas a serem ensinados poderá ser realizada com base nos seguintes critérios de prioridade: assuntos "fundamentais; pré-requisitos para outros assuntos; atuais e interessantes". A pesquisa ROSE colabora neste sentido, porém considera "assuntos interessantes" não apenas do ponto de vista do professor, mas principalmente da perspectiva do aluno.

\footnotetext{
${ }^{19}$ Gostaria de salientar que tendo em vista minha formação inicial ser Biologia, irei comentar detalhamentos apenas desta disciplina.
} 
Cachapuz et al. (2011, p. 63) apontam, dentre os aspectos a incluir em um currículo de ciências que favoreça a construção de conhecimentos científicos, "a reflexão sobre o possível interesse das situações propostas”. Neste sentido, os autores consideram a necessidade de se “potenciar atitudes positivas". A presente pesquisa permite a identificação de interesses que potencializam atitudes positivas para com as situações propostas em sala de aula.

É vital finalizarmos esta discussão com as reflexões de Baram-Tsabari e Yarden, (2005, p. 822)

Os resultados também levantam questões interessantes sobre as grandes áreas de interesse das crianças e o tempo dedicado a elas no currículo escolar. (...) Isto não significa que temas como a fotossíntese, a célula, a conservação de energia ou o modelo de partículas não devam ser ensinados apenas porque eles não aparecem na lista dos assuntos de interesse dos alunos. (...) A questão é tornar possível a introdução do interesse dos alunos como elemento, até então ignorado nos debates, necessário para a discussão da forma e do conteúdo da educação científica.

Krasilchik (1987, p. 53) comenta que um dos problemas do ensino das ciências é a falta de vínculo com a realidade dos alunos. Para a autora,

esta limitação das aulas de ciências determina que a disciplina se torne irrelevante e sem significado, pois não se baseia no conhecimento que os jovens trazem de forma intuitiva, e não é ancorada no seu universo de interesses.

A aprendizagem, quando vinculada ao contexto social e cultural em que o aluno vive, torna o conhecimento possível e as ações significativas. Cada aluno traz consigo conhecimentos pré-existentes e quando o ensino consegue estimular tais conhecimentos para tornar significativos os novos, a aprendizagem se torna relevante (BELL, 2005).

Osborne e Collins (2001, p. 442) consideram que o ensino de ciências é dominado por um currículo tradicional, onde as necessidades de uma ciência já estabelecida são vozes muito mais poderosas que a dos alunos. Para que a ciência se torne significativa e interessante, é necessário conhecer os aspectos da ciência que influenciam a vida dos alunos. Não que o currículo deve ser construído somente em função dos interesses dos alunos, mas há necessidade de pelo menos reconhecer sua contribuição na discussão.

Assim, o ensino de ciências só irá engajar os alunos quando estabelecer vínculos com a vida cotidiana dos estudantes e instigar sua curiosidade (GARDNER, 1987). A Biologia Hu- 
mana, nesse sentido, corresponde a estas expectativas, uma vez que sua aplicação é transparente e imediata (OSBORNE; COLLINS, 2001). O ensino das outras disciplinas, de qualquer forma, deve priorizar situações contextualizadas com a realidade dos alunos, onde suas aplicações e sua utilidade sejam compreensíveis e atendam aos seus interesses.

\subsection{A CIÊNCIA APRESENTADA NA ESCOLA: DIFERENÇAS OBSERVADAS EM RELAÇÃO A CONTEÚDOS E CONTEXTOS}

Os currículos de ciências, de modo geral, ainda estão organizados em conteúdos estanques, fragmentados e descontextualizados. Maldaner e Zanon (2006, p. 48-49) apontam, neste sentido, para o fato de que

Se, eventualmente, são trabalhados determinados temas fora da proposta original de um programa de ensino, isso permanece como mera inserção pontual. Terminada a discussão do tema, volta-se ao mesmo ponto, dando seguimento ao programa tradicional de ensino. Os conteúdos do ensino, os novos conceitos e linguagens continuam pouco relacionados entre si e os contextos sociais de vivência fora da escola, resultado em aprendizados superficiais e restritos (...).

Algumas pesquisas têm enfatizado a diferença existente entre o conteúdo científico e seu contexto. Por exemplo, Häussler e Hoffmann (2000) verificaram que o interesse dos alunos pela Física é mais influenciado pelo contexto em que o assunto é abordado do que pelo conteúdo em particular ou pelas atividades pedagógicas propostas. Sjøberg (2000) apresentou diversos dados que indicaram que a popularidade das várias áreas da ciência está fortemente relacionada com o contexto em que elas aparecem para os alunos. Murray e Reiss (2005) observaram esta tendência quando os alunos indicaram que o interesse pela química era diferente quando a abordagem era relacionada à indústria (menor) ou ao corpo humano (maior).

Assim, procuramos verificar se esta tendência também é observada junto aos alunos brasileiros. Para isso, agrupamos questões envolvendo preponderantemente conteúdos e questões abrangendo contextos. A matriz de conteúdos e contextos utilizada como base é a discriminada no quadro 3.1. As áreas de conhecimento da Ciência selecionadas para esta análise foram: Zoologia, Botânica, Óptica, Química, Geociências, Astrofísica e Biologia Humana e estão descritos no quadro 5.1 e 5.2 . 


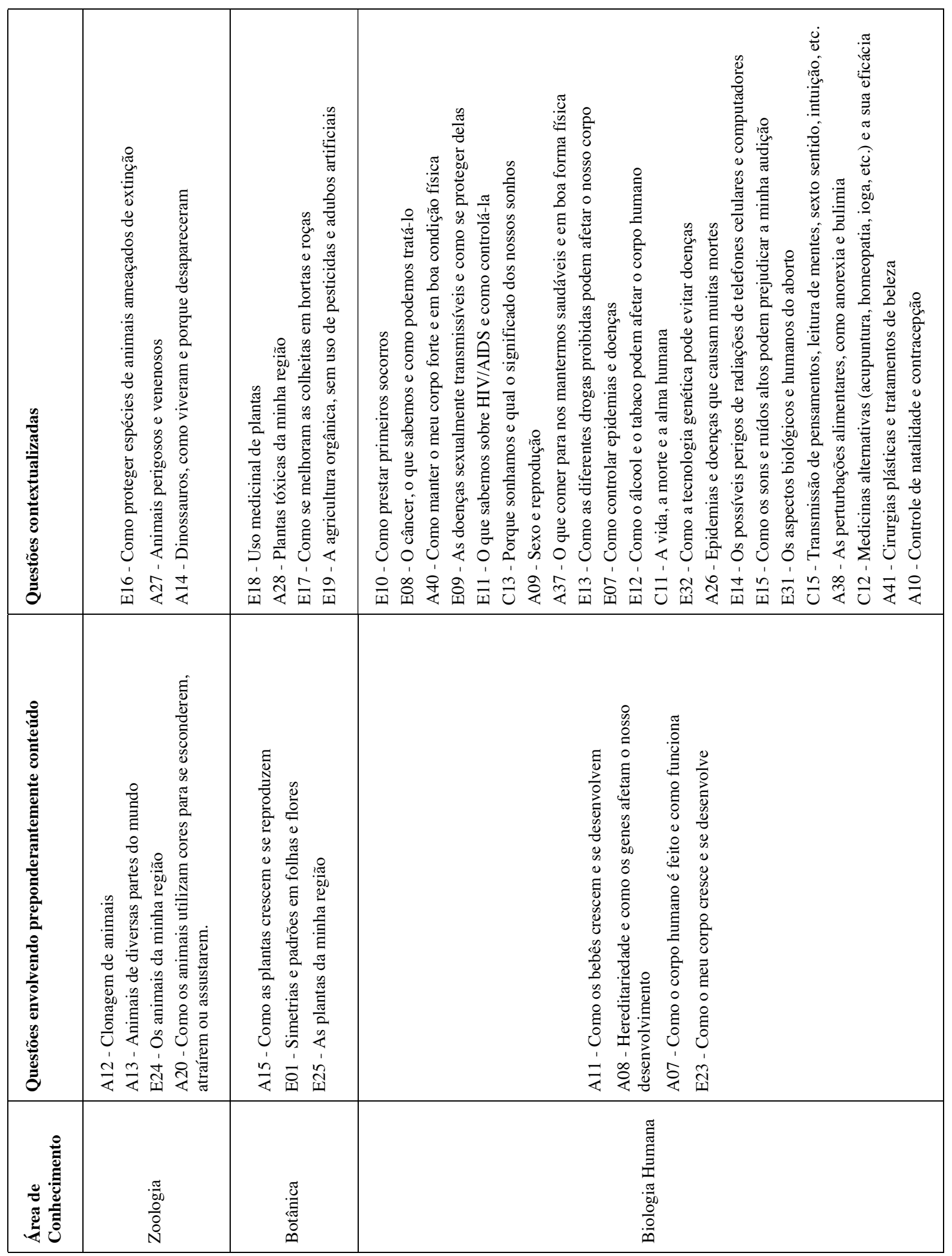

Quadro 5.1 - Grupos de questões envolvendo preponderantemente conteúdo e questões contextualizadas da área de Biologia. 


\begin{tabular}{|c|c|c|c|c|}
\hline 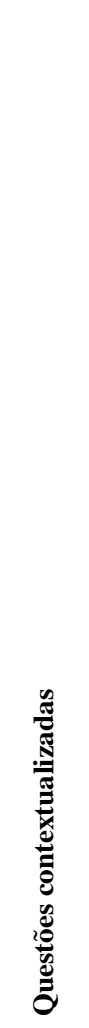 & 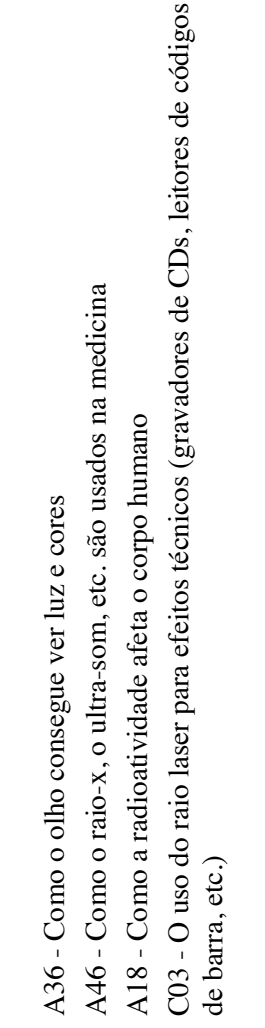 & 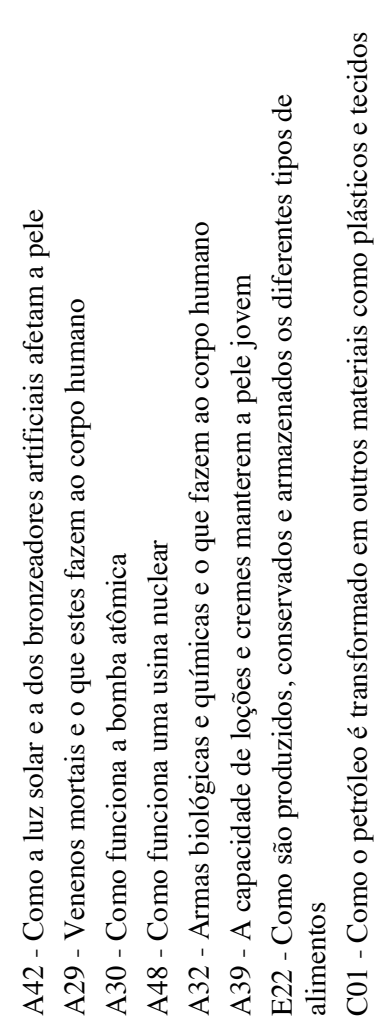 & 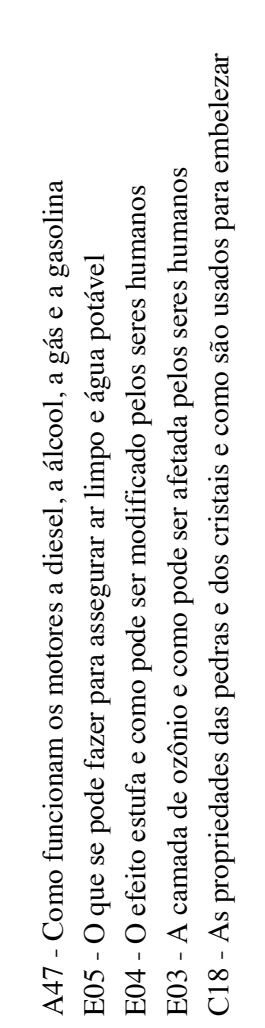 & 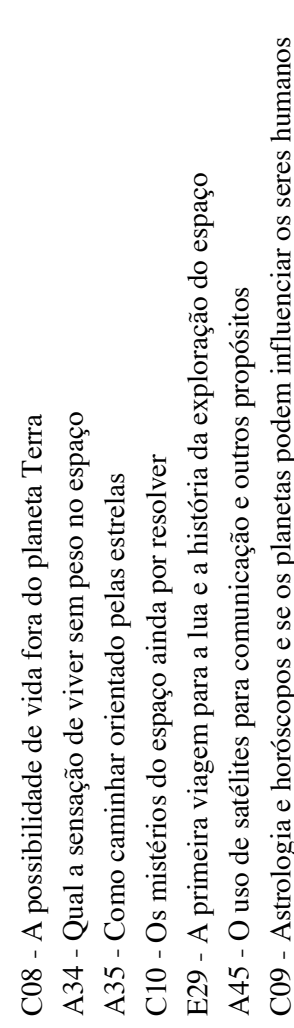 \\
\hline 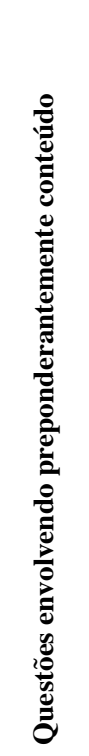 & 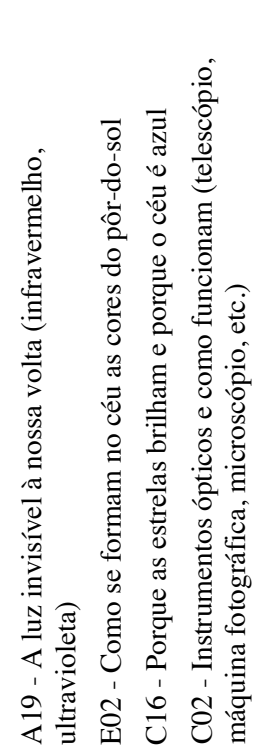 & 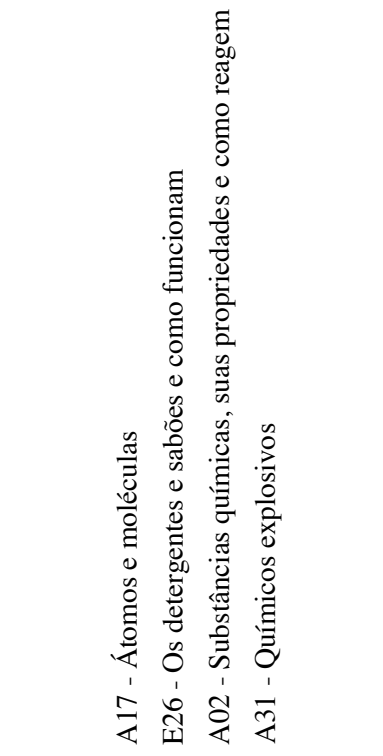 & 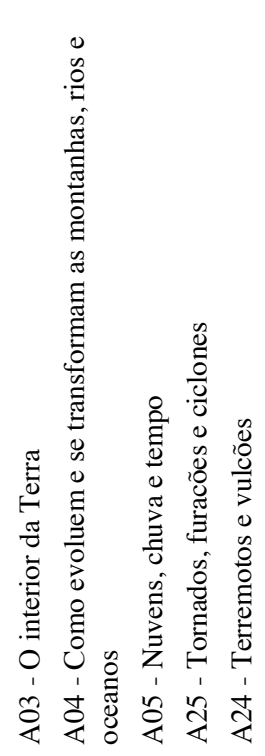 & 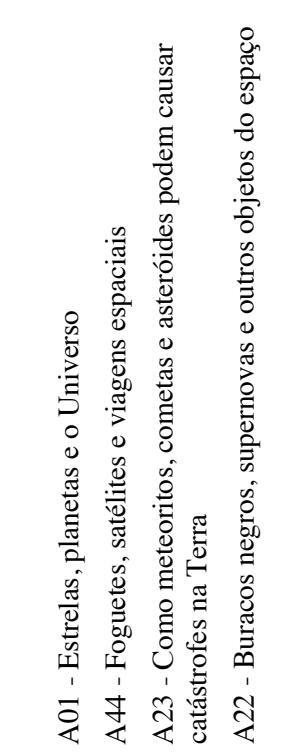 \\
\hline 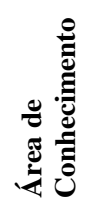 & 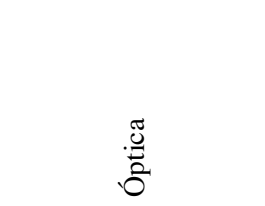 & 。ँّ. & $\begin{array}{l}\frac{\pi}{0} \\
\frac{\pi}{0} \\
\frac{0}{0} \\
0 \\
0 \\
0 \\
0\end{array}$ & 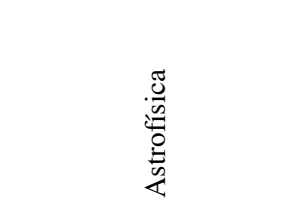 \\
\hline
\end{tabular}

Quadro 5.2 - Grupos de questões envolvendo preponderantemente conteúdo e questões contextualizadas das áreas da Física, Química, Geociência e Astrofísica. 
Os resultados da análise das médias em cada grupo de questões podem ser observados na tabela 5.5. As questões que envolvem preponderantemente conteúdo são denominadas na tabela de Questões Conteúdo.

Tabela 5.5 - Médias obtidas nos grupos de questões contextualizadas e questões envolvendo preponderantemente conteúdo.

\begin{tabular}{|c|c|c|c|}
\hline \multicolumn{4}{|c|}{ Assuntos e as diferentes médias observadas } \\
\hline Zoologia & Geral & Meninos & Meninas \\
\hline Média das Questões contextualizadas & 2,86 & 2,89 & 2,84 \\
\hline Média das Questões Conteúdo & 2,74 & 2,74 & 2,74 \\
\hline Diferença & 0,11 & 0,15 & 0,09 \\
\hline p-valor & 0,325 & 0,084 & 0,525 \\
\hline Botânica & Geral & Meninos & Meninas \\
\hline Média das Questões contextualizadas & 2,42 & 2,41 & 2,43 \\
\hline Média das Questões Conteúdo & 2,11 & 2,11 & 2,11 \\
\hline Diferença & 0,31 & 0,30 & 0,33 \\
\hline p-valor & 0,218 & 0,237 & 0,211 \\
\hline Óptica & Geral & Meninos & Meninas \\
\hline Média das Questões contextualizadas & 2,74 & 2,63 & 2,82 \\
\hline Média das Questões Conteúdo & 2,66 & 2,61 & 2,70 \\
\hline Diferença & 0,08 & 0,02 & 0,12 \\
\hline p-valor & 0,343 & 0,863 & 0,255 \\
\hline Química & Geral & Meninos & Meninas \\
\hline Média das Questões contextualizadas & 2,66 & 2,69 & 2,64 \\
\hline Média das Questões Conteúdo & 2,34 & 2,37 & 2,31 \\
\hline Diferença & 0,32 & 0,32 & 0,33 \\
\hline p-valor & 0,073 & 0,154 & 0,046 \\
\hline Geociências & Geral & Meninos & Meninas \\
\hline Média das Questões contextualizadas & 2,72 & 2,66 & 2,76 \\
\hline Média das Questões Conteúdo & 2,55 & 2,53 & 2,57 \\
\hline Diferença & 0,17 & 0,13 & 0,19 \\
\hline p-valor & 0,367 & 0,540 & 0,285 \\
\hline Astrofísica & Geral & Meninos & Meninas \\
\hline Média das Questões contextualizadas & 2,66 & 2,65 & 2,67 \\
\hline Média das Questões Conteúdo & 2,66 & 2,74 & 2,61 \\
\hline Diferença & 0,00 & $-0,09$ & 0,06 \\
\hline p-valor & 0,998 & 0,483 & 0,646 \\
\hline Energia & Geral & Meninos & Meninas \\
\hline Média das Questões contextualizadas & 2,84 & 2,89 & 2,80 \\
\hline Média das Questões Conteúdo & 2,52 & 2,65 & 2,42 \\
\hline Diferença & 0,32 & 0,24 & 0,39 \\
\hline p-valor & 0,035 & 0,011 & 0,051 \\
\hline Biologia Humana & Geral & Meninos & Meninas \\
\hline Média das Questões contextualizadas & 2,91 & 2,72 & 3,05 \\
\hline Média das Questões Conteúdo & 2,80 & 2,55 & 2,98 \\
\hline Diferença & 0,12 & 0,17 & 0,07 \\
\hline p-valor & 0,504 & 0,422 & 0,625 \\
\hline
\end{tabular}


Os resultados obtidos revelam que, com exceção da Astrofísica, cujas médias atribuídas às questões foram iguais, em todos os demais assuntos as médias verificadas nas questões contextualizadas foram maiores que nas questões que abordam preponderantemente o conteúdo.

Em especial podemos destacar as áreas: Química, que com um nível de significância de 5\%, há uma evidência estatística de que entre as meninas da população amostrada há uma preferência pelas questões contextualizadas e Energia, que com nível de significância de 5\%, há evidência estatística de preferência, na população amostrada, por perguntas contextualizadas para meninos, meninas e na média geral.

O currículo de ciências é dominado ainda pelo conhecimento factual, sobre o quê e como, dando pouca ênfase a uma visão crítica da ciência ou da prática científica. "Como inevitável consequência, tem-se um currículo com ênfase fundamentalista, baseada em conceitos básicos que falham em dar aos alunos uma visão dos grandes temas, processos e práticas da ciência" (OSBORNE; COLLINS, 2001, p. 442).

Neste sentido, Teixeira (2001) traz a reflexão para o fato de que muitos conteúdos da Biologia, como Citologia, Fisiologia Vegetal, Ciclos Bioquímicos e outros, são difíceis de estabelecer conexões com uma realidade mais ampla, o que pode levar ao ensino de fatos inócuos, sem nenhum significado para os alunos.

Além da questão da contextualização com a realidade do aluno, é necessário considerar os dados obtidos na pesquisa de Nasr e Soltani (2011). Os autores indicaram haver uma relação estatisticamente significativa entre o aprendizado da Biologia e o fato dela ser divertida para os alunos, o que significa a necessidade de se considerar aspectos "divertidos" da biologia no ensino. Neste sentido, um currículo que pretende ser significativo para o aluno deve ser contextualizado e alegre.

Outra questão que merece destaque no quesito contextualização é a utilidade da ciência. George (2006), em uma pesquisa realizada com estudantes de 9, 13 e 17 anos, observou que, apesar do interesse geral pela ciência diminuir ao longo dos alunos, o interesse pela utilidade da ciência apresenta uma tendência crescente ao longo da escolaridade.

Os dados brasileiros também sinalizam as conclusões acima, uma vez que as médias para questões contextualizadas foram maiores em quase todos os assuntos analisados, em especial para a Química e Energia. 


\subsection{OS INTERESSES DOS JOVENS BRASILEIROS: ASPECTOS REGIONAIS}

O interesse dos alunos pelas disciplinas científicas ou por alguns temas da ciência foi verificado através das regiões brasileiras. A tabela 5.6 apresenta as médias obtidas por região.

Tabela 5.6 - Médias de interesse (média geral) por assuntos entre as regiões brasileiras.

\begin{tabular}{lcccccc}
\hline \multicolumn{1}{c}{ Assuntos } & $\begin{array}{c}\text { Centro- } \\
\text { Oeste }\end{array}$ & Nordeste & Norte & Sudeste & Sul & $\begin{array}{c}\text { P- } \\
\text { valor }\end{array}$ \\
\hline $\begin{array}{l}\text { 1. Física (astronomia, óptica, } \\
\text { eletricidade) }\end{array}$ & $2.64 \pm 0.62$ & $2.72 \pm 0.66$ & $\mathbf{2 . 8 3} \pm 0.59$ & $2.59 \pm 0.63$ & $2.61 \pm 0.60$ & 0 \\
$\begin{array}{l}\text { 2. Biologia (biologia geral, } \\
\text { botânica, zoologia, evolução }\end{array}$ & $2.52 \pm 0.55$ & $2.63 \pm 0.58$ & $\mathbf{2 . 6 9} \pm 0.54$ & $2.46 \pm 0.57$ & $2.52 \pm 0.57$ & 0 \\
e ecologia) & & & & & & \\
$\begin{array}{l}\text { 3. Geologia, meteorologia e } \\
\text { ciências da terra }\end{array}$ & $2.39 \pm 0.65$ & $2.53 \pm 0.69$ & $\mathbf{2 . 5 8} \pm 0.62$ & $2.31 \pm 0.64$ & $2.37 \pm 0.67$ & 0 \\
$\begin{array}{l}\text { 4. Química } \\
\text { 5. Saúde, forma física e }\end{array}$ & $2.27 \pm 0.69$ & $2.40 \pm 0.77$ & $\mathbf{2 . 4 7} \pm 0.71$ & $2.19 \pm 0.70$ & $2.11 \pm 0.70$ & 0 \\
beleza & $2.76 \pm 0.58$ & $2.96 \pm 0.60$ & $\mathbf{2 . 9 8} \pm 0.56$ & $2.75 \pm 0.58$ & $2.70 \pm 0.65$ & 0 \\
$\begin{array}{l}\text { 6. Tecnologia } \\
\text { 7. Ciência \& cientistas }\end{array}$ & $2.62 \pm 0.68$ & $2.77 \pm 0.70$ & $\mathbf{2 . 8 2} \pm 0.67$ & $2.58 \pm 0.70$ & $2.61 \pm 0.68$ & 0 \\
$\begin{array}{l}\text { 8. Proteção ambiental } \\
\text { 9. Mistério, horror e }\end{array}$ & $2.73 \pm 0.77$ & $2.49 \pm 0.85$ & $\mathbf{2 . 5 0} \pm 0.83$ & $2.27 \pm 0.79$ & $2.22 \pm 0.82$ & 0 \\
fenômenos inexplicáveis & $2.61 \pm 0.66$ & $2.72 \pm 0.67$ & $\mathbf{2 . 7 8} \pm 0.68$ & $2.61 \pm 0.70$ & $2.67 \pm 0.69$ & 0 \\
\hline
\end{tabular}

A análise da tabela acima revela que os jovens estudantes da região Norte são os que possuem maior interesse, em todos os assuntos, que os das demais regiões, seguidos dos jovens da região Nordeste. Para verificar a existência de diferenças significativas de médias por pares (entre duas regiões) realizou-se o teste Tukey.

As diferenças apontam que, excetuando-se a região Norte, os alunos do Nordeste possuem mais interesse pela Física, Biologia, Geologia, Química, Saúde, Forma Física e Beleza, Tecnologia, Ciência \& Cientistas que os do Sudeste. Além disso, os jovens nordestinos possuem mais interesse pela Geologia e Saúde e Forma Física que os jovens do Centro-Oeste e os do Sul e pela Química, Ciência \& Cientistas e Proteção ambiental mais que os do Sul. 
Em relação aos tópicos de maior interesse (discriminados por questão da seção ACE), selecionamos as dez questões com maior pontuação de cada região. Os dados estão apresentados na tabela 5.7.

Tabela 5.7 - Itens com as dez maiores médias em questões das seções ACE, distribuídos pelas regiões brasileiras`.

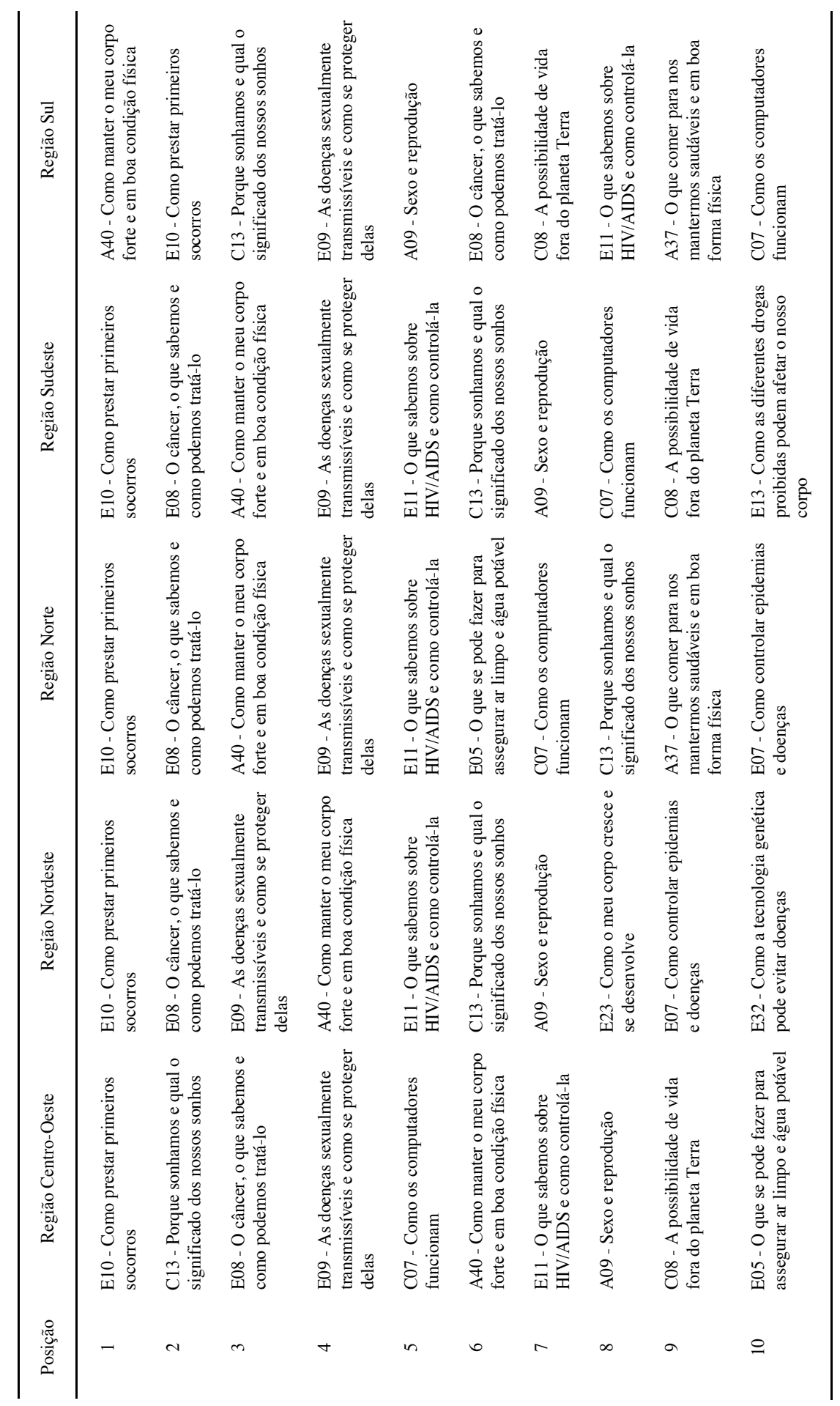


Os dados obtidos confirmam a tendência observada nos dados gerais: o jovem brasileiro possui grande interesse por temas da Biologia Humana. Dentre as regiões, $60 \%$ dos tópicos de interesse dos alunos do Centro-Oeste são desta área, da região Norte e Sudeste, 70\%, do Sul 80\% e do Nordeste $90 \%$, confirmando pesquisas já discutidas anteriormente (TOLENTINO NETO, 2008; JENKINS; NELSON, 2005; JENKINS; PELL, 2006; JIDESJÖ; OSCARSSON; KARLSSON, 2009; ANDERSON, 2006; KENNEDY, 2008).

Em relação à questão destacada na seção 1 deste capítulo, referente à Controle da Natalidade e Contracepção (A10), verificou-se que ela foi pouco valorizada em todas as regiões, conforme mostra a tabela 5.8.

Tabela 5.8 - Médias obtidas junto às regiões brasileiras para a questão A10

\begin{tabular}{ccccccc}
\hline Questão & $\begin{array}{c}\text { Centro- } \\
\text { Oeste }\end{array}$ & Nordeste & Norte & Sudeste & Sul & p-valor \\
\hline A10 & $1.95 \pm 0.98$ & $2.17 \pm 1.04$ & $2.19 \pm 1.01$ & $2.01 \pm 0.97$ & $1.96 \pm 0.93$ & 0,001 \\
\hline
\end{tabular}

A aplicação do teste Tukey indicou que os jovens do Centro-Oeste e Sul possuem menos interesse pelo controle da natalidade e concepção que os do Norte e Nordeste, e os do Sudeste menos interesse que os do Norte, tornando clara a necessidade de discussão de tais aspectos junto a nossos jovens, conforme discutido anteriormente (ANTUNES et al., 2002; BORGES; SCHOR, 2005; VILLELA; DORETO, 2006).

Os dados apresentados na tabela 5.6, relacionados aos tópicos de maior interesse, permitem o destaque de algumas questões: A09 - Sexo e reprodução - não aparece na lista dos alunos da região Norte; E13 - Como as diferentes drogas proibidas podem afetar o nosso corpo, aparece apenas no Sudeste; E23 - Como o meu corpo cresce e se desenvolve, aparece apenas na lista dos alunos do Nordeste; A37 - O que comer para nos mantermos saudáveis e em boa forma física, aparece apenas nas listas dos alunos do Norte e do Sul; E05 - O que se pode fazer para assegurar ar limpo e água potável, aparece apenas no Centro-Oeste e Norte e E32 - Como a tecnologia genética pode evitar doenças, apareceu na lista apenas dos alunos do Nordeste. Esses resultados mostram que apesar de grande similaridade entre as regiões, alguns temas que interessam o jovem brasileiro não são unânimes em todas as regiões. Uma análise a partir do teste de Tukey aponta para outras diferenças, tal como observadas na tabela 5.9. 
Tabela 5.9 - Resultados do Teste de Tukey para questões A09, E13, E23, A37, E05 e E32

\begin{tabular}{lccc}
\hline Questão & Teste Tukey para & Diferença & P-value \\
\hline A09 & Nordeste - Centro-Oeste & 0,21 & 0,011 \\
E13 & Nordeste - Centro-Oeste & 0,21 & 0,022 \\
E13 & Norte - Centro-Oeste & 0,28 & 0,001 \\
E13 & Sudeste - Norte & $-0,18$ & 0,034 \\
E23 & Nordeste - Centro-Oeste & 0,3 & $<0.001$ \\
E23 & Norte - Centro-Oeste & 0,28 & $<0.001$ \\
E23 & Sudeste - Nordeste & $-0,3$ & $<0.001$ \\
E23 & Sul - Nordeste & $-0,29$ & 0,001 \\
E23 & Sudeste - Norte & $-0,28$ & $<0.001$ \\
E23 & Sul - Norte & $-0,27$ & 0,003 \\
A37 & Nordeste - Centro-Oeste & 0,23 & 0,008 \\
A37 & Norte - Centro-Oeste & 0,3 & $<0.001$ \\
A37 & Sudeste - Nordeste & $-0,23$ & 0,002 \\
A37 & Sudeste - Norte & $-0,3$ & $<0.001$ \\
A37 & Sul - Norte & $-0,23$ & 0,02 \\
E05 & Norte - Centro-Oeste & 0,26 & 0,001 \\
E05 & Sudeste - Nordeste & $-0,3$ & $<0.001$ \\
E05 & Sul - Nordeste & $-0,24$ & 0,009 \\
E05 & Sudeste - Norte & $-0,38$ & $<0.001$ \\
E05 & Sul - Norte & $-0,32$ & $<0.001$ \\
E32 & Nordeste - Centro-Oeste & 0,4 & $<0.001$ \\
E32 & Norte - Centro-Oeste & 0,33 & $<0.001$ \\
E32 & Sudeste - Nordeste & $-0,48$ & $<0.001$ \\
E32 & Sul - Nordeste & $-0,47$ & $<0.001$ \\
E32 & Sudeste - Norte & $-0,41$ & $<0.001$ \\
E32 & Sul - Norte & $-0,4$ & $<0.001$ \\
& & & \\
\hline & &
\end{tabular}

Em relação à questão A09 - Sexo e reprodução, apesar de não aparecer na lista dos dez temas mais interessantes dos alunos da região Norte, a média por eles atribuída é similar à média atribuída pelos jovens das demais regiões. A diferença neste caso reside apenas entre os alunos do Nordeste, que atribuíram valor significativamente maior que os alunos da região Centro-Oeste.

Sobre a questão E13 - Como as diferentes drogas proibidas podem afetar o nosso corpo, que aparece apenas na lista dos jovens do Sudeste, duas diferenças mostraram-se significativas: os alunos do Sudeste atribuíram a esta questão nota inferior aos alunos da região Norte; e os alunos do Centro-Oeste atribuíram menor nota a ela que os do Nordeste e Norte. 
Na questão E23 - Como o meu corpo cresce e se desenvolve, que aparece apenas na lista dos alunos do Nordeste, há diferenças significativas entre todas as regiões, sendo que os alunos do Nordeste e Norte foram os que atribuíram maior valor e os estudantes do Centro-Oeste e Sudeste foram os que atribuíram menor valor.

A questão A37 - O que comer para nos mantermos saudáveis e em boa forma física, que aparece apenas nas listas dos alunos do Norte e do Sul foi maior valorizada pelos alunos do Nordeste e Norte e menor valorizada pelos do Sudeste e Centro-Oeste.

Sobre a questão E05 - O que se pode fazer para assegurar ar limpo e água potável, que aparece apenas no Centro-Oeste e Norte e a questão E32 - Como a tecnologia genética pode evitar doenças, que apareceu apenas na lista dos alunos do Nordeste, ambas foram mais valorizadas pelos alunos do Nordeste e Norte.

Sjøberg (2002) comenta que em muitos países ocidentais, há um movimento de crenças “alternativas" relacionadas a questões metafísicas, espirituais e sobrenaturais que favorece o afastamento dos jovens da ciência. Rotulado também de "Nova Era", tal movimento abrange uma ampla variedade de visões de mundo, terapias e crenças. Um denominador comum, entretanto, é a rejeição da racionalidade científica, muitas vezes caracterizado como mecanicista e reducionista. Não foram observadas diferenças estatisticamente significativas entre regiões nas questões relacionadas aos temas classificados como "alternativos", porém verifica-se que em todas as regiões há grande interesse por alguns desses temas (em especial nas questões C13 e C15). Os resultados estão apresentados na tabela 5.10 .

Tabela 5.10 - Médias nas regiões para temas não científicos ou “alternativos”.

\begin{tabular}{lccccc}
\hline Questão & $\begin{array}{c}\text { Centro- } \\
\text { Oeste }\end{array}$ & Nordeste & Norte & Sudeste & Sul \\
\hline $\begin{array}{l}\text { C09 - Astrologia e horóscopos e se os } \\
\text { planetas podem influenciar os seres } \\
\text { humanos }\end{array}$ & $2.38 \pm 1.15$ & $2.44 \pm 1.13$ & $2.53 \pm 1.14$ & $2.35 \pm 1.11$ & $2.45 \pm 1.12$ \\
$\begin{array}{l}\text { C13 - Porque sonhamos e qual o } \\
\text { significado dos nossos sonhos }\end{array}$ & $3.12 \pm 1.04$ & $3.21 \pm 1.02$ & $3.21 \pm 1.02$ & $3.09 \pm 1.07$ & $3.17 \pm 1.04$ \\
$\begin{array}{l}\text { C14 - Bruxas e fantasmas, e se } \\
\text { existem ou não. }\end{array}$ & $2.18 \pm 1.19$ & $2.13 \pm 1.22$ & $2.28 \pm 1.26$ & $2.14 \pm 1.20$ & $2.30 \pm 1.24$ \\
$\begin{array}{l}\text { C15 - Transmissão de pensamentos, } \\
\text { leitura de mentes, sexto sentido, } \\
\text { intuição, etc. }\end{array}$ & $2.60 \pm 1.14$ & $2.62 \pm 1.18$ & $2.73 \pm 1.18$ & $2.62 \pm 1.15$ & $2.82 \pm 1.17$ \\
\hline
\end{tabular}


A grande diversidade existente entre as regiões brasileiras proporcionou a verificação de possíveis diferenças pontuais entre elas. Por exemplo, há alguma região brasileira com maior interesse por temas ligados à agricultura? Os resultados obtidos podem ser observados na tabela 5.11.

Tabela 5.11 - Médias das regiões brasileiras para as questões relacionadas à agricultura.

\begin{tabular}{|c|c|c|c|c|c|c|}
\hline Questões & $\begin{array}{c}\text { Centro- } \\
\text { Oeste }\end{array}$ & Nordeste & Norte & Sudeste & Sul & P-value \\
\hline $\begin{array}{l}\text { E17 - Como se melhoram } \\
\text { as colheitas em hortas } \\
\text { e roças }\end{array}$ & $2,30 \pm 1,06$ & $2,35 \pm 1,10$ & $2,36 \pm 1,06$ & $2,14 \pm 1,01$ & $2,20 \pm 1,08$ & 0,003 \\
\hline $\begin{array}{l}\text { E19 - A agricultura } \\
\text { orgânica, sem uso de } \\
\text { pesticidas e adubos } \\
\text { artificiais }\end{array}$ & $2,24 \pm 1,08$ & $2,33 \pm 1,13$ & $2,43 \pm 1,09$ & $2,07 \pm 1,00$ & $2,22 \pm 1,09$ & 0,001 \\
\hline $\begin{array}{l}\text { E33 - Os benefícios e os } \\
\text { possíveis perigos dos } \\
\text { métodos modernos da } \\
\text { agricultura }\end{array}$ & $2.25 \pm 1.04$ & $2.35 \pm 1.07$ & $2.39 \pm 1.05$ & $2.03 \pm 0.97$ & $2.13 \pm 1.03$ & 0,001 \\
\hline
\end{tabular}

Nas três questões verificadas, as maiores médias foram dos alunos da região Norte. O teste ANOVA indicou que há diferença estatisticamente significativa entre as regiões, porém o teste Tukey indicou, na questão E33, que os jovens da região Centro-Oeste possuem mais interesse que os do Sudeste, e que os jovens do Sul possuem menor interesse que os do Nordeste e Norte, conforme observado na tabela 5.12.

Tabela 5.12 - Teste de Tukey para observação de diferenças entre regiões nas questões E17, E19 e E33.

\begin{tabular}{lccc}
\hline Questão & Teste Tukey para & Diferença & P-value \\
\hline E17 & Sudeste - Nordeste & $-0,22$ & 0,009 \\
E17 & Sudeste - Norte & $-0,22$ & 0,005 \\
E19 & Sudeste - Nordeste & $-0,26$ & 0,001 \\
E19 & Sudeste - Norte & $-0,35$ & $<0.001$ \\
E33 & Sudeste - Centro-Oeste & $-0,22$ & 0,031 \\
E33 & Sudeste - Nordeste & $-0,32$ & $<0.001$ \\
E33 & Sul - Nordeste & $-0,22$ & 0,037 \\
E33 & Sudeste - Norte & $-0,37$ & $<0.001$ \\
E33 & Sul - Norte & $-0,27$ & 0,005 \\
\hline
\end{tabular}


Através da tabela 5.12 observa-se que os jovens da região Nordeste e Norte possuem maior interesse pela questão E17 e E19 que os do Sudeste. Entre as demais regiões não houve diferenças significativas. Assim, verificamos que os jovens das regiões Norte e Nordeste são os mais interessados por esses temas, porém, tendo em vista que eles foram os que demonstraram maior interesse por todas as questões, não podemos concluir que há diferenças regionais especificamente sobre temas relacionados à agricultura.

Outra questão que merece ser verificada é se há diferenças de interesse por questões que abordam especificamente temas relacionados ao meio ambiente. Os resultados obtidos estão apresentados na tabela 5.13.

Tabela 5.13 - Médias verificadas nas regiões brasileiras para questões relacionadas ao meio ambiente.

\begin{tabular}{lcccccc}
\hline Questões & $\begin{array}{c}\text { Centro- } \\
\text { Oeste }\end{array}$ & Nordeste & Norte & Sudeste & Sul & $\begin{array}{c}\text { p- } \\
\text { value }\end{array}$ \\
\hline $\begin{array}{l}\text { E03 - A camada de ozônio e } \\
\text { como pode ser afetada pelos } \\
\text { seres humanos }\end{array}$ & $2.56 \pm 1.07$ & $2.76 \pm 1.06$ & $\mathbf{2 . 8 5} \pm 1.01$ & $2.45 \pm 1.03$ & $2.4 \pm 1.06$ & 0,001 \\
$\begin{array}{l}\text { E04 - O efeito estufa e como } \\
\text { pode ser modificado pelos } \\
\text { seres humanos }\end{array}$ & $2.68 \pm 1.03$ & $2.82 \pm 1.05$ & $\mathbf{2 . 9 2} \pm 1.03$ & $2.53 \pm 1.04$ & $2.52 \pm 1.07$ & 0,001 \\
$\begin{array}{l}\text { E05 - O que se pode fazer } \\
\text { para assegurar ar limpo }\end{array}$ & $2.97 \pm 1.03$ & $3.15 \pm 0.98$ & $\mathbf{3 . 2 3} \pm 0.93$ & $2.85 \pm 1.00$ & $2.91 \pm 1.02$ & 0,001 \\
e água potável & & & & & & \\
$\begin{array}{l}\text { E06 - Como a tecnologia nos } \\
\text { ajuda a tratar de resíduos, } \\
\text { lixo e esgotos }\end{array}$ & $2.69 \pm 1.06$ & $\mathbf{2 . 9 6} \pm 1.00$ & $\mathbf{2 . 9 6} \pm 0.99$ & $2.61 \pm 0.98$ & $2.59 \pm 1.05$ & 0,001 \\
$\begin{array}{l}\text { E16 - Como proteger } \\
\text { espécies de animais } \\
\text { ameaçados de extinção }\end{array}$ & $2.92 \pm 1.03$ & $3.01 \pm 1.02$ & $\mathbf{3 . 1 4} \pm 0.97$ & $2.87 \pm 0.99$ & $2.89 \pm 1.06$ & 0,001 \\
$\begin{array}{l}\text { E19 - A agricultura orgânica, } \\
\text { sem uso de pesticidas e } \\
\text { adubos artificiais }\end{array}$ & $2.24 \pm 1.08$ & $2.33 \pm 1.13$ & $\mathbf{2 . 4 3} \pm 1.09$ & $2.07 \pm 1.00$ & $2.22 \pm 1.09$ & 0,001 \\
$\begin{array}{l}\text { E20 - Como a energia pode } \\
\text { ser poupada e usada de forma } \\
\text { mais eficaz }\end{array}$ & $2.61 \pm 1.03$ & $2.85 \pm 1.07$ & $\mathbf{2 . 9 0} \pm 1.01$ & $2.63 \pm 1.01$ & $2.74 \pm 1.07$ & 0,001 \\
$\begin{array}{l}\text { E21 - Novos recursos de energia } \\
\text { - sol, vento, marés, ondas, etc. }\end{array}$ & $2.63 \pm 1.09$ & $2.86 \pm 1.06$ & $\mathbf{2 . 9 0} \pm 1.04$ & $2.60 \pm 1.06$ & $2.70 \pm 1.04$ & 0,001 \\
\hline & & & & & & \\
\hline
\end{tabular}

Os dados obtidos mostram que os jovens da região Norte possuem maior interesse em relação aos temas ambientais que os demais. Porém, tendo em vista que os jovens da região Norte atribuíram maior pontuação na maioria das questões, não podemos afirmar que a diferença obtida é por que eles realmente mostram-se mais dispostos às questões ambientais ou por que eles, de modo geral, atribuíram notas mais altas nas questões. 


\subsection{O JOVEM BRASILEIRO NO CENÁRIO INTERNACIONAL}

\section{ALGUMAS QUESTÕES DE INTERESSE}

Apresentaremos aqui alguns aspectos relacionados diretamente com as questões das seções ACE que foram discutidos em análises comparativas internacionais do projeto ROSE, e a posição do jovem brasileiro em relação aos jovens de outras nações. Para tanto, é necessário esclarecer o modo com que os países foram ranqueados.

Sjøberg e Schreiner (2010, p. 15) ranquearam os países participantes do ROSE utilizando a média das 108 questões das seções ACE para definir "o interesse global em aprender" tópicos da ciência. As médias obtidas podem ser verificadas na figura 5.1. Nesta figura foram incluídos os dados levantados junto aos jovens brasileiros, que estão destacados no gráfico.

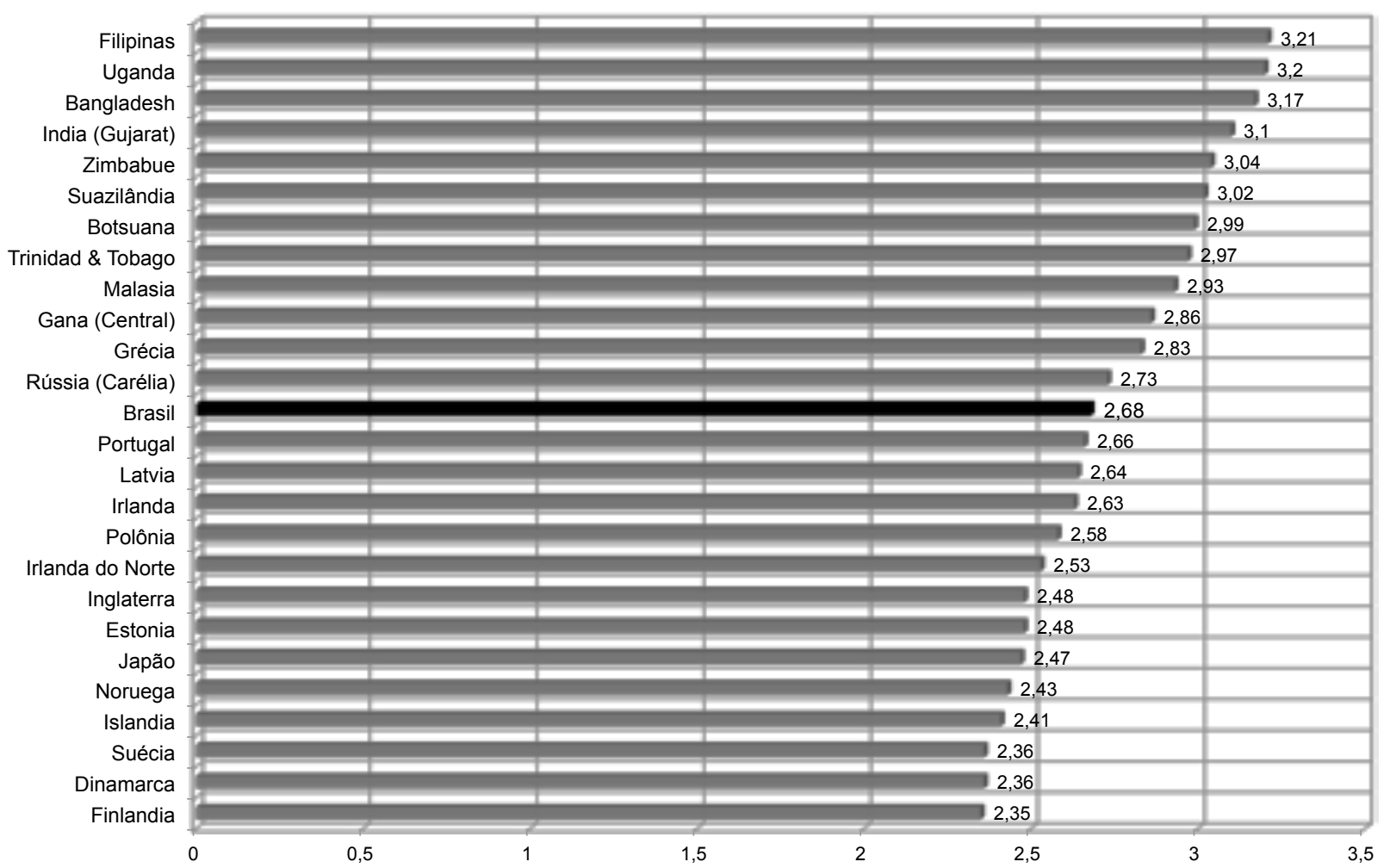

Figura 5.1 - Média obtida pelos países participantes do ROSE nas 108 questões das seções ACE. Figura adaptada de Sjøberg e Schreiner (2010). 
Sjøberg e Schreiner (2005) verificaram que os dados coletados através do projeto ROSE mostraram uma forte relação entre o Índice de Desenvolvimento Humano (IDH) dos países participantes e as respostas dos alunos expressas nas médias globais obtidas junto a todos os itens das seções ACE. O coeficiente de Pearson obtido foi de - 0,85 , indicando que há uma correlação negativa forte entre o IDH e a média dos itens ACE (SANTOS, 2007). Assim, países com IDH alto possuem uma tendência de apresentarem médias na seção ACE menores e países com IDH baixo, médias maiores. A figura 5.2 ilustra esta tendência.

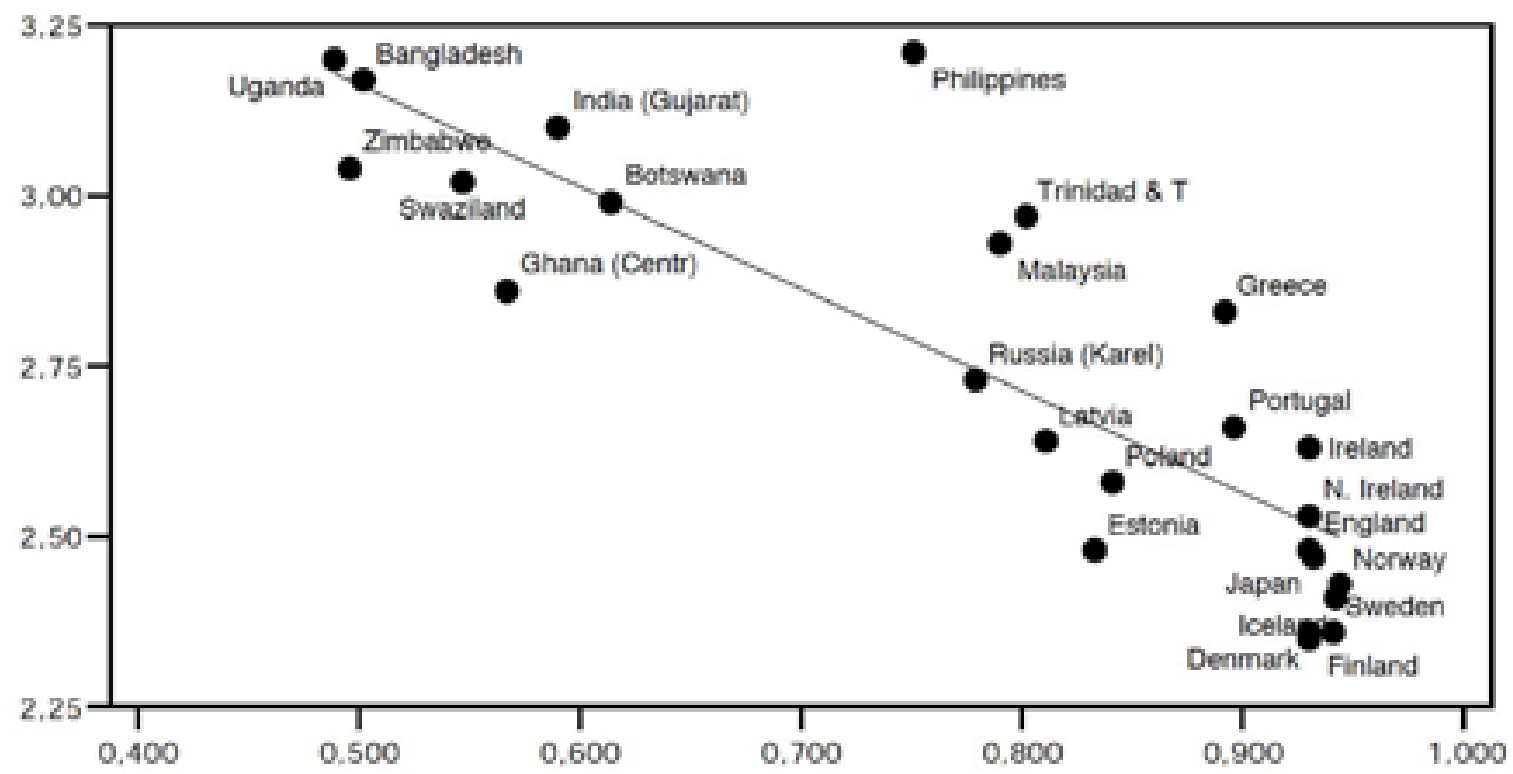

Figura 5.2 - Linha de regressão obtida a partir dos valores de IDH (eixo horizontal) e a pontuação média global nos itens ACE (eixo vertical) para países participantes do ROSE. Fonte: Sjøberg e Schreiner (2005).

A inclusão do Brasil na análise acima obteve como resultado o coeficiente de Pearson no valor de $-0,857$, indicando que a tendência observada por Sjøberg e Schreiner (2005) se mantém. A linha de regressão obtida e a posição do Brasil podem ser observadas na figura 5.3. 


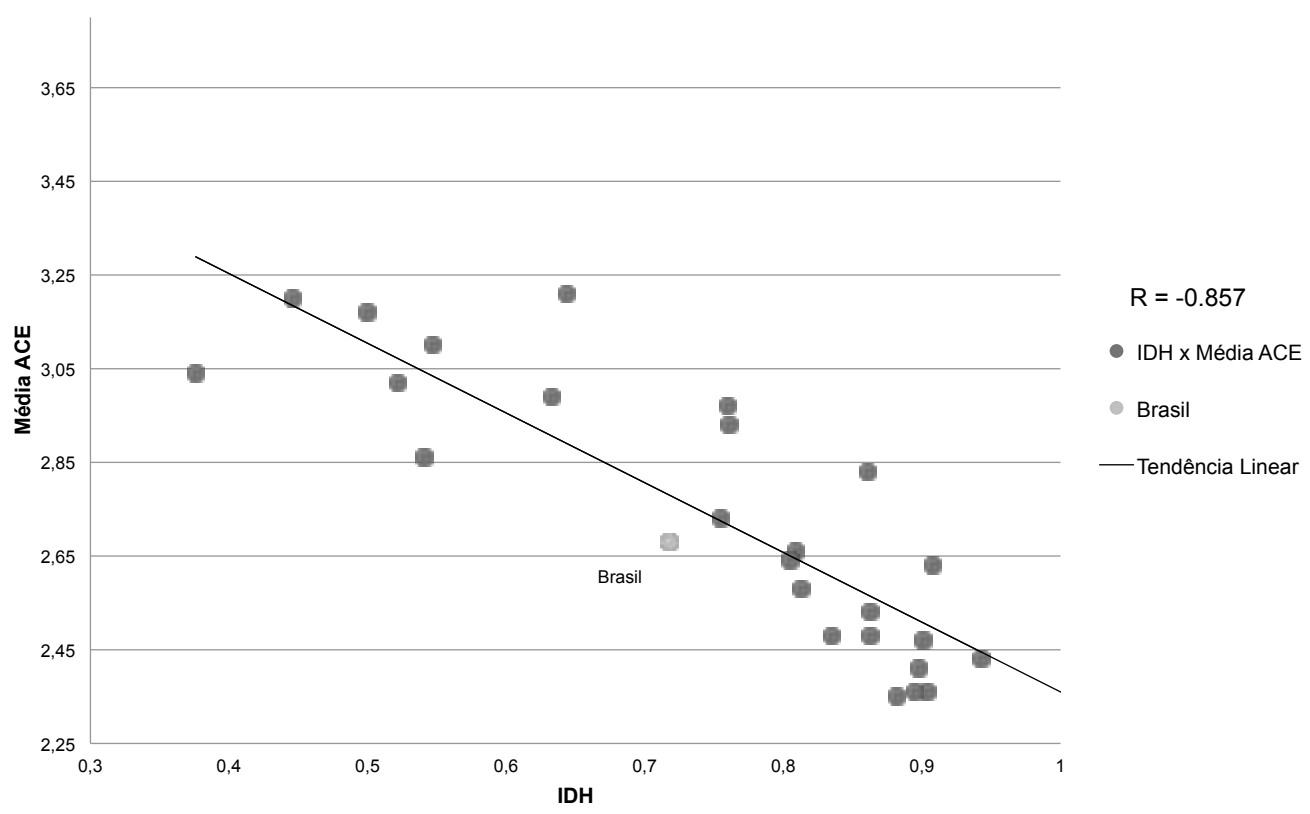

Figura 5.3 - Linha de regressão obtida a partir dos valores de IDH e a pontuação média geral em todos os itens das questões ACE para países participantes do ROSE incluindo o Brasil.

Este mesmo teste foi realizado utilizando o valor geral do IDH dos municípios participantes da pesquisa ROSE no Brasil (dados PNUD, 2003a). O valor obtido para o coeficiente de Pearson foi de $-0,39$, indicando uma associação linear negativa fraca entre o IDH e média das questões ACE (SANTOS, 2007). Os dados brasileiros (municípios) podem ser observados na figura 5.4.

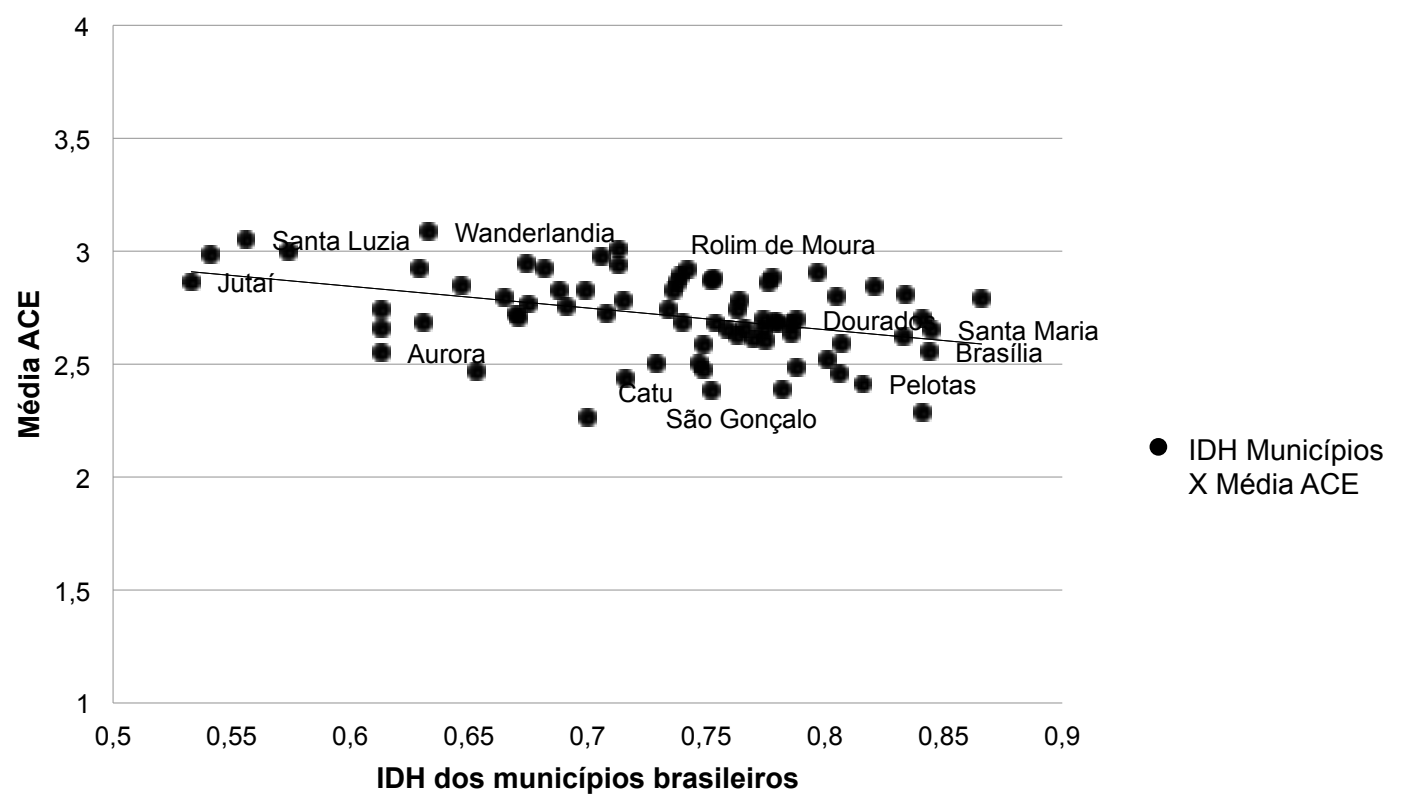

Figura 5.4 - Linha de regressão obtida a partir dos valores de IDH dos municípios brasileiros participantes da pesquisa ROSE Brasil e a pontuação média geral em todos os itens das questões ACE. 
Vale ressaltar que o desenho amostral das pesquisa não contemplou estratos secundários referentes à IDH. Desta forma, não podemos considerar que a amostra possui municípios que representem todas as faixas de IDH presentes no Brasil. Porém, o teste acima descrito foi realizado com o intuito de se verificar se havia correlação entre o IDH e os municípios presentes na amostra. Portanto, podemos afirmar que há uma associação linear negativa fraca entre o IDH e os municípios presentes na amostra ROSE, porém não podemos afirmar que esse padrão se repete no âmbito nacional.

Sjøberg e Schreiner (2009) apontaram que há um padrão geral para os 108 itens das seções ACE “O que eu quero aprender”: quanto mais desenvolvido é o país, menor é o interesse global de seus jovens pela ciência, ou ainda, quanto mais desenvolvido é o país, "mais seletivos são seus estudantes". Segundo Sjøberg e Schreiner (2005), um importante desafio das localidades com baixo IDH é a melhoria das condições materiais e o crescimento econômico. Pode-se supor que, em tais sociedades, a ciência é percebida como importante para a sociedade e, assim, significativa para o indivíduo.

Quanto às diferenças de gênero entre os países participantes, os autores indicaram que os meninos (e não as meninas) se interessam por tecnologia, mecânica, eletricidade, fenômenos espetaculares (tais como explosivos ou violentos). Por outro lado, as meninas (e não os meninos) possuem grande interesse por saúde e medicina, beleza e corpo humano, ética, estética, descobertas e fenômenos sobrenaturais (SJØBERG; SCHREINER, 2009). Tais dados também foram observados entre os jovens brasileiros.

Sjøberg (2007) aponta para a importância de darmos atenção a questões científicas que são abordados de forma implícita no currículo de ciências: o papel da ciência na sociedade, o trabalho dos cientistas, a natureza do conhecimento científico etc. Tais questões são o que provavelmente mais influenciam as atitudes dos alunos em relação às ciências.

Partindo deste ponto de vista, alguns itens presentes no questionário ROSE foram eleitos emblemáticos e significativos para análises comparativas entre os países participantes, visando desvelar certos aspectos ocultos da ciência escolar. Uma delas é a questão "Cientistas famosos e suas vidas" (E37). Esta questão é considerada emblemática por que o interesse dos jovens pelos cientistas e suas vidas indicam interesse pela carreira científica. A figura 5.5 apresenta médias de diversos países para a questão E37. 


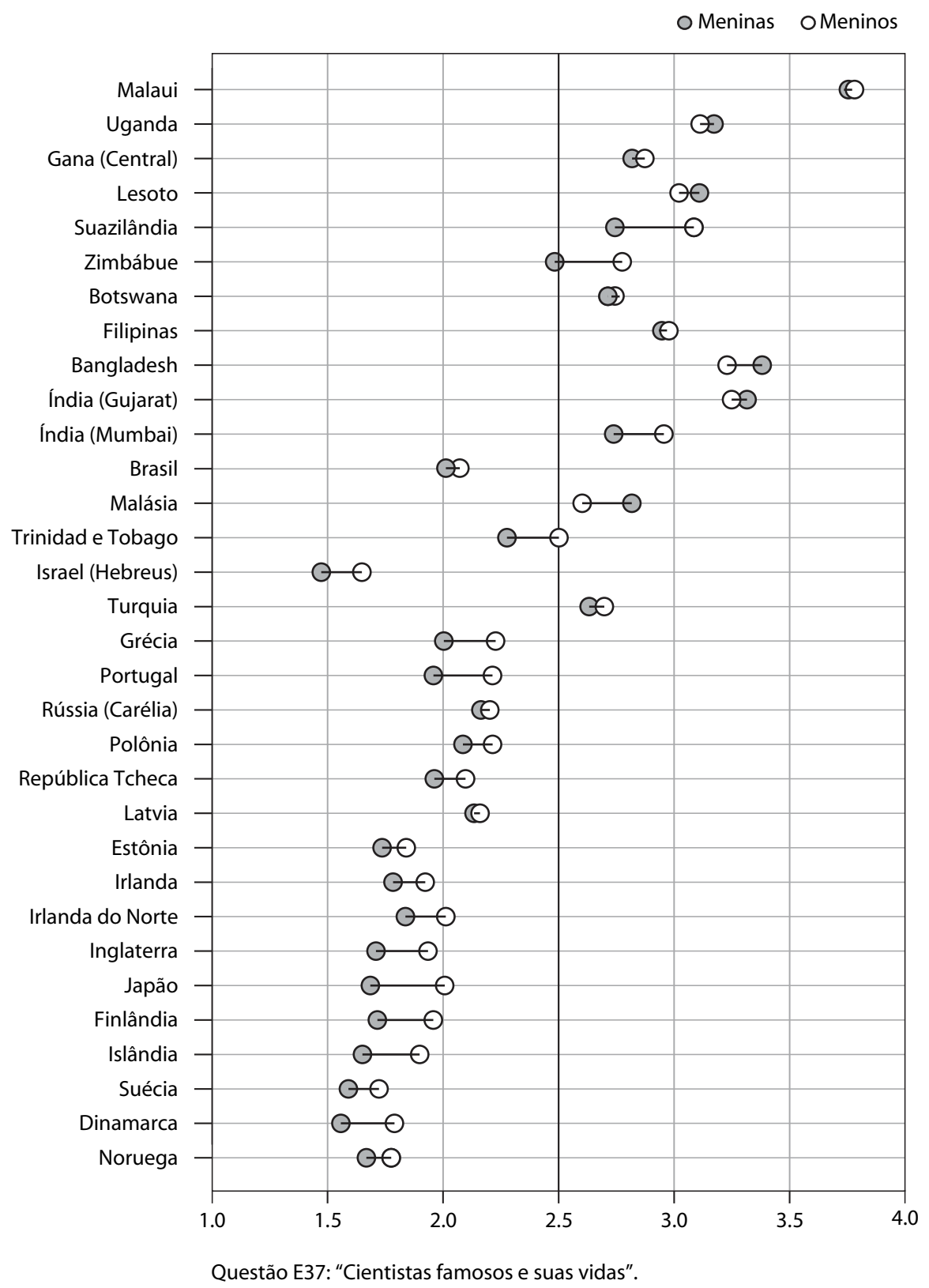

Figura 5.5 - Respostas dos alunos sobre interesse por "Cientistas famosos e suas vidas" - Questão E37. Adaptado de Matthews (2007).

Observa-se que a média dos brasileiros é pequena, e está localizada entre os países europeus da República Tcheca e Latvia. Também não se observa diferença significativa entre meninas e meninos. Tais dados apontam que a posição dos jovens brasileiros foi semelhante ao grupo de países localizados na região central do gráfico, entre a Grécia e República Tcheca. Este padrão irá se repetir em outras questões, conforme observado nos capítulos que se seguem. 


\section{OS JOVENS BRASILEIROS FRENTE}

\section{AOS DESAFIOS AMBIENTAIS}

Neste capítulo serão apresentados e discutidos os resultados obtidos junto à seção D "Eu e os desafios ambientais", que questionavam ao aluno: "Até que ponto você concorda com as seguintes afirmações sobre os problemas do ambiente (poluição do ar e da água, abuso de recursos ambientais, mudanças climáticas globais etc.)?" através de 18 itens. Conforme declaram Schreiner e Sjøberg (2004), um importante objetivo da educação é capacitar os estudantes a lidar de forma responsável com as questões ambientais, uma vez que o conhecimento acerca dos problemas do meio ambiente não implica ações positivas e conscientes acerca deles. Assim, este capítulo traz importantes dados acerca da posição do jovem brasileiro frente a essas questões.

Para conhecer e discutir sobre as atitudes dos jovens em prol do meio ambiente é necessário compreender os fatores que levam uma pessoa a se preocupar com as questões ambientais. Para isso, diversas pesquisas tem se dedicado a identificar os valores que subsidiam as atitudes em prol do meio ambiente. Em geral, tem se considerado que as atitudes ambientais são resultados de uma série de valores mais específicos, chamados de preditores (DIETZ; STERN; GUAGNANO, 1998; SCHULTZ; ZELEZNY, 1999; STERN, 2000; GARCÍA-MIRA; EULOGIO, 2001).

Os pesquisadores consideram que há uma relação causal entre os preditores, ou seja, atitudes positivas gerais em prol do ambiente dependem da ativação de diversas atitudes específicas, dispostas em vários níveis. Dietz et al. (1998, p. 454) consideram, por exemplo, o seguinte modelo causal de comportamento relacionado ao meio ambiente:

(a) fatores contextuais, incluindo as variáveis que refletem posição na estrutura social e nas experiências de socialização, (b) visão de mundo e ideologias sobre a humanidade e o ambiente; (c) atitudes específicas, crenças e cognições sobre as questões ambientais, e (d) os indicadores comportamentais, incluindo intenções e comportamento.

Stern (2000) e colaboradores desenvolveram uma teoria baseada nas relações causais entre valores, crenças e normas (Teoria VBN), utilizando cinco variáveis que levam ao comportamento. A relação entre as variáveis pode ser observada na figura 6.1. 


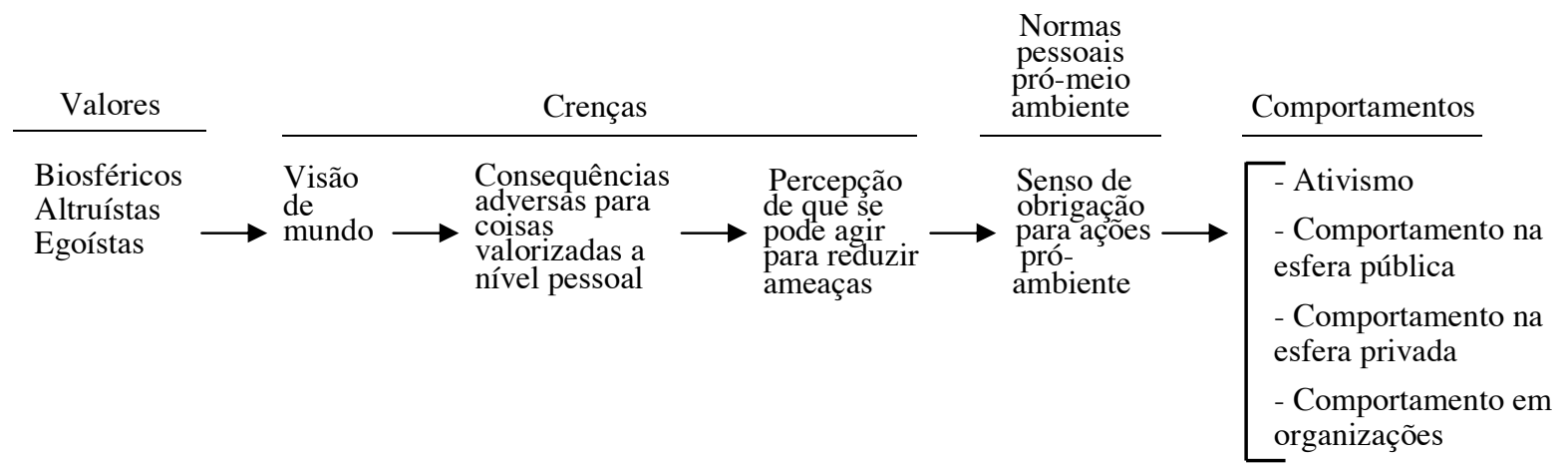

Figura 6.1 - Representação esquemática das variáveis da teoria VBN segundo STERN (2000, p. 412).

A teoria VBN proposta acima trouxe subsídios positivos para estudos envolvendo as variáveis causais do comportamento ambiental significativo: variáveis atitudinais (predisposição ambiental geral, comportamentos específicos ligados a normas e crenças, percepção dos custos e benefícios das ações); capacidades pessoais (alfabetização, status social e recursos financeiros); fatores contextuais (custos materiais, leis e regulamentos, tecnologia disponível, normas sociais e expectativas de políticas de apoio) e hábitos e rotina (STERN, 2000).

García-Mira e Eulogio (2001) empregaram, em um estudo relacionado à preocupação ambiental, um modelo causal semelhante, porém baseado nos seguintes níveis: 1) valores; 2) atitudes e crenças gerais; 3 ) atitudes e crenças específicas e 4) intenções de conduta/normas pessoais, onde cada um dos níveis possui uma série de valores, atitudes e crenças.

Cientes das relações causais existentes entre valores, atitudes e comportamento, não podemos assumir que o aumento de conhecimento e consciência leve a mudanças comportamentais em prol do meio ambiente. Assim, campanhas e atividades educativas que visem informar e conscientizar não terão sucesso na tentativa de atingirem o comportamento das pessoas (KOLLMUSS; AGYEMAN, 2002).

Neste sentido, a pesquisa aqui descrita possui extrema relevância por que busca conhecer os valores e atitudes dos jovens que podem levar a comportamentos positivos relacionados ao meio ambiente. A busca por uma educação que vise atitudes positivas em prol do ambiente não deve estar focada apenas nos conceitos curriculares teóricos, mas sim em estratégicas metodológicas que visem ações (HUNGERFORD; VOLK, 1990; JENKINS, 2003).

Para Jacobi (2005, p. 243), uma educação para o exercício da cidadania implica o desenvolvimento de ações autônomas, justas e solidárias, alinhavadas com os problemas ambientais 
que a sociedade enfrenta. Para isso, deve-se "sensibilizar alunos e professores para uma participação mais consciente no contexto da sociedade, questionando comportamentos, atitudes e valores, além de propor novas práticas".

Para Schreiner e Sjøberg (2005), a educação científica possui “papel fundamental na preparação dos jovens para enfrentar e lidar responsavelmente com os desafios ambientais". Neste sentido, o ensino de ciências deve ser baseado no conhecimento das atitudes dos alunos para a questão da proteção ambiental.

A ênfase da educação ambiental tradicional tem sido fornecer conhecimentos básicos dos princípios ecológicos, resultando em pouca atenção aos valores e ao desenvolvimento de habilidades analíticas e ao comportamento ambientalmente consciente. As atitudes, caracterizadas como importantes determinantes do comportamento, devem ser o foco de ações educativas pró-ambientais (POOLEY; O’CONNOR, 2000), por isso, conhecer as atitudes dos jovens brasileiros em relação ao meio ambiente poderá subsidiar tais iniciativas.

Novamente, a palavra inglesa empowerment, com a acepção de autorizar, capacitar, habilitar e dar poderes, assume papel central no ensino, uma vez que ela é pré-requisito para a ação, abrangendo não só conhecimentos e habilidades cognitivas, mas também valores pessoais e motivação. Assim, empowerment em prol do meio ambiente passa a significar encorajamento para ação e crença na possibilidade e habilidade de um indivíduo influenciar seu entorno (SCHREINER; SJØBERG, 2004; SCHREINER; SJØBERG, 2005).

Schreiner e Sjøberg (2005, p. 02) consideram que o aluno, para desenvolver a capacidade de influenciar positivamente seu entorno, necessita:

\footnotetext{
Ter esperanças e visões para o futuro;

Ter um sentimento geral de que pode influenciar o futuro do mundo e ser motivado para ações em prol do ambiente;

Pensar que a proteção ambiental é importante para a sociedade e

Estar interessado e engajado no assunto.
}

Assim, os itens que compõem a seção D do questionário ROSE procuram contemplar estas questões, de forma que o jovem possa demonstrar suas atitudes em relação a diversos aspectos envolvendo a temática ambiental. Através dos resultados descritos poderemos verificar se os jovens brasileiros possuem valores altruístas ou egoístas em relação ao meio ambiente, suas crenças relacionadas a visões de mundo, sua disposição em agir e até mesmo a influência das crenças religiosas. 
Os resultados foram organizados de forma a contemplar: 1) as médias de meninos e meninas para todas as questões presentes na seção $\mathrm{D} ; 2$ ) as médias distribuídas nas regiões brasileiras; 3 ) tipos de posicionamento assumidos pelos jovens brasileiros face aos problemas ambientais e 4) a posição dos jovens brasileiros no cenário internacional.

Para a verificação de diferenças entre gênero, foram utilizados testes de Mann-Whitney. Diferenças com valores de $\mathrm{p}<0,05$ foram consideradas significativas. Para verificação de diferenças entre regiões brasileiras, foram utilizados os testes ANOVA e Tukey, conforme discriminado no capítulo 3 .

\subsection{OS JOVENS BRASILEIROS FRENTE AOS PROBLEMAS AMBIENTAIS: UM PANORAMA GERAL}

Espera-se que através da educação formal os jovens aprendam a lidar de forma responsável com as questões ambientais, não só adquirindo conhecimentos, mas também consciência do seu papel no enfrentamento dos problemas do meio ambiente. A seção D do questionário ROSE traz elementos que nos ajudam a aprofundar nossa compreensão de como os jovens se relacionam com algumas dessas questões. As respostas obtidas junto às questões estão apresentadas em sua totalidade na tabela 6.1 e agrupadas por assuntos na tabela 6.2. As médias destacadas em negrito são as que possuem diferenças significativas entre meninos e meninas. 
Tabela 6.1 - Médias e testes de Mann-Whitney para diferença em relação ao gênero dos estudantes para o grupo de questões D.

\begin{tabular}{|c|c|c|c|c|c|c|}
\hline \multirow{2}{*}{ Questões: "Eu e os desafios ambientais" } & \multirow{2}{*}{$\begin{array}{l}\text { Média } \\
\text { Geral }\end{array}$} & \multicolumn{2}{|c|}{ Média } & \multirow{2}{*}{$\begin{array}{l}\text { Diferença } \\
\text { (H-M) }\end{array}$} & \multirow{2}{*}{ IC 95 (Dif) } & \multirow{2}{*}{$\begin{array}{l}\text { P- } \\
\text { valor }\end{array}$} \\
\hline & & Homem & Mulher & & & \\
\hline $\begin{array}{l}\text { D01 - As ameaças ao ambiente não são da minha } \\
\text { conta }\end{array}$ & 1,71 & 1,89 & 1,57 & 0,32 & {$[0.22 ; 0.40]$} & 0,010 \\
\hline $\begin{array}{l}\text { D02 - Os problemas do ambiente dão um aspecto } \\
\text { sombrio e sem esperança ao futuro do mundo }\end{array}$ & 2,80 & 2,75 & 2,83 & $-0,08$ & {$[-0.17 ; 0.01]$} & 0,067 \\
\hline D03 - Os problemas do ambiente são exagerados & 2,38 & 2,50 & 2,29 & 0,21 & {$[0.11 ; 0.31]$} & 0,010 \\
\hline $\begin{array}{l}\text { D04 - A ciência e a tecnologia podem resolver } \\
\text { todos os problemas do ambiente }\end{array}$ & 2,08 & 2,25 & 1,96 & 0,29 & {$[0.21 ; 0.38]$} & 0,010 \\
\hline $\begin{array}{l}\text { D05 - Desejo ver resolvidos os problemas do } \\
\text { ambiente mesmo que isso implique sacrificar } \\
\text { produtos de consumo }\end{array}$ & 2,97 & 2,89 & $\mathbf{3 , 0 3}$ & $-0,14$ & {$[-0.23 ;-0.05]$} & 0,002 \\
\hline $\begin{array}{l}\text { D06 - Eu pessoalmente posso influenciar o que } \\
\text { acontece no ambiente }\end{array}$ & 2,99 & 2,90 & 3,05 & $-0,15$ & {$[-0.24 ;-0.06]$} & 0,010 \\
\hline $\begin{array}{l}\text { D07 - Ainda podemos encontrar soluções para os } \\
\text { problemas do ambiente }\end{array}$ & 3,45 & 3,33 & $3, \mathbf{5 3}$ & $-0,2$ & {$[-0.28 ;-0.13]$} & 0,010 \\
\hline $\begin{array}{l}\text { D08 - As pessoas se preocupam demais com os } \\
\text { problemas do ambiente }\end{array}$ & 1,88 & 2,04 & 1,76 & 0,28 & {$[0.19 ; 0.36]$} & 0,010 \\
\hline $\begin{array}{l}\text { D09 - Os problemas do ambiente podem ser } \\
\text { resolvidos sem grandes mudanças no nosso estilo } \\
\text { da vida }\end{array}$ & 2,51 & 2,49 & 2,52 & $-0,03$ & {$[-0.13 ; 0.06]$} & 0,480 \\
\hline $\begin{array}{l}\text { D10 - As pessoas deveriam interessar-se mais pela } \\
\text { proteção do ambiente }\end{array}$ & 3,59 & $\mathbf{3}, \mathbf{4 3}$ & 3,71 & $-0,28$ & {$[-0.34 ;-0.21]$} & 0,010 \\
\hline $\begin{array}{l}\text { D11 - É responsabilidade dos países ricos } \\
\text { resolverem os problemas do ambiente no mundo }\end{array}$ & 2,30 & 2,44 & 2,19 & 0,25 & {$[0.15 ; 0.34]$} & 0,010 \\
\hline $\begin{array}{l}\text { D12 - Penso que cada um de nós pode dar uma } \\
\text { contribuição significativa para a proteção do } \\
\text { ambiente }\end{array}$ & 3,50 & 3,31 & 3,63 & $-0,32$ & {$[-0.39 ;-0.25]$} & 0,010 \\
\hline $\begin{array}{l}\text { D13 - Os problemas do ambiente devem ser } \\
\text { deixados aos especialistas }\end{array}$ & 1,65 & 1,82 & 1,53 & 0,29 & {$[0.21 ; 0.37]$} & 0,010 \\
\hline D14 - Eu estou otimista quanto ao futuro & 2,77 & 2,71 & 2,8 & $-0,09$ & {$[-0.18 ; 0.00]$} & 0,041 \\
\hline $\begin{array}{l}\text { D15 - Os animais devem ter o mesmo direito à } \\
\text { vida que as pessoas }\end{array}$ & 3,26 & 3,20 & 3,31 & $-0,11$ & {$[-0.19 ;-0.03]$} & 0,001 \\
\hline $\begin{array}{l}\text { D16 - É correto usar animais para experiências } \\
\text { médicas se assim se pode salvar vidas humanas }\end{array}$ & 2,38 & 2,51 & 2,29 & 0,22 & {$[0.12 ; 0.31]$} & 0,010 \\
\hline $\begin{array}{l}\text { D17 - Quase toda a atividade humana prejudica o } \\
\text { ambiente }\end{array}$ & 2,76 & 2,78 & 2,75 & 0,03 & {$[-0.06 ; 0.11]$} & 0,524 \\
\hline $\begin{array}{l}\text { D18 - O mundo natural é sagrado e devemos } \\
\text { deixá-lo em paz }\end{array}$ & 3,13 & 3,08 & 3,16 & $-0,08$ & {$[-0.17 ; 0.00]$} & 0,020 \\
\hline
\end{tabular}


Sobre esperanças e visões para o futuro (Questões D2, D7 e D14). A visão de mundo foi categorizada por Stern (2000) como crença que possui vínculo causal com o comportamento ( $2^{\circ}$ nível da teoria VBN). Schreiner e Sjøberg (2005) comentam que esperanças encorajam as ações, uma vez que as imagens que temos do futuro afetam nossas ações no presente. Apesar de muitos jovens brasileiros concordarem com o fato de que os problemas ambientais dão aspecto sombrio ao mundo (D2), em média se declaram otimistas quanto ao futuro (D14), especialmente as meninas, e consideram fortemente que podemos encontrar soluções para os problemas ambientais (D7).

As questões D2 e D14 não devem ser consideradas opostas, ou que constituem uma versão positiva e negativa do mesmo fator subjacente. Tanto a construção do item em si - as frases referem-se a problemas ambientais (D2) e ao futuro do mundo (D14), como os resultados obtidos junto a elas demonstram que as questões são diferentes. Há uma fraca (quase nula) correlação entre essas duas questões (coeficiente de Pearson $=0,058$ ), o que corrobora o fato de elas não se referirem à mesma coisa de forma inversa. Por isso, podemos afirmar com certeza que os jovens brasileiros se declaram otimistas em relação ao futuro.

Sobre estar motivado para ações em prol do ambiente (D1, D5). A questão D1 está proposta na negativa, ou seja, quanto menor o valor atribuído à questão, mais positiva é a postura do jovem, o que denota que os problemas ambientais são também de sua responsabilidade. A média geral obtida é menor que a média da escala $(2,5)$, o que indica a disponibilidade dos jovens em agirem a favor do meio ambiente. Os jovens brasileiros são bastante motivados para a ação, inclusive dispostos a fazerem sacrifícios em prol do meio ambiente (D5), especialmente as meninas. A questão D5, em particular, revela um valor altruísta em prol do meio ambiente, que pode levar a comportamentos ambientalmente positivos.

Sobre o sentimento geral de que pode influenciar o futuro do mundo (D6, D12). O jovem brasileiro acredita que pode influenciar o futuro do mundo e, mais ainda, que pode dar uma contribuição significativa para a proteção ambiental. Este sentimento é extremamente positivo por que está relacionado diretamente com a tomada de decisões pró-ambientais. A “percepção de que se pode agir para reduzir ameaças" foi categorizada por Stern (2000) como crença que possui vínculo causal com o comportamento ( $4^{\circ}$ nível). Também nesta categoria as meninas pontuaram mais, com uma diferença estatisticamente maior em relação aos meninos.

Sobre pensar que a proteção ambiental é importante para a sociedade (D3, D8, D9 e 
D10). As questões D3 e D8 estão formuladas de modo inverso, de forma que uma maior pontuação indica uma atitude negativa, e menor pontuação uma atitude ambiental positiva. A média geral para a questão D3 foi 2,38, e para a D8 foi 1,88 e tanto meninos quanto meninas não pontuaram mais que a média da escala $(2,5)$. Tais resultados indicam que os jovens brasileiros não acreditam que os problemas do ambiente são exagerados ou que as pessoas se preocupam em demasia com eles. Quanto à questão D9, podemos considerá-la também como relacionada aos valores pessoais, já que aponta para uma posição direcionada ao egoísmo. Os brasileiros neste sentido têm uma atitude "neutra", uma vez que a média obtida foi em torno de 2,5. Isso significa que o jovem ainda pensa que não são necessárias grandes mudanças no estilo de vida para que os problemas ambientais sejam amenizados ou solucionados. Sobre a questão D10, os jovens brasileiros acreditam fortemente que as pessoas devam interessar-se mais pela proteção ambiental, especialmente as meninas.

As questões acima apontam que o jovem brasileiro demonstra estar engajado positivamente nas questões ambientais. Em especial as questões D10 e D12 indicam que nossos jovens interessam-se pela temática do meio ambiente, uma vez que consideram que as pessoas deveriam interessar-se mais pela proteção do ambiente e que todos podem contribuir nesta questão.

Sobre a solução para os problemas ambientais. O jovem brasileiro não credita à ciência a solução pelos problemas ambientais (D04), tampouco aos países ricos (D11) ou aos especialistas (D13), o que indica que de fato, ele considera-se responsável pela temática ambiental e possui um senso de obrigação para ações, conforme observado em Stern (2000).

Sobre a relação entre ambiente e crenças religiosas. Muitas das visões ambientais possuem relações com as crenças religiosas. Dietz et al. (1998, p. 465) verificaram que há uma relação significativa entre o ambientalismo e religião, uma vez "que pessoas que acreditam que a natureza é sagrada por que é uma criação de Deus são mais dispostas a fazerem sacrifícios em prol do meio ambiente que os demais". Os jovens brasileiros, neste sentido, declararam que o mundo natural é sagrado (D18), uma vez que 48,2\% dos estudantes valoraram 4 nesta questão. Também acreditam que as pessoas têm o mesmo direito à vida que os animais (D15), já que 56,5\% dos alunos atribuíram valor 4 a esta questão. Eles não concordam com o uso de animais em experimentos para o salvamento de vidas humanas (D16), porém concordam com a afirmação de que quase toda a atividade humana prejudica o ambiente (D17).

Para verificar se a consideração de Dietz et al. (1998, p. 465) também era observada na 
amostra brasileira, foi realizado um teste de correlação entre a questão D5 - "Desejo ver resolvidos os problemas do ambiente mesmo que isso implique sacrificar produtos de consumo" e D18 - “o mundo natural é sagrado e devemos deixá-lo em paz”. O coeficiente de Pearson obtido foi 0,206 , o que indica haver uma correlação fraca entre as duas questões. Não foi observada correlação média ou forte entre a questão D18 e as demais questões da seção D.

Sobre gênero e meio ambiente. Muitos estudos têm procurado relacionar questões de gênero e comportamentos pró-ambientais, uma vez que diversas pesquisas apontam que as mulheres possuem maior preocupação ambiental e comportamento ambiental mais pró-ativo que os homens. As razões para esta diferença têm sido relacionadas ao cuidado parental, ao trabalho exercido na família e sociedade, à socialização e à ética (DIETZ; STERN; GUAGNANO, 1998; BLOCKER; ECKBERG, 1997; CAVAS et al., 2009; MACDONALD; HARA, 1994; NORGAARD; YORK, 2005; ZELEZNY; CHUA; ALDRICH, 2000).

Dietz et al. (1998) apontaram que suas pesquisas empíricas confirmaram que as mulheres têm crenças mais fortemente pró-ambientais do que os homens, inclusive por serem mais dispostas a se envolverem em comportamentos relacionados ao consumo ambientalmente correto.

Zelezny et al. (2000) comentam que os estudos relacionados ao papel do gênero nas questões ambientais estão baseados nas abordagens ligadas à socialização. Tais teorias consideram que o comportamento é moldado pelo processo de socialização, que contempla expectativas culturais e de gênero. Neste sentido, as mulheres, através do processo de socialização, demonstram uma forte "ética do cuidado", de forma que são mais compassivas, carinhosas e cooperativas. Os homens, por outro lado, são educados para serem independentes e competitivos. Por conta disso, as mulheres costumam apresentar comportamentos ambientais mais pró-ativos.

Blocker e Eckberg (1997) comentam que historicamente o processo de socialização e o funcionamento da estrutura social/ocupacional têm negado o acesso às mulheres ao mercado de trabalho e aos domínios científicos e tecnológicos, que eram preponderantemente masculinos. Assim, às mulheres sempre foi delegado o papel de cuidadora familiar. Tal situação tem incentivado as mulheres a um cuidado maior com o meio ambiente, em contraste com o comportamento masculino, que costuma ser mais destrutivo.

Macdonald e Hara (1994) também comentam que diversos estudos apontam que os homens são socializados para adquirirem qualidades "masculinas", tais como a racionalidade, a competitividade e domínio do ambiente, enquanto que as mulheres são socializadas para mani- 
festarem qualidades "femininas", como o cuidado e a provisão do alimento para a prole, o que gera um tipo de mentalidade de maternidade.

Em um estudo que procurou relacionar a representação feminina na política e a ratificação de tratados ambientais em diversas nações, Norgaard e York (2005) verificaram que os países com maior proporção de mulheres no parlamento são mais propensos a ratificar tratados ambientais do que outros, o que nos leva à reflexão da importância do papel do gênero nas políticas ambientais.

Os resultados obtidos na aplicação do projeto ROSE no Brasil corroboram a maioria dos estudos acima citados, pois revelam que as meninas brasileiras declaram-se mais otimistas quanto ao futuro e acreditam que podem ainda encontrar soluções para os problemas ambientais mais que os meninos (DIETZ; STERN; GUAGNANO, 1998; BLOCKER; ECKBERG, 1997; CAVAS et al., 2009; NORGAARD; YORK, 2005; ZELEZNY; CHUA; ALDRICH, 2000). Tais diferenças, relacionadas às visões de futuro, podem ser observadas na figura 6.2.

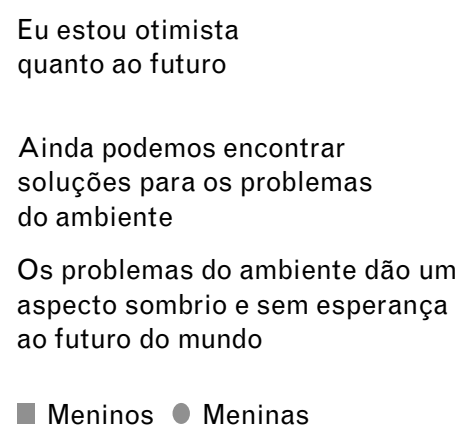

Meninos Meninas

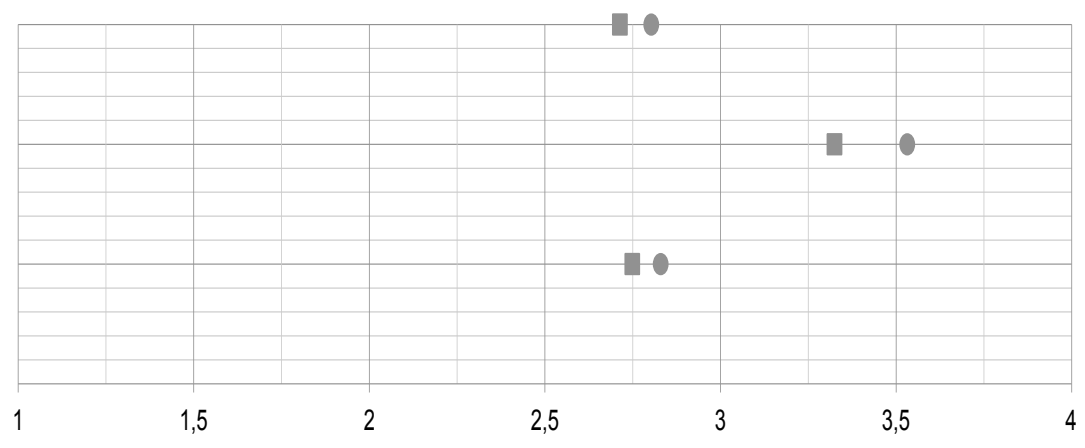

Figura 6.2 - Gráfico que apresenta diferenças de gênero dos jovens brasileiros quanto as visões de futuro.

Quanto à motivação para ação, as meninas brasileiras estão mais dispostas a sacrificar bens de consumo que os meninos e acreditam que podem pessoalmente influenciar o que acontece no meio ambiente mais que os meninos. Já a pergunta (na negativa) "As ameaças ao ambiente não são da minha conta" (D01), as meninas também discordam mais que os meninos, indicando motivação pessoal para a ação. As respostas podem ser observadas na figura 6.3. 
Desejo ver resolvidos os problemas do ambiente mesmo que isso implique sacrificar produtos de consumo

As ameaças do ambiente não são da minha conta

Meninos Meninas

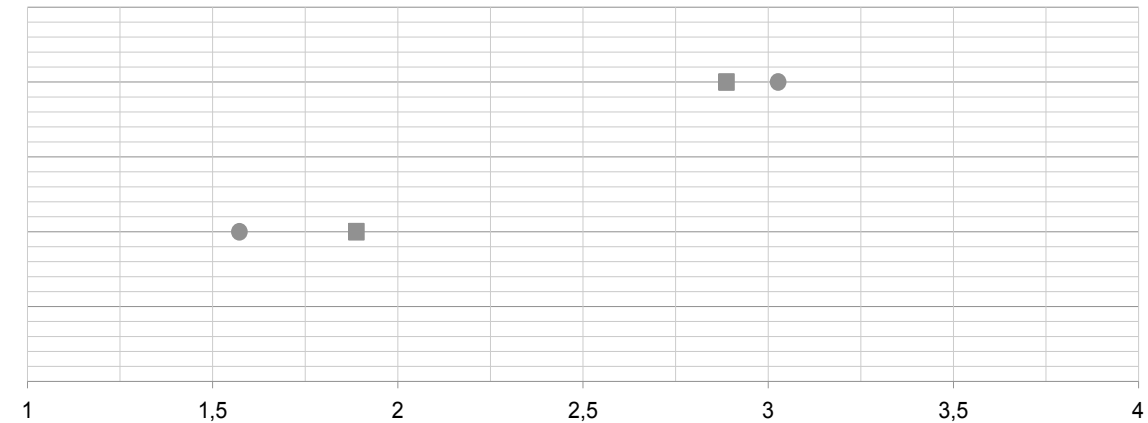

Figura 6.3 - Gráfico que apresenta diferenças de gênero dos jovens brasileiros quanto à motivação para a ação.

Por outro lado, alguns posicionamentos podem ser considerados contraditórios. Tanto meninas como meninos concordam com o fato de que os problemas ambientais podem ser resolvidos sem grandes mudanças no estilo de vida (D9), já que a média obtida para esta questão foi 2,51, sem diferenças estatisticamente significativas de gênero.

Assim, podemos afirmar que as jovens brasileiras possuem atitudes ambientais mais próativas que os meninos, tendo visões de futuro mais otimistas, e apresentando crenças de que ainda se pode fazer algo em prol do meio ambiente. Os meninos, apesar de terem atitudes menos pró-ativas, demonstraram mais interesse em aprender temas ambientais que as meninas, conforme discutido no capítulo 5.

\subsection{OS JOVENS BRASILEIROS FRENTE AOS PROBLEMAS AMBIENTAIS: UM PANORAMA POR REGIÃO}

Observando as questões que compõem a seção D, podemos perceber que apenas em metade delas foram observadas diferenças entre as regiões brasileiras, a saber, nas questões D05, D07, D10, D11, D12, D15, D16, D17 e D18. As médias regionais estão apresentadas na tabela 6.2. Os valores destacados em negrito referem-se aos itens com diferenças estatisticamente significativas entre regiões ( $p$-valor $<0,05$ ). 
Tabela 6.2 - Médias por região da seção "Eu e os desafios ambientais".

\begin{tabular}{|c|c|c|c|c|c|c|}
\hline $\begin{array}{l}\text { Questões: "Eu e os desafios } \\
\text { ambientais" }\end{array}$ & $\begin{array}{l}\text { Centro- } \\
\text { Oeste }\end{array}$ & Nordeste & Norte & Sudeste & Sul & P-valor \\
\hline $\begin{array}{l}\text { D01 - As ameaças ao ambiente não são } \\
\text { da minha conta }\end{array}$ & $1.73 \pm 1.09$ & $1.68 \pm 1.1$ & $1.75 \pm 1.13$ & $1.62 \pm 1.00$ & $1.79 \pm 1.06$ & 0,178 \\
\hline $\begin{array}{l}\text { D02 - Os problemas do ambiente dão um } \\
\text { aspecto sombrio e sem esperança ao } \\
\text { futuro do mundo }\end{array}$ & $2.69 \pm 1.09$ & $2.88 \pm 1.12$ & $2.80 \pm 1.13$ & $2.77 \pm 1.07$ & $2.75 \pm 1.07$ & 0,124 \\
\hline $\begin{array}{l}\text { D03 - Os problemas do ambiente são } \\
\text { exagerados }\end{array}$ & $2.32 \pm 1.20$ & $2.39 \pm 1.20$ & $2.47 \pm 1.19$ & $2.31 \pm 1.10$ & $2.36 \pm 1.15$ & 0,206 \\
\hline $\begin{array}{l}\text { D04 - A ciência e a tecnologia podem } \\
\text { resolver todos os problemas do ambiente }\end{array}$ & $2.06 \pm 1.00$ & $2.14 \pm 1.10$ & $2.08 \pm 1.07$ & $2.00 \pm 0.99$ & $2.12 \pm 1.09$ & 0,283 \\
\hline $\begin{array}{l}\text { D05 - Desejo ver resolvidos os } \\
\text { problemas do ambiente mesmo que isso } \\
\text { implique sacrificar produtos de consumo }\end{array}$ & $2.93 \pm 1.06$ & $3.09 \pm 1.02$ & $3.04 \pm 1.06$ & $2.79 \pm 1.06$ & $2.86 \pm 1.06$ & 0,001 \\
\hline $\begin{array}{l}\text { D06 - Eu pessoalmente posso influenciar } \\
\text { o que acontece no ambiente }\end{array}$ & $3.06 \pm 1.00$ & $3.02 \pm 1.03$ & $3.01 \pm 1.07$ & $2.90 \pm 1.06$ & $2.89 \pm 1.08$ & 0,106 \\
\hline $\begin{array}{l}\text { D07 - Ainda podemos encontrar soluções } \\
\text { para os problemas do ambiente }\end{array}$ & $3.43 \pm 0.89$ & $3.51 \pm 0.87$ & $3.51 \pm 0.86$ & $3.34 \pm 0.91$ & $3.36 \pm 0.86$ & 0,005 \\
\hline $\begin{array}{l}\text { D08 - As pessoas se preocupam demais } \\
\text { com os problemas do ambiente }\end{array}$ & $1.81 \pm 1.01$ & $1.87 \pm 1.07$ & $1.97 \pm 1.09$ & $1.86 \pm 1.02$ & $1.82 \pm 0.97$ & 0,149 \\
\hline $\begin{array}{l}\text { D09 - Os problemas do ambiente podem } \\
\text { ser resolvidos sem grandes mudanças no } \\
\text { nosso estilo da vida }\end{array}$ & $2.56 \pm 1.09$ & $2.55 \pm 1.17$ & $2.53 \pm 1.16$ & $2.41 \pm 1.10$ & $2.48 \pm 1.05$ & 0,282 \\
\hline $\begin{array}{l}\text { D10 - As pessoas deveriam interessar-se } \\
\text { mais pela proteção do ambiente }\end{array}$ & $3.54 \pm 0.84$ & $3.64 \pm 0.76$ & $3.65 \pm 0.73$ & $3.54 \pm 0.80$ & $3.51 \pm 0.77$ & 0,024 \\
\hline $\begin{array}{l}\text { D11 - É responsabilidade dos países } \\
\text { ricos resolverem os problemas do } \\
\text { ambiente no mundo }\end{array}$ & $2.26 \pm 1.14$ & $2.42 \pm 1.19$ & $2.33 \pm 1.15$ & $2.14 \pm 1.06$ & $2.23 \pm 1.18$ & 0,002 \\
\hline $\begin{array}{l}\text { D12 - Penso que cada um de nós pode } \\
\text { dar uma contribuição significativa para a } \\
\text { proteção do ambiente }\end{array}$ & $3.40 \pm 0.90$ & $3.57 \pm 0.83$ & $3.60 \pm 0.76$ & $3.35 \pm 0.91$ & $3.44 \pm 0.83$ & $\mathbf{0 , 0 0 1}$ \\
\hline $\begin{array}{l}\text { D13 - Os problemas do ambiente devem } \\
\text { ser deixados aos especialistas }\end{array}$ & $1.70 \pm 0.97$ & $1.66 \pm 0.97$ & $1.60 \pm 0.92$ & $1.61 \pm 0.90$ & $1.75 \pm 0.97$ & 0,154 \\
\hline D14 - Eu estou otimista quanto ao futuro & $2.77 \pm 0.98$ & $2.83 \pm 1.07$ & $2.77 \pm 1.08$ & $2.67 \pm 1.05$ & $2.76 \pm 1.02$ & 0,175 \\
\hline $\begin{array}{l}\text { D15 - Os animais devem ter o mesmo } \\
\text { direito à vida que as pessoas }\end{array}$ & $3.18 \pm 0.96$ & $3.39 \pm 0.95$ & $3.25 \pm 1.00$ & $3.16 \pm 1.04$ & $3.28 \pm 0.94$ & 0,002 \\
\hline $\begin{array}{l}\text { D16 - É correto usar animais para } \\
\text { experiências médicas se assim se pode } \\
\text { salvar vidas humanas }\end{array}$ & $2.28 \pm 1.12$ & $2.48 \pm 1.15$ & $2.46 \pm 1.13$ & $2.24 \pm 1.06$ & $2.3 \pm 1.12$ & $\mathbf{0 , 0 0 1}$ \\
\hline $\begin{array}{l}\text { D17 - Quase toda a atividade humana } \\
\text { prejudica o ambiente }\end{array}$ & $2.73 \pm 1.01$ & $2.78 \pm 1.10$ & $2.88 \pm 1.03$ & $2.65 \pm 0.99$ & $2.66 \pm 1.03$ & 0,003 \\
\hline $\begin{array}{l}\text { D18 - O mundo natural é sagrado e } \\
\text { devemos deixá-lo em paz }\end{array}$ & $3.14 \pm 0.98$ & $3.22 \pm 1.02$ & $3.16 \pm 0.99$ & $2.98 \pm 0.99$ & $3.04 \pm 1.02$ & 0,002 \\
\hline
\end{tabular}

A fim de localizar a diferença entre as regiões, foi necessário verificar a existência de diferenças significativas através de médias por pares (entre duas regiões) através do teste Tukey. Os resultados podem ser observados na tabela 6.3 . 
Tabela 6.3 - Diferenças existentes entre as regiões (teste Tukey) para a seção D.

\begin{tabular}{|c|c|c|c|}
\hline Questões Seção D & Teste & Diferença & P-valor \\
\hline $\begin{array}{l}\text { D05 - Desejo ver resolvidos os problemas do ambiente mesmo } \\
\text { que isso implique sacrificar produtos de consumo }\end{array}$ & Sudeste - Nordeste & $-0,31$ & $<0.001$ \\
\hline $\begin{array}{l}\text { D05 - Desejo ver resolvidos os problemas do ambiente mesmo } \\
\text { que isso implique sacrificar produtos de consumo }\end{array}$ & Sul - Nordeste & $-0,23$ & 0,025 \\
\hline $\begin{array}{l}\text { D05 - Desejo ver resolvidos os problemas do ambiente mesmo } \\
\text { que isso implique sacrificar produtos de consumo }\end{array}$ & Sudeste - Norte & $-0,26$ & 0,001 \\
\hline $\begin{array}{l}\text { D07 - Ainda podemos encontrar soluções para os problemas do } \\
\text { ambiente }\end{array}$ & Sudeste - Nordeste & $-0,17$ & 0,018 \\
\hline $\begin{array}{l}\text { D07 - Ainda podemos encontrar soluções para os problemas do } \\
\text { ambiente }\end{array}$ & Sudeste - Norte & $-0,17$ & 0,016 \\
\hline $\begin{array}{l}\text { D11 - É responsabilidade dos países ricos resolverem os } \\
\text { problemas do ambiente no mundo }\end{array}$ & Sudeste - Nordeste & $-0,28$ & 0,001 \\
\hline $\begin{array}{l}\text { D12 - Penso que cada um de nós pode dar uma contribuição } \\
\text { significativa para a proteção do ambiente }\end{array}$ & Nordeste - Centro-Oeste & 0,16 & 0,043 \\
\hline $\begin{array}{l}\text { D12 - Penso que cada um de nós pode dar uma contribuição } \\
\text { significativa para a proteção do ambiente }\end{array}$ & Norte - Centro-Oeste & 0,2 & 0,005 \\
\hline $\begin{array}{l}\text { D12 - Penso que cada um de nós pode dar uma contribuição } \\
\text { significativa para a proteção do ambiente }\end{array}$ & Sudeste - Nordeste & $-0,21$ & $<0.001$ \\
\hline $\begin{array}{l}\text { D12 - Penso que cada um de nós pode dar uma contribuição } \\
\text { significativa para a proteção do ambiente }\end{array}$ & Sudeste - Norte & $-0,25$ & $<0.001$ \\
\hline $\begin{array}{l}\text { D15 - Os animais devem ter o mesmo direito à vida que as } \\
\text { pessoas }\end{array}$ & Nordeste - Centro-Oeste & 0,21 & 0,015 \\
\hline $\begin{array}{l}\text { D15 - Os animais devem ter o mesmo direito à vida que as } \\
\text { pessoas }\end{array}$ & Sudeste - Nordeste & $-0,23$ & 0,002 \\
\hline $\begin{array}{l}\text { D16 - É correto usar animais para experiências médicas se assim } \\
\text { se pode salvar vidas humanas }\end{array}$ & Sudeste - Nordeste & $-0,24$ & 0,005 \\
\hline $\begin{array}{l}\text { D16 - É correto usar animais para experiências médicas se assim } \\
\text { se pode salvar vidas humanas }\end{array}$ & Sudeste - Norte & $-0,22$ & 0,015 \\
\hline D17 - Quase toda a atividade humana prejudica o ambiente & Sudeste - Norte & $-0,23$ & 0,003 \\
\hline D17 - Quase toda a atividade humana prejudica o ambiente & Sul - Norte & $-0,22$ & 0,033 \\
\hline D18 - O mundo natural é sagrado e devemos deixá-lo em paz & Sudeste - Nordeste & $-0,24$ & 0,001 \\
\hline D18 - O mundo natural é sagrado e devemos deixá-lo em paz & Sudeste - Norte & $-0,18$ & 0,029 \\
\hline
\end{tabular}

No que se refere a sacrificar bens de consumo, os jovens do Nordeste e Norte são mais dispostos que os do Sudeste, e os do Nordeste mais que os do Sul. Os jovens do Nordeste e Norte são também mais otimistas quanto ao futuro que os do Sudeste, uma vez que acreditam mais na existência de soluções para os problemas ambientais. Já os jovens do Sudeste concordaram menos com a afirmação de que é de responsabilidade dos países ricos os problemas ambientais que os do Norte. 
Sobre as visões envolvendo direito à vida e crenças religiosas, como por exemplo, se é correto usar animais em experimentos médicos, a maioria dos jovens brasileiros discorda, porém os jovens do Sudeste discordam mais desta afirmação que os do Norte e Nordeste. Por outro lado, os jovens nordestinos acreditam mais que os animais têm o mesmo direito à vida que as pessoas que os do Sudeste e Centro-Oeste. Já os jovens da região Norte acreditam que quase toda a atividade humana prejudica o ambiente mais que os jovens do Sudeste e Sul.

\subsection{TIPOS DE POSICIONAMENTO DOS JOVENS BRASILEIROS FACE AOS PROBLEMAS AMBIENTAIS}

Os resultados obtidos junto às médias gerais foram submetidos à Análise por Componentes Principais (PCA), o que permitiu a redução do conjunto de dados em 4 componentes principais, denominados aqui de fatores. Foram considerados apenas fatores cujo autovalor foi maior que 1 . Os fatores explicam $43,9 \%$ da variância total das questões originais.

Cada fator reflete um agrupamento de opiniões/atitudes dos alunos, o que não implica uma tipagem de alunos (JENKINS, 2006a). Assim, cada fator possui um atributo, vinculado às opiniões a ele relacionadas. Dentro do fator 1, as questões D10 e D12 são as que apresentam mais peso (maior valor), e apontam para a consciência da necessidade de atitudes positivas em relação ao meio ambiente. As demais questões estão relacionadas com prontidão para ações, com exceção das questões D15 e D18. Assumindo os atributos utilizados por Vázquez Alonso e Manassero Mas (2005) na análise da seção D do questionário ROSE aplicado nas Ilhas Baleares, Espanha, podemos denominar este fator como Eco-centrismo, uma vez que integra questões relacionadas a atitudes pró-ativas.

O segundo fator agrega questões com atitudes indiferentes ou passivas frente aos problemas ambientais, como por exemplo, as ameaças ao ambiente não são da minha conta, as pessoas se preocupam demais com os problemas do ambiente, os problemas do ambiente podem ser resolvidos sem grandes mudanças no nosso estilo de vida etc. Por esta razão, este fator pode ser denominado como Eco-apatia.

O terceiro fator é constituído por duas questões que possuem caráter negativo: os problemas do ambiente dão aspecto sombrio ao mundo (D2) e são exagerados (D3). Por esta razão, ele foi denominado como Eco-pessimista. 
O quarto fator também agrega duas questões, porém de caráter contrário ao anterior: a questão D14, onde o aluno afirma ser otimista quanto ao futuro e a questão D17, que afirma que quase toda a atividade humana prejudica o ambiente. Esta última possui valor negativo, o que indica que os estudantes expressaram uma atitude contrária ao fator, ou seja, discordaram dela. Assim, podemos denominar este fator como eco-otimista.

As questões pertencentes a cada fator podem ser observadas na tabela 6.4. Os valores de correlação existentes entre as questões originais e os fatores obtidos estão descritos na tabela 6.5. Nesta tabela estão presentes apenas os valores que foram considerados para compor cada fator, excluindo-os valores cruzados, ou aqueles cujo fator possuía autovalor menor que 1.

Tabela 6.4 - Fatores (e questões) obtidos a partir da Análise por Componentes Principais da seção D.

\begin{tabular}{|c|c|}
\hline Fatores & Questões \\
\hline \multirow[t]{7}{*}{$\begin{array}{l}\text { Fator } 1-\text { fator } \\
\text { principal }\end{array}$} & $\begin{array}{l}\text { D05 - Desejo ver resolvidos os problemas do ambiente mesmo que isso } \\
\text { implique sacrificar produtos de consumo }\end{array}$ \\
\hline & D06 - Eu pessoalmente posso influenciar o que acontece no ambiente \\
\hline & D07 - Ainda podemos encontrar soluções para os problemas do ambiente \\
\hline & D10 - As pessoas deveriam interessar-se mais pela proteção do ambiente \\
\hline & $\begin{array}{l}\text { D12 - Penso que cada um de nós pode dar uma contribuição significativa } \\
\text { para a proteção do ambiente }\end{array}$ \\
\hline & D15 - Os animais devem ter o mesmo direito à vida que as pessoas \\
\hline & D18 - O mundo natural é sagrado e devemos deixá-lo em paz \\
\hline \multirow[t]{6}{*}{ Fator 2} & D01 - As ameaças ao ambiente não são da minha conta \\
\hline & $\begin{array}{l}\text { D04 - A ciência e a tecnologia podem resolver todos os problemas do } \\
\text { ambiente }\end{array}$ \\
\hline & D08 - As pessoas se preocupam demais com os problemas do ambiente \\
\hline & $\begin{array}{l}\text { D09 - Os problemas do ambiente podem ser resolvidos sem grandes } \\
\text { mudanças no nosso estilo da vida }\end{array}$ \\
\hline & $\begin{array}{l}\text { D11 - É responsabilidade dos países ricos resolverem os problemas do } \\
\text { ambiente no mundo }\end{array}$ \\
\hline & D13 - Os problemas do ambiente devem ser deixados aos especialistas \\
\hline \multirow[t]{2}{*}{ Fator 3} & $\begin{array}{l}\text { D02 - Os problemas do ambiente dão um aspecto sombrio e sem esperança } \\
\text { ao futuro do mundo }\end{array}$ \\
\hline & D03 - Os problemas do ambiente são exagerados \\
\hline \multirow[t]{2}{*}{ Fator 4} & D14 - Eu estou otimista quanto ao futuro \\
\hline & D17 - Quase toda a atividade humana prejudica o ambiente \\
\hline
\end{tabular}


Tabela 6.5 - Os valores de correlação existentes entre as questões originais e os fatores obtidos.

\begin{tabular}{|c|c|c|c|c|}
\hline Questões/Fator & Eco-centrismo & Eco-apatia & Eco-pessimista & Eco-otimista \\
\hline D01 & & 0,523299 & & \\
\hline D02 & & & 0,691196 & \\
\hline D03 & & & 0,474897 & \\
\hline D04 & & 0,553422 & & \\
\hline D05 & 0,556664 & & & \\
\hline D06 & 0,528933 & & & \\
\hline D07 & 0,684599 & & & \\
\hline D08 & & 0,59076 & & \\
\hline D09 & & 0,463496 & & \\
\hline D10 & 0,749373 & & & \\
\hline D11 & & 0,5449 & & \\
\hline D12 & 0,741080 & & & \\
\hline D13 & & 0,627536 & & \\
\hline D14 & & & & 0,420714 \\
\hline D15 & 0,564995 & & & \\
\hline D16 & & $0,359372 *$ & & \\
\hline D17 & & & & $-0,47266$ \\
\hline D18 & 0,450825 & & & \\
\hline $\begin{array}{l}\text { Variância } \\
\text { acumulada (\%) }\end{array}$ & 18,044 & 32,12 & 38,17 & 43,92 \\
\hline
\end{tabular}

*Valor desconsiderado no fator, por ter valor menor que 0,4 .

Assim, observamos que as atitudes dos jovens brasileiros em relação aos problemas podem ser agrupadas em 4 grupos (fatores): o maior grupo, que responde à 18,04\% da variância das questões originais, é chamado de Eco-centrismo, e reúne opiniões pró-ativas relacionadas ao meio ambiente; o segundo grupo, Eco-apatia, reúne atitudes apáticas em relação ao ambiente, responde à 14,4\% da variância; o terceiro, denominado Eco-pessimista, agrupa duas questões que expressam atitudes negativas em relação ao ambiente, e respondem à 5,9\% da variância; por fim, o quarto grupo, chamado de Eco-otimista, reúne atitudes otimistas em relação ao futuro e às atividades humanas, e responde individualmente à 5,7\% da variância entre as questões.

As médias atribuídas pelos jovens de modo geral, e pelos meninos e meninas, nas questões pertencentes a cada fator, podem ser observadas na tabela 6.6. 
Tabela 6.6 - Média geral, por meninos e meninas, obtidas em cada fator.

\begin{tabular}{|c|c|c|c|c|c|c|c|}
\hline \multirow[b]{2}{*}{ Fatores } & \multicolumn{2}{|c|}{ Geral } & \multicolumn{2}{|c|}{ Homem } & \multicolumn{2}{|c|}{ Mulher } & \multirow[b]{2}{*}{ p-valor } \\
\hline & Média & $\begin{array}{l}\text { Desvio } \\
\text { padrão }\end{array}$ & Média & $\begin{array}{l}\text { Desvio } \\
\text { padrão }\end{array}$ & Média & $\begin{array}{l}\text { Desvio } \\
\text { padrão }\end{array}$ & \\
\hline Eco-centrismo & 3,27 & 0,59 & 3,16 & 0,64 & 3,34 & 0,54 & $<0,001$ \\
\hline Eco-apatia & 2,02 & 0,64 & 2,16 & 0,65 & 1,92 & 0,62 & $<0,001$ \\
\hline Eco-pessimista & 2,59 & 0,88 & 2,63 & 0,86 & 2,56 & 0,89 & 0,055 \\
\hline Eco-otimista & 2,77 & 0,77 & 2,75 & 0,78 & 2,78 & 0,77 & 0,522 \\
\hline
\end{tabular}

A tabela 6.6 mostra que as atitudes positivas dos jovens concentram-se nos grupos ecocentrismo e eco-otimista, que foram os fatores nos quais se atribuíram maiores pontuações, tanto no geral como em relação aos meninos e meninas, com mais destaque para as meninas. Os grupos eco-pessimistas e eco-apáticos foram os que obtiveram maior pontuação entre os meninos, com destaque para o grupo eco-apáticos, que possui $\mathrm{p}$-valor $>0,05$, indicando haver diferença estatística significativa entre meninos e meninas. 


\subsection{A POSIÇÃO DOS JOVENS BRASILEIROS EM RELAÇÃO AO MEIO AMBIENTE NO CENÁRIO INTERNACIONAL}

Algumas questões da seção D foram selecionadas para comparações entre o Brasil e os demais países participantes. A questão D01 "As ameaças do ambiente não são da minha conta" iniciam as comparações através da figura 6.4.

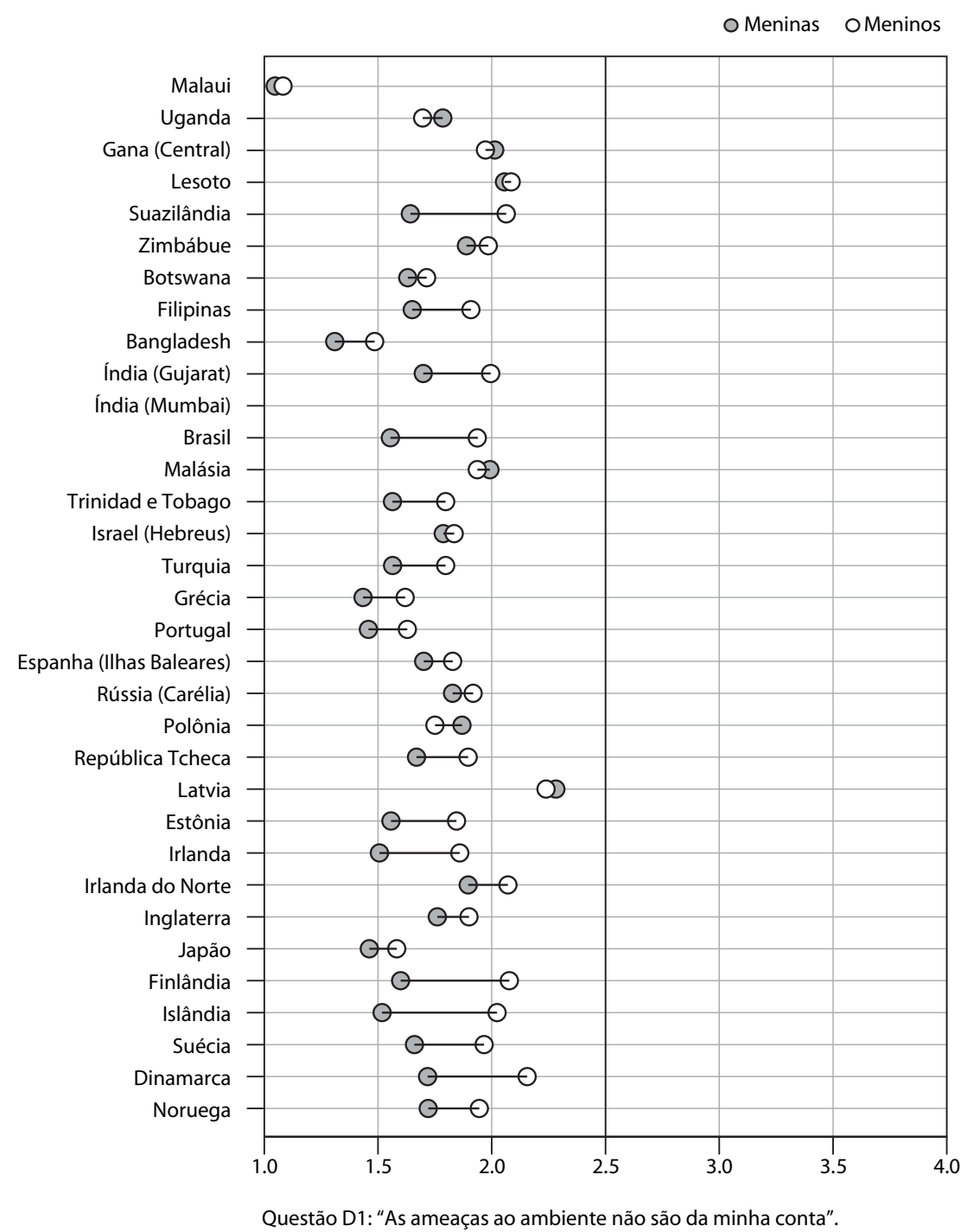

Figura 6.4 - Distribuição das respostas médias de meninos e meninas na questão D1, adaptado de Matthews (2007). 
Podemos observar uma grande diferença existente entre meninos e meninos para esta questão na maioria dos países. O Brasil possui um padrão de respostas semelhante aos jovens de Trinidad e Tobago, Turquia, Estônia e Irlanda.

A figura 6.5 mostra as respostas dos alunos em relação à questão D04 "A ciência e a tecnologia podem resolver todos os problemas do ambiente". O Brasil apresenta resultados semelhantes aos países de maior IDH, que estão situados na parte inferior do gráfico e pontuaram abaixo da média de 2,5. Interessante notar que exceto em Malawi e Uganda, os meninos respondem mais positivamente a esta questão que as meninas, indicando uma atitude mais ingênua.

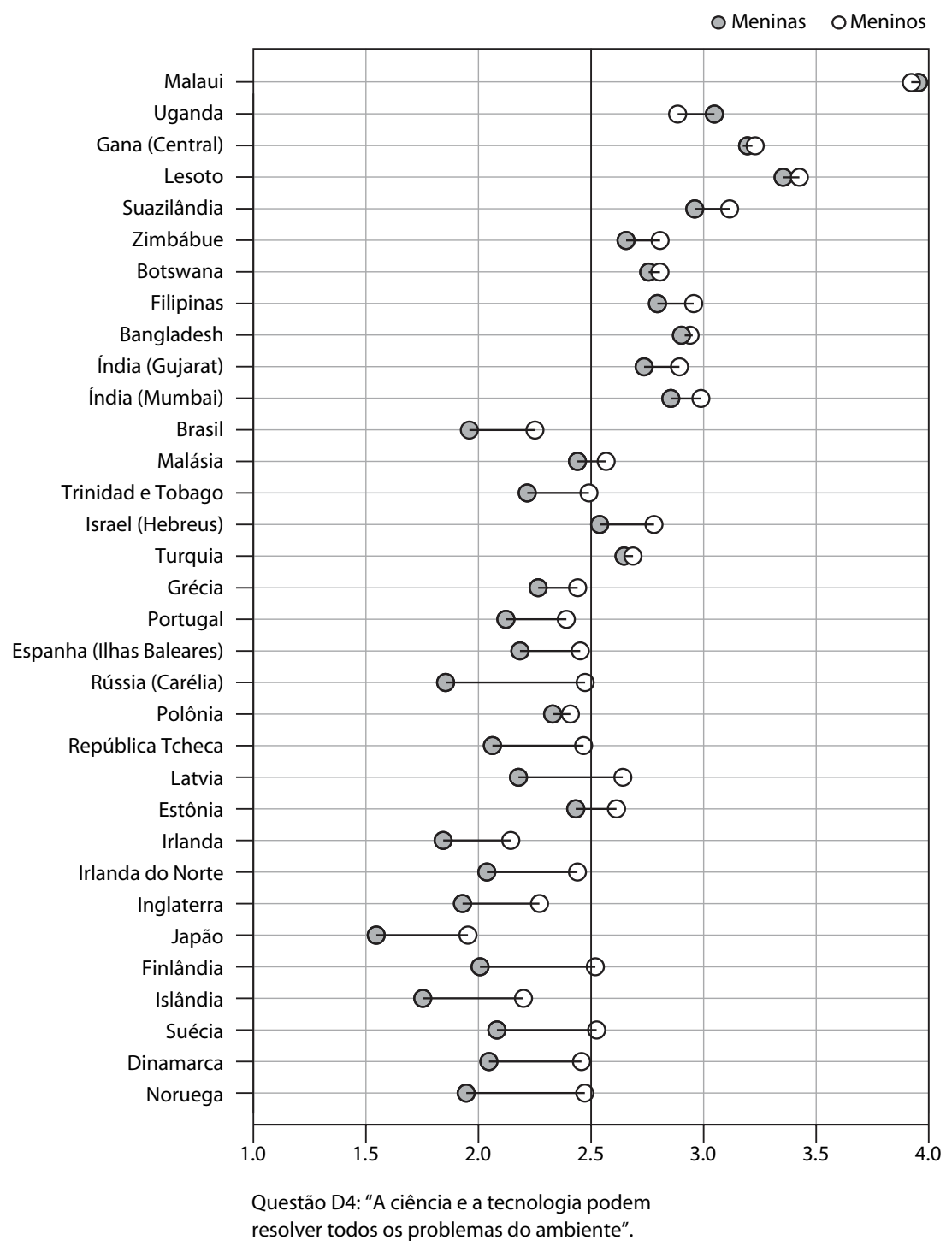

Figura 6.5 - Distribuição das respostas médias de meninos e meninas na questão D4, adaptado de Matthews (2007). 
A última questão comparada é a D14 "Eu estou otimista quanto ao futuro". A figura 6.6 mostra que o Brasil apresenta atitudes semelhantes à Suécia, Estônia e Latvia.

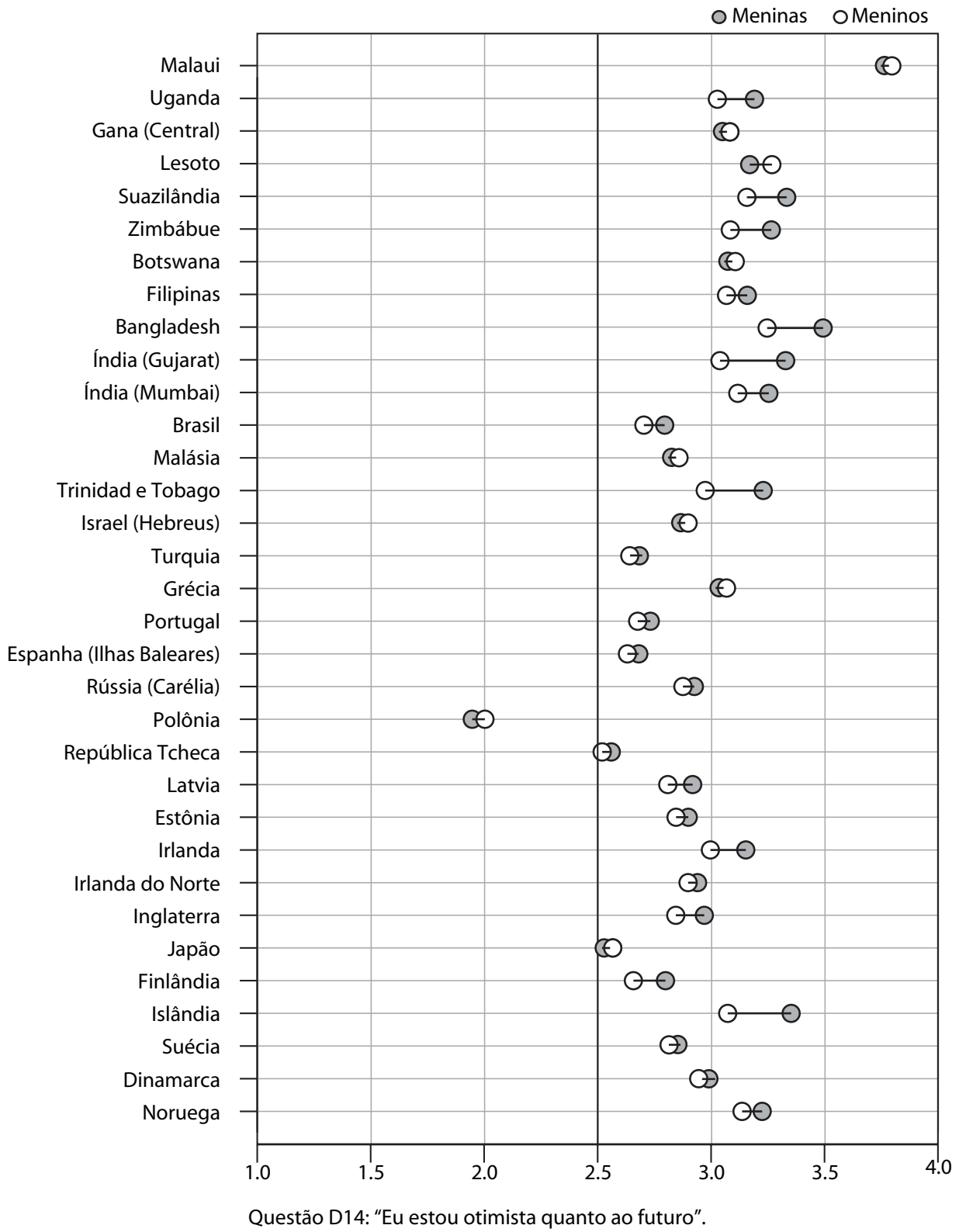

Figura 6.6 - Distribuição das respostas médias de meninos e meninas na questão D14, adaptado de Matthews (2007). 


\section{O QUE OS JOVENS BRASILEIROS PENSAM DAS SUAS AULAS DE CIÊNCIAS?}

Neste capítulo serão apresentados e discutidos os resultados obtidos junto à seção F "As minhas aulas de ciências", que questionavam ao aluno: "Até que ponto você concorda com as seguintes afirmações sobre a ciência que já aprendeu na escola?", seguido de 16 itens. Conforme declaram Schreiner e Sjøberg (2004, p. 66), a seção F tem como objetivo “conhecer diferentes aspectos da percepção dos estudantes sobre suas aulas de ciências, tais como motivação, habilidades em relação à ciência escolar, a necessidade da educação científica etc."

Sjøberg (2004, p. 7) comenta que tanto meninas quanto meninos não se interessam pela ciência escolar. Ele aponta que ao mesmo tempo em que os jovens demonstram interesse pela ciência real, a ciência escolar é considerada difícil e chata, sobrecarregada por "respostas certas", sem espaço para a criatividade.

Osborne, Simon e Collins (2003) consideram que o papel da educação científica formal é fomentar atitudes positivas para com a ciência, o que gera uma apreciação geral das pessoas pela ciência. Tais atitudes, uma vez formadas, são duradouras e difíceis de mudar, por isso, a necessidade de conhecer quais são as atitudes dos alunos brasileiros para com a ciência na escola se torna necessária.

Vázquez Alonso e Manassero Mas (2008, p. 275) destacam o fato que de o interesse dos jovens pela ciência escolar começa a diminuir na pré-adolescência, por volta dos 12 anos, na passagem do ensino primário para o secundário; o interesse e curiosidade natural da criança passam a se transformar "em desinteresse, aborrecimento e experiências de fracasso escolar", o que tem levado ao abandono das carreiras científicas.

De fato, diversas pesquisas têm relacionado o baixo interesse dos jovens em seguir as carreiras científicas diretamente às suas aulas de ciências (AIKENHEAD, 2005; KARDASH; WALLACE, 2001; BERNARDO et al., 2008; BROK et al., 2006; DARBY, 2005; SMITH; EZEIFE, 2006; VÁZQUEZ ALONSO; MANASSERO MAS, 2008). Fensham (2004b, p. 2) aponta para três pontos que fazem com que a ciência escolar seja desinteressante para os alunos: "1) transmissão de conhecimentos de respostas certas; 2) conteúdo irrelevante e chato e 3) dificuldade, em comparação à outras disciplinas".

Osborne et al. (2003) apontaram também para a falta de desafio intelectual como um dos 
fatores que levam ao desinteresse dos alunos pela ciência escolar. Poucas aulas experimentais, trabalho pedagógico repetitivo e conteúdo curricular inapropriado também foram apontados por Murphy e Beggs (2003) como motivos para a falta de interesse dos alunos pelas aulas de ciências na educação primária.

Barman et al. (1997), em uma pesquisa realizada com alunos do $5^{\circ}$ ano primário, apontam que a maioria dos alunos não vê conexão entre o que aprendem na escola e sua vida diária. Para eles, a ciência escolar precisa apresentar exemplos concretos que demonstrem sua ligação com o que os alunos fazem fora da escola, tais como a observação, a medição etc. Ao final, apenas $9 \%$ dos alunos pesquisados foram capazes de conectar as habilidades e conhecimentos adquiridos da ciência e as atividades cotidianas, citando como exemplos a solução de problemas, a observação, a identificação de animais e plantas, a previsão do tempo etc.

É de se notar, entretanto, que em uma pesquisa realizada com jovens ingleses de 16 anos, Osborne e Collins (2001) verificaram que os jovens consideram o conhecimento científico como importante componente da educação. As razões apontadas foram a possibilidade de através da ciência se conhecer o mundo, conhecer seu próprio corpo, consertar coisas, além da utilidade da ciência para as pessoas e para a sociedade em geral.

Bevins et al. (2005) também verificaram, em uma pesquisa realizada com jovens ingleses de 12-14 anos, que há interesse dos alunos na ciência, mas há também uma aparente falta de entusiasmo para com a ciência escolar, uma vez que esta presta pouca ou nenhuma atenção a questões científicas relacionadas com a vida diária dos alunos, além de ser pouco atrativa pedagogicamente, já que está centrada em aulas teóricas, sendo as aulas práticas as que de fato despertam o interesse dos alunos.

Em uma pesquisa realizada na Espanha com estudantes de diversas faixas etárias, Vázquez Alonso e Manassero Mas (2008) verificaram que o declínio nas atitudes dos alunos se restringe à ciência escolar, não sendo verificada em relação à imagem da ciência em si ou ao meio ambiente.

Danaia et al. (2012) relatam, em pesquisa realizada com estudantes de ensino médio australianos em 2001, 2005 e 2011, que os jovens raramente consideram a ciência escolar relevante para seu futuro ou para a vida cotidiana. Parece que para a maioria dos estudantes nas três amostras, a ciência escolar raramente lida com as coisas que os estudantes estão preocupados ou os ajudam a tomar decisões sobre sua saúde.

Em 2005, o relatório do Eurobarômetro apontou que apenas 15\% dos europeus estão sa- 
tisfeitos com a qualidade das aulas de ciências na escola. A mesma pesquisa realizada em 2001 verificou que o motivo pelo baixo interesse dos jovens em seguir as carreiras científicas reside no fato das aulas de ciências na escola não serem suficientemente atraentes (EUROPEAN COMMISSION, 2007).

Observa-se uma aparente contradição entre as atitudes dos jovens para com a ciência de modo geral e para com a ciência escolar. Algumas pesquisas apontam para o fato de que os jovens possuem atitudes positivas para com a ciência, considerando-a interessante e útil para o futuro emprego, em contrapartida a ciência escolar é vista como difícil, teórica e chata (OSBORNE; SIMON; COLLINS, 2003).

Verificamos assim que há uma lacuna entre a percepção do jovem em relação à ciência e a ciência escolar. Através da análise da seção F do questionário ROSE verificaremos se tal situação também é observada entre os jovens brasileiros. Para tanto, procuramos apresentar os dados da seguinte forma: 1) através das médias de meninos e meninas para todas as questões presentes na seção F; 2) através das médias distribuídas nas regiões brasileiras da seção F; 3) através do interesse do jovem brasileiro pela carreira científica; 4) tipos de posicionamento assumidos pelos jovens brasileiros em relação à ciência escolar; e 5) a posição dos jovens brasileiros no cenário internacional.

Para a verificação de diferenças entre gênero foram utilizados testes de Mann-Whitney. Diferenças com valores de $\mathrm{p}<0,05$ foram consideradas significativas. Para verificação de diferenças entre regiões brasileiras foram utilizados os testes ANOVA e Tukey, conforme discriminado no capítulo 3.

\subsection{O QUE PENSAM OS JOVENS BRASILEIROS SOBRE SUAS AULAS DE CIÊNCIAS: UM PANORAMA GERAL}

A ciência escolar é um importante meio de fomentar o interesse dos jovens pelos temas científicos e pela carreira científica. Conhecer o que os jovens brasileiros pensam da ciência na escola poderá elucidar importantes questões relacionadas com seu interesse pela disciplina, sua utilidade e sua relação com as opções futuras de carreira. As médias obtidas na totalidade das 16 questões da seção F "As minhas aulas de ciências" podem ser observadas na tabela 7.1. Os valores destacados em negrito referem-se a diferenças estatisticamente significativas entre meninos e meninas. 
Tabela 7.1 - Médias e testes de Mann-Whitney para diferença em relação ao gênero dos estudantes para o grupo de questões F.

\begin{tabular}{|c|c|c|c|c|c|c|}
\hline \multirow{2}{*}{ Questões: "As minhas aulas de ciências" } & \multirow{2}{*}{$\begin{array}{l}\text { Média } \\
\text { Geral }\end{array}$} & \multicolumn{2}{|c|}{ Média } & \multirow{2}{*}{$\begin{array}{l}\text { Diferença } \\
\text { (H-M) }\end{array}$} & \multirow{2}{*}{ IC 95 (Dif) } & \multirow{2}{*}{ P-valor } \\
\hline & & Homem & Mulher & & & \\
\hline $\begin{array}{l}\text { F01 - A disciplina Ciências aborda conteúdos } \\
\text { difíceis }\end{array}$ & 2,38 & 2,41 & 2,35 & 0,06 & {$[-0.03 ; 0.16]$} & 0,213 \\
\hline F02 - A disciplina Ciências é interessante & 3,17 & 3,06 & 3,26 & $-0,20$ & {$[-0.28 ;-0.12]$} & $\mathbf{0 , 0 1}$ \\
\hline $\begin{array}{l}\text { F03 - As Ciências, para mim, são bastante } \\
\text { fáceis de aprender }\end{array}$ & 2,42 & 2,46 & 2,39 & 0,07 & {$[-0.02 ; 0.15]$} & 0,11 \\
\hline $\begin{array}{l}\text { F04 - As Ciências abriram-me os olhos para } \\
\text { empregos novos e emocionantes }\end{array}$ & 2,36 & 2,39 & 2,34 & 0,05 & {$[-0.04 ; 0.14]$} & 0,194 \\
\hline $\begin{array}{l}\text { F05 - Gosto mais de Ciências do que das } \\
\text { outras disciplinas }\end{array}$ & 2,10 & 2,08 & 2,12 & $-0,04$ & {$[-0.13 ; 0.05]$} & 0,688 \\
\hline $\begin{array}{l}\text { F06 - Penso que todos deverão aprender } \\
\text { Ciências }\end{array}$ & 2,68 & 2,56 & 2,78 & $-0,22$ & {$[-0.31 ;-0.13]$} & $\mathbf{0 , 0 1}$ \\
\hline $\begin{array}{l}\text { F07 - Os conhecimentos que adquiro em } \\
\text { Ciências serão úteis na minha vida cotidiana }\end{array}$ & 3,00 & 2,83 & 3,13 & $-0,30$ & {$[-0.38 ;-0.21]$} & $\mathbf{0 , 0 1}$ \\
\hline $\begin{array}{l}\text { F08 - Penso que a ciência que eu aprendo na } \\
\text { escola melhorará as minhas oportunidades de } \\
\text { carreira }\end{array}$ & 2,75 & 2,68 & 2,81 & $-0,13$ & {$[-0.21 ;-0.04]$} & 0,004 \\
\hline $\begin{array}{l}\text { F09- As Ciências tornaram-me mais crítico e } \\
\text { cético }\end{array}$ & 2,31 & 2,35 & 2,27 & 0,08 & {$[-0.01 ; 0.17]$} & 0,071 \\
\hline $\begin{array}{l}\text { F10 - As Ciências estimularam a minha } \\
\text { curiosidade acerca das coisas que ainda não } \\
\text { conseguimos explicar }\end{array}$ & 2,85 & 2,74 & 2,93 & $-0,19$ & {$[-0.28 ;-0.10]$} & $\mathbf{0 , 0 1}$ \\
\hline $\begin{array}{l}\text { F11 - As Ciências aumentaram o meu gosto } \\
\text { pela natureza }\end{array}$ & 2,76 & 2,69 & 2,82 & $-0,13$ & {$[-0.22 ;-0.04]$} & $\mathbf{0 , 0 0 7}$ \\
\hline $\begin{array}{l}\text { F12 - As Ciências mostraram-me a } \\
\text { importância da ciência para a forma como } \\
\text { vivemos }\end{array}$ & 2,80 & 2,69 & 2,87 & $-0,18$ & {$[-0.27 ;-0.10]$} & $\mathbf{0 , 0 1}$ \\
\hline $\begin{array}{l}\text { F13 - A ciência que aprendo na escola ensina- } \\
\text { me a cuidar melhor da minha saúde }\end{array}$ & 2,91 & 2,81 & 2,98 & $-0,17$ & {$[-0.25 ;-0.08]$} & $\mathbf{0 , 0 1}$ \\
\hline F14 - Gostaria de ser cientista & 1,98 & 2,10 & 1,89 & 0,21 & {$[0.11 ; 0.30]$} & 0,01 \\
\hline $\begin{array}{l}\text { F15 - Gostaria de aprender tanta ciência } \\
\text { quanto possível na escola }\end{array}$ & 2,43 & 2,43 & 2,42 & 0,01 & {$[-0.09 ; 0.10]$} & 0,895 \\
\hline $\begin{array}{l}\text { F16 - Gostaria de ter um emprego que lide } \\
\text { com tecnologia avançada }\end{array}$ & 2,71 & 2,89 & 2,58 & 0,31 & {$[0.22 ; 0.40]$} & 0,01 \\
\hline
\end{tabular}

Vázquez Alonso e Manassero Mas (2008) utilizaram como primeiro parâmetro de análise da seção F a média global dos alunos (média para todas as questões). A média global dos brasileiros foi de 2,60 , superior à média da escala $(2,5)$ e superior ao valor atribuído aos jovens 
espanhóis $(2,44)$, o que indica uma atitude geral favorável em relação às aulas de ciências.

Os jovens brasileiros consideram a disciplina ciências interessante e não concordam que ela aborda conteúdos difíceis. Por outro lado, eles não a consideram fácil de aprender. Assim, os resultados das três primeiras questões vão de encontro aos dados obtidos na análise geral do ROSE, que apontam para o pouco interesse dos jovens pela ciência escolar, e pelo fato deles a considerarem uma disciplina difícil (SJØBERG, 2004). Por outro lado, os coordenadores do ROSE verificaram que os jovens dos países desenvolvidos apresentam pouco interesse pela ciência escolar quando comparados com os jovens dos países em desenvolvimento (SCHREINER; SJØBERG, 2007), corroborando assim os dados brasileiros.

As demais questões foram analisadas conforme as categorias expressas no quadro 3.5. O critério utilizado para o agrupamento foi reunir questões com a mesma orientação. Algumas destas questões foram agrupadas da mesma forma por outros pesquisadores, tais como Ogawa e Shimode (2004) no Japão e Jenkins e Nelson (2005) na Inglaterra. As médias obtidas nestas categorias podem ser observadas na tabela 7.2.

Tabela 7.2 - Médias de meninas, meninos e geral para categorias da seção F.

\begin{tabular}{|c|c|c|c|c|c|c|}
\hline \multirow{2}{*}{ Categorias (seção F) } & \multirow{2}{*}{$\begin{array}{l}\text { Média } \\
\text { Geral }\end{array}$} & \multicolumn{2}{|c|}{ Média } & \multirow{2}{*}{$\begin{array}{l}\text { Diferença } \\
\text { (H-M) }\end{array}$} & \multirow{2}{*}{$\begin{array}{c}\text { IC } 95 \% \\
\text { (Diferença) }\end{array}$} & \multirow{2}{*}{$\begin{array}{c}\text { P- } \\
\text { valor }\end{array}$} \\
\hline & & Homem & Mulher & & & \\
\hline $\begin{array}{l}\text { Relação entre a disciplina e a futura } \\
\text { carreira }\end{array}$ & 2,45 & 2,52 & 2,40 & 0,12 & {$[0.05 ; 0.180]$} & 0,001 \\
\hline Interesse pessoal pela disciplina & 2,59 & 2,53 & 2,64 & $-0,11$ & {$[-0.18 ;-0.04]$} & 0,003 \\
\hline $\begin{array}{l}\text { Vantagens diretas da aprendizagem da } \\
\text { disciplina }\end{array}$ & 2,77 & 2,68 & 2,84 & $-0,16$ & {$[-0.22 ;-0.09]$} & 0,000 \\
\hline
\end{tabular}

O agrupamento das questões revelou que os meninos veem mais relações entre a ciência e a futura carreira que as meninas. Já as meninas possuem mais interesse pela ciência e vêm mais vantagens diretas do aprendizado da disciplina que os meninos.

O interesse em aprender sobre ciência também foi abordado pelo PISA em 2006. Quando comparadas as médias entre PISA e ROSE (ambos possuem escala de Likert com 4 pontos) observamos que os dois instrumentos permitiram verificar que os alunos brasileiros possuem interesse pela ciência escolar. As médias atribuídas pelos alunos foram elevadas: 3,25 no PISA e 3,17 no ROSE, uma diferença de apenas 2,5\% a mais do PISA (ver tabela 7.3). 


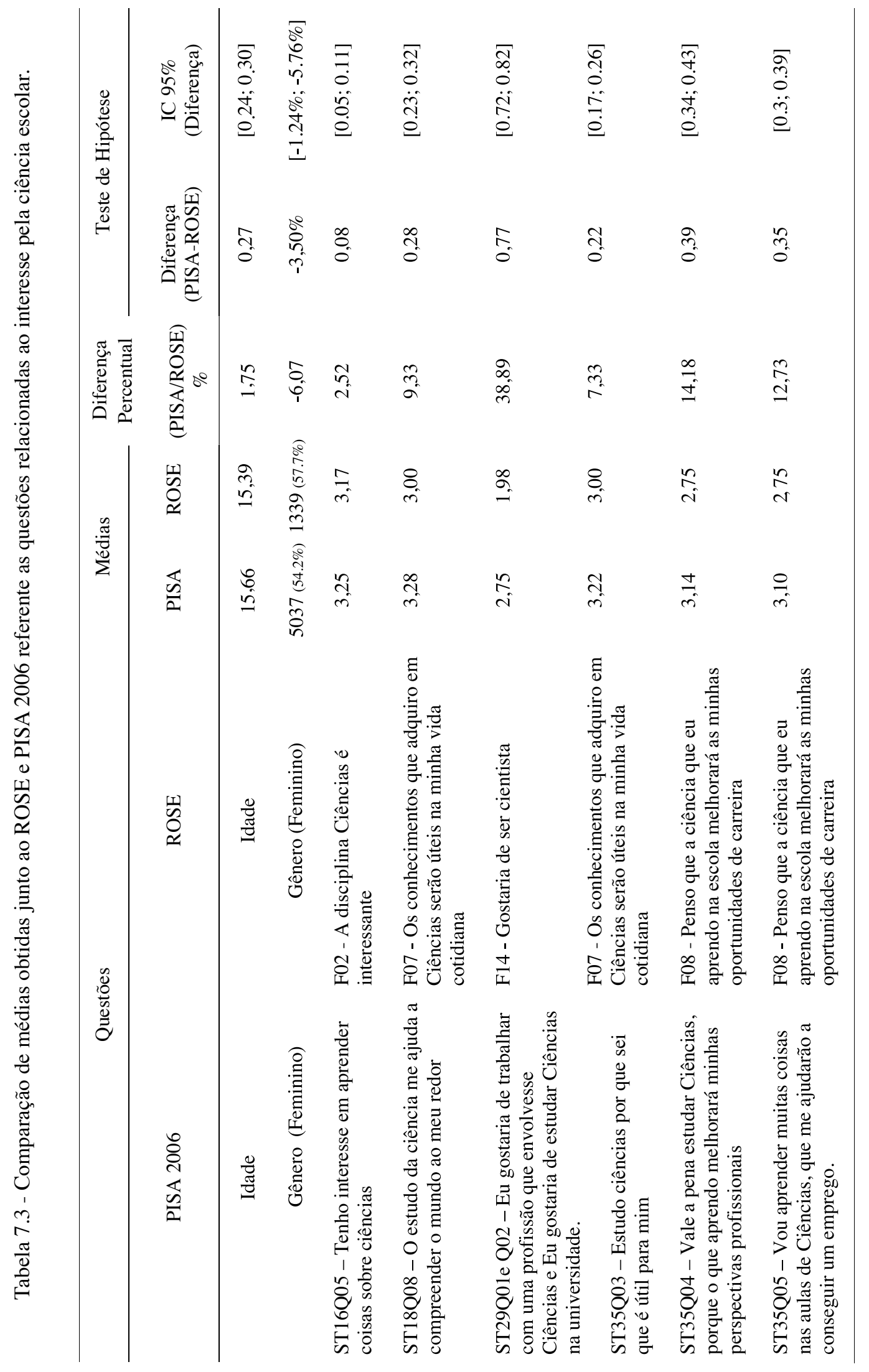


Para as demais questões comparadas na tabela 7.3, observamos que, no geral, os alunos respondentes do PISA atribuíram notas maiores para todas as questões, sendo as diferenças estatisticamente significativas. Levando-se em conta diferenças referentes ao ano de aplicação e a idade (sendo que há no PISA uma grande defasagem série/idade e no ROSE participam apenas alunos no $1^{\mathrm{o}}$ ano), observamos uma mesma tendência em relação ao interesse pela ciência nos dois instrumentos. As diferenças mais sensíveis são aquelas relacionadas a seguir uma carreira científica: enquanto que os alunos participantes do ROSE não tem interesse (média menor que 2,5) os alunos participantes do PISA apresentaram médias maiores que 2,5.

A seção F permitiu-nos verificar que, ao contrário da tendência observada na maioria dos países desenvolvidos, os jovens brasileiros possuem interesse pela ciência escolar, apesar de não terem preferência pela ciência em relação à outras disciplinas. Há uma atitude positiva geral em relação à disciplina, tanto no que se refere à importância da disciplina como à sua utilidade. 


\subsection{OS JOVENS BRASILEIROS E SUAS AULAS DE CIÊNCIAS: UM PANORAMA POR REGIÃO}

A média de cada questão da seção F obtida nas regiões brasileiras pode ser observada na tabela 7.4. Os valores em negrito são os que apresentam diferenças significativas estatisticamente.

Tabela 7.4 - Médias por região da seção “As minhas aulas de ciências”.

\begin{tabular}{|c|c|c|c|c|c|c|}
\hline $\begin{array}{l}\text { Questões: "As minhas aulas de } \\
\text { ciências" }\end{array}$ & $\begin{array}{l}\text { Centro- } \\
\text { Oeste }\end{array}$ & Nordeste & Norte & Sudeste & Sul & $\begin{array}{c}\text { P- } \\
\text { valor }\end{array}$ \\
\hline $\begin{array}{l}\text { F01 - A disciplina Ciências aborda } \\
\text { conteúdos difíceis }\end{array}$ & $2.36 \pm 1.14$ & $2.39 \pm 1.18$ & $2.34 \pm 1.12$ & $2.38 \pm 1.06$ & $2.46 \pm 1.09$ & 0,683 \\
\hline $\begin{array}{l}\text { F02 - A disciplina Ciências é } \\
\text { interessante }\end{array}$ & $3.02 \pm 1.01$ & $3.35 \pm 0.90$ & $3.31 \pm 0.90$ & $2.99 \pm 0.99$ & $2.94 \pm 1.05$ & $\mathbf{0 , 0 0 1}$ \\
\hline $\begin{array}{l}\text { F03 - As Ciências, para mim, são } \\
\text { bastante fáceis de aprender }\end{array}$ & $2.49 \pm 1.01$ & $2.44 \pm 1.04$ & $2.53 \pm 1.04$ & $2.27 \pm 0.97$ & $2.27 \pm 1.00$ & $\mathbf{0 , 0 0 1}$ \\
\hline $\begin{array}{l}\text { F04 - As Ciências abriram-me os } \\
\text { olhos para empregos novos e } \\
\text { emocionantes }\end{array}$ & $2.30 \pm 1.08$ & $2.46 \pm 1.1$ & $2.48 \pm 1.07$ & $2.20 \pm 1.01$ & $2.18 \pm 1.03$ & $\mathbf{0 , 0 0 1}$ \\
\hline $\begin{array}{l}\text { F05 - Gosto mais de Ciências do } \\
\text { que das outras disciplinas }\end{array}$ & $2.10 \pm 1.07$ & $2.12 \pm 1.09$ & $2.20 \pm 1.13$ & $1.98 \pm 1.09$ & $2.03 \pm 1.1$ & $\mathbf{0 , 0 1 8}$ \\
\hline $\begin{array}{l}\text { F06 - Penso que todos deverão } \\
\text { aprender Ciências }\end{array}$ & $2.64 \pm 1.08$ & $2.85 \pm 1.11$ & $2.81 \pm 1.09$ & $2.42 \pm 1.08$ & $2.51 \pm 1.08$ & $\mathbf{0 , 0 0 1}$ \\
\hline $\begin{array}{l}\text { F07 - Os conhecimentos que } \\
\text { adquiro em Ciências serão úteis na } \\
\text { minha vida cotidiana }\end{array}$ & $2.92 \pm 0.96$ & $3.16 \pm 0.99$ & $3.17 \pm 0.96$ & $2.77 \pm 1.02$ & $2.74 \pm 1.05$ & $\mathbf{0 , 0 0 1}$ \\
\hline $\begin{array}{l}\text { F08 - Penso que a ciência que eu } \\
\text { aprendo na escola melhorará as } \\
\text { minhas oportunidades de carreira }\end{array}$ & $2.68 \pm 1.03$ & $2.91 \pm 1.02$ & $2.89 \pm 0.99$ & $2.48 \pm 1.03$ & $2.61 \pm 0.99$ & $\mathbf{0 , 0 0 1}$ \\
\hline $\begin{array}{l}\text { F09 - As Ciências tornaram-me } \\
\text { mais crítico e cético }\end{array}$ & $2.27 \pm 1.01$ & $2.36 \pm 1.04$ & $2.43 \pm 1.04$ & $2.17 \pm 1.00$ & $2.17 \pm 0.96$ & $\mathbf{0 , 0 0 1}$ \\
\hline $\begin{array}{l}\text { F10 - As Ciências estimularam a } \\
\text { minha curiosidade acerca das } \\
\text { coisas que ainda não conseguimos } \\
\text { explicar }\end{array}$ & $2.82 \pm 1.06$ & $2.98 \pm 1.05$ & $2.93 \pm 1.07$ & $2.67 \pm 1.05$ & $2.71 \pm 1.05$ & $\mathbf{0 , 0 0 1}$ \\
\hline $\begin{array}{l}\text { F11 - As Ciências aumentaram o } \\
\text { meu gosto pela natureza }\end{array}$ & $2.70 \pm 1.06$ & $2.90 \pm 1.04$ & $2.97 \pm 1.01$ & $2.47 \pm 1.04$ & $2.50 \pm 1.09$ & $\mathbf{0 , 0 0 1}$ \\
\hline $\begin{array}{l}\text { F12 - As Ciências mostraram-me a } \\
\text { importância da ciência para a } \\
\text { forma como vivemos }\end{array}$ & $2.74 \pm 0.99$ & $2.92 \pm 1.00$ & $2.98 \pm 0.97$ & $2.59 \pm 0.95$ & $2.50 \pm 1.00$ & $\mathbf{0 , 0 0 1}$ \\
\hline $\begin{array}{l}\text { F13 - A ciência que aprendo na } \\
\text { escola ensina-me a cuidar melhor } \\
\text { da minha saúde }\end{array}$ & $2.80 \pm 1.08$ & $3.05 \pm 1.02$ & $3.08 \pm 0.98$ & $2.67 \pm 1.01$ & $2.74 \pm 1.03$ & $\mathbf{0 , 0 0 1}$ \\
\hline F14 - Gostaria de ser cientista & $2.03 \pm 1.16$ & $1.99 \pm 1.13$ & $2.06 \pm 1.15$ & $1.89 \pm 1.06$ & $1.87 \pm 1.06$ & 0,049 \\
\hline $\begin{array}{l}\text { F15 - Gostaria de aprender tanta } \\
\text { ciência quanto possível na escola }\end{array}$ & $2.39 \pm 1.15$ & $2.56 \pm 1.13$ & $2.58 \pm 1.09$ & $2.20 \pm 1.03$ & $2.19 \pm 1.03$ & 0,001 \\
\hline $\begin{array}{l}\text { F16 - Gostaria de ter um emprego } \\
\text { que lide com tecnologia avançada }\end{array}$ & $2.60 \pm 1.17$ & $2.81 \pm 1.16$ & $2.88 \pm 1.09$ & $2.59 \pm 1.13$ & $2.44 \pm 1.12$ & 0,001 \\
\hline
\end{tabular}

Duas questões apresentaram resultados semelhantes em todas as regiões: F1 e F14, indicando que os jovens brasileiros, em todas as regiões, não consideram a disciplina difícil e não tem interesse em seguir a carreira científica. 
Em geral os alunos da região Norte e Nordeste foram os que obtiveram maior pontuação nas questões: os do Nordeste foram os que consideraram a disciplina interessante mais que os das demais regiões, além de assinalarem que todos devem aprender ciências, e que as ciências são úteis no dia-a-dia. Já os do Norte foram os que tiveram maiores médias no que se refere aos benefícios da ciência: aumentaram o gosto pela natureza, a maneira de viver e os cuidados com a saúde. Foram os alunos nortistas que também gostariam de ser cientistas, aprender mais ciências e ter um emprego que lide com tecnologia avançada mais que os jovens das demais regiões.

Os jovens da região Sul e Sudeste foram os que mais demonstraram atitudes negativas para com a ciência. Eles atribuíram médias menores que a média da escala para sete questões, apontando que: não consideram que a ciência despertam seu interesse por empregos novos e emocionantes, não tem preferência pela disciplina na escola, não se tornaram mais críticos através da ciência e tampouco tiveram o gosto pela natureza aumentado. Também foram os que menos pontuaram na questão F14, sobre a preferência em ser cientista.

As questões com maiores e menores médias gerais foram selecionadas para se verificar diferenças significativas entre regiões: F5, F14 (médias menores); F2, F7 (médias maiores) e a F16, que junto da F14 está relacionada com as escolhas futuras. Para isso, foi utilizado o teste de Tukey, que verifica a existência de diferenças significativas de médias por pares (entre duas regiões). Os resultados podem ser observados na figura 7.5 e 7.6.

Tabela 7.5 - Diferenças existentes entre duas regiões para as questões F5 e F16.

\begin{tabular}{|c|c|c|c|}
\hline Questões (Seção F) & Teste de Tukey & Diferença & P-valor \\
\hline F05 - Gosto mais de Ciências do que das outras disciplinas & Sudeste - Norte & $-0,22$ & 0,009 \\
\hline $\begin{array}{l}\text { F16 - Gostaria de ter um emprego que lide com tecnologia } \\
\text { avançada }\end{array}$ & Norte - Centro-Oeste & 0,29 & 0,002 \\
\hline $\begin{array}{l}\text { F16 - Gostaria de ter um emprego que lide com tecnologia } \\
\text { avançada }\end{array}$ & Sudeste - Nordeste & $-0,22$ & 0,015 \\
\hline $\begin{array}{l}\text { F16 - Gostaria de ter um emprego que lide com tecnologia } \\
\text { avançada }\end{array}$ & Sul - Nordeste & $-0,37$ & $<0.001$ \\
\hline $\begin{array}{l}\text { F16 - Gostaria de ter um emprego que lide com tecnologia } \\
\text { avançada }\end{array}$ & Sudeste - Norte & $-0,3$ & $<0.001$ \\
\hline $\begin{array}{l}\text { F16 - Gostaria de ter um emprego que lide com tecnologia } \\
\text { avançada }\end{array}$ & Sul - Norte & $-0,45$ & $<0.001$ \\
\hline
\end{tabular}


A preferência pela ciência na escola foi mais evidente entre os jovens do Norte, principalmente em relação aos jovens do Sudeste. A questão F14 não apresentou diferenças significativas entre regiões, ou seja, brasileiros de todas as regiões não têm interesse na carreira científica. Já interesse por um emprego que lide com tecnologia avançada foi alto entre os jovens da região Norte, que apresentam interesse maior que os do Centro-Oeste, Sudeste e Sul e entre os nordestinos, que apresentam mais interesse que os jovens do Sul e Sudeste.

Tabela 7.6 - Diferenças existentes entre duas regiões para as questões F2 e F7.

\begin{tabular}{lccc}
\hline Questões (Seção F) & Teste & Diferença & P-valor \\
\hline F02 - A disciplina Ciências é interessante & Nordeste - Centro-Oeste & 0,33 & $<0.001$ \\
F02 - A disciplina Ciências é interessante & Norte - Centro-Oeste & 0,29 & $<0.001$ \\
F02 - A disciplina Ciências é interessante & Sudeste - Nordeste & $-0,36$ & $<0.001$ \\
F02 - A disciplina Ciências é interessante & Sul - Nordeste & $-0,41$ & $<0.001$ \\
F02 - A disciplina Ciências é interessante & Sudeste - Norte & $-0,32$ & $<0.001$ \\
$\begin{array}{l}\text { F02 - A disciplina Ciências é interessante } \\
\text { F07 - Os conhecimentos que adquiro em Ciências serão úteis na } \\
\text { minha vida cotidiana }\end{array}$ & Nordeste - Centro-Oeste & $-0,36$ & $<0.001$ \\
$\begin{array}{l}\text { F07 - Os conhecimentos que adquiro em Ciências serão úteis na } \\
\text { minha vida cotidiana }\end{array}$ & Norte - Centro-Oeste & 0,004 \\
$\begin{array}{l}\text { F07 - Os conhecimentos que adquiro em Ciências serão úteis na } \\
\text { minha vida cotidiana }\end{array}$ & Sudeste - Nordeste & $-0,4$ & $<0,002$ \\
$\begin{array}{l}\text { F07 - Os conhecimentos que adquiro em Ciências serão úteis na } \\
\text { minha vida cotidiana }\end{array}$ & Sul - Nordeste & $-0,42$ & $<0.001$ \\
$\begin{array}{l}\text { F07 - Os conhecimentos que adquiro em Ciências serão úteis na } \\
\text { minha vida cotidiana }\end{array}$ & Sudeste - Norte & $-0,41$ & $<0.001$ \\
$\begin{array}{l}\text { F07 - Os conhecimentos que adquiro em Ciências serão úteis na } \\
\text { minha vida cotidiana }\end{array}$ & Sul - Norte & $-0,43$ & $<0.001$ \\
\hline
\end{tabular}

Nas questões com maiores pontuações, F2 e F7, podemos destacar que os jovens da região Nordeste e Norte consideram a ciência escolar mais interessante que os jovens do Centro-Oeste, Sudeste e Sul. Também são os jovens do Nordeste e Norte que consideram os conhecimentos científicos úteis para a vida cotidiana mais que os do Centro Oeste, Sudeste e Sul. 


\subsection{O INTERESSE DO JOVEM BRASILEIRO PELA CARREIRA CIENTÍFICA}

Apesar do interesse pela carreira científica ter sido abordado anteriormente, gostaríamos de destacar alguns dados específicos sobre as questões F14 e F16, que se referem ao interesse em seguir carreiras na área científica ou tecnológica, a fim de verificar, inclusive, se os resultados obtidos na primeira aplicação do ROSE em 2007 se repetem em âmbito nacional.

Observamos através da aplicação do ROSE em âmbito nacional que tanto meninas como meninos têm pouco interesse em ingressar na carreira científica. Já os meninos gostariam mais de ter um emprego que lide com tecnologia avançada que as meninas. A figura 7.1 ilustra a diferença entre meninos e meninas em relação ao interesse pela carreira científica e tecnológica.

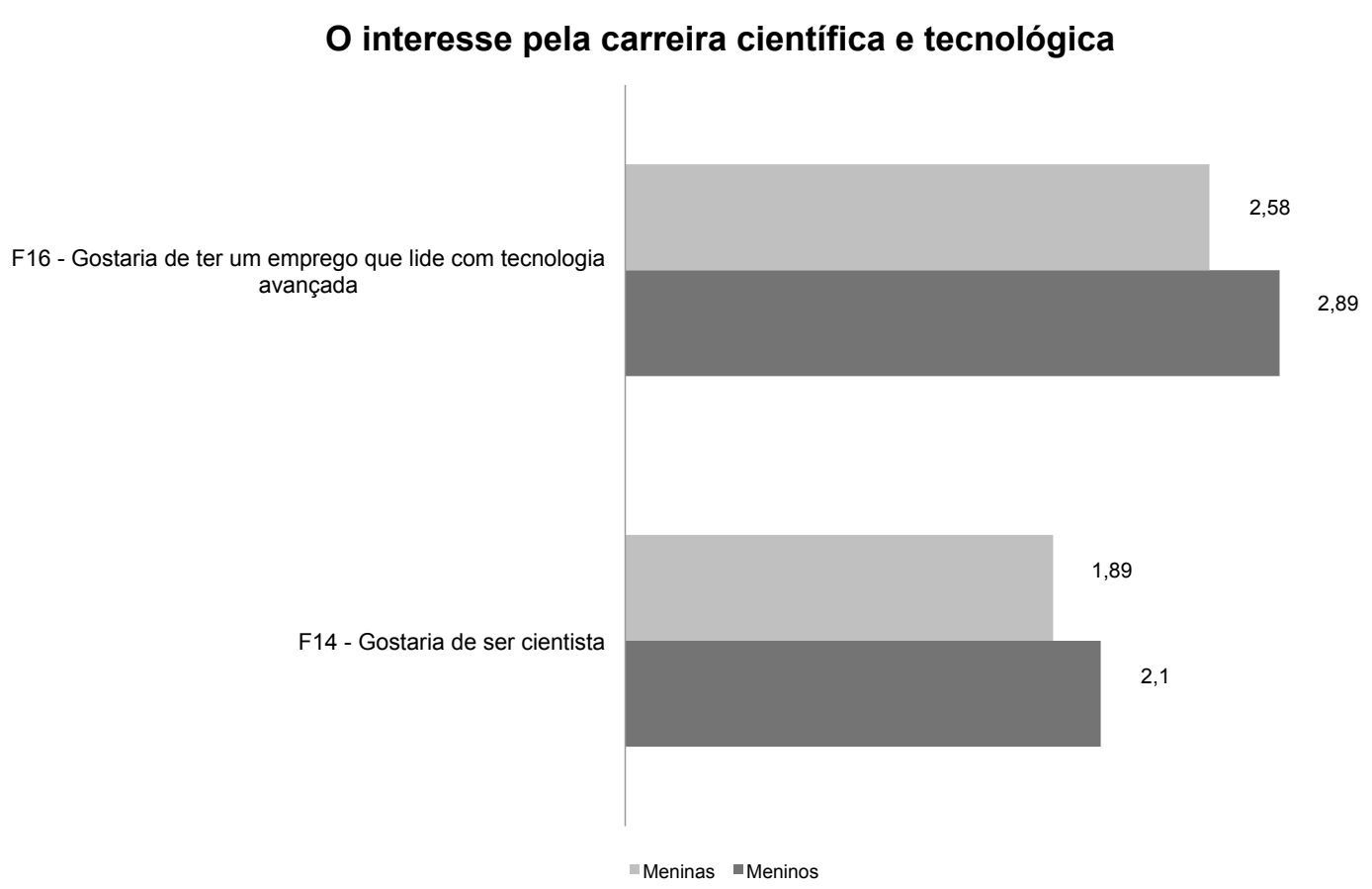

Figura 7.1 - O interesse de meninos e meninos pelas carreiras científicas e tecnológicas.

A primeira aplicação do projeto ROSE no Brasil trouxe uma interessante constatação: o interesse pela carreira científica foi maior no município com menor IDH, Tangará da Serra (MT) do que em São Caetano do Sul (SP), o município com maior IDH. São Caetano do Sul (SP), que possui o maior IDH do Brasil (PNUD, 2013b) obteve médias próximas às de países como a Noruega, Dinamarca e Suécia (TOLENTINO NETO, 2008). 
Os dados se alinhavam aos dados internacionais, que apontam que quanto maior o IDH de um país, menor é o interesse pela carreira científica. O autor do trabalho conclui que "Muito provavelmente nestes estudantes de regiões menos industrializadas reside a ideia (e por que não dizer a esperança) de que a Ciência é a resposta e a solução para o desenvolvimento e para uma vida melhor" (TOLENTINO NETO, 2008, p. 89).

Para saber se havia relação entre o interesse pela carreira científica e tecnológica, expressas através das médias das questões F14 e F16, e a situação socioeconômica da amostra nacional, realizou-se dois tipos de análise: a) teste de correlação entre o IDH dos municípios e as médias obtidas nas questões F14 e F16 e b) teste qui-quadrado para verificar associação entre as respostas das questões F14 e F16 e as questões socioeconômicas presentes no início do questionário (número de livros e número de banheiros). Os resultados podem ser observados nas tabelas 7.7 e 7.8 .

Tabela 7.7 - Valores obtidos para o teste de correlação entre IDH e média das questões F14 e F16.

\begin{tabular}{lcc}
\hline IDH dos municípios vs & Coeficiente de Pearson & Tipo de correlação \\
\hline Média F14 & -0.08986679 & Ínfima negativa \\
Média F16 & -0.3608768 & Fraca negativa \\
\hline
\end{tabular}

Os dados da tabela 7.7 indicam não haver correlação entre o IDH dos municípios participantes do ROSE e os valores atribuídos para as questões F14 e F16.

Os resultados da análise de associação entre as questões F14 e F16 e número de livros e número de banheiros encontra-se na tabela 7.8.

Tabela 7.8 - Resultados obtidos da associação entre as respostas das questões F14 e F16 e número de livros e número de banheiros.

\begin{tabular}{ccc}
\hline \multirow{2}{*}{ Associação entre as respostas } & \multicolumn{2}{c}{ p-valor (teste qui-quadrado) } \\
& Número de livros & Número de Banheiros \\
\cline { 2 - 3 } Respostas F14 & 0,358 & 0,422 \\
Respostas F16 & 0,221 & 0,927 \\
\hline
\end{tabular}


Os valores obtidos para o p-valor são maiores que 0,05 , o que indica que não há associação entre as respostas das questões socioeconômicas e as questões F14 e F16.

A observação das respostas por região aponta que há diferença significativa entre as médias atribuídas para a questão F16, conforme observado na tabela 7.9.

Tabela 7.9 - Médias por região das questões F14 e F16.

\begin{tabular}{lcccccc}
\hline $\begin{array}{l}\text { Questões: "As minhas aulas } \\
\text { de ciências" }\end{array}$ & $\begin{array}{c}\text { Centro- } \\
\text { Oeste }\end{array}$ & Nordeste & Norte & Sudeste & Sul & $\begin{array}{c}\text { P- } \\
\text { valor }\end{array}$ \\
\hline F14 - Gostaria de ser cientista & $2.03 \pm 1.16$ & $1.99 \pm 1.13$ & $2.06 \pm 1.15$ & $1.89 \pm 1.06$ & $1.87 \pm 1.06$ & 0,049 \\
$\begin{array}{l}\text { F16 - Gostaria de ter um } \\
\text { emprego que lide com } \\
\text { tecnologia avançada }\end{array}$ & $2.60 \pm 1.17$ & $2.81 \pm 1.16$ & $2.88 \pm 1.09$ & $2.59 \pm 1.13$ & $2.44 \pm 1.12$ & $\mathbf{0 , 0 0 1}$ \\
\hline
\end{tabular}

Conforme destacado na seção anterior, os alunos da região Sul e Sudeste possuem menor interesse na carreira científica (questão F14) e tecnológica (questão F16) que os jovens das demais regiões.

Algumas hipóteses tentam justificar esta tendência. Sjøberg (2001) consideram 13 possíveis razões para o fato dos jovens não optarem pelas carreiras científicas: 1) currículo de ciências teórico, abstrato, autoritário e sem relevância para os estudantes; 2) necessidade de grande empenho para aprender ciências, fato não muito valorizado entre os jovens da atualidade; 3 ) falta de professores qualificados, principalmente no Ensino Médio; 4) crenças alternativas que vão de encontro à atividade científica, de cunho supersticioso, metafísico ou mesmo com apelo de "supernatural”, 5) ataques pós-modernos à ciência e à tecnologia, alicerçados em grande parte em crenças alternativas; 6) imagem estereotipada dos cientistas e engenheiros como pessoas chatas, fechadas e autoritárias; 7) desacordos entre os próprios cientistas a respeito das questões científicas que envolvem a sociedade, como o aquecimento global, a preservação ambiental etc.; 8) falta de ética na atividade científica; 9) a não apreciação da supervalorização da ciência em atividades como a biotecnologia, que pode passar a ideia do cientista querer "brincar de Deus", ultrapassando os limites humanos; 10) mudança do papel dos cientistas, de grandes "descobridores" para colaboradores da atividade industrial e bélica; 11) mudança na imagem do cientista de herói para vilão, responsável pelos grandes males, principalmente ambientais, da humanidade; 12) a vida não glamourosa dos cientistas, que possuem pouco apelo aos jovens, 
que têm como modelos artistas, músicos e esportistas e 13) comunicação entre ciência e público em geral falha.

Nos dias atuais, uma questão que merece ser observada é a tendência em se valorizar, de modo excessivo, tudo o que é natural, desde a opção pela alimentação orgânica até na neutralização de emissão de gás carbônico relacionada a bens de consumo. Esse apelo tem implicado uma postura anti-científica e anti-tecnológica, que tem influenciado os jovens de alguma forma. Além disso, o jovem, ao refletir sobre o futuro, vislumbra um cenário onde os cientistas têm pouca expressão no mercado de trabalho.

Não podemos nos esquivar, contudo, do papel da escola no fomento do interesse pela carreira científica. Vázquez Alonso e Manassero Mas (2009b, p. 215) comentam que as

escolhas por carreiras em C\&T dependem significativamente da educação científica e dos conteúdos escolares, que tanto podem desenvolver a curiosidade, o interesse e o gosto pela ciência como o contrário, o aborrecimento, a dificuldade e o fracasso, que conduzem ao desinteresse e rejeição.

A análise da seção F do questionário apontou que o jovem brasileiro considera a disciplina escolar ciência interessante. Estudos futuros, que procurem compreender a lacuna existente entre o interesse pela disciplina e o pouco interesse pela carreira serão úteis para a compreensão dos dados aqui apresentados, e poderão trazer contribuições que estimulem o ingresso do brasileiro na carreira científica e tecnológica.

Nos dados discutidos no capítulo 5, referentes ao interesse pelos temas da ciência escolar, observou-se que a média global do interesse do jovem brasileiro pela ciência foi 2,68 (numa escala cuja média é 2,5). A média do brasileiro foi maior que os jovens de Portugal, Latvia, Irlanda, Polônia, Irlanda do Norte. Também foi maior que as médias atribuídas pelos jovens da Inglaterra, Estônia, Japão, Noruega, Islândia, Suécia, Dinamarca e Finlândia, sendo que nestes países, a média global foi menor que 2,5, indicando desinteresse pelos temas da disciplina.

A pesquisa de percepção pública realizada pela FAPESP apontou para a necessidade de estabelecer relações entre o entendimento dos jovens sobre o papel da ciência e tecnologia na sociedade e sua relação com a opção ou não pela carreira científica. Para os autores, a carreira científica é frequentemente mitificada, o que pode influenciar na tomada de decisões dos jovens (FAPESP, 2011). 
Um trabalho interessante realizado por Vázquez Alonso e Manassero Mas (2009b) procurou identificar, dentro da amostra espanhola que participou do projeto ROSE, as variáveis atitudinais consideradas preditores para a vocação científica e tecnológica. Os preditores positivos mais importantes foram: trabalhar com máquinas ou ferramentas, fazer, desenhar ou inventar algo, crenças que a ciência escolar pode melhorar as oportunidades de carreira, gostar mais de ciências que as outras disciplinas e considerar que a ciência abre perspectivas para trabalhos novos e excitantes.

Este mesmo trabalho poderá ser realizado a partir dos dados coletados nesta pesquisa, uma vez que é possível identificar os preditores atitudinais que mais influenciam a vocação científica e tecnológica do jovem brasileiro. Entretanto, uma vez que este não era o escopo deste trabalho, não foi possível contemplá-lo na tese.

A pesquisa ROSE aqui descrita apontou que o jovem brasileiro considera a ciência escolar interessante, o que já é um princípio para o aprofundamento da questão da falta de interesse pela carreira científica. O interesse pela ciência escolar é um dos caminhos trilhados para se chegar à ciência acadêmica. Resta-nos averiguar em que momento deste percurso, ou que elementos nele presentes, influenciam os jovens na determinação de suas opções de futuro.

\subsection{TIPOS DE POSICIONAMENTO DOS JOVENS BRASILEIROS EM RELAÇÃO ÀS AULAS DE CIÊNCIAS}

Os resultados obtidos junto às médias gerais da seção $\mathrm{F}$ foram submetidos à Análise Fatorial, o que proporcionou a identificação de 4 fatores com autovalores maiores que 1 para resumir as 16 questões presentes na seção. Esses fatores explicam 52,77\% da variação total das questões originais. A questão F1, por possuir caráter negativo, foi recodificada a fim de que todas as questões apresentassem a mesma orientação $(1=4,2=3,3=2,4=1)$. Os fatores e as respectivas questões que através deles se agrupam podem ser observados na tabela 7.10. 
Tabela 7.10 - Fatores (e questões) obtidos a partir da Análise Fatorial da seção F.

\begin{tabular}{|c|c|c|}
\hline Fatores & $\begin{array}{l}\text { Alpha de } \\
\text { Cronbach }\end{array}$ & Questões \\
\hline \multirow{8}{*}{$\begin{array}{l}\text { Fator 1- } \\
\text { fator } \\
\text { principal }\end{array}$} & \multirow[t]{8}{*}{0,852} & F02 - A disciplina Ciências é interessante \\
\hline & & F06 - Penso que todos deverão aprender Ciências \\
\hline & & $\begin{array}{l}\text { F07 - Os conhecimentos que adquiro em Ciências serão úteis na minha } \\
\text { vida cotidiana }\end{array}$ \\
\hline & & $\begin{array}{l}\text { F08 - Penso que a ciência que eu aprendo na escola melhorará as minhas } \\
\text { oportunidades de carreira }\end{array}$ \\
\hline & & $\begin{array}{l}\text { F10 - As Ciências estimularam a minha curiosidade acerca das coisas que } \\
\text { ainda não conseguimos explicar }\end{array}$ \\
\hline & & F11 - As Ciências aumentaram o meu gosto pela natureza \\
\hline & & $\begin{array}{l}\text { F12 - As Ciências mostraram-me a importância da ciência para a forma } \\
\text { como vivemos }\end{array}$ \\
\hline & & $\begin{array}{l}\text { F13 - A ciência que aprendo na escola ensina-me a cuidar melhor da } \\
\text { minha saúde }\end{array}$ \\
\hline \multirow[t]{6}{*}{ Fator 2} & \multirow[t]{6}{*}{0,786} & $\begin{array}{l}\text { F04 - As Ciências abriram-me os olhos para empregos novos e } \\
\text { emocionantes }\end{array}$ \\
\hline & & F05 - Gosto mais de Ciências do que das outras disciplinas \\
\hline & & F09 - As Ciências tornaram-me mais crítico e cético \\
\hline & & F14 - Gostaria de ser cientista \\
\hline & & F15 - Gostaria de aprender tanta ciência quanto possível na escola \\
\hline & & F16 - Gostaria de ter um emprego que lide com tecnologia avançada \\
\hline \multirow[t]{2}{*}{ Fator 3} & \multirow[t]{2}{*}{0,120} & F01 - A disciplina Ciências aborda conteúdos difíceis \\
\hline & & F03 - As Ciências, para mim, são bastante fáceis de aprender \\
\hline
\end{tabular}

A questão F01 apresentou homogeneidade em relação a todas as categorias de resposta. Devido a isso, o valor do Alpha de Cronbach não é alto para o fator a qual pertence: 0,120. Porém, mantê-lo no fator 3 foi a melhor configuração de combinação de questões.

Cada fator reflete um agrupamento de opiniões/atitudes dos alunos, o que não implica uma tipagem de alunos (JENKINS, 2006a). Assim, cada fator possui um atributo, vinculado às opiniões a ele relacionadas. Dentro do fator 1, as questões F12 e F07 são as que apresentam mais peso (maior valor), e apontam para a importância da ciência nas nossas vidas. As demais questões estão relacionadas com os benefícios e vantagens de se aprender ciências, além das 
questões F2 e F6, relacionadas ao interesse pela disciplina e à consideração de que todos devem aprender ciências. Assim podemos denominar o fator 1 de Pró-Ciência.

O segundo fator agrupa questões relacionadas diretamente com a preferência pela ciência. A questão de maior peso é justamente a F14, relacionada ao interesse em seguir a carreira científica. As demais questões envolvem a preferência pela ciência na escola e futuro emprego. Podemos assim denominar este fator de Prefiro-Ciência.

O terceiro e último fator agrupa duas questões relacionadas diretamente com o aprendizado, a F1, significando que a ciência não aborda conteúdos difíceis (por que teve valores invertidos, conforme explicitado anteriormente) e a F3, que afirma que a ciência é fácil de aprender. Por ter significado direto com a aprendizagem de forma positiva, podemos denominar este fator de Aprendo-Ciência.

Os valores de correlação existentes entre as questões originais e os fatores obtidos estão descritos na tabela 7.11. Nesta tabela estão presentes apenas os valores que foram considerados para compor cada fator, excluindo-os valores cruzados, ou aqueles cujo fator possuía autovalor menor que 1 .

Tabela 7.11 - Os valores de correlação existentes entre as questões originais e os fatores obtidos.

\begin{tabular}{lccc}
\hline Questões/Fator & Pró-Ciência & Prefiro-Ciência & Aprendo-Ciência \\
\hline F01 & & & 0,817 \\
F02 & 0,667 & & 0,642 \\
F03 & & 0,597 & \\
F04 & & 0,601 & \\
F05 & & & \\
F06 & 0,558 & & \\
F07 & 0,741 & 0,512 & \\
F08 & 0,638 & & \\
F09 & & & \\
F10 & 0,513 & & \\
F11 & 0,686 & & \\
F12 & 0,743 & 0,812 & \\
F13 & 0,724 & 0,695 & \\
F14 & & 0,612 & \\
F15 & & 45,53 & \\
F16 & & & \\
Variância & 37,08 & & \\
acumulada (\%) & & & \\
\hline
\end{tabular}


Assim, observamos que as atitudes dos jovens brasileiros em relação às aulas de ciências podem ser agrupadas em três grupos: o maior grupo, que responde à 37,08\% da variância das questões originais, é chamado de Pró-ciência, e reúne opiniões positivas relacionadas a ciência escolar. O segundo grupo, Prefiro-ciência, reúne atitudes relacionadas com a preferência pela ciência em relação a outras disciplinas e pela opção científica na futura carreira, responde a 8,45\% da variância das questões; por fim, o terceiro grupo, denominado Aprendo-ciência, agrupa duas questões que expressam atitudes positivas relacionadas ao aprendizado da disciplina, e responde individualmente à $7,24 \%$ da variância entre as questões.

Os escores médios apresentados pelos fatores sugeridos na Análise Fatorial, obtidos a partir das médias das questões que compõem cada fator, foram testados para identificar possíveis diferenças em relação ao gênero dos alunos. As médias atribuídas pelos meninos e meninas e geral nas questões pertencentes a cada fator podem ser observadas na tabela 7.12.

Tabela 7.12 - Medidas e testes de Mann-Whitney para diferença em relação ao gênero dos estudantes para os fatores do grupo de questões F.

\begin{tabular}{lccccccc}
\hline & \multicolumn{2}{c}{ Mulher } & \multicolumn{2}{c}{ Homem } & \multicolumn{2}{c}{ Geral } & \\
\cline { 2 - 7 } \multicolumn{1}{c}{ Fator } & Média & $\begin{array}{c}\text { Desvio } \\
\text { Padrão }\end{array}$ & Média & Padrão & Média & $\begin{array}{l}\text { Desvio } \\
\text { Padrão }\end{array}$ & p-valor \\
Pró-ciência & 2,95 & 0,692 & 2,76 & 0,750 & 2,87 & 0,723 & $<0,001$ \\
Prefiro-ciência & 2,27 & 0,763 & 2,37 & 0,759 & 2,32 & 0,763 & 0,001 \\
Aprendo-ciência & 2,63 & 3,091 & 2,52 & 0,809 & 2,58 & 2,411 & 0,982 \\
\hline
\end{tabular}

A tabela 7.12 mostra que as atitudes positivas dos jovens concentram-se nos grupos Pró-ciência e Aprendo-ciência, que foram os grupos nos quais se atribuíram maiores pontuações, tanto no geral como em relação aos meninos e meninas, com mais destaque para as meninas no grupo Pró-ciência. Pelo teste de Mann-Whitney o fator Aprendo-ciência não apresentou diferença significativa de gênero. O grupo Prefiro-ciência foi o que obteve menor pontuação, independente do gênero. Tal configuração sugere que o jovem brasileiro de fato possui atitudes positivas em relação à ciência e a seu aprendizado, porém não tem preferência pela ciência na escola e tampouco como opção para a futura carreira. 


\subsection{A POSIÇÃO DOS JOVENS BRASILEIROS EM RELAÇÃO À CIÊNCIA ESCOLAR NO CENÁRIO INTERNACIONAL}

Algumas questões da seção F foram selecionadas para comparações entre o Brasil e os demais países participantes do projeto ROSE. A questão F01 - “A disciplina Ciências aborda conteúdos difíceis" está apresentada na figura 7.2.

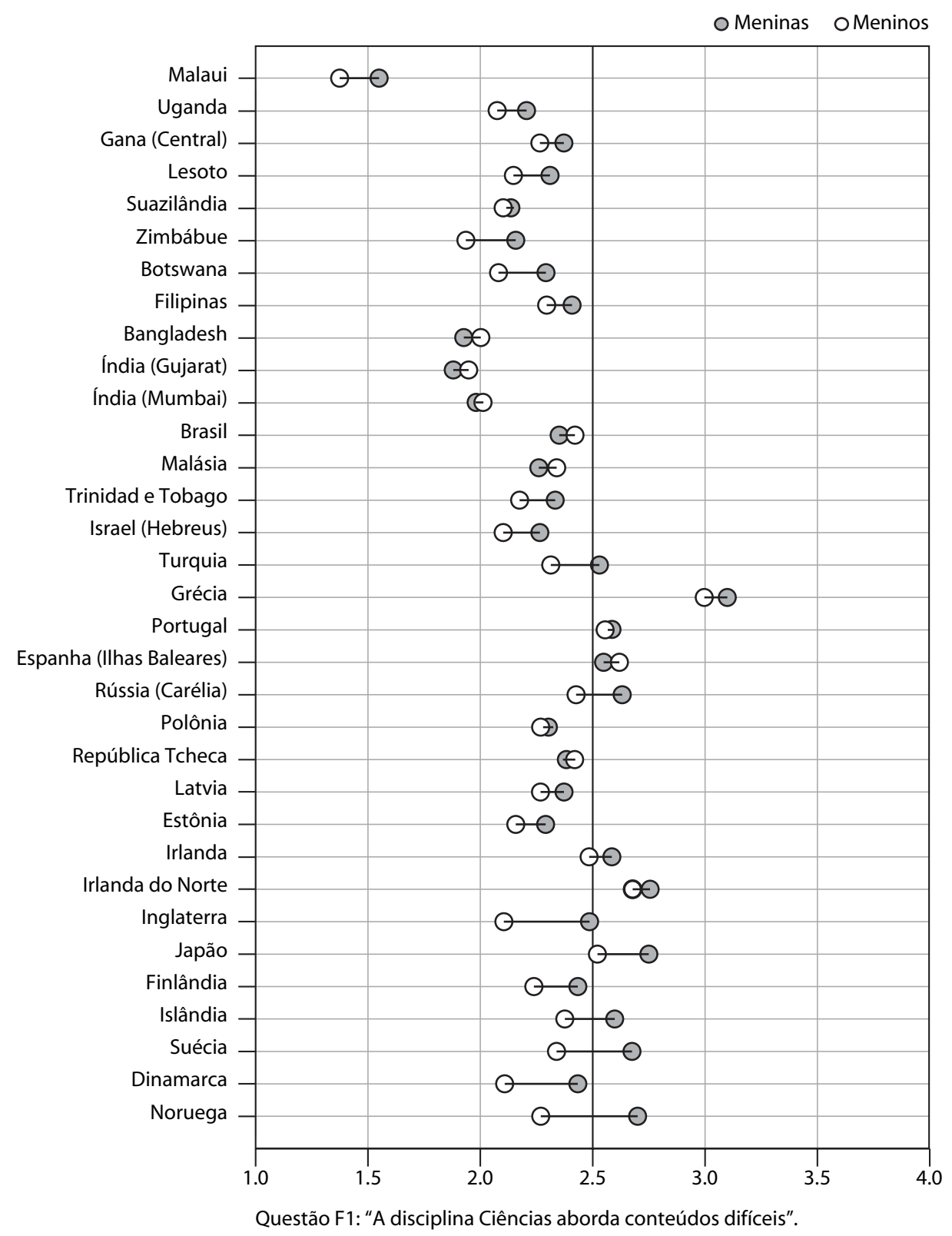

Figura 7.2 - Distribuição das respostas médias de meninos e meninas na questão F1, adaptado de Matthews (2007). 
As médias obtidas pelos jovens brasileiros aproximam-se das médias obtidas pelos jovens dos países com IDH menor, localizados na parte superior do gráfico. Dentro deste grupo observa-se pequena diferença de gênero, fato não observado entre os países com maior IDH.

Tais resultados aproximam o Brasil dos resultados obtidos em outros países: os jovens da Finlândia e Latvia também não consideram a disciplina difícil (média 2,33), porém a média obtida para o fato da disciplina ser interessante foi bem abaixo da média brasileira (2,65 para os finlandeses e 2,80 para os jovens da Latvia) (LAVONEN et al., 2008), conforme ilustrado na figura 7.2. O gráfico comparativo para a questão F2 "A disciplina Ciências é interessante" pode ser observado na figura 7.3.

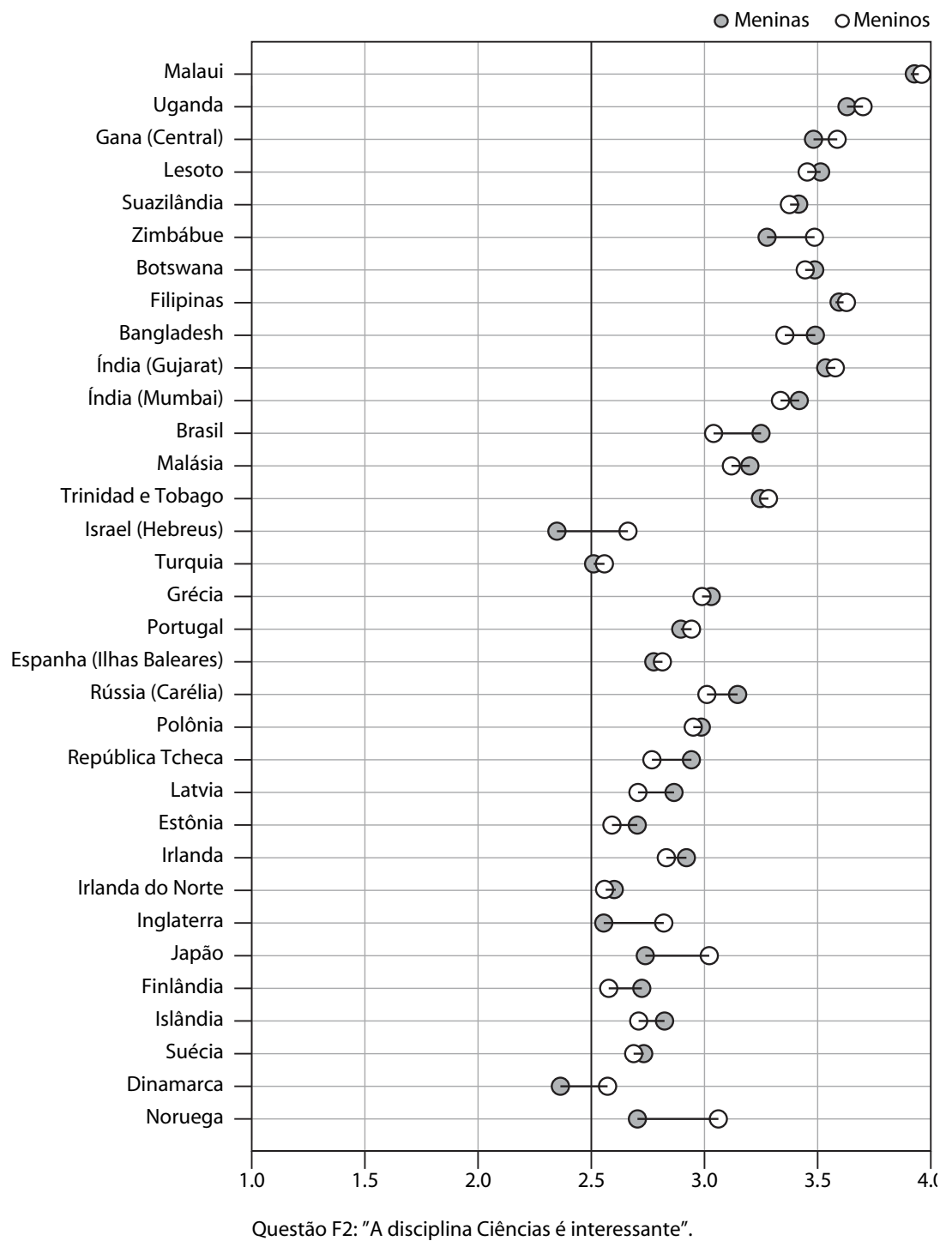

Figura 7.3 - Distribuição das respostas médias de meninos e meninas na questão F2, adaptado de Matthews (2007). 
O Brasil apresentou novamente um padrão de resposta semelhante aos países da metade superior do gráfico, ou seja, países com menor IDH. Os jovens finlandeses, que são conhecidos como tendo grande proficiência em ciências (OECD, 2007), possuem pouco interesse pela disciplina de modo geral. Tal dado foi observado tanto na aplicação do ROSE como através do PISA 2006. Apenas em três questões da seção F do questionário ROSE (F7, F2 e F8) as médias foram um pouco acima da média da escala. Nas demais questões os finlandeses valoraram as questões da seção F abaixo de 2,5 (OECD, 2007; LAVONEN et al., 2005).

As respostas para as duas questões envolvendo escolhas profissionais podem ser obervadas nas figuras 7.4 e 7.5. A questão F14 "Gostaria de ser cientista” está apresentada na figura 7.4.

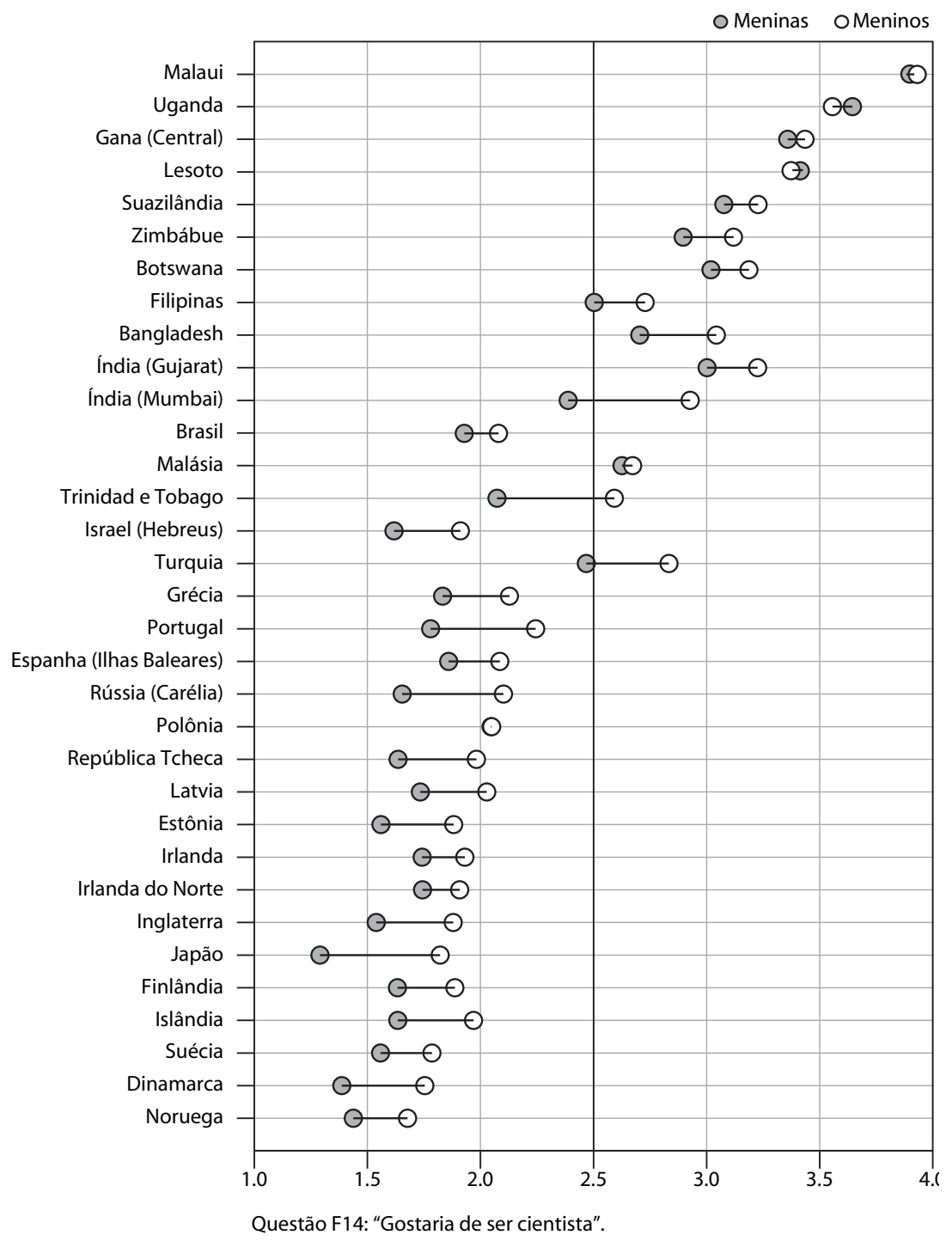

Figura 7.4 - Distribuição das respostas médias de meninos e meninas na questão F14, adaptado de Matthews (2007). 
Observamos que o jovem brasileiro, no que se refere à futura profissão, não tem interesse pela carreira científica, distanciando-se dos jovens dos países com menor IDH e aproximandose de países europeus como Espanha, Grécia e Polônia.

A questão F16 “Gostaria de ter um emprego que lide com tecnologia avançada” está apresentada na figura 7.5.

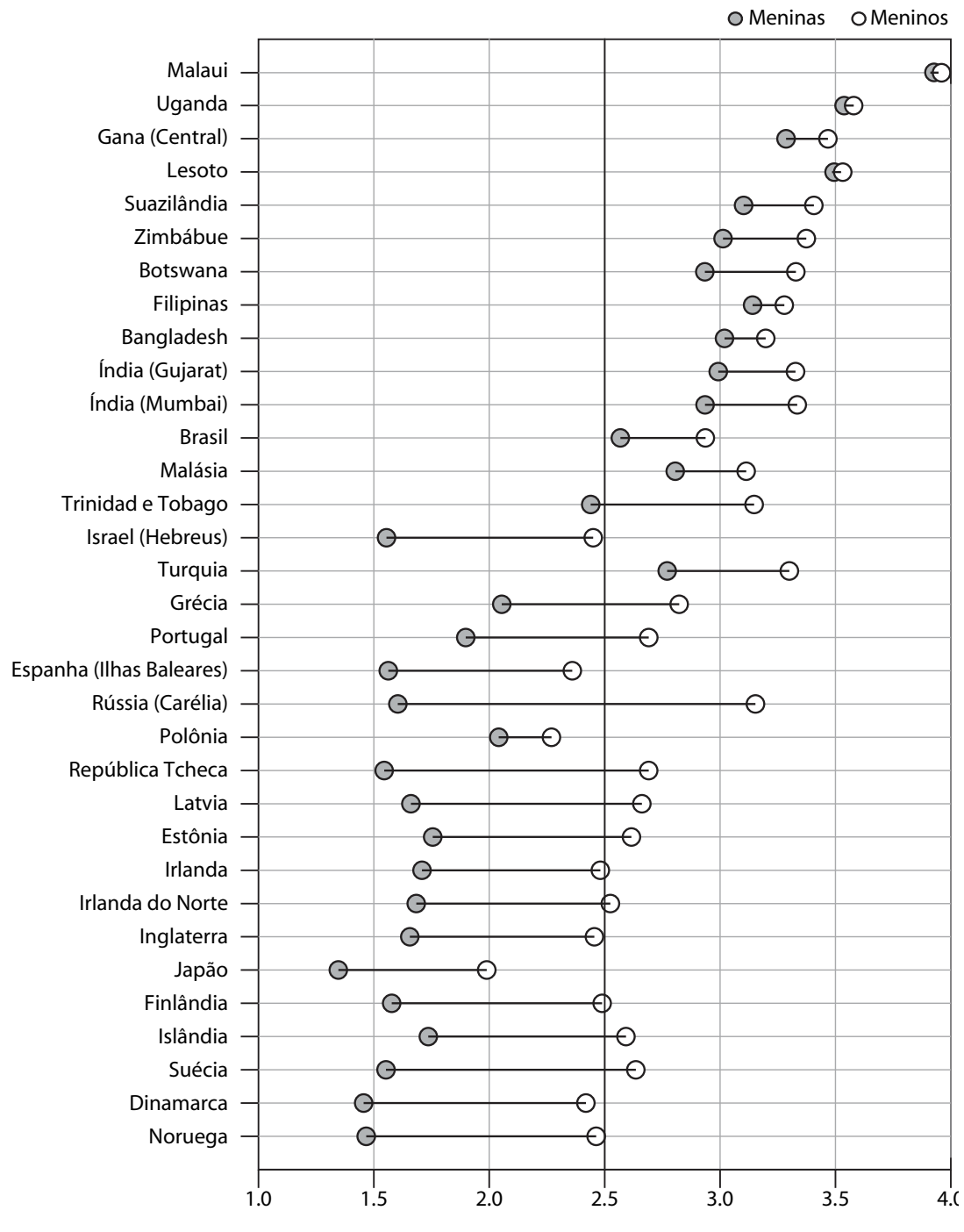

Questão F16: "Gostaria de ter um emprego que lide com tecnologia avançada”.

Figura 7.5 - Distribuição das respostas médias de meninos e meninas na questão F16, adaptado de Matthews (2007).

Observa-se nos países com maior IDH uma grande diferença de gênero nesta questão, diferença que vai diminuindo na parte superior do gráfico. Neste caso, os jovens brasileiros apresentaram tendência semelhante aos países com menor IDH, localizados na parte superior do gráfico. 


\section{OPINIÕES DOS JOVENS BRASILEIROS FRENTE À CIÊNCIA E À TECNOLOGIA}

Neste capítulo serão apresentados e discutidos os resultados obtidos junto à seção G “As minhas opiniões sobre ciência e tecnologia", que questionavam ao aluno: "Até que ponto você concorda com as seguintes afirmações?” seguido de 16 itens. Schreiner e Sjøberg (2004, p. 67) argumentam que a seção $\mathrm{G}$ tem como objetivo "conhecer a percepção dos jovens sobre o papel da ciência e tecnologia (C\&T) na sociedade", explorando questões relacionadas com a confiança, interesses e apoio ao empreendimento científico.

Os interesses e atitudes dos jovens frente às questões da ciência e tecnologia constituem indicadores da percepção pública da ciência, campo do conhecimento que visa compreender a dinâmica de relações existentes entre a ciência, a tecnologia e a sociedade. Conhecer os interesses e atitudes que os jovens demonstram pela cultura científica e tecnológica permite adequar as prioridades científicas às demandas deste setor da sociedade e verificar seu interesse pela carreira científica ou acadêmica (FAPESP, 2005; VOGT; POLINO, 2003; FAPESP, 2011).

O interesse pela ciência e tecnologia não é fomentado apenas pela ciência escolar, porém a escola, e em particular as aulas de ciências, continuam sendo um importante meio dos jovens despertarem seu interesse e curiosidade pela ciência, mesmo que na vida adulta não escolham carreiras na área (FALK et al, 2007; JENKINS, 1999).

Aikenhead (2005) comenta que é papel da ciência escolar abordar tanto as características inerentes da prática científica como as relações existentes entre a ciência, a tecnologia e a sociedade. $\mathrm{O}$ autor destaca que o objetivo da educação científica é preparar os jovens para o exercício da cidadania através da compreensão das dimensões humanas e sociais da prática científica e suas consequências nos mais diversos âmbitos.

Roth e Désautels (2004), dentro desta perspectiva, argumentam que o principal esforço dos educadores de ciência deve ser a problematização da ciência e da tecnologia mediante a sociedade e a socialização de informações que permitam a tomada de decisões e posturas adequadas em relação ao conhecimento científico e aos artefatos tecnológicos.

O preparo dos jovens para tais aspectos da educação pode ser observado através de investigações que visem conhecer o interesse e conhecimento da população adulta sobre a ciência e tecnologia, buscando relações com a ciência apresentada na idade escolar. Assim, conhecimen- 
tos científicos, mesmo que fragmentados ou residuais, interesses e atitudes, podem permanecer na vida adulta e ser indicativos do papel exercido pela ciência na escola (FENSHAM; HARLEN, 1999).

Neste sentido, uma interessante reflexão sobre a importância da educação científica foi feita por Hodson (2003, p. 650)

O que está claro é que os cidadãos comuns serão cada vez mais solicitados a fazerem julgamentos sobre questões relacionadas ao conhecimento científico ou tecnológico (...). Aqueles sem uma compreensão básica das maneiras em que a ciência e a tecnologia atuam sobre o meio ambiente físico e sociopolítico estarão suscetíveis a julgamentos equivocados (...).

Vázquez Alonso e Manassero Mas (2007a, p. 248) corroboram este aspecto ao afirmarem que

\begin{abstract}
a Ciência e Tecnologia têm um importante papel em muitos aspectos da vida na sociedade moderna, afetando tanto a esfera privada dos indivíduos, como consumidores e trabalhadores, quanto a esfera pública, como cidadãos ou membros de um comunidade. Em ambas as áreas, a importância das decisões sociais em curso sobre questões científicas exige uma sólida formação científica (...).
\end{abstract}

A despeito da importância da ciência e da tecnologia na sociedade e da necessidade de conhecimento a respeito dela, Sjøberg (2001) comenta que têm se observado em muitos países um desencanto pela ciência e pela carreira científica, expressos tanto em relação à ciência escolar, como em relação às escolhas acadêmicas e profissionais.

O autor elenca uma série de possíveis motivos para esta tendência, dentre estes, o ataque de alguns setores da sociedade (como o místico) à atividade científica, à discordância das pessoas em relação aos embates científicos que alcançam popularidade nos meios de comunicação, a visão que muitos têm da ciência ser "fria" em relação aos problemas que as pessoas enfrentam, ao fato dos cientistas quererem "brincar de Deus", principalmente na área de biotecnologia e medicina, à associação muitas vezes realizada entre os avanços científicos e tecnológicos e os problemas ambientais, ao fato dos cientistas não terem uma vida glamourosa, como os artistas, esportistas, jornalistas etc. e a falhas de comunicação entre a ciência e o público em geral (SJØBERG, 2001).

Por isso, a questões presentes na seção $\mathrm{G}$ procuram conhecer a percepção dos jovens so- 
bre diversos assuntos relacionados à ciência e tecnologia: aos aspectos relacionados a favorecer a vida das pessoas, tanto no que se refere ao trabalho, como ao combate à pobreza, à destruição do meio ambiente e à confiabilidade nos cientistas.

Conhecer as concepções e crenças dos estudantes sobre C\&T se constituem fundamentais para que os jovens construam uma visão adequada da ciência e da tecnologia, fato que na maioria das vezes é abordado de forma implícita no currículo de ciências. Muitas vezes, não está claro o papel da ciência e tecnologia na sociedade atual, e mais ainda, de sua própria dinâmica interna (VÁZQUEZ ALONSO; MANASSERO MAS, 2007).

Para suprir esta demanda, através da análise da seção G do questionário ROSE, iremos verificar que posturas os jovens brasileiros demonstram em relação à ciência e tecnologia. Para isso, os dados serão apresentados da seguinte forma: 1) através das médias de meninos e meninas para todas as questões presentes na seção G; 2) através das médias distribuídas nas regiões brasileiras; 3) tipos de posicionamento assumidos pelos jovens brasileiros em relação à ciência e tecnologia e 4) a posição dos jovens brasileiros no cenário internacional.

Para a verificação de diferenças entre gênero, foram utilizados testes de Mann-Whitney. Diferenças com valores de $\mathrm{p}<0,05$ foram consideradas significativas. Para verificação de diferenças entre regiões brasileiras, foram utilizados os testes ANOVA e Tukey, conforme discriminado no capítulo 3 .

\subsection{OPINIÕES DOS JOVENS BRASILEIROS FRENTE À CIÊNCIA E À TECNOLOGIA: UM PANORAMA GERAL}

As médias obtidas nas 16 questões presentes na seção G “As minhas opiniões sobre a ciência e a tecnologia" podem ser observadas na tabela 8.1. Os valores em negrito referem-se a diferenças estatisticamente significativas de gênero. 
Tabela 8.1 - Médias e testes de Mann-Whitney para diferenças em relação ao gênero dos estudantes para o grupo de questões $\mathrm{G}$.

\begin{tabular}{|c|c|c|c|c|c|c|}
\hline \multirow{2}{*}{$\begin{array}{l}\text { Questões: “As minhas opiniões sobre ciência e } \\
\text { tecnologia" }\end{array}$} & \multirow{2}{*}{$\begin{array}{l}\text { Média } \\
\text { Geral }\end{array}$} & \multicolumn{2}{|c|}{ Média } & \multirow{2}{*}{$\begin{array}{l}\text { Diferença } \\
\text { (H-M) }\end{array}$} & \multirow{2}{*}{ IC 95 (Dif) } & \multirow{2}{*}{$\begin{array}{c}\text { P- } \\
\text { valor }\end{array}$} \\
\hline & & Homem & Mulher & & & \\
\hline $\begin{array}{l}\text { G01 - A ciência e a tecnologia têm grande } \\
\text { importância para a Sociedade }\end{array}$ & 3,25 & 3,17 & 3,31 & $-0,14$ & {$[-0.22 ;-0.06]$} & 0,001 \\
\hline $\begin{array}{l}\text { G02 - A ciência e a tecnologia encontrarão curas } \\
\text { para doenças como a AIDS, o câncer, etc. }\end{array}$ & 3,09 & 2,99 & 3,16 & $-0,17$ & {$[-0.25 ;-0.08]$} & $\mathbf{0 , 0 1}$ \\
\hline $\begin{array}{l}\text { G03 - Devido à ciência e à tecnologia, haverá } \\
\text { melhores oportunidades para as futuras gerações. }\end{array}$ & 3,13 & 3,05 & 3,18 & $-0,13$ & {$[-0.21 ;-0.05]$} & 0,002 \\
\hline $\begin{array}{l}\text { G04 - A ciência e a tecnologia tornam as nossas } \\
\text { vidas mais saudáveis, mais fáceis e mais } \\
\text { confortáveis. }\end{array}$ & 2,85 & 2,87 & 2,83 & 0,04 & {$[-0.05 ; 0.12]$} & 0,372 \\
\hline $\begin{array}{l}\text { G05 - As novas tecnologias tornarão o trabalho } \\
\text { mais interessante }\end{array}$ & 3,00 & 3,00 & 3,00 & 0,00 & {$[-0.08 ; 0.08]$} & 0,795 \\
\hline $\begin{array}{l}\text { G06 - Os benefícios da ciência são maiores do } \\
\text { que os efeitos negativos que possa ter }\end{array}$ & 2,55 & 2,58 & 2,53 & 0,05 & {$[-0.04 ; 0.13]$} & 0,208 \\
\hline $\begin{array}{l}\text { G07 - A ciência e a tecnologia ajudarão a } \\
\text { erradicar a pobreza e a fome no mundo }\end{array}$ & 2,33 & 2,39 & 2,28 & 0,11 & {$[0.02 ; 0.2]$} & $\mathbf{0 , 0 2 0}$ \\
\hline $\begin{array}{l}\text { G08 - A ciência e a tecnologia podem resolver } \\
\text { quase todos os problemas }\end{array}$ & 2,26 & 2,38 & 2,18 & 0,20 & {$[0.12 ; 0.29]$} & $\mathbf{0 , 0 1 0}$ \\
\hline G09 - A ciência e a tecnologia ajudam os pobres & 1,99 & 2,08 & 1,92 & 0,16 & {$[0.08 ; 0.25]$} & $\mathbf{0 , 0 1 0}$ \\
\hline $\begin{array}{l}\text { G10 - A ciência e a tecnologia são as causas dos } \\
\text { problemas do ambiente }\end{array}$ & 2,37 & 2,46 & 2,30 & 0,16 & {$[0.07 ; 0.25]$} & 0,001 \\
\hline $\begin{array}{l}\text { G11 - Um país precisa de ciência e de tecnologia } \\
\text { para se desenvolver }\end{array}$ & 3,14 & 3,09 & 3,17 & $-0,08$ & {$[-0.17 ; 0]$} & 0,086 \\
\hline $\begin{array}{l}\text { G12 - A ciência e a tecnologia beneficiam } \\
\text { principalmente os países desenvolvidos }\end{array}$ & 3,01 & 3,00 & 3,02 & $-0,02$ & {$[-0.11 ; 0.06]$} & 0,580 \\
\hline $\begin{array}{l}\text { G13 - Os cientistas seguem o método científico } \\
\text { que os leva sempre às respostas corretas }\end{array}$ & 2,29 & 2,38 & 2,22 & 0,16 & {$[0.07 ; 0.24]$} & $\mathbf{0 , 0 1 0}$ \\
\hline $\begin{array}{l}\text { G14 - Podemos sempre confiar no que os } \\
\text { cientistas dizem }\end{array}$ & 1,80 & 1,95 & 1,68 & 0,27 & {$[0.19 ; 0.35]$} & $\mathbf{0 , 0 1 0}$ \\
\hline G15 - Os cientistas são neutros e objetivos & 2,32 & 2,37 & 2,28 & 0,09 & {$[0.01 ; 0.18]$} & $\mathbf{0 , 0 1 6}$ \\
\hline $\begin{array}{l}\text { G16 - As teorias científicas desenvolvem-se e } \\
\text { mudam constantemente }\end{array}$ & 2,86 & 2,88 & 2,84 & 0,04 & {$[-0.04 ; 0.13]$} & 0,303 \\
\hline
\end{tabular}

Sobre os benefícios da C\&T para a sociedade. Conforme observado na tabela acima, os jovens brasileiros dão grande importância à ciência e à tecnologia, e as consideram responsáveis não só pela cura de doenças, mas também por melhores oportunidades futuras, trabalho 
mais interessante e o desenvolvimento adequado de um país. Os jovens atribuem à C\&T a possibilidade de uma vida mais saudável, fácil e confortável, além de tornar o trabalho mais interessante. Em relação às diferenças de gênero, as meninas dão mais importância à ciência que os meninos, no que se refere tanto a cura de doenças como a melhores oportunidades para futuras gerações.

Tais dados corroboram a pesquisa de percepção pública da ciência realizada pela FAPESP (2011, p. 49) em 2010, cuja amostra envolveu o estado de São Paulo. Nela verificouse que "a visão dos paulistas sobre C\&T é substancialmente positiva, otimista, e marcada pelo apoio à C\&T”.

Sobre os benefícios e malefícios da $C \& T$. Os jovens brasileiros discordam que a C\&T é culpada pelos problemas ambientais (G12), porém possuem uma atitude "neutra" em relação aos benefícios e malefícios que a ciência pode causar (G6).

Sobre os benefícios sociais da $C \& T$. Os jovens brasileiros não acreditam que a ciência e tecnologia ajudam os pobres, ao contrário, consideram que ela beneficia principalmente os países ricos. Ainda, nossos jovens não supervalorizam a C\&T a ponto de acreditarem que ela pode resolver quase todos os problemas.

Tais dados corroboram a pesquisa de Vogt e Polino (2003, p. 81). Nela, a maioria dos entrevistados "concorda que o desenvolvimento da ciência e da tecnologia é o principal motivo da melhoria da qualidade de vida da sociedade", porém, a visão de que a ciência e tecnologia podem resolver todos os problemas não é compartilhada pelos entrevistados.

Sobre a confiança na $C \& T$ e nos cientistas. A maioria dos jovens brasileiros discorda que sempre podemos confiar nos cientistas, que o trabalho científico leva sempre a respostas certas e que os cientistas são neutros e objetivos. Apesar da pequena confiança do brasileiro nos cientistas e na ciência, os meninos confiam neles mais que as meninas.

Algumas questões abordadas nas pesquisas de percepção pública realizadas pela FAPESP e pelo Ministério da Ciência e Tecnologia (MCT) assemelham-se às questões do ROSE, inclusive com respostas expressas em uma escala de Likert, porém as análises foram realizadas na forma de porcentagem e não por médias. Para facilitarmos a comparação, selecionamos alguns dados obtidos na pesquisa FAPESP (2005 e 2010) e MCT (2010) e os dados do ROSE, desta vez expressos em porcentagem dos pontos 3 e 4 da escala de Likert. Os resultados podem ser observados na tabela 8.2 . 


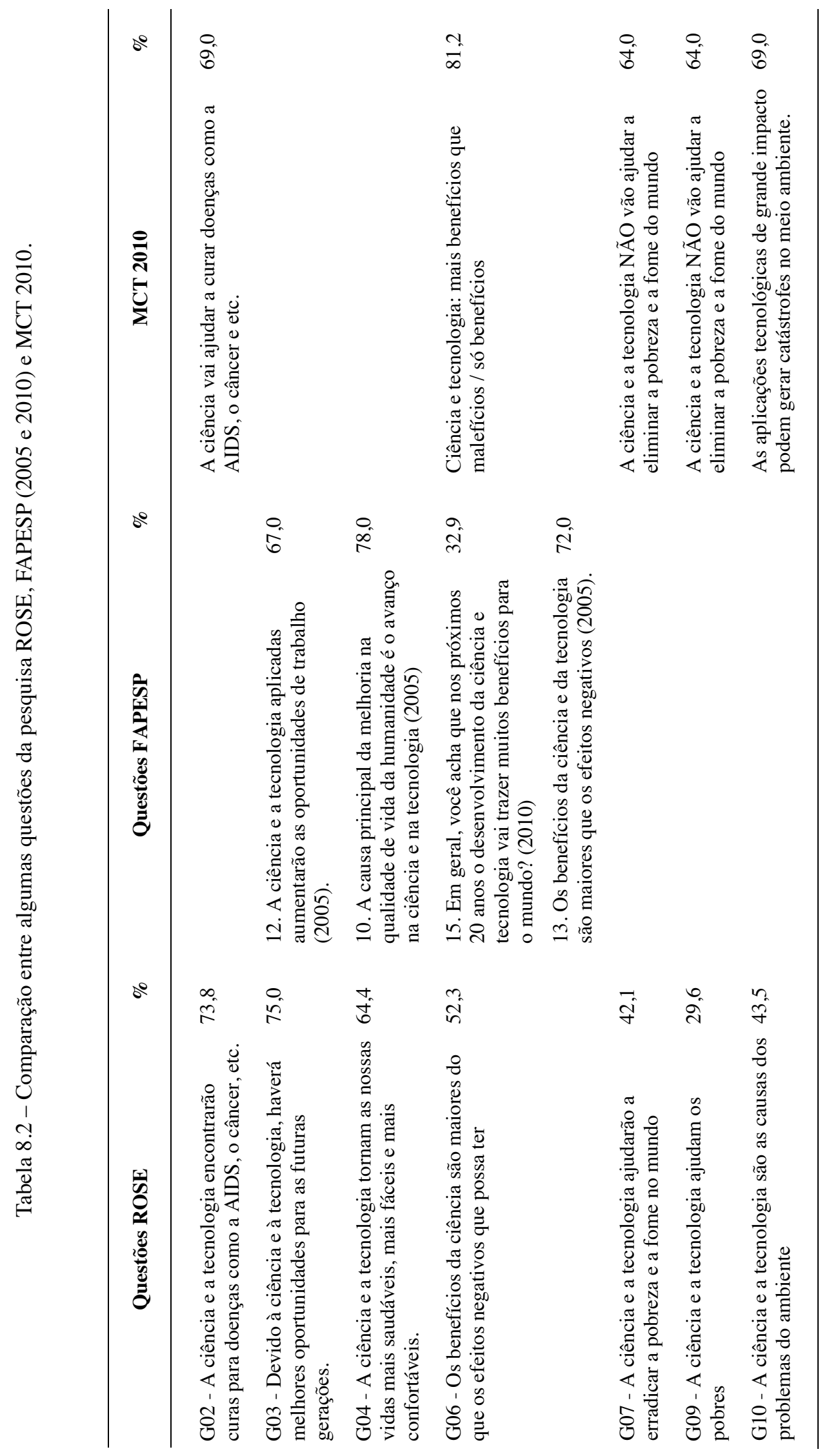


Podemos observar que os jovens brasileiros e os brasileiros adultos compartilham as opiniões acerca dos benefícios que a C\&T podem trazer à sociedade, expressos em termos de cura para doenças, melhores oportunidades de trabalho e qualidade de vida. Quanto aos benefícios/ malefícios da atividade científica, o jovem brasileiro demonstrou uma atitude "neutra", enquanto que os adultos das demais pesquisas demonstraram atitudes ou de conformidade, ou de contraposição.

A descrença no fato da C\&T ajudar os pobres é compartilhada pelas pesquisas ROSE e MCT, porém enquanto que os jovens não acreditam que a C\&T prejudique o meio ambiente, a população adulta participante da pesquisa do MCT acredita que sim.

A aplicação do PISA no ano de 2006 também procurou conhecer as opiniões dos jovens em relação à C\&T. Acevedo-Díaz (2007) considera que um dos grandes avanços do PISA neste ano foi avaliar as atitudes dos alunos para com a ciência, em especial o interesse pela ciência, o apoio à investigação científica e a responsabilidade para com os recursos ambientais.

Assim, algumas questões da seção $\mathrm{G}$ foram comparadas com algumas questões do PISA 2006. Foram incluídas nesta comparação duas questões da seção H do questionário ROSE relacionadas ao consumo de informação científica. Uma síntese pode ser observada na tabela 8.3.

Tabela 8.3 - Comparação entre ROSE e PISA 2006 sobre questões que abordam o papel da C\&T na sociedade.

\begin{tabular}{|c|c|c|c|c|c|c|}
\hline \multirow{2}{*}{$\begin{array}{c}\text { Questões } \\
\text { PISA }\end{array}$} & \multirow[b]{2}{*}{ ROSE } & \multicolumn{2}{|c|}{ Médias } & \multirow{2}{*}{$\begin{array}{c}\text { Diferença } \\
\text { Percentual } \\
\text { (PISA } \\
\text { /ROSE) }\end{array}$} & \multicolumn{2}{|c|}{ Teste de Hipótese } \\
\hline & & PISA & ROSE & & $\begin{array}{l}\text { Diferença } \\
\text { (PISA- } \\
\text { ROSE) }\end{array}$ & $\begin{array}{c}\text { IC 95\% } \\
\text { (Diferença) }\end{array}$ \\
\hline Idade & Idade & 15,66 & 15,39 & 1,75 & 0,27 & {$[0.24 ; 0.30]$} \\
\hline Gênero (Feminino) & Gênero (Feminino) & $5037(54.2 \%)$ & $1339(57.7 \%)$ & 6,07 & $-3,50 \%$ & {$[-1.24 \% ;-5.76 \%]$} \\
\hline $\begin{array}{l}\text { ST18Q01 - Em geral, os avanços } \\
\text { científicos e tecnológicos melhoram } \\
\text { as condições de vida das pessoas }\end{array}$ & $\begin{array}{l}\text { G04 - A ciência e a tecnologia tornam } \\
\text { as nossas vidas mais saudáveis, mais } \\
\text { fáceis e mais confortáveis }\end{array}$ & 3,44 & 2,85 & 20,70 & 0,59 & {$[0.55 ; 0.64]$} \\
\hline $\begin{array}{l}\text { ST18Q06 - Os conhecimentos } \\
\text { científicos são úteis para a sociedade }\end{array}$ & $\begin{array}{l}\text { G01 - A ciência e a tecnologia têm } \\
\text { grande importância para a Sociedade }\end{array}$ & 3,36 & 3,25 & 3,38 & 0,11 & {$[0.07 ; 0.16]$} \\
\hline $\begin{array}{l}\text { ST19Q01 - Com que frequência você } \\
\text { assiste a programas científicos na } \\
\text { televisão }\end{array}$ & $\begin{array}{l}\text { H13 - Quantas vezes você já viu } \\
\text { documentários sobre a natureza na } \\
\text { televisão ou cinema }\end{array}$ & 2,38 & 3,04 & $-21,71$ & $-0,66$ & {$[-0.71 ;-0.61]$} \\
\hline $\begin{array}{l}\text { ST19Q05 - Com que frequência você } \\
\text { lê revistas científicas ou artigos sobre } \\
\text { Ciências em jornais }\end{array}$ & $\begin{array}{l}\text { H12 - Quantas vezes você já leu sobre } \\
\text { a natureza ou ciências em livros ou } \\
\text { revistas }\end{array}$ & 2,39 & 2,95 & $-18,98$ & $-0,56$ & {$[-0.61 ;-0.51]$} \\
\hline
\end{tabular}

Os jovens respondentes do ROSE possuem uma visão menos otimista em relação à C\&T que os do PISA 2006, porém consomem mais informação no âmbito não-formal relacionada à ciência e tecnologia que os do participantes do PISA 2006. 


\subsection{OPINIÕES DOS JOVENS BRASILEIROS FRENTE À CIÊNCIA E À TECNOLOGIA: UM PANORAMA POR REGIÃO}

A média de cada questão da seção $G$ por região brasileira pode ser observada na tabela 8.4. Os valores em negrito são os que apresentam diferenças estatísticas significativas.

Tabela 8.4 - Médias por região da seção G.

\begin{tabular}{|c|c|c|c|c|c|c|}
\hline Questões da seção G & $\begin{array}{l}\text { Centro- } \\
\text { Oeste }\end{array}$ & Nordeste & Norte & Sudeste & Sul & $\begin{array}{l}\text { P- } \\
\text { valor }\end{array}$ \\
\hline $\begin{array}{l}\text { G01 - A ciência e a tecnologia têm grande } \\
\text { importância para a Sociedade }\end{array}$ & $3.14 \pm 1.04$ & $3.36 \pm 0.94$ & $3.32 \pm 0.92$ & $3.18 \pm 0.95$ & $3.06 \pm 0.96$ & $\mathbf{0 , 0 0 1}$ \\
\hline $\begin{array}{l}\text { G02 - A ciência e a tecnologia encontrarão } \\
\text { curas para doenças como a AIDS, o } \\
\text { câncer, etc. }\end{array}$ & $3.03 \pm 1.01$ & $3.13 \pm 0.96$ & $3.11 \pm 1.01$ & $3.09 \pm 0.99$ & $2.98 \pm 0.98$ & 0,206 \\
\hline $\begin{array}{l}\text { G03 - Devido à ciência e à tecnologia, } \\
\text { haverá melhores oportunidades para as } \\
\text { futuras gerações. }\end{array}$ & $3.06 \pm 0.94$ & $3.2 \pm 0.91$ & $3.19 \pm 0.93$ & $3.07 \pm 0.94$ & $3.02 \pm 0.96$ & 0,014 \\
\hline $\begin{array}{l}\text { G04 - A ciência e a tecnologia tornam as } \\
\text { nossas vidas mais saudáveis, mais fáceis e } \\
\text { mais confortáveis. }\end{array}$ & $2.88 \pm 1.01$ & $2.83 \pm 1.02$ & $2.92 \pm 1.02$ & $2.76 \pm 0.97$ & $2.83 \pm 0.94$ & 0,155 \\
\hline $\begin{array}{l}\text { G05 - As novas tecnologias tornarão o } \\
\text { trabalho mais interessante }\end{array}$ & $2.92 \pm 1.00$ & $3.05 \pm 0.97$ & $3.05 \pm 0.98$ & $2.96 \pm 1.00$ & $2.92 \pm 0.93$ & 0,094 \\
\hline $\begin{array}{l}\text { G06 - Os benefícios da ciência são } \\
\text { maiores do que os efeitos negativos que } \\
\text { possa ter }\end{array}$ & $2.57 \pm 1.03$ & $2.58 \pm 1.03$ & $2.57 \pm 0.98$ & $2.5 \pm 0.99$ & $2.45 \pm 0.86$ & 0,321 \\
\hline $\begin{array}{l}\text { G07 - A ciência e a tecnologia ajudarão a } \\
\text { erradicar a pobreza e a fome no mundo }\end{array}$ & $2.45 \pm 1.05$ & $2.30 \pm 1.08$ & $2.41 \pm 1.05$ & $2.18 \pm 0.99$ & $2.29 \pm 0.99$ & 0,001 \\
\hline $\begin{array}{l}\text { G08 - A ciência e a tecnologia podem } \\
\text { resolver quase todos os problemas }\end{array}$ & $2.32 \pm 1.07$ & $2.30 \pm 1.07$ & $2.27 \pm 1.06$ & $2.21 \pm 0.95$ & $2.18 \pm 0.96$ & 0,366 \\
\hline $\begin{array}{l}\text { G09 - A ciência e a tecnologia ajudam os } \\
\text { pobres }\end{array}$ & $2.12 \pm 1.07$ & $1.96 \pm 1.04$ & $2.02 \pm 1.02$ & $1.89 \pm 0.94$ & $1.96 \pm 0.99$ & $\mathbf{0 , 0 3 5}$ \\
\hline $\begin{array}{l}\text { G10 - A ciência e a tecnologia são as } \\
\text { causas dos problemas do ambiente }\end{array}$ & $2.39 \pm 1.06$ & $2.38 \pm 1.09$ & $2.46 \pm 1.08$ & $2.26 \pm 0.98$ & $2.24 \pm 0.96$ & $\mathbf{0 , 0 1}$ \\
\hline $\begin{array}{l}\text { G11 - Um país precisa de ciência e de } \\
\text { tecnologia para se desenvolver }\end{array}$ & $3.08 \pm 0.99$ & $3.22 \pm 0.97$ & $3.21 \pm 0.93$ & $3.07 \pm 0.96$ & $2.95 \pm 0.94$ & 0,001 \\
\hline $\begin{array}{l}\text { G12 - A ciência e a tecnologia beneficiam } \\
\text { principalmente os países desenvolvidos }\end{array}$ & $3.03 \pm 0.96$ & $3.08 \pm 0.99$ & $3.09 \pm 0.96$ & $2.94 \pm 1.00$ & $2.75 \pm 1.01$ & $\mathbf{0 , 0 0 1}$ \\
\hline $\begin{array}{l}\text { G13 - Os cientistas seguem o método } \\
\text { científico que os leva sempre às respostas } \\
\text { corretas }\end{array}$ & $2.26 \pm 1.03$ & $2.26 \pm 1.04$ & $2.36 \pm 1.03$ & $2.22 \pm 0.96$ & $2.35 \pm 0.97$ & 0,142 \\
\hline $\begin{array}{l}\text { G14 - Podemos sempre confiar no que os } \\
\text { cientistas dizem }\end{array}$ & $1.86 \pm 0.95$ & $1.80 \pm 0.98$ & $1.81 \pm 0.98$ & $1.73 \pm 0.88$ & $1.79 \pm 0.91$ & 0,455 \\
\hline G15 - Os cientistas são neutros e objetivos & $2.37 \pm 0.97$ & $2.33 \pm 1.03$ & $2.35 \pm 1.00$ & $2.23 \pm 0.93$ & $2.3 \pm 0.97$ & 0,277 \\
\hline $\begin{array}{l}\text { G16 - As teorias científicas desenvolvem- } \\
\text { se e mudam constantemente }\end{array}$ & $2.88 \pm 1.02$ & $2.90 \pm 1.05$ & $2.92 \pm 1.00$ & $2.82 \pm 0.96$ & $2.69 \pm 0.96$ & $\mathbf{0 , 0 2 7}$ \\
\hline
\end{tabular}


Nas questões onde se observa diferenças significativas entre as regiões, destacam-se os jovens da região Norte, que consideram a ciência e tecnologia como causadoras dos problemas do ambiente mais que os jovens das demais regiões. Além disso, os nortistas acreditam mais que um país precisa da ciência e tecnologia para se desenvolver e que a C\&T beneficiam principalmente os países ricos $(\mathrm{G} 10, \mathrm{G} 11, \mathrm{G} 12)$.

Já os jovens do Centro-Oeste foram os que mais pontuaram as questões que apontam que a ciência e tecnologia ajudam os pobres e a erradicação da pobreza (G7, G8), demonstrando uma visão mais otimista. Em contrapartida, foram os jovens nordestinos que mais pontuaram nas questões referentes à importância da ciência para a sociedade e para oportunidades futuras (G1, G3).

Para verificar a existência de diferenças significativas de médias por pares (entre duas regiões) realizou-se o teste Tukey, conforme observado na tabela 8.5.

Tabela 8.5 - Diferenças existentes entre duas regiões (teste Tukey) para a seção G.

\begin{tabular}{|c|c|c|c|}
\hline Questões: “As minhas opiniões sobre ciência e tecnologia" & Teste & Diferença & P-valor \\
\hline $\begin{array}{l}\text { G01 - A ciência e a tecnologia têm grande importância para a } \\
\text { Sociedade }\end{array}$ & Nordeste - Centro-Oeste & 0,22 & 0,009 \\
\hline $\begin{array}{l}\text { G01 - A ciência e a tecnologia têm grande importância para a } \\
\text { Sociedade }\end{array}$ & Sudeste - Nordeste & $-0,18$ & 0,018 \\
\hline $\begin{array}{l}\text { G01 - A ciência e a tecnologia têm grande importância para a } \\
\text { Sociedade }\end{array}$ & Sul - Nordeste & $-0,3$ & $<0.001$ \\
\hline $\begin{array}{l}\text { G01 - A ciência e a tecnologia têm grande importância para a } \\
\text { Sociedade }\end{array}$ & Sul - Norte & $-0,26$ & 0,002 \\
\hline $\begin{array}{l}\text { G07 - A ciência e a tecnologia ajudarão a erradicar a pobreza e a } \\
\text { fome no mundo }\end{array}$ & Sudeste - Centro-Oeste & $-0,27$ & 0,004 \\
\hline $\begin{array}{l}\text { G07 - A ciência e a tecnologia ajudarão a erradicar a pobreza e a } \\
\text { fome no mundo }\end{array}$ & Sudeste - Norte & $-0,23$ & 0,004 \\
\hline G09 - A ciência e a tecnologia ajudam os pobres & Sudeste - Centro-Oeste & $-0,23$ & 0,02 \\
\hline $\begin{array}{l}\text { G10 - A ciência e a tecnologia são as causas dos problemas do } \\
\text { ambiente }\end{array}$ & Sudeste - Norte & $-0,2$ & 0,02 \\
\hline $\begin{array}{l}\text { G10 - A ciência e a tecnologia são as causas dos problemas do } \\
\text { ambiente }\end{array}$ & Sul - Norte & $-0,22$ & 0,04 \\
\hline $\begin{array}{l}\text { G11 - Um país precisa de ciência e de tecnologia para se } \\
\text { desenvolver }\end{array}$ & Sul - Nordeste & $-0,27$ & 0,002 \\
\hline $\begin{array}{l}\text { G11 - Um país precisa de ciência e de tecnologia para se } \\
\text { desenvolver }\end{array}$ & Sul - Norte & $-0,26$ & 0,003 \\
\hline $\begin{array}{l}\text { G12 - A ciência e a tecnologia beneficiam principalmente os } \\
\text { países desenvolvidos }\end{array}$ & Sul - Centro-Oeste & $-0,28$ & 0,008 \\
\hline $\begin{array}{l}\text { G12 - A ciência e a tecnologia beneficiam principalmente os } \\
\text { países desenvolvidos }\end{array}$ & Sul - Nordeste & $-0,34$ & $<0.001$ \\
\hline $\begin{array}{l}\text { G12 - A ciência e a tecnologia beneficiam principalmente os } \\
\text { países desenvolvidos }\end{array}$ & Sul - Norte & $-0,35$ & $<0.001$ \\
\hline $\begin{array}{l}\text { G16 - As teorias científicas desenvolvem-se e mudam } \\
\text { constantemente }\end{array}$ & Sul - Nordeste & $-0,21$ & 0,044 \\
\hline $\begin{array}{l}\text { G16 - As teorias científicas desenvolvem-se e mudam } \\
\text { constantemente }\end{array}$ & Sul - Norte & $-0,23$ & 0,022 \\
\hline
\end{tabular}


Corroborando as informações obtidas na tabela 8.4, a tabela 8.5 apontou que os jovens do Nordeste acreditam mais na importância da ciência e tecnologia para a sociedade que os jovens do Centro-Oeste, Sudeste e Sul. No que se refere a esta questão, os do Norte valorizam a importância da C\&T mais que os do Sul.

Os jovens do Centro-Oeste acreditam mais que os do Sudeste que a ciência e tecnologia ajudam os pobres. Os jovens do Norte consideram mais que os do Sudeste e Sul que a C\&T são as causas dos problemas do ambiente.

Os jovens do Sul acreditam menos que um país precisa da ciência e tecnologia para sobreviver que os do Norte e Nordeste e ainda, não acreditam que a ciência e tecnologia beneficiem principalmente os países ricos (em relação aos do Centro-Oeste, Norte e Nordeste). Os jovens do Sul também atribuíram menor valor na questão que indica o caráter dinâmico da ciência que os do Nordeste e Norte, assumindo uma postura mais conservadora.

\subsection{POSICIONAMENTOS DOS JOVENS BRASILEIROS FRENTE À CIÊNCIA E À TECNOLOGIA}

As médias gerais obtidas na seção $\mathrm{G}$ foram submetidas à Análise Fatorial, o que permitiu a identificação de 3 fatores que resumem as questões da seção (fatores com autovalores maiores que 1). Esses fatores explicam $49,57 \%$ da variação total das questões originais. As características dos fatores e suas respectivas questões podem ser observadas na tabela 8.6.

Tabela 8.6 - Variância explicada pelos fatores com autovalores maiores que 1 para o grupo de questões G.

\begin{tabular}{lccc}
\hline Fatores & \% da variância & \multicolumn{1}{c}{ Questões } & Alpha de Cronbach \\
\hline 1 & 30,39 & G01, G02, G03, G04, G05, G06, G11 & 0,801 \\
2 & 12,44 & G07, G08, G09, G13, G14, G15 & 0,781 \\
3 & 6,74 & G10, G12, G16 & 0,348 \\
\hline
\end{tabular}

A consistência interna pelo Alpha de Cronbach mostra valores altos com exceção do último fator que apresenta valor 0,348 . Os valores de correlação entre as questões e o fator podem ser observados na tabela 8.7. 
Tabela 8.7 - Os valores de correlação existentes entre as questões originais e os fatores obtidos.

\begin{tabular}{|c|c|c|c|}
\hline Questões/Fator & $\begin{array}{c}\text { Fator } 1 \\
\text { C\&T- } \\
\text { Otimista }\end{array}$ & $\begin{array}{c}\text { Fator } 2 \\
\text { C\&T- } \\
\text { Ingênuo }\end{array}$ & $\begin{array}{c}\text { Fator } 3 \\
\text { C\&T- } \\
\text { Pessimista }\end{array}$ \\
\hline $\begin{array}{l}\text { G01 - A ciência e a tecnologia têm grande importância para a } \\
\text { Sociedade }\end{array}$ & 0,677 & & \\
\hline $\begin{array}{l}\text { G02 - A ciência e a tecnologia encontrarão curas para doenças como a } \\
\text { AIDS, o câncer, etc. }\end{array}$ & 0,582 & & \\
\hline $\begin{array}{l}\text { G03 - Devido à ciência e à tecnologia, haverá melhores oportunidades } \\
\text { para as futuras gerações. }\end{array}$ & 0,768 & & \\
\hline $\begin{array}{l}\text { G04 - A ciência e a tecnologia tornam as nossas vidas mais saudáveis, } \\
\text { mais fáceis e mais confortáveis. }\end{array}$ & 0,651 & & \\
\hline G05 - As novas tecnologias tornarão o trabalho mais interessante & 0,700 & & \\
\hline $\begin{array}{l}\text { G06 - Os benefícios da ciência são maiores do que os efeitos } \\
\text { negativos que possa ter }\end{array}$ & 0,489 & & \\
\hline $\begin{array}{l}\text { G07 - A ciência e a tecnologia ajudarão a erradicar a pobreza e a fome } \\
\text { no mundo }\end{array}$ & & 0,666 & \\
\hline $\begin{array}{l}\text { G08 - A ciência e a tecnologia podem resolver quase todos os } \\
\text { problemas }\end{array}$ & & 0,665 & \\
\hline G09 - A ciência e a tecnologia ajudam os pobres & & 0,717 & \\
\hline $\begin{array}{l}\text { G10 - A ciência e a tecnologia são as causas dos problemas do } \\
\text { ambiente. }\end{array}$ & & & 0,700 \\
\hline G11 - Um país precisa de ciência e de tecnologia para se desenvolver & 0,593 & & \\
\hline $\begin{array}{l}\text { G12 - A ciência e a tecnologia beneficiam principalmente os países } \\
\text { desenvolvidos. }\end{array}$ & & & 0,576 \\
\hline $\begin{array}{l}\text { G13 - Os cientistas seguem o método científico que os leva sempre às } \\
\text { respostas corretas }\end{array}$ & & 0,609 & \\
\hline G14 - Podemos sempre confiar no que os cientistas dizem & & 0,746 & \\
\hline G15 - Os cientistas são neutros e objetivos & & 0,552 & \\
\hline G16 - As teorias científicas desenvolvem-se e mudam constantemente & & & 0,573 \\
\hline
\end{tabular}

Cada fator reflete um agrupamento de opiniões/atitudes dos alunos. Assim, cada fator possui um atributo, relacionado às opiniões a ele relacionadas. Dentro do fator 1, as questões G03 e G05 são as que apresentam mais peso (maior valor), e apontam para a importância da ciência no trabalho. As demais questões estão relacionadas com a importância e os benefícios sociais da C\&T. Podemos denominar o fator 1 de $C \& T$-Otimista, uma vez que as questões agrupadas indicam uma opinião positiva da C\&T.

O segundo fator agrupa questões relacionadas com uma visão superlativa da ciência e do trabalho científico, já que expressa opiniões acerca do papel da C\&T na erradicação da pobreza e da fome, e dos problemas de modo geral. A questão de maior peso é "podemos sempre confiar no que os cientistas dizem", que ao lado das questões G13 e G15 apontam para uma visão ingênua da atividade científica. Assim, denominamos este fator de $C \& T$-Ingênuo. 
O terceiro e último fator agrupa duas questões que apontam para uma visão negativa da ciência (G10 e G12), ao lado da última questão que aborda o caráter dinâmico da ciência. As duas primeiras questões, que possuem maior peso dentro do fator, foram responsáveis pela atribuição do nome $C \& T$-pessimista para o fator 3 .

Assim, observamos que as atitudes dos jovens brasileiros em relação à Ciência e Tecnologia podem ser resumidas em três grupos: o maior grupo, que responde a 30,39\% da variância das questões originais, é chamado de C\&T-Otimista, e reúne opiniões positivas relacionadas à C\&T. O segundo grupo, C\&T-Ingênuo, reúne atitudes que supervalorizam a ciência e os cientistas, responde a 12,44\% da variância das questões; por fim, o terceiro grupo, denominado C\&T-Pessimista, agrupa em especial duas questões que expressam atitudes negativas para com a C\&T, e responde individualmente a 6,74\% da variância entre as questões.

Os escores médios apresentados pelos fatores sugeridos na Análise Fatorial, obtidos a partir das médias das questões que compõem cada fator, foram testados para identificar possíveis diferenças em relação ao gênero dos alunos. As médias atribuídas pelos meninos e meninas e geral nas questões pertencentes a cada fator podem ser observadas na tabela 8.8.

Tabela 8.8 - Medidas e testes de Mann-Whitney para diferença em relação ao gênero dos estudantes para os fatores do grupo de questões $\mathrm{G}$.

\begin{tabular}{lccccccc}
\hline & \multicolumn{2}{c}{ Mulher } & \multicolumn{2}{c}{ Homem } & \multicolumn{2}{c}{ Geral } & \\
\cline { 2 - 7 } Fator & Média & $\begin{array}{c}\text { Desvio } \\
\text { Padrão }\end{array}$ & Média & $\begin{array}{c}\text { Desvio } \\
\text { Padrão }\end{array}$ & Média & $\begin{array}{l}\text { Desvio } \\
\text { Padrão }\end{array}$ & p-valor \\
\hline C\&T-Otimista & 3,03 & 0,635 & 2,96 & 0,689 & 3,00 & 0,658 & 0,094 \\
C\&T-Ingênuo & 2,09 & 0,677 & 2,26 & 0,711 & 2,16 & 0,696 & $<0,001$ \\
C\&T-Pessimista & 2,66 & 0,795 & 2,72 & 0,814 & 2,69 & 0,804 & 0,055 \\
\hline
\end{tabular}

O fator com maior pontuação, tanto para meninas como para meninos, foi o C\&T-Otimista, indicando que o jovem brasileiro em geral possui uma atitude positiva para com a ciência e a tecnologia.

Os dados obtidos se alinhavam aos da pesquisa realizada pela FAPESP em 2005, onde se verificou que $74 \%$ dos entrevistados possuem uma visão positiva da ciência, relacionando-a com "grandes descobertas", "avanço técnico", "melhora da vida humana" e "compreensão do mundo natural". As visões negativas da ciência foram compartilhadas por apenas $13 \%$ dos en- 
trevistados, que a relacionaram com "perigo de descontrole", "concentração de poder" e "ideias que poucos entendem" (FAPESP, 2005, p. 13).

Em todos os grupos observaram-se diferenças significativas entre meninos e meninas: as meninas são mais otimistas que os meninos, os meninos mais ingênuos em relação à atividade científica e também mais pessimistas. 


\subsection{A POSIÇÃO DOS JOVENS BRASILEIROS EM RELAÇÃO À CIÊNCIA E À TECNOLOGIA NO CENÁRIO INTERNACIONAL}

Algumas questões da seção $G$ foram selecionadas para comparações entre o Brasil e os demais países participantes do projeto ROSE. A questão G01 "A ciência e tecnologia têm grande importância para a Sociedade" pode ser observada na figura 8.1.

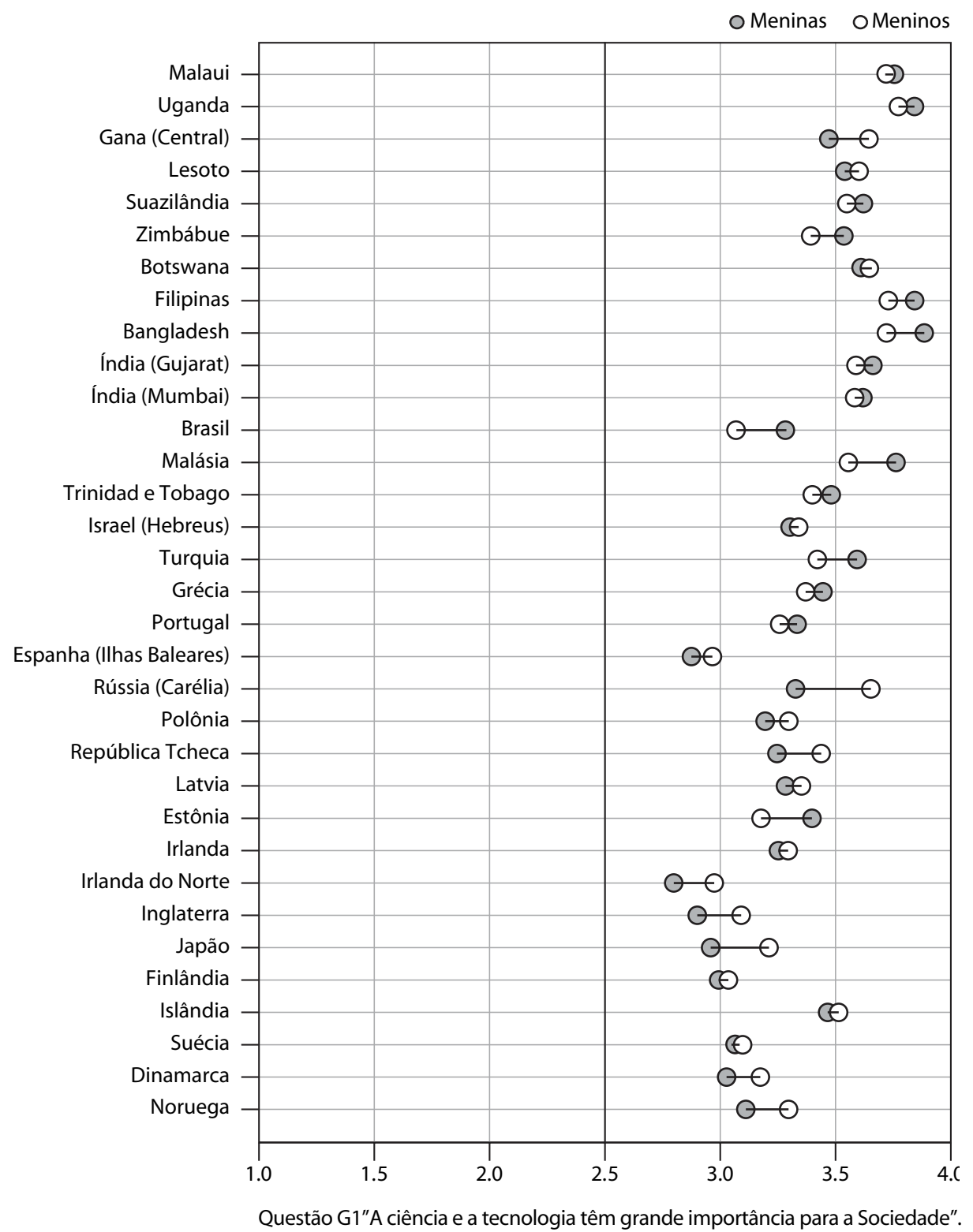

Figura 8.1 - Distribuição das respostas médias de meninos e meninas na questão G01, adaptado de Matthews (2007) 
Observamos que a posição do jovem brasileiro quanto à importância da ciência e tecnologia para a sociedade é semelhante à dos jovens da Grécia, Polônia e Latvia. Nos países com alto IDH (parte inferior do gráfico) o valor atribuído a esta questão foi menor, em especial no que se refere às meninas, com exceção da Islândia e Noruega.

O gráfico comparativo para a questão G08 "A ciência e a tecnologia podem resolver quase todos os problemas" pode ser observado na figura 8.2.

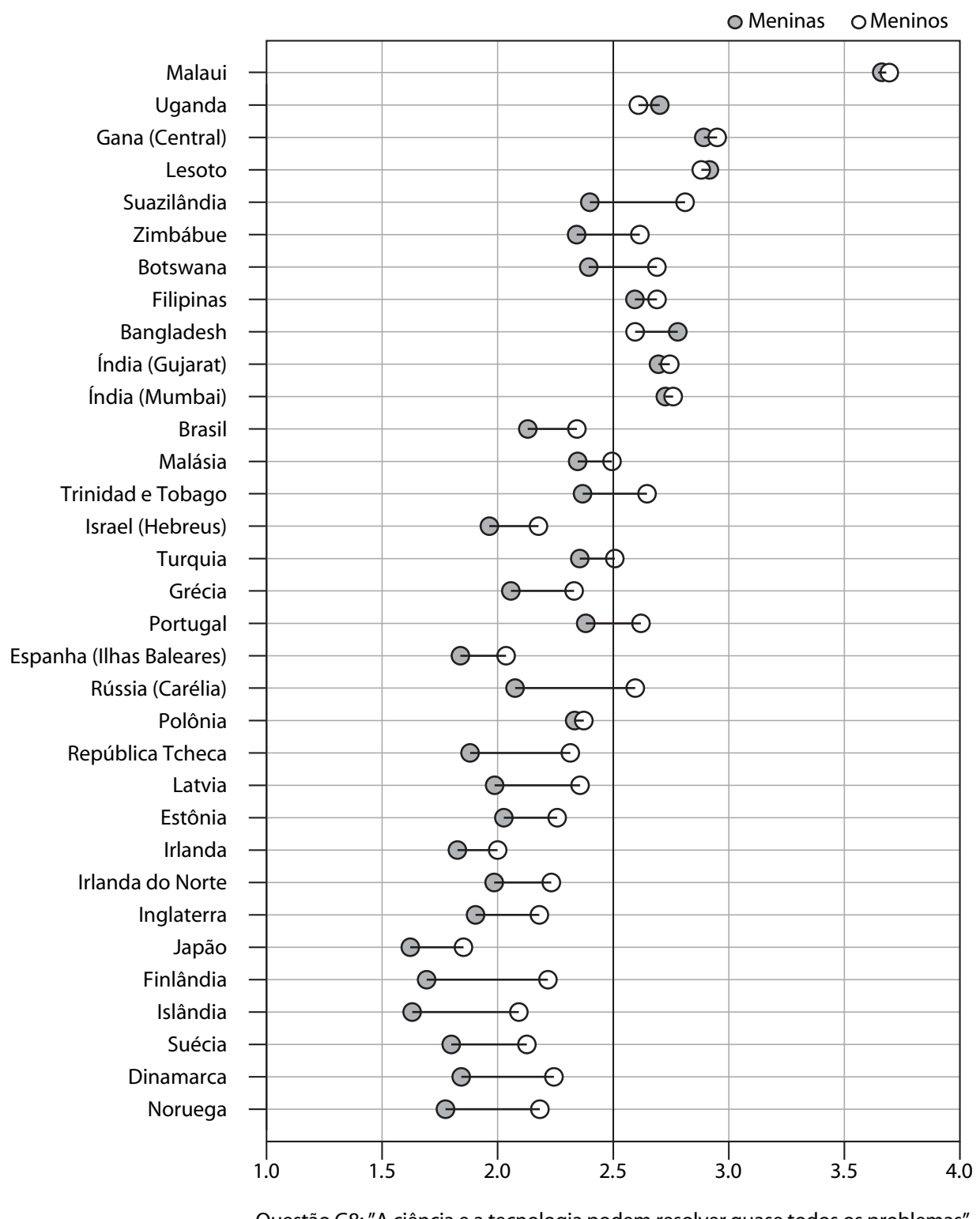

Figura 8.2 - Distribuição das respostas médias de meninos e meninas na questão G08, adaptado de Matthews (2007). 
Da mesma forma que na questão anterior, os jovens brasileiros apresentaram um padrão que se assemelha à faixa central do gráfico, distinguindo-se tanto dos jovens de países com alto IDH como dos jovens de países com baixo IDH. Novamente, os gregos e poloneses foram os mais semelhantes, porém no caso dos poloneses há pouca diferença de gênero, fato não observado dentre os brasileiros.

Os resultados para a questão G14 "Podemos confiar sempre no que os cientistas dizem" pode ser observada na figura 8.3.

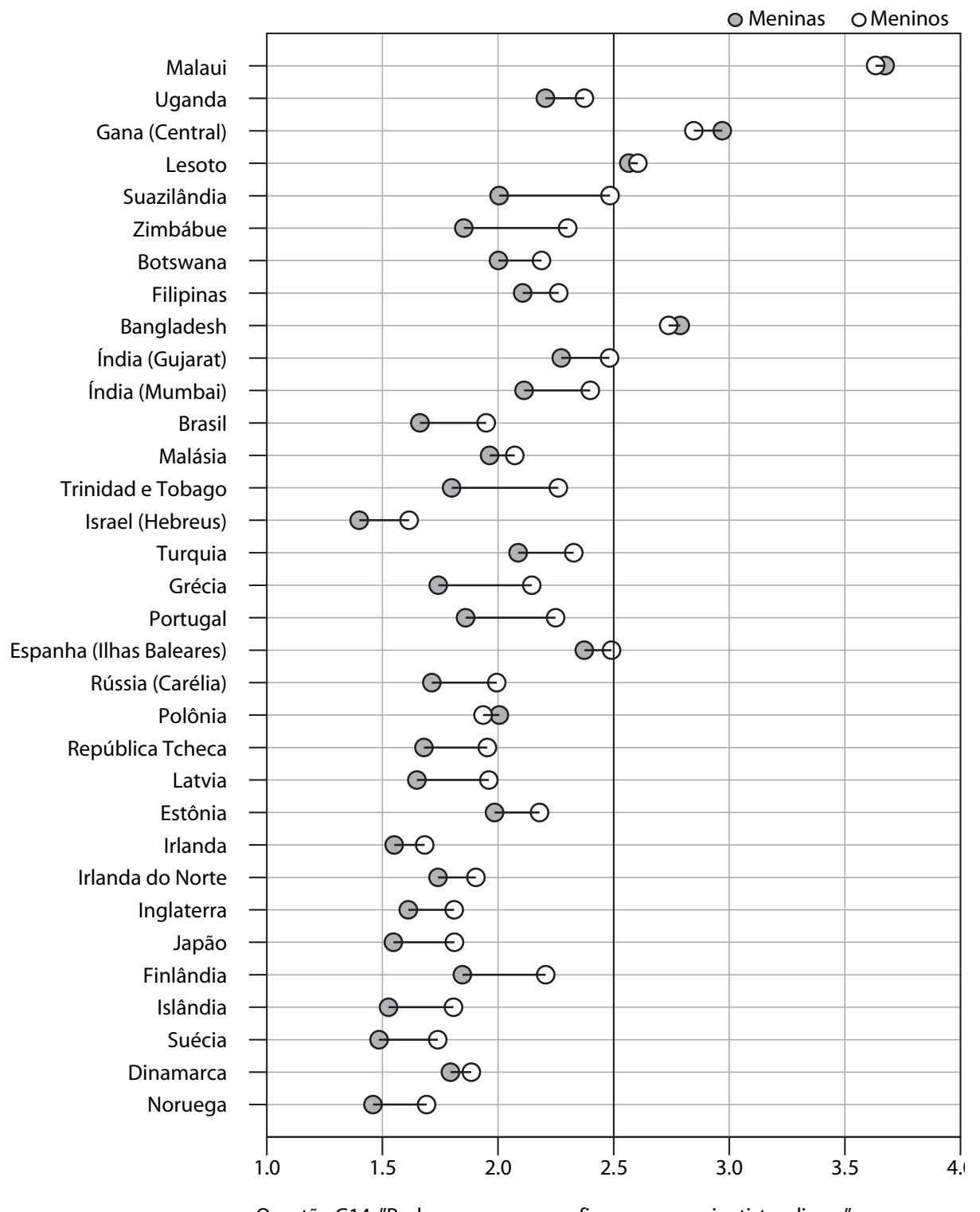

Questão G14: "Podemos sempre confiar no que os cientistas dizem".

Figura 8.3 - Distribuição das respostas médias de meninos e meninas na questão G14, adaptado de Matthews (2007). 
Observamos que, com exceção dos jovens do Malauí, Gana, Lesoto e Bangladesh, os jovens de modo geral não confiam sempre no que os cientistas dizem, em especial as meninas, demonstrando uma visão mais madura da atividade científica. A posição dos brasileiros foi semelhante aos jovens dos países da faixa central, como Rússia, República Tcheca e Latvia. 


\section{COMENTÁRIOS SOBRE A APLICAÇÃO DO PROJETO ROSE NO BRASIL}

Neste capítulo faremos alguns comentários sobre a aplicação do projeto ROSE no Brasil, de forma a contribuir com pesquisas de opiniões e atitudes que visem à coleta de dados em âmbito nacional em escolas e que possuam questionários de longa extensão.

O projeto ROSE, por ter caráter internacional, possui um guia denominado Sowing the Seeds of $\operatorname{ROSE}^{20}$, elaborado pelos organizadores do projeto na Noruega, Camilla Schreiner, pesquisadora sênior, que através do projeto fez seu doutoramento, e Svein Sjøberg, professor da Universidade de Oslo e coordenador do projeto. Neste guia há instruções específicas para os pesquisadores que irão aplicar o projeto em outros países. Neste capítulo faremos comentários sobre alguns itens que constam nas instruções, acrescentando elementos que consideramos importantes para a concretização do projeto no Brasil.

\subsection{RECURSOS HUMANOS E FINANCEIROS}

Realizar um projeto de pesquisa com representatividade nacional no Brasil só é possível se houver recursos financeiros que o viabilize e uma equipe de pesquisa que atue de forma colaborativa nas diversas fases do projeto.

Os recursos financeiros foram obtidos no ano de 2009 junto ao CNPq, através do Edital Universal 14/2009. Assim, as despesas envolvendo o estudo amostral, as análises estatísticas, a impressão do questionário ROSE e materiais consumíveis diversos foram realizadas mediante recursos do CNPq. Especificamente sobre a impressão do questionário, foi necessário:

- O preparo de folhas de respostas para Intelligent Character Recognition (ICR), que proporciona a captura automática de dados;

- O desenvolvimento de cadernos de respostas em formato A3, com papel $90 \mathrm{~g} / \mathrm{m} 2$, que permite o escaneamento posterior;

- Personalização a laser das folhas ópticas através de códigos de barras;

- Captura automática de dados através do ICR. A leitura é feita com o reconhecimento de caracteres ICR nos formulários preenchidos à mão pelos respondentes.

\footnotetext{
${ }^{20}$ SCHREINER, C.; SJØBERG, S. Sowing the seeds of Rose. Acta Didactica 4/2004, p. 120, 2004.
} 
As despesas de correio, que envolveram remessa de questionários por SEDEX e selos para o retorno dos mesmos foram realizadas com recursos da Faculdade de Educação da USP.

A equipe de pesquisa foi constituída pelo coordenador do projeto, Prof. Dr. Nelio Bizzo, duas alunas de doutorado, Ana Maria Santos Gouw, bolsista CAPES, autora desta tese, e Helenadja Mota Rios Pereira, bolsista CAPES, cujo projeto é intitulado "Atitudes de estudantes no contexto brasileiro de Ensino Médio em relação à teoria da evolução biológica" e alunos de iniciação científica.

Quatro alunos de graduação atuaram em diferentes fases do projeto: no $1^{\circ}$ semestre de 2010, Carolina Canton Maciel, graduanda, cujo trabalho de Conclusão de Curso foi "Projeto ROSE Brasil - Estudo exploratório sobre a aplicação da ferramenta de coleta de dados”, atuou na coleta de dados de algumas escolas do estado de São Paulo, onde realizou entrevistas com os aplicadores e Felipe Simões, graduando cujo trabalho de Conclusão de Curso foi "Projeto ROSE Brasil - Estudo exploratório das opiniões dos estudantes inquiridos quanto a sua percepção sobre o papel e a função de ciência e tecnologia na sociedade”. Pedro Henrique de Mattos Kurtz (bolsista CNPq) atuou no $2^{\circ}$ semestre de 2010 na primeira fase da coleta de dados (nacional) e Mariana Antonieta Barreto do Prado (bolsista CNPq), cujo projeto de iniciação científica foi intitulado "Pesquisa sobre as tendências dos jovens brasileiros frente aos problemas ambientais", que atuou em 2011/2012 na segunda fase de coleta de dados, verificando também as remessas e retornos de questionários.

Os alunos de graduação atuaram diretamente na coleta de dados, estabelecendo contatos telefônicos com as escolas, quer para conhecer os gestores, quer para apresentar o projeto, quer para solicitar a retorno dos questionários preenchidos.

Ainda houve alunos de graduação que atuaram indiretamente no projeto, que através do estágio supervisionado da disciplina EDM 433/434 - Metodologia de Ensino de Ciências Biológicas (ano 2011 e 2012) aplicaram voluntariamente o questionário a turmas de alunos com o objetivo de verificar o processo de aplicação em si. Vale ressaltar que tais questionários não fizeram parte da amostra do projeto ROSE Brasil, uma vez que foram aplicados na Grande São Paulo, região onde já havia sido realizada a coleta de dados no ano de 2010. 


\subsection{SOBRE A AMOSTRA E A LOGÍSTICA DE COLETA DE DADOS}

As instruções sobre a amostra contidas no guia do projeto ROSE são: o tamanho amostral deve representar a população-alvo, ou seja, alunos que estão finalizando os estudos compulsórios e que por consequência tenham cerca de 15 anos de idade; o questionário deve ser aplicado a turmas de alunos, e não a alunos individualmente; as escolas participantes devem ser selecionadas por sorteio; em cada escola, uma única classe deve participar da pesquisa; 25 escolas no mínimo devem participar da amostra, o que envolve 625 estudantes. Os autores ainda sugerem a obtenção de listas de escolas junto a órgãos governamentais, o que simplificaria tanto o sorteio quanto a definição do tamanho amostral (SCHREINER; SJØBERG, 2004).

A opção do projeto ROSE no Brasil ter como referência a aplicação do PISA no ano de 2009 foi adequada aos propósitos da pesquisa, uma vez que possibilitou:

- a obtenção de uma lista de escolas atualizada e acessível;

- a obtenção de contatos junto às diretorias de ensino,

caso as escolas não estivessem disponíveis;

- a seleção de uma amostra que mantivesse as mesmas características da amostra PISA 2009, ou seja, a representatividade nacional;

- o sorteio de escolas em todos os estados brasileiros,

proporcional à lista original do PISA e

- um modelo já testado para a coleta de dados, ou seja, para a aplicação do questionário.

No que se refere à aplicação do questionário, o projeto ROSE também foi organizado nos moldes do PISA 2009, e utilizou o serviço de correios como meio de entrega dos questionários e os próprios funcionários e/ou professores das escolas como aplicadores. Este modelo, além de ser de baixo custo, uma vez que não envolve deslocamento de aplicadores, mostrou-se extremamente viável e adequado aos objetivos do projeto.

Como forma de incentivar os professores/funcionários da escola em participar da pesquisa e valorizar o trabalho por eles realizado, optamos por enviar a cada um deles uma declaração onde constava sua participação como aplicador e/o colaborador do projeto ROSE no Brasil. Um modelo da declaração enviada pode ser observado na figura 9.1 . 


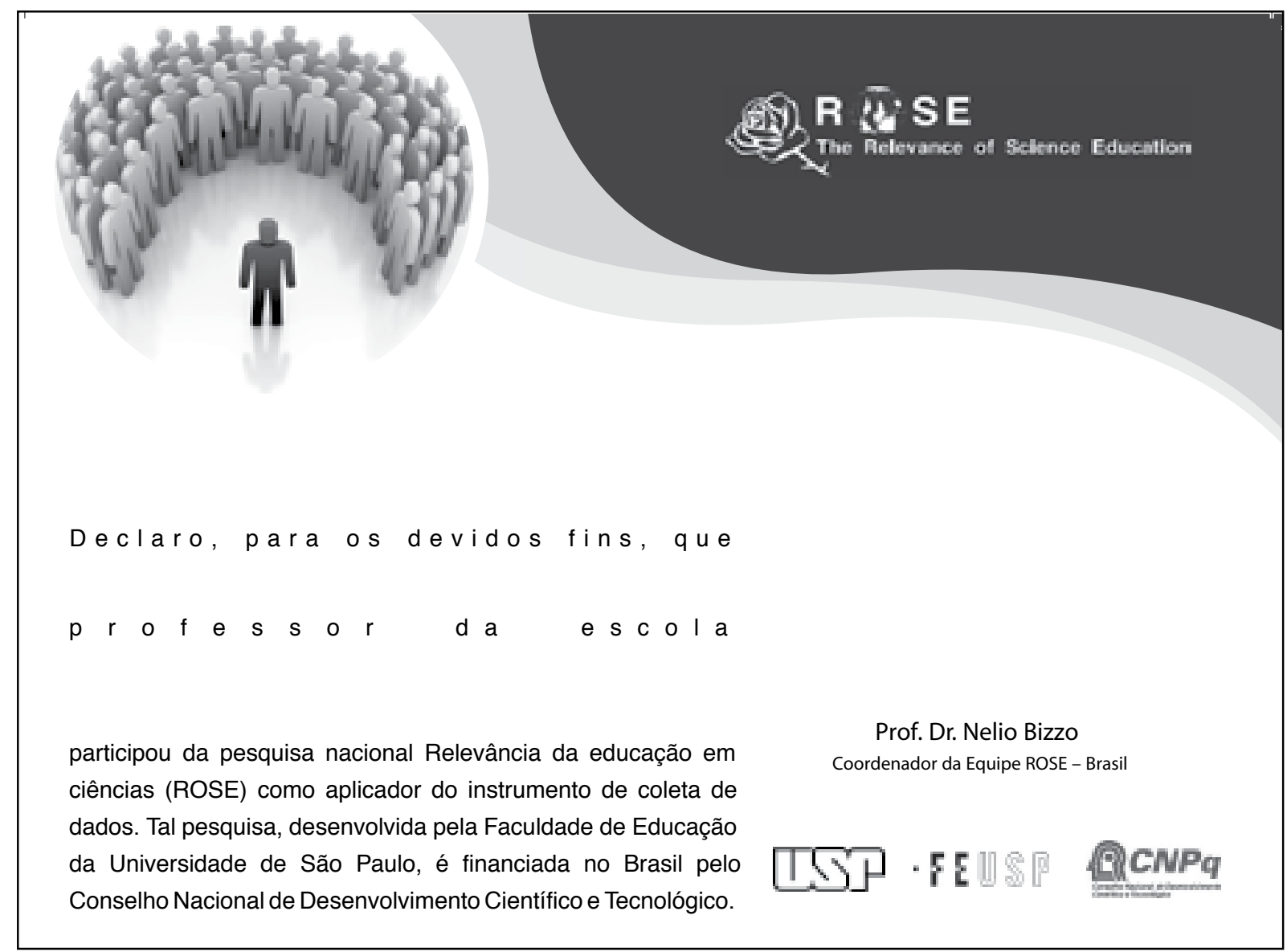

Figura 9.1 - Imagem com o modelo de declaração enviado aos aplicadores do questionário nas escolas.

A fim de tornar possível uma troca de informações mais ágil entre a equipe de pesquisa e as escolas foi criado e utilizado um email especificamente para o projeto, denominado "projetorose2010@gmail.com".Através deste email, muitos professores e coordenadores manifestaram interesse em participar, solicitaram mais informações e até mesmo enviaram fotos da aplicação do projeto na escola. A figura 9.2 refere-se a aplicação do questionário em uma escola do município de Limoeiro - PE. 


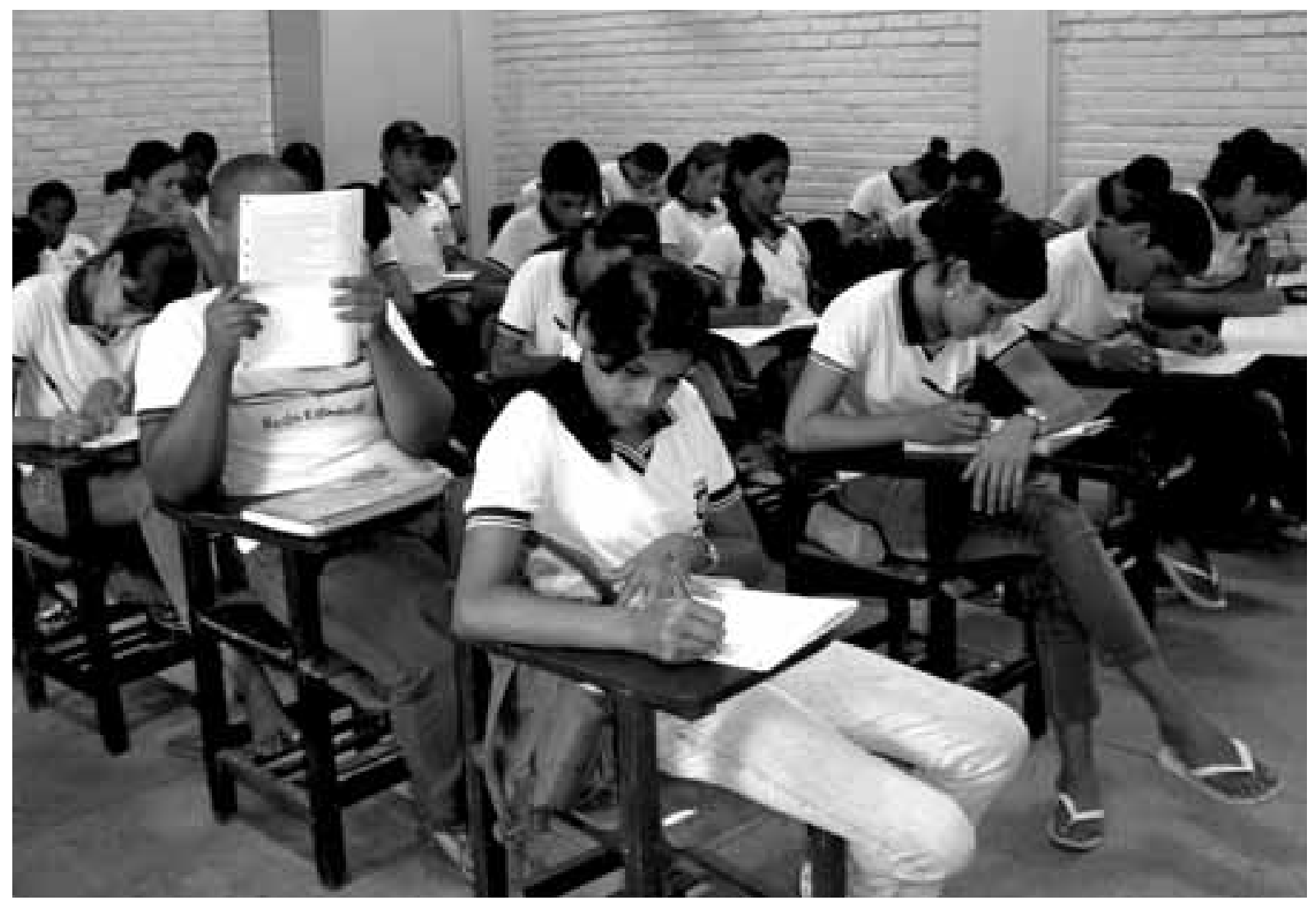

Figura 9.2 - Aplicação do questionário ROSE em uma escola do município de Limoeiro - PE.

Assim, verificamos ser altamente recomendável uma parceria com órgãos do Ministério da Educação ou das secretarias estaduais de educação para a realização de pesquisas junto às escolas no Brasil. No caso do presente trabalho, a disposição do INEP, mediante a gerência do PISA no Brasil, em fornecer os dados das escolas para a aplicação do questionário, foi imprescindível para que a pesquisa fosse realizada.

Sobre a representatividade da amostra, é interessante considerar que a pesquisa no Brasil teve o mérito de ser representativa do país, fato que não foi possível em diversos países. Tolentino Neto (2008) faz considerações a este respeito ao citar como exemplos, a Rússia, onde apenas o sul de um estado (Carélia) foi amostrado, a Espanha, cuja amostra se restringiu às Ilhas Baleares, Israel, que aplicou o questionário apenas à estudantes de origem judaica (85\% da população) e Gana, cuja amostra representa a região central do país.

Os dados amostrais de 25 países participantes do ROSE podem ser observados na tabela 9.1, cuja fonte é a tabela 4-2 de Schreiner (2006, p. 104). 
Tabela 9.1 - Dados amostrais de alguns países participantes do ROSE.

\begin{tabular}{|c|c|c|c|c|}
\hline País & $\begin{array}{c}\text { Tamanho da } \\
\text { amostra }\end{array}$ & Meninas & Meninos & $\begin{array}{l}\text { Idade } \\
\text { Média }\end{array}$ \\
\hline Bangladesh & 1669 & 647 & 1014 & 15,0 \\
\hline Botswana & 644 & 388 & 255 & 15,7 \\
\hline Dinamarca & 520 & 268 & 251 & 15,0 \\
\hline Inglaterra & 1266 & 653 & 612 & 14,5 \\
\hline Estônia & 640 & 331 & 308 & 15,4 \\
\hline Finlândia & 3550 & 1765 & 1782 & 15,4 \\
\hline Gana (Central) & 782 & 374 & 408 & 15,0 \\
\hline Grécia & 547 & 284 & 263 & 14,6 \\
\hline Islândia & 618 & 310 & 308 & 15,2 \\
\hline Índia (Gujarat) & 1136 & 508 & 627 & 14,7 \\
\hline Irlanda & 640 & 313 & 327 & 15,4 \\
\hline Japão & 560 & 268 & 291 & 14,9 \\
\hline Latvia & 1041 & 611 & 426 & 15,4 \\
\hline Malasia & 1527 & 724 & 793 & 16,0 \\
\hline Irlanda do Norte & 832 & 410 & 422 & 14,7 \\
\hline Noruega & 1204 & 596 & 607 & 15,0 \\
\hline Filipinas & 4434 & 2922 & 1506 & 15,9 \\
\hline Polônia & 615 & 343 & 272 & 15,8 \\
\hline Portugal & 523 & 273 & 250 & 14,7 \\
\hline Rússia (Carélia) & 707 & 346 & 361 & 14,7 \\
\hline Suazilândia & 534 & 336 & 197 & 15,4 \\
\hline Suécia & 746 & 356 & 390 & 15,5 \\
\hline Trinidad e Tobago & 638 & 362 & 276 & 14,6 \\
\hline Uganda & 758 & 408 & 349 & 15,3 \\
\hline Zimbábue & 533 & 310 & 222 & 15,6 \\
\hline Brasil & 2365 & 1339 & 983 & 15,4 \\
\hline Total & 29029 & 15445 & 13500 & 15,18 \\
\hline
\end{tabular}

Fonte: Tradução da tabela 4-2 de Schreiner (2006, p. 104) com inclusão dos dados brasileiros.

Observamos através da tabela acima que a amostra brasileira é a $3^{\mathrm{a}}$ em volume de alunos participantes, o que revela uma significativa contribuição do país às discussões futuras do projeto. 


\subsection{A LEITURA ÓPTICA}

A tabulação dos questionários no Brasil foi realizada através do sistema de leitura ICR, conforme descrito acima. Tal sistema foi uma inovação brasileira para a pesquisa, e contribui na diminuição dos erros oriundos da tabulação manual e do tempo necessário para esta tabulação. Na Noruega, por exemplo, os 1204 questionários foram tabulados de forma manual por ajudantes do projeto (SCHREINER, 2006).

Assim, a amostra brasileira, além de ser representativa da população alvo em âmbito nacional, também possui um erro menor no que se refere à tabulação, uma vez que não consideramos erros na tabulação.

\subsection{FORMATO DO QUESTIONÁRIO}

As instruções contidas no documento Sowing the Seeds of ROSE solicitam a tradução do instrumento com a conservação do formato original do questionário: "o layout, quebra de páginas, fonte e tamanho de texto e número de páginas deve ser exatamente igual ao do questionário original em inglês". Assim, a versão brasileira do questionário, que foi realizada por Tolentino Neto (2008), manteve as mesmas características que a versão original (SCHREINER; SJØBERG, 2004, p. 95).

Tendo em vista que o projeto ROSE foi preparado para atender à diversidade cultural encontrada nos países participantes, foi permitido que "cada país incluísse seções ou questões ao final do questionário" (SCHREINER; SJØBERG, 2004, p. 95), chamadas de "Questões Nacionais". No Brasil elas contemplaram aspectos do ensino de evolução e religião, e foram objeto de estudo do doutoramento de Helenadja Mota Rios Pereira.

Durante o Seminário Internacional Brasil-Itália Youngsters and Science, realizado em novembro de 2012 em Brasília, aplicadores do projeto ROSE no Brasil (em 2007 e 2010) e na Itália (BIZZO; PELLEGRINI, 2013; SANTOS GOUW, 2013), reuniram-se para a discussão de um instrumento semelhante ao ROSE, porém que fosse mais ajustado à realidade ítalo-brasileira. Um dos pontos discutidos com bastante cuidado foi o formato do questionário, que possui o mesmo layout através de 12 páginas: uma pergunta no cabeçalho em negrito seguida de um bloco único com os itens dispostos em tabela. 
Do ponto de vista dos pesquisadores presentes, tal formato é repetitivo e não oferece conforto visual ao respondente, o que pode levar ao cansaço precoce. A sugestão foi a produção de questionários com quebras visuais, através de inserção de imagens e de rupturas ou mudanças no layout do próprio questionário.

A inserção das "Questões Nacionais" no Brasil propiciou uma ruptura na estrutura visual do questionário: a primeira seção (seção I) desta parte é constituída por uma questão de múltipla escolha, e não por um item com escala de Likert, o que difere da estrutura visual anterior. Além disso, esta seção é seguida por 2 blocos de questões distintas, que constituem a seção J e L do questionário, que rompem com a estrutura de bloco único utilizada. A mudança de layout verificada nas seções I, J e L (que constituem a página 13 do questionário) favoreceram a retomada de atenção dos respondentes, que será explicitada no item 9.5.

\subsection{TAMANHO DO QUESTIONÁRIO}

O questionário ROSE no Brasil possui um total de 14 páginas (incluindo as "Questões Nacionais"). Na primeira página estão descritas as instruções de preenchimento e os dados censitários (gênero, localidade, número de livros e banheiros do domicílio do aluno). Nas páginas seguintes estão dispostos 268 itens que convidam o aluno a assinalar seu nível de interesse nos mais diversos assuntos e temas (11 páginas para o questionário original e 2 páginas para as "Questões Nacionais").

O tamanho do questionário no Brasil provocou a princípio desconforto nos alunos, principalmente devido ao tempo necessário para o seu término. Enquanto que na Noruega (no pré-teste) foi indicado que o tempo de 40 minutos (uma aula) era suficiente para a aplicação (SCHREINER; SJØBERG, 2004), no Brasil, em muitos casos, 50 minutos (uma aula) não foram suficientes. Na Itália, os alunos necessitaram de, em média, uma hora para responder o questionário, segundo depoimento dado durante o Seminário Internacional Brasil-Itália Youngsters and Science.

Uma das alunas de iniciação científica participante do projeto, Carolina Canton Maciel, entrevistou pessoalmente quatro aplicadores de quatro escolas diferentes no estado de São Paulo. Em três escolas foi observado um descontentamento dos alunos ao observarem o tamanho do questionário. Uma das aplicadoras relatou que "existe aquele preconceito em ver um ques- 
tionário grande, cheio de perguntas, e os alunos já desgostam antes mesmo de começar a aplicação" (escola de Mogi das Cruzes). Duas destas aplicadoras revelaram que os alunos iniciaram o preenchimento do questionário com reclamações, mesmo antes de observarem seu conteúdo.

A doutoranda Helenadja Mota Rios Pereira aplicou o questionário em uma escola de Salvador (BA) também percebeu um desconforto inicial dos alunos em relação ao tamanho do questionário.

Dezesseis alunos aplicaram o projeto ROSE durante o estágio supervisionado da disciplina Metodologia de Ensino de Ciências Biológicas (EDM-433/434) e registraram suas observações em um relatório específico. O tamanho do questionário foi apontado com extenso e cansativo por 9 turmas, o preenchimento integral do quadradinho no campo de respostas, que demanda mais tempo, foi apontado como negativo por 3 turmas, a ausência de legendas intermediárias na escala de Likert foi considerada difícil por duas turmas. Por fim, em seis turmas foi observado que 50 minutos não foram suficientes para o preenchimento completo do questionário, e em duas turmas foi observado que 40 minutos foram suficientes para a tarefa.

O efeito do tamanho do questionário pode ser observado no cansaço demonstrado ao longo do seu preenchimento. Para isso, foram considerados dois aspectos: questionários incompletos e questionários com padrão repetitivo, cujas respostas passam a assumir aspecto uniforme, com a indicação da mesma(s) alternativa(s) na folha de respostas. Os dados obtidos através da observação de tais aspectos estão descritos na tabela 9.2.

Tabela 9.2 - Resultados da análise do cansaço do aluno (abandono e padrão repetitivo).

\begin{tabular}{lc}
\hline Tipos de Cansaço Aparente & $\begin{array}{c}\text { Porcentagem } \\
(\mathbf{\%})\end{array}$ \\
\hline Abandono (questionários incompletos) & 2,67 \\
Abandono com retomada das “Questões Nacionais” (Seções I, J, L, M, N) & 1,08 \\
Questionários com padrão repetitivo & 1,08 \\
Total & 4,83 \\
\hline
\end{tabular}

Conforme observado na tabela acima, o cansaço do aluno, expresso no abandono do preenchimento do questionário ou no padrão repetitivo de preenchimento, foi observado em menos de 5\% dos questionários, o que demonstra que o cansaço não afetou de forma sensível a amostra. Vale ressaltar que a análise do padrão repetitivo tem um caráter subjetivo, uma vez que não sabemos se o aluno, de fato, estava respondendo de forma intencional a escala ou não. 
Observa-se que em cerca de 1/4 dos questionários incompletos houve uma retomada no preenchimento após o início das "Questões Nacionais". Atribuímos esta retomada à quebra de layout e à mudança do assunto presente no questionário, que passa a estar relacionado com a religião dos alunos. Tal fato corrobora a viabilidade de um questionário cuja estrutura visual ofereça rupturas propositais, quebras de blocos ou mesmo inserção de elementos para descanso no preenchimento.

\subsection{OPINIÕES DOS ALUNOS E PROFESSORES SOBRE O QUESTIONÁRIO ROSE}

Uma professora, aplicadora do questionário de uma escola da Bahia, que enviou depoimento via e-mail, relatou que apesar do tamanho do questionário gerar um estranhamento inicial, os alunos se mostraram contentes por estarem expressando suas próprias opiniões, algo não muito usual na escola.

Um dos alunos da disciplina EDM-434 perguntou, após a aplicação do questionário, se os alunos acharam que as questões eram interessantes. Cerca de $80 \%$ dos alunos (total de 40) consideraram as questões interessantes, por que abordavam sua vida cotidiana e por que levavam em consideração suas opiniões.

Durante a aplicação do questionário realizada em Salvador (BA) pela doutoranda Helenadja Mota Rios Pereira, foi observado que o tamanho do questionário causou desconforto inicial. Porém, após o início do preenchimento, ao perceberem que era um questionário de opinião, os alunos demonstraram interesse em preencher e não demonstraram cansaço.

Nas entrevistas realizadas pela aluna Carolina Canton Maciel, depoimentos relacionados ao fato de ser um questionário de interesses foram destacados por dois aplicadores: "os alunos gostaram de realizar o preenchimento da atividade e sentiram que esse era o espaço adequado para dar sua opinião" (escola de Mogi das Cruzes - SP) e "os alunos gostaram de dar sua opinião pelo fato da atividade não ser uma avaliação de proficiência e sim de interesse, (...) eles fizeram o exame do PISA, mas esse era diferente porque era uma prova, não era tão focado em perguntar a opinião deles sobre um determinado assunto" (escola de São Paulo - SP).

Assim, observou-se que os alunos participantes do ROSE Brasil demonstraram interesse em estarem sendo consultadas suas opiniões acerca de diversos assuntos relacionados à ciência e tecnologia. 


\title{
10 CONSIDERAÇÕES FINAIS
}

Este trabalhou procurou, através da aplicação do projeto ROSE no Brasil em âmbito nacional, ouvir o que os estudantes têm a dizer sobre seus temas científicos preferidos, sua posição frente aos desafios ambientais, o que pensam de suas aulas de ciências e suas opiniões sobre o papel da ciência e da tecnologia na sociedade.

Nós compactuamos com as considerações de Schreiner e Sjøberg (2004, p. 20-21)

\begin{abstract}
a única maneira do ensino de ciências ter sucesso é conhecer as visões e percepções dos estudantes. É somente tendo como ponto de partida suas visões é que a educação científica pode recrutar mais cientistas, promover o exercício da cidadania qualificado e o desenvolvimento sustentável. Somente através do encontro com os alunos em seus ambientes é que a ciência pode contribuir com o desenvolvimento dos jovens, de forma a capacitá-los e prepará-los para o exercício de sua autonomia.
\end{abstract}

De fato, 2365 jovens provenientes de todos os estados brasileiros deram suas opiniões sobre os mais diversos assuntos relacionados à educação científica escolar. Assim sendo, de maneira a legitimar as considerações manifestas por esses estudantes, cabe uma reflexão sobre as eventuais ações que podem ser tomadas a fim de que suas opiniões dialoguem com professores, currículos, livros didáticos e outros.

Por exemplo, esta pesquisa constatou que o assunto que mais desperta o jovem brasileiro é a Biologia Humana, considerando as preferências de meninos e meninas. Questões relacionadas à sexualidade, cuidados com o corpo, doenças, os alimentos que ingerimos etc., despertam o interesse e a curiosidade dos nossos jovens. Os materiais didáticos e o próprio currículo de ciências não podem se esquivar deste fato e continuar repetindo um modelo de abordagem de conteúdos que valorizem pouco tais assuntos.

O engajamento dos alunos pela ciência e pelas aulas de ciências poderá ser impulsionado por estratégias que abordem tais temas, de forma que o interesse já existente, que é intrínseco ao jovem, poderá favorecer o despertar de interesse pelos demais conteúdos abordados na escola.

Em contrapartida, um tema que interessa pouco, tanto meninos quanto meninas, é o Controle da Natalidade e Contracepção. Os dados apontam para a necessidade de a escola estimular 
o interesse e atitudes positivas em relação aos métodos contraceptivos, tendo em vista os vários problemas existentes acerca da vulnerabilidade sexual dos jovens.

Assim, concordamos com as considerações de Jenkins (2006a, p. 4), quando afirmou que "ouvir o estudante" é uma maneira de transformar a escolaridade, uma vez que "torna o currículo mais relevante para as necessidades e interesses dos alunos". Conhecer os temas que interessam os alunos e considerá-los nas práticas educativas pode melhorar sua motivação e contribuir para melhorias no processo de ensino-aprendizagem.

Uma boa notícia para os colegas da área de ensino de Física é que a disciplina foi mais valorizada pelos jovens que a Biologia, a Química e a Geociências. Este fato é deveras surpreendente por que a Física foi tradicionalmente evitada pelos alunos, quer por que dialoga com a matemática, quer por que é considerada difícil (OSBORNE; COLLINS, 2001).

Dentro da Biologia, a saúde/biologia humana é o que mais interessa as meninas, e os temas ambientais os que mais interessam os meninos. Assim, o ensino desta disciplina deve procurar se vincular ao contexto social e cultural em que o aluno vive, estimulando seus conhecimentos e interesses pré-existentes, a fim de tornar o conhecimento significativo e a aprendizagem relevante.

Assim, devemos considerar o comentário de Aikenhead (2004, p. 6), que considera que "a educação científica tradicional tem desempenhado um papel insignificante na vida da maioria dos alunos”. A ciência escolar só irá envolver os alunos quando o currículo tiver valor pessoal para os estudantes.

Recomendamos que os currículos e os materiais didáticos levem em consideração a opinião daqueles que irão cursá-lo, dando destaque aos seus temas de interesse, privilegiando assuntos contextualizados em sua realidade e principalmente, organizando-se de tal forma que os assuntos que já despertam o interesse, como por exemplo, a saúde, estejam vinculado aos assuntos que os jovens não demonstram tanto interesse, como os tópicos de química.

Em relação à posição dos jovens frente aos desafios ambientais, consideramos que os brasileiros apresentam atitudes preditoras de comportamento ambiental positivo (DIETZ; STERN; GUAGNANO, 1998; SCHULTZ; ZELEZNY, 1999; STERN, 2000; GARCÍA-MIRA; EULOGIO, 2001). Por exemplo, nossos jovens possuem uma visão otimista quanto ao futuro, especialmente as meninas, e consideram fortemente que podemos encontrar soluções para os problemas ambientais. Mais ainda, nossos jovens estão dispostos a agirem em favor do meio ambiente. 
Fato observado na realidade brasileira que confirma diversos estudos que relacionam gênero e questões ambientais é a questão das meninas estarem mais comprometidas com a questão ambiental. Tais estudos indicam que o papel histórico exercido pela mulher na sociedade, relacionado com a família, com a maternidade, com a ética e com o cuidado com o outro, favorecem comportamentos ambientais mais pró-ativos que os homens (DIETZ; STERN; GUAGNANO, 1998; BLOCKER; ECKBERG, 1997; CAVAS et al., 2009; MACDONALD; HARA, 1994; NORGAARD; YORK, 2005; ZELEZNY; CHUA; ALDRICH, 2000).

Através dos dados coletados pudemos classificar as atitudes dos jovens brasileiros em quatro grupos: eco-cêntrico, eco-otimista, eco-pessimista e eco-apático. Os grupos mais representativos foram os dois primeiros, já o eco-pessimista e eco-apático foram os que obtiveram maior pontuação entre os meninos, reforçando os resultados relacionados ao gênero.

As atitudes do jovem brasileiro frente aos problemas ambientais foram consideradas altamente positivas, o que nos leva a refletir sobre o seu potencial de engajamento nas questões ambientais que permeiam nossa sociedade e na capacidade de influenciar positivamente seu entorno, quer escolar, quer familiar, quer na comunidade em que vive.

Acreditamos que as ações educativas em prol do meio ambiente devem procurar, acima de tudo, estimular atitudes preditoras de comportamentos ambientais positivos. No contexto brasileiro, tais ações não devem concentrar-se em informar o jovem, mas em de fato engajá-los na questão ambiental, desenvolvendo comportamentos autônomos e ambientalmente responsáveis, uma vez que eles já apresentam atitudes preditoras positivas.

Em relação à ciência escolar, diversas pesquisas tem relacionado o baixo interesse dos jovens em seguir as carreiras científicas diretamente com suas aulas de ciências (AIKENHEAD, 2005; KARDASH; WALLACE, 2001; BERNARDO et al., 2008; BROK et al., 2006; DARBY, 2005; SMITH; EZEIFE, 2006; VÁZQUEZ ALONSO; MANASSERO MAS, 2008; VÁZQUEZ ALONSO; MANASSERO MAS, 2009b). A ciência na escola tem sido apontada como desinteressante para os alunos por que é excessivamente teórica, abstrata, difícil, com poucas aulas práticas, desconectada da realidade do aluno, e por que aborda conteúdos irrelevantes (FENSHAM, 2004b; OSBORNE; SIMON; COLLINS, 2003; MURPHY; BEGGS, 2003; BARMAN et al., 1997; BEVINS; BRODIE; BRODIE, 2005; DANAIA; FITZGERALD; MCKINNON, 2012).

Os jovens brasileiros consideram a disciplina ciências interessante, apesar de não terem preferência pela ciência em relação a outras disciplinas. Há uma atitude positiva geral em re- 
lação à disciplina, tanto no que se refere à sua importância como à sua utilidade. Apesar de demonstrarem interesse pela ciência escolar, tanto meninas como meninos têm pouco interesse em ingressar na carreira científica. Já os meninos gostariam mais de ter um emprego que lide com tecnologia avançada que as meninas.

Como o ponto de partida para a análise da preferência pela carreira científica é o interesse pela ciência escolar, é necessária a realização de estudos futuros que procurem compreender a lacuna existente entre o interesse pela disciplina e o pequeno interesse pela carreira. Sem dúvida, tais estudos serão úteis para a compreensão dos dados aqui apresentados, e poderão trazer contribuições que estimulem o ingresso do brasileiro na carreira científica e tecnológica.

A pesquisa aqui descrita também procurou conhecer a percepção dos jovens sobre diversos assuntos relacionados à ciência e tecnologia: aos aspectos relacionados a favorecer a vida das pessoas, tanto no que se refere ao trabalho, como ao combate à pobreza, à destruição do meio ambiente e à confiabilidade nos cientistas.

Verificamos que os jovens brasileiros têm uma atitude geral otimista em relação à ciência e à tecnologia, e a consideram responsável não só pela cura de doenças, mas também por melhores oportunidades futuras, trabalho mais interessante e o desenvolvimento adequado de um país. Os jovens atribuem à C\&T a possibilidade de uma vida mais saudável, fácil e confortável, além de tornar o trabalho mais interessante.

Foi curioso observar, entretanto, que mesmo tendo uma atitude geral positiva para com a ciência e a tecnologia, o jovem brasileiro apresentou pouca confiança no empreendimento científico, uma vez que discorda que sempre podemos confiar nos cientistas, que o trabalho científico leva sempre a respostas certas e que os cientistas são neutros e objetivos.

Assim, a pesquisa aqui apresentada verificou que o jovem brasileiro, de modo geral, tem interesse global pelos temas científicos abordados na escola, considera a ciência escolar interessante e possui uma visão otimista do papel da ciência e da tecnologia na sociedade. Além disso, demonstram ter atitudes positivas em relação ao meio ambiente. Diante deste quadro com tantos aspectos positivos, causa estranhamento verificar que o brasileiro não tem interesse pela carreira científica.

Pesquisas que procurem compreender as razões pelas quais nossos jovens não se interessam em ingressar nas carreiras científicas serão importantes até mesmo para compreender a dinâmica existente na sala de aula, de forma que ações que favoreçam a opção pela ciência sejam identificadas e estimuladas. 
Temos em mãos as opiniões dos jovens brasileiros acerca de 245 itens diferentes relacionados à ciência e à tecnologia. A consulta a eles realizada não foi uma tarefa fácil. Foi necessária a colaboração de uma equipe de pessoas dispostas a contatar escolas em todo o Brasil e muitas vezes convencê-las da importância da pesquisa. A tarefa de coletar os dados necessitou de mais de um ano de trabalho.

Foi necessário selecionar, dentro de um universo de 579.425 dados, questões relevantes para um maior aprofundamento, que foram abordadas ao longo dos capítulos referentes a resultados e discussão. Como pôde ser observado, muitos dados não puderam ser contemplados na análise. Tais dados poderão subsidiar outras pesquisas, e ser objeto de outros estudos.

Nosso maior desejo, entretanto, é que os resultados contemplados nesta tese possam de fato auxiliar outros pesquisadores, subsidiando discussões acerca do currículo de ciências, do interesse pela carreira científica, da relação entre os jovens e o meio ambiente e dos jovens e a ciência e tecnologia.

Nossos jovens foram ouvidos, agora é necessário que suas falas alcancem professores, gestores, acadêmicos da área de ensino de ciências, elaboradores de materiais didáticos e os elaboradores de políticas públicas da área de educação. 


\section{REFERÊNCIAS BIBLIOGRÁFICAS ${ }^{21}$}

ACEVEDO-DÍAZ, J. A. Las actitudes relacionadas con la Ciencia y la Tecnología en el estudio PISA 2006. Rev. Eureka Enseñ. Divul. Cien., v. 4, n. 3, p. 394-416, 2007.

AIKENHEAD, G. S. Science Education: Border Crossing into the Subculture of Science. Studies in Science Education, v. 27, p. 1-52, 1996.

AIKENHEAD, G. S. Student views on the influence of culture on science. International Journal of Science Education, v. 19, n. 4, p. 419-428, abr. 1997.

AIKENHEAD, G. S. STS Education: A Rose by Any Other Name. In: CROSS, R. (Ed.). A Vision for Science Education: responding to the Work of Peter J. Fensham. New York: Routledge, 2003.

AIKENHEAD, G. S. The Humanistic and Cultural Aspects of Science \& Technology Education. In: XI INTERNATIONAL ORGANIZATION FOR SCIENCE AND TECHNOLOGY EDUCATION (IOSTE) SYMPOSIUM: SCIENCE AND TECHNOLOGY EDUCATION FOR A DIVERSE WORLD. 2004. Anais... Lublin: IOSTE, 2004.

AIKENHEAD, G. S. Research Into STS Science Education. Educación Química, v. 16, p. 384-397, 2005.

AIKENHEAD, G. S.; RYAN, A. G. The development of a new instrument: "Views on science-technology-society" (VOSTS). Science Education, v. 5, n. 76, p. 477-491, 1992.

AIKENHEAD, G. S.; RYAN, A. G.; FEMING, R. W. Views on Science-Technology Society. Form CDN.mc.5 Most, 1989.

ALSOP, S.; WATTS, M. Science education and affect. International Journal of Science Education, v. 25, n. 9, p. 1043-1047, set. 2003.

ALVES, M. C. G. P. ISA-Campinas 2008/09 - Plano de Amostragem. Disponível em: <http:// www.fcm.unicamp.br/centros/ccas/plano_amostragem.pdf>. Acesso em 2012-07-10.

ALVES-MAZOTTI, A. J. Relevância e aplicabilidade da pesquisa em educação. Cadernos de Pesquisa, n. 113, p. 39-50, jul. 2001.

ANDERSON, I. K. The Relevance of Science Education: As seen by Pupils in Ghanaian Junior Secondary Schools. 2006.376p. Tese (Doctor of Philosophy) - Department of Mathematics and Science Education, University of the Western Cape, Western Cape, 2006.

ANTUNES, M. C.; PERES, C.A.; PAIVA, V.; STALL, R.; HEARST, N. Diferenças na prevenção da Aids entre homens e mulheres jovens de escolas públicas em São Paulo, SP. Rev Saúde Pública, v. 36, n. 4 Supl, p. 88-95, 2002.

\footnotetext{
${ }^{21}$ De acordo com a Associação Brasileira de Normas Técnicas. NBR 6023.
} 
ARANTES, V. A. Afetividade, cognição e moralidade na perspectiva dos modelos organizadores do pensamento. In: ARANTES, V.; AQUINO, J. G. (Coords.). Afetividade na Escola: Alternativas Teóricas e Práticas. São Paulo: Summus Editorial, 2003. 237p.

ARTES, R. Aspectos estatísticos da análise fatorial de escalas de avaliação. Revista de Psiquiatria Clínica, v. 5, n. 5, p. 223-228, 1998.

AULER, D.; DELIZOICOV, D. Visões de professores sobre as interações entre Ciência- Tecnologia-Sociedade (CTS). In: II Encontro Nacional de Pesquisa em Educação em Ciências (ENPEC). 1999. Anais...Valinhos: ABRAPEC, 1999.

AYRES, J. R. C. M.; FRANÇA JUNIOR, I.; CALAZANS, G. J.; SALETTI FILHO, H. C. O conceito de vulnerabilidade e as práticas de saúde: novas perspectivas e desafios. In: CZERESNIA, D.; FREITAS, C. M. DE. (Eds.). Promoção da saúde: conceitos, reflexões, tendências. Rio de Janeiro: Fiocruz, 2003. p. 117-139.

BARAM-TSABARI, A.; SETHI, R.; BRY, L.; YARDEN, A. Asking scientists: A decade of questions analyzed by age, gender, and country. Science Education, v. 93, n. 1, p. 131-160, jan. 2009.

BARAM-TSABARI, A.; YARDEN, A. Characterizing children's spontaneous interests in science and technology. International Journal of Science Education, v. 27, n. 7, p. 803-826, jan. 2005.

BARMAN, C. R.; OSTLUND, K. L.; GATTO, C. C.; HALFERTY, M. Fifth grade students' perceptions about scientists and how they study and use science. In: AETS Conference Proceedings. Anais...1997.

BELL, B. Learning in Science - The Waikato Research. New York: RoutledgeFalmer, 2005. 239 p.

BERNARDO, A. B. I.; LIMJAP, A. A.; PRUDENTE, M. S.; ROLEDA, L. S. Students' perceptions of science classes in the Philippines. Asia Pacific Education Review, v. 9, n. 3, p. 285-295, ago. 2008.

BEVINS, S.; BRODIE, M.; BRODIE, E. A study of UK secondary school students' perceptions of science and engineering. In: European Educational Research Association Annual Conference. Anais...Dublin: Sheffield Hallam University, 2005.

BIZZO, N.; PELLEGRINI, G. Os jovens e a ciência. Curitiba: CRV, 2013. 154p.

BIZZO, N. M. V. Ciências: fácil ou difícil? São Paulo: Editora Biruta, 2009. 159p.

BIZZO, N. M. V. Pensamento Científico: A Natureza da Ciência no Ensino Fundamental. São Paulo: Editora Melhoramentos, 2012. 175p. 
BLOCKER, T. J.; ECKBERG, D. L. Gender and Envirolmentalism: Results from the 1993 General Social Survey. Social Science Quarterly, v. 78, n. 4, p. 841-858, 1997.

BOLFARINE, H.; BUSSAB, W. O. Elementos de Amostragem. São Paulo: Edgar Blücher, 2005. 269p.

BORGES, A. L. V.; SCHOR, N. Início da vida sexual na adolescência e relações de gênero: um estudo transversal em São Paulo, Brasil, 2002. Cad. Saúde Pública, v. 21, n. 2, p. 499-507, 2005.

BRASIL. Projeto Básico: Contratação de Serviços para Execução do Programa Internacional para Avaliação de Alunos - PISA 2009 no Brasil. 2008. Disponível em: <http://download. inep.gov.br/download/internacional/pisa/PISA_2009_Projeto_Basico.pdf.>. Acesso em 201003-02.

BROK, P. D.; FISHER, D.; RICKARDS, T.; BULL, E. Californian Science Students' Perceptions of their Classroom Learning Environments. Educational Research and Evaluation: An International Journal on Theory and Practice, v. 12, n. 1, p. 3-25, 2006.

BROKS, P. The authority of science and the postmodern reformation. Interdisciplinary Science Reviews, v. 28, n. 2, p. 76-82, jun. 2003.

BURIASCO, R. L. C. DE. Algumas Considerações sobre Avaliação Educacional. Estudos em Avaliação Educacional, v. 22, p. 155-178, 2000.

BUSCH, H. Is Science Education Relevant? Europhysics News, v. 36, n. 5, p. 162-167, 2005.

CACHAPUZ, A.; GIL-PEREZ, D.; CARVALHO, A. M. P. de; PRAIA, J.; VILCHES, A. A necessária renovação no ensino das ciências. São Paulo: Ed. Cortez, 2011. 263p.

CATES, W. M. A practical guide to educational research. Englewood Cliffs, N.J.: PrenticeHall, 1985. 252p.

CAVAS, B.; CAVAS, P.; TEKKAYA, C.; CAKIROGLU, J.; KESERCIOGLU, T. Turkish Students' Views on Environmental Challenges with respect to Gender: An Analysis of ROSE Data. Science Education International, v. 20, n. 1/2, p. 69-78, 2009.

CHANG, S.-N.; YEUNG, Y.-Y.; CHENG, M. H. Ninth Graders' Learning Interests, Life Experiences and Attitudes Towards Science \& Technology. Journal of Science Education and Technology, v. 18, n. 5, p. 447-457, abr. 2009.

CHASSOT, A. Alfabetização científica: questões e desafios para a educação. 4a ed. ed. Ijuí: Ed. Unijuí, 2006. 440p.

COOK-SATHER, A. Authorizing Students' Perspectives: Toward Trust, Dialogue, and Change in Education. Educational Researcher, v. 31, n. 4, p. 3-14, maio. 2002. 
COOK-SATHER, A. Sound, Presence, and Power: "Student Voice" in Educational Research and Reform. Curriculum Inquiry, v. 36, n. 4, p. 359-390, dez. 2006.

COSSONS, N. Let Us Take Science into Our Culture. Interdisciplinary Science Reviews, v. 18, n. 4, p. 337-342, dez. 1993.

COSTA, E. F. Prática de atividade física e sua relação com a escolaridade em adultos de Ermelino Matarazzo, Zona Leste de São Paulo, SP. 2009. 97p. Dissertação (Mestrado em Nutrição em Saúde Pública) - Faculdade de Saúde Pública, Universidade de São Paulo, São Paulo, 2009.

DANAIA, L.; FITZGERALD, M.; MCKINNON, D. Students' Perceptions of High School Science: What has Changed Over the Last Decade? Research in Science Education, 14 set. 2012.

DARBY, L. Science Students' Perceptions of Engaging Pedagogy. Research in Science Education, v. 35, n. 4, p. 425-445, dez. 2005.

DEBOER, G. E. Scientific Literacy : Another Look at Its Historical and Contemporary Meanings and Its Relationship to Science Education Reform. Journal of Research in Science Education, v. 37, n. 6, p. 582-601, 2000.

DELIZOICOV, D.; ANGOTTI, J. A.; PERNAMBUCO, M. M. Ensino de Ciências: fundamentos e métodos. São Paulo: Ed. Cortez, 2002.364p.

DIETZ, T.; STERN, P. C.; GUAGNANO, G. A. Social Structural and Social Psychological Bases of Environmental Concern. Environment and Behavior, v. 30, n. 4, p. 450-471, jul. 1998.

EUROPEAN COMMISSION. Europe needs more scientists! Report by the High Level Group on Increasing Human Resources for Science and Technology in Europe. Luxembourg: Office for Official Publications of the European Communities, 2004. 187p.

EUROPEAN COMMISSION. Science Education NOW: A Renewed Pedagogy for the Future of Europe. Luxembourg: Office for Official Publications of the European Communities, 2007. $22 \mathrm{p}$.

FALK, J. H.; STORKSDIECK, M.; DIERKING, L. D. Investigating public science interest and understanding: evidence for the importance of free-choice learning. Public Understanding of Science, v. 16, p. 455-469, out. 2007.

FAPESP. Percepção pública da ciência: uma revisão metodológica e resultados para São Paulo. In: FAPESP (Ed.). Indicadores de Ciência, Tecnologia e Inovação em São Paulo - 2004. São Paulo: FAPESP, 2005. p. 1-28.

FAPESP. Percepção pública da ciência e da tecnologia no Estado de São Paulo. In: FAPESP (Ed.). Indicadores de Ciência, Tecnologia e Inovação em São Paulo - 2010. São Paulo: 
FAPESP, 2011. p. 1-52.

FENSHAM, P.; HARLEN, W. School science and public understanding of science. International Journal of Science Education, v. 21, n. 7, p. 755-763, 1999.

FENSHAM, P. J. Engagement with Science: An international issue that goes beyond knowledge. In: Science and Mathematics Education Conference Series. 2004. Anais... Dublin: 2004a. Disponível em: <www.dcu.ie/smec/plenary/Fensham, Peter.pdf>. Acesso em 2013-06-03.

FENSHAM, P. J. Increasing the Relevance of Science and Technology Education for All Students in the 21st Century. Science Education International, v. 15, n. 1, p. 7-26, 2004 b.

FIELDING, M. Students as radical agents of change. Journal of Educational Change, v. 2, p. 123-141, 2001.

FOUREZ, G. Crise no ensino de ciências? Investigações em Ensino de Ciências, v. 8, n. 2, p. 109-123, 2003. Disponível em: <http://www.if.ufrgs.br/public/ensino/vol8/n2/v8_n2_ a1.html>. Acesso em 2013-06-03.

FREITAS, D. N. T. DE. A Avaliação Educacional como Objeto de Recomendações Internacionais. Estudos em Avaliação Educacional, v. 16, n. 31, p. 79-100, 2005.

GARCÍA-MIRA, R.; EULOGIO, R.-D. Valores, actitudes y creencias: hacia un modelo predictivo del ambientalismo. Medio Ambiente y Comportamiento Humano, v. 2, n. 1, p. 21-43, 2001.

GARDNER, P. L. Comments on "toward the development of a children's science curiosity scale”. Journal of Research in Science Teaching, v. 24, n. 2, p. 175-176, 1987.

GATTI, B. A. Estudos quantitativos em educação. Educação e Pesquisa, v. 30, n. 1, p. 11-30, abr. 2004.

GEORGE, R. A Cross-domain Analysis of Change in Students' Attitudes toward Science and Attitudes about the Utility of Science. International Journal of Science Education, v. 28, n. 6, p. 571-589, maio. 2006.

GOODSON, I. F. Currículo: teoria e história. Petrópolis: Ed. Vozes, 1995. p. 140.

GUIOMAR, M.; TOMAZELLO, C. Avaliação das ideias e atitudes relacionadas com sustentabilidade: metodologia e instrumentos. Ciência \& Educação, v. 10, n. 2, p. 173-183, 2004.

GÜNTHER, H. Pesquisa Qualitativa Versus Pesquisa Quantitativa: Esta É a Questão ? Psicol, v. 22, n. 2, p. 201-209, 2006.

GUSSO, D. A. Medidas e Avaliação Educacional: problemas e tendências. Estudos em Avaliação Educacional, n. 5, p. 77-80, 1992. 
HÄUSSLER, P.; HOFFMANN, L. A Curricular Frame for Physics Education: Development, Comparison with Students' Interests, and Impact on Students' Achievement and Self-Concept. Science Education, v. 84, n. 6, p. 689-705, 2000.

HODSON, D. Time for action: Science education for an alternative future. International Journal of Science Education, v. 25, n. 6, p. 645-670, 2003.

HUNGERFORD, H. R.; VOLK, T. L. Changing learner behavior through environmental education. The Journal of Environmental Education, v. 21, n. 3, p. 257-270, 1990.

INEP. BRASIL. Pisa 2000 - Relatório Nacional. Brasília: INEP, 2001. Brasília: INEP. Disponível em: <http://www.oei.es/quipu/brasil/pisa2000.pdf>. Acesso em 2008-10-10.

INEP. Resultados Nacionais - PISA 2006: Programa Internacional de Avaliação de Alunos (PISA). Brasília: 2008. Disponível em: <http://download.inep.gov.br/download/internacional/ pisa/Relatorio_PISA2006.pdf>. Acesso em 2008-10-10.

JACOBI, P. R. Educação Ambiental: o desafio da construção de um pensamento crítico, complexo e reflexivo. Educação \& Sociedade, v. 31, n. 2, p. 233-250, 2005.

JENKINS, E. W. Environmental education and the public understanding of science. Frontiers in Ecology and the Environment, v. 1, n. 8, p. 437-443, 2003.

JENKINS, E. W. Research in Science Education: Time for a Health Check? Studies in Science Education, v. 35, n. 1, p. 1-25, 2000.

JENKINS, E. W. School science, citizenship and the public understanding of science. International Journal of Science Education, v. 21, n. 7, p. 703-710, 1999.

JENKINS, E. W. The Student Voice and School Science Education. Studies in Science Education, v. 42, n. 1, p. 49-88, 2006a.

JENKINS, E. W. Student opinion in England about science and technology. Research in Science \& Technological Education, v. 24, n. 1, p. 59-68, maio 2006b.

JENKINS, E. W.; NELSON, N. W. Important but not for me: students' attitudes towards secondary school science in England. Research in Science \& Technological Education, v. 23, n. 1, p. 41-57, 2005.

JENKINS, E. W.; PELL, R. G. The Relevance of Science Education Project (ROSE) in England: a summary of findings. Leeds: Centre for Studies in Science and Mathematics Education, 2006. 84p.

JIDESJÖ, A.; OSCARSSON, M.; KARLSSON, K.-G. Science for all or science for some: What Swedish students want to learn about in secondary science and technology and their opinions on science lessons. NorDiNa, v. 5, n. 2, p. 213-229, 2009. 
JONES, M. G.; HOWE, A. N. N.; RUA, M. J. Gender Differences in Students' Experiences , Interests , and Attitudes toward Science and Scientists. Science Education, v. 84, n. 2, p. 180192, 2000.

KARDASH, C. M.; WALLACE, M. L. The Perceptions of Science Classes Survey: What Undergraduate Science Reform Efforts Really Need to Address. Journal of Educational Psychology, v. 93, n. 1, p. 199-210, 2001.

KENNEDY, D. Students' Attitudes to Science. Physical Sciences Magazine, v. 10, p. 20-22, 2008.

KOBALLA JR., T. R.; GLYNN, S. M. Attitudinal and Motivational Constructs in Science Learning. In: ABELL, S. K.; LEDERMAN, N. G. (Eds.). Handbook of Research on Science Education. New York: Routledge, 2006. p. 75-102.

KOLLMUSS, A.; AGYEMAN, J. Mind the Gap: Why do people act environmentally and what are the barriers to pro-environmental behavior? Environmental Education Research, v. 8, n. 3, p. 239-260, 2002.

KOLSTØ, S. D. Scientific Literacy for Citizenship: Tools for Dealing with the Science Dimension of Controversial Socioscientific Issues. Science Education, v. 85, n. 3, p. 291-310, 2001.

KRASILCHIK, M. O professor e o currículo das ciências. São Paulo: EPU - Editora da Universidade de São Paulo, 1987. 80p.

KRASILCHIK, M. Caminhos do ensino de Ciências no Brasil. Em aberto, v. 11, n. 55, p. 3-8, 1992.

KRASILCHIK, M. Reformas e realidade: O caso do ensino das ciências. São Paulo em Perspectiva, v. 14, n. 1, p. 85-93, 2000.

KRASILCHIK, M. Prática de Ensino de Biologia. São Paulo: EDUSP, 2004. 197p.

KWIEK, N. C.; HALPIN, M. J.; REITER, J. P.; HOEFFLER, L. A.; SCHWARTZ-BLOOM, R. D. Pharmacology in the High-School Classroom. Science, v. 317, p. 1871-1872, 2007.

LAUGKSCH, R. C. Scientific Literacy: A Conceptual Overview. Science Education, v. 84, n. 1, p. 71-94, 2000.

LAVONEN, J.; JUUTI, K.; UITTO, A.; MEISALO, V.; BYMAN, R. Attractiveness of science education in the Finnish comprehensive school. In: MANNINEN, A.; MIETTINEN, K.; KIVINIEMI, K. (Eds.). Research Findings on Young People's Perceptions of Technology and Science Education: Mirror results and good practice. Hensinki: Technology Industries of Finland, 2005. p. 2-43.

LAVONEN, J.; GEDROVICS, J.; BYMAN, R.; MEISALO, V.; JUUTI, K.; UITTO,A. Student's 
motivational orientations and career choice in science and technology: a comparative investigation in Finland and Latvia. Journal of Baltic Science Education, v. 7, n. 2, p. 86-102, 2008.

MACDONALD, W. L.; HARA, N. Gender differences in environmental concern among college students. Sex Roles, v. 31, n. 5-6, p. 369-374, set. 1994.

MALDANER, O. A.; ZANON, L. B. Situação de estudo: uma organização do ensino que extrapola a formação disciplinar em Ciências. In: MORAES, R.; MANCUSO, R. (Eds.). Educação em Ciências: produção de currículos e formação de professores. 2a edição. Ijuí: Ed. Unijuí, 2006. 304p.

MANASSERO MAS, M. A.; VÁZQUEZ ALONSO, Á. Instrumentos y Métodos para la Evaluación de las Actitudes Relacionadas con la Ciencia, la Tecnología y la Sociedad. Enseñanza de las Ciencias, v. 1, n. 20, p. 15-27, 2001.

MARTINS, C. M. de C.; TOLEDO, M. I. M. de; SANTOS, M. B. L. dos; BRAGA, S. A. DE M.. Proposta curricular: Biologia. Belo Horizonte: [s.n.], [2007?].

MATTHEWS, P. The relevance of Science Education in Ireland. Dublin: Royal Irish Academy, 2007. 106p.

MCINTYRE, D.; PEDDER, D.; RUDDUCK, J. Pupil voice: comfortable and uncomfortable learnings for teachers. Research Papers in Education, v. 20, n. 2, p. 149-168, jun. 2005.

MCT. Percepção Pública da Ciência e Tecnologia: Pesquisa nacional promovida pelo Ministério da Ciência e Tecnologia, com a parceria da Academia Brasileira de Ciências.Coordenada pelo DEPDI/SECIS/MCT e pelo Museu da Vida/COC/Fiocruz, com colaboração do Labjor/ Unicam e FAPESP. 2007. Disponível em: <http://www.cnpq.br/documents/10157/c52098dc9364-4661-a8a9-d99c0b2bb9ef>. Acesso em 2010-04-10.

MCT. Percepção Pública da Ciência e Tecnologia no Brasil - Resultados da enquete de 2010. 2010. Disponível em: <http://www.mct.gov.br/upd_blob/0214/214770.pdf>. Acesso em 201303-21.

MINAYO, M. C. D. S.; SANCHES, O. Quantitativo-Qualitativo: Oposição ou Complementaridade? Cad. Saúde Públ., v. 9, n. 3, p. 239-248, 1993.

MORAES, R. Ninguém se banha duas vezes no mesmo rio: currículos em processo permanente de superação. In: MORAES, R.; MANCUSO, R. (Eds.). Educação em Ciências: produção de currículos e formação de professores. 2o edição ed. Ijuí: Ed. Unijuí, 2006. 304p.

MOUTINHO, S. Ciência: uma paixão nacional? Revista Ciência Hoje On-line, p. 1-4, 2011. Disponível em: <http://cienciahoje.uol.com.br/noticias/2011/01/ciencia-uma-paixao-nacional>. Acesso em 2013-06-03.

MURPHY, C.; BEGGS, J. Children's perceptions of school science. School Science Review, 
v. 84, n. 308, p. 109-116, 2003.

MURRAY, I.; REISS, M. The Student Review of the Science Curriculum. School Science Review, v. 87, n. 318, p. 83-93, 2005.

NARDI, R. Memórias da Educação em Ciências no Brasil: A Pesquisa em Ensino de Física. Investigações em Ensino de Ciências, v. 10, n. 1, p. 63-101, 2005.

NASR, A. R.; SOLTANI, A. K. Attitude towards Biology and Its Effects on Student's Achievement. International Journal of Biology, v. 3, n. 4, p. 100-104, set. 2011.

NERESINI, F.; CROVATO, S.; SARACINO, B. Scienza e nuove generazioni - I risultati dell'indagine internazionale ROSE. Vicenza: Edizioni Observa Science in Society, 2010. 189p.

NG, K. T.; LAY, Y. F.; AREEPATTAMANNIL, S. Relationship between affect and achievement in science and mathematics in Malaysia and Singapore. Research in Science \& Technological Education, v. 30, n. 3, p. 225-237, 2012.

NORGAARD, K.; YORK, R. Gender Equality and State Environmentalism. Gender \& Society, v. 19, n. 4, p. 506-522, ago. 2005.

OECD. Evolution of Student Interest in Science and Technology Studies: Policy Report. Global Science Forum: OECD, 2006, 18p.

OECD. PISA 2006: Competências em ciências para o mundo de amanhã (Volume 1: Análise). Ed Moderna/OECD Publishing, 2007. v. 1. 404p.

OECD/PISA. School sampling preparation manual. Pisa 2006 main study. OECD, 2005.

OGAWA, M.; SHIMODE, S. Three distinctive groups among japanese students in terms of their school science preference: from preliminary analysis of japanese data of an international survey "The Relevance of Science Education" (ROSE). Journal of Science Education in Japan, v. 28, n. 4, p. 1-11, 2004.

OLIVEIRA, G. da S. Aceitação/rejeição da evolução biológica: atitudes de alunos da educação básica. 2009. 162p. Dissertação (Mestrado em Educação) - Faculdade de Educação, Universidade de São Paulo, São Paulo, 2009.

OSBORNE, J. Message from the president. E-NARST News, v. 49, n. 2, p. 1-2, 2006.

OSBORNE, J.; COLLINS, S. Pupils' views of the role and value of the science curriculum: A focus-group study. International Journal of Science Education, v. 23, n. 5, p. 441-467, maio 2001.

OSBORNE, J.; DILLON, J. Science Education in Europe: Critical Reflections. A Report to The Nuffield Foundation. London: The Nuffield Foundation, 2008. 32p. 
OSBORNE, J.; SIMON, S.; COLLINS, S. Attitudes towards science: a review of the literature and its implications. International Journal of Science Education, v. 25, n. 9, p. 1049-1079, set. 2003.

PELL, T.; JARVIS, T. Developing attitude to science scales for use with children of ages from five to eleven years. International Journal of Science Education, v. 23, n. 8, p. 847-862, ago. 2001.

PHELAN, P.; DAVIDSON, A. L.; CAO, H. T. Students' Multiple Worlds: Negotiating the Boundaries of Family, Peer, and School Cultures. Anthropology \& Education Quarterly, v. 22, n. 3, p. 224-250, set. 1991.

PNUD. Atlas do Desenvolvimento Humano 2003. 2003a. Disponível em: <http://www.pnud. org.br/IDH/Atlas2003.aspx ?indiceAccordion=1\&li=li_Atlas2003> . Acesso em 2012-09-20.

PNUD. Ranking do IDH dos Municípios do Brasil 2003. 2003b. Disponível em: <http://www. pnud.org.br/atlas/ranking/IDH_Municipios_Brasil_2000.aspx?indiceAccordion=1\&li=li_ Ranking2003>. Acesso em 2013-04-04.

POOLEY, J. A.; O'CONNOR, M. Environmental Education and Attitudes: Emotions and Beliefs are What is Needed. Environment and Behavior, v. 32, n. 5, p. 711-723, set. 2000.

RANSON, S. Recognizing the Pedagogy of Voice in a Learning Community. Educational Management Administration \& Leadership, v. 28, n. 3, p. 263-279, jul. 2000.

ROBINSON, C.; TAYLOR, C. Theorizing student voice: values and perspectives. Improving Schools, v. 10, n. 1, p. 5-17, mar. 2007.

ROSE. ROSE - International Partners. 2012. Disponível em: <http://roseproject.no/?page_ $\mathrm{id}=16>$. Acesso em 2013-05-10.

ROTH, W.-M.; DÉSAUTELS, J. Educating for Citizenship: Reappraising the Role of Science Education. Canadian Journal of Science, Mathematics and Technology Education, v. 2, p. $1-27,2004$.

RUDDUCK, J.; FIELDING, M. Student voice and the perils of popularity. Educational Review, v. 58, n. 2, p. 219-231, maio. 2006.

RUDDUCK, J.; FLUTTER, J. Pupil Participation and Pupil Perspective: 'carving a new order of experience'. Cambridge Journal of Education, v. 30, n. 01, p. 75-89, 2000.

SALVADOR, E. P.; FLORINDO, A. A.; REIS, R. S.; COSTA, E. F. Percepção do ambiente e prática de atividade física no lazer entre idosos. Rev Saúde Pública, v. 43, n. 6, p. 972-980, 2009.

SANTOS, C. Estatística Descritiva - Manual de auto-aprendizagem. Lisboa: Edições Silabo, 
2007. 264p.

SANTOS GOUW, A. M. Um breve panorama do projeto internacional "The Relevance of Science Education" (ROSE). In: Os jovens e a ciência. Curitiba: CRV, 2013. p. 13-30.

SÃO PAULO. Currículo do Estado de São Paulo: Ciências da Natureza e suas tecnologias. São Paulo: SE, 2011. 152p.

SARJOU, A. A.; SOLTANI, A.; AFSANEH, K.; MAHMOUDI, S. A Study of Iranian Students' Attitude towards Science and Technology, School Science and Environment, Based on the ROSE Project. Journal of Studies in Education, v. 2, n. 1, p. 90-103, 2012.

SCHREINER, C. Exploring a ROSE-garden: Norwegian youth's orientations towards science - seen as signs of late modern identities. 2006. 317p. Tese (Doctor Scientiarum) - Faculty of Education, University of Oslo, Oslo, 2006.

SCHREINER, C.; SJØBERG, S. Sowing the seeds of ROSE. Acta Didactica 4/2004. 2004, 120 .

SCHREINER, C.; SJØBERG, S. Empowered for action? How do young people relate to environmental challenges? In: ALSOP, S. (Ed.). Beyond Cartesian Dualism: Encountering affect in the teaching and learning of science. Dordrecht: Springer, 2005.

SCHREINER, C.; SJØBERG, S. Science education and youth's identity construction - two incompatible projects? In: CORRIGAN, D.; DILLON, J.; GUNSTONE, R. (Eds.). The Reemergence of Values in the Science Curriculum. Rotterdam: Sense Publishers, 2007.p. 1-16.

SCHULTZ, P. W.; ZELEZNY, L. Values as Predictors of Environmental Attitudes: Evidence for Consistency Across 14 Countries. Journal of Environmental Psychology, v. 19, p. 255-265, 1999.

SHAMOS, M. H. Guest Comment: The real threat of scientific illiteracy. American Journal of Physics, v. 64, n. 9, p. 1102, 1996.

SHAMOS, M. H.; HOWES, R. The Myth of Scientific Literacy. Physics Today, v. 49, n. 3, p. 89, 1996.

SHANK, G. D.; BROWN, L. Exploring educational research literacy. London: Routledge, 2007. 256p.

SIEGEL, M. A.; RANNEY, M. A. Developing the changes in attitude about the relevance of science (CARS) questionnaire and assessing two high school science classes. Journal of Research in Science Teaching, v. 40, n. 8, p. 757-775, out. 2003.

SILVA, A. M. da. Acesso aos serviços de saúde em Municípios da Baixada Santista (Temas em Saúde Coletiva, 8). São Paulo: Instituto de Saúde, 2008. 215p. 
SIMPSON, R. D.; KOBALLA JR., T. R.; OLIVER, J. S.; CRAWLEY III, F. E. Research on the Affective Dimension of Science Learning. In: GABEL, D. L. (Ed.). Handbook of Research on Science and Teaching and Learning. New York: Macmillan, 1993. p. 211-234.

SJØBERG, S. Science And Scientists: The SAS-study. Acta Didactica 1/2000, v. 1, p. 75, 2000 .

SJØBERG, S. Science and Technology in Education - Current Challenges and Possible Solutions. In: JENKINS, E. W. (Ed.). Innovations in Science and Technology Education (Vol. VIII). Paris: UNESCO, United Nations Educational, Science and Cultural Organization, 2001. p. 1-13.

SJØBERG, S. What can we learn from the learners? Some results and implications from "Science and Scientists" a comparative study in 22 countries. In: 10th INTERNATIONAL ORGANIZATION FOR SCIENCE AND TECHNOLOGY EDUCATION (IOSTE) SYMPOSIUM: Rethinking Science and Technology Education to Meet the Demands of Future Generations in a Changing World, 2002, Vol. 2. Proceedings... São Paulo: IOSTE, 2002.

SJØBERG, S. Science Education: The voice of the learners. Brussels, 2004. Disponível em: $<$ http://roseproject.no/network/countries/norway/eng/nor-sjoberg-eu2004.pdf>. Acesso em 2010-12-02.

SJØBERG, S. Challenges for science education: a personal view. In: Proceedings of the Linnaeus Tercentenary Symposium - Promoting Scientific Literacy: Science Education Research in Transaction. 2007. Anais... Uppsala: Uppsala University, 2007.

SJØBERG, S.; SCHREINER, C. How do learners in different cultures relate to science and technology? Asia-Pacific Forum on Science Learning and Teaching, v. 6, n. 2, p. 1-17, 2005.

SJØBERG, S.; SCHREINER, C. Gender and Science education: good news, bad news and surprising news - Results and perspectives from recent research. May, 2009.

SJØBERG, S.; SCHREINER, C. The ROSE project: An overview and key findings. Oslo: [s.n.], 2010.

SMITH, C. B.; EZEIFE, A. N. The Relationship between Students' Perceptions of their Classroom Environment and their Attitudes Toward Science in Grade Nine Applied Science Classes. Academic Exchange - EXTRA. p. 1-14, 2006. Disponível em: <http://www.unco.edu/AEExtra/2010/4/ezeife.html>. Acesso em 2013-01-04.

STEFÁNSSON, K. K. 'I just don' $\mathbf{t}$ think it' $\mathbf{s}$ me' - a study on the willingness of Iceland learners to engage in science related issues. 2006. 117p. Dissertação (Master in Science Education) - Department of Teacher Education and School Development, University of Oslo, Oslo, 2006.

STERN, P. C. Toward a Coherent Theory of Environmentally Significant Behavior. Journal of 
Social Issues, v. 56, n. 3, p. 407-424, 2000.

TEIXEIRA, P. M. M. Reflexões sobre o Ensino de Biologia realizado em nossas escolas. In: III Encontro Nacional de Pesquisa em Educação em Ciências (ENPEC). Atas...Atibaia: ABRAPEC, 2001.

TEPPO, M.; RANNIKMÄE, M. Relevant science education in the eyes of grade nine students. In: XI International Organization for Science and Technology Education (IOSTE) Symposium: Science and Technology Education for a Diverse World. Anais...Lublin: IOSTE, 2004.

TOLENTINO NETO, L. C. B. de. Os interesses e posturas de jovens alunos frente às ciências: resultados do Projeto ROSE aplicado no Brasil. 2008. 172p. Tese (Doutorado em Educação) - Faculdade de Educação, Universidade de São Paulo, São Paulo, 2008.

TOMEI, A. Foreword. In: OSBORNE, J.; DILLON, J. (Eds.). Science Education in Europe: Critical Reflections. A Report to The Nuffield Foundation. London: The Nuffield Foundation, 2008. p. 5-5.

TONATTO, S.; SAPIRO, C. M. Os novos parâmetros curriculares das escolas brasileiras e educação sexual: uma proposta de intervenção em ciências. Psicologia \& Sociedade, v. 14, n. 2, p. 163-175, 2002.

TRUMPER, R. Factors Affecting Junior High School Students' Interest in Biology. Science Education International, v. 17, n. 1, p. 31-48, 2006.

TURNER, S. School science and its controversies; or, whatever happened to scientific literacy? Public Understanding of Science, v. 17, p. 55-72, jan. 2008.

UEBERSAX, J. S. Likert Scales: Dispelling the Confusion. 2006. Disponível em: <http:// www.john-uebersax.com/stat/likert.htm>. Acesso em 2013-02-13.

VÁZQUEZ ALONSO, Á.; MANASSERO MAS, A. Actitudes de los jóvenes en relación con los desafíos medio-ambientales. Infancia y Aprendizaje, v. 28, n. 3, p. 309-327, set. 2005.

VÁZQUEZ ALONSO, Á.; MANASSERO MAS, A. El declive de las actitudes hacia la ciencia de los estudiantes: un indicador inquietante para la educación científica. Rev. Eureka Enseñ. Divul. Cien., v. 5, n. 3, p. 274-292, 2008.

VÁZQUEZ ALONSO, Á.; MANASSERO MAS, M.A. En defensa de las actitudes y emociones en la educación científica (I): Evidencias y argumentos generales. Rev. Eureka Enseñ. Divul. Cien., v. 4, n. 2, p. 247-271, 2007a.

VÁZQUEZ ALONSO, Á.; MANASSERO MAS, M.A. En defensa de las actitudes y emociones en la educación científica (II): Evidencias empíricas. Rev. Eureka Enseñ. Divul. Cien., v. 4, n. 3, p. 417-441, 2007b. 
VÁZQUEZ ALONSO, Á.; MANASSERO MAS, M. A. La relevancia de la educación científica: actitudes y valores de los estudiantes relacionados con la ciencia y la tecnología. Enseñanza de las Ciencias, v. 27, n. 1, p. 33-48, 2009a.

VÁZQUEZ ALONSO, Á.; MANASSERO MAS, M. A. La Vocación Científica y Tecnológica: Predictores Actitudinales Significativos. Rev. Eureka Enseñ. Divul. Cien., v. 6, n. 2, p. 213231, 2009b.

VIANNA, H. M. Avaliação Educacional nos Cadernos de Pesquisa. Estudos em Avaliação Educacional, n. 80, p. 100-105, 1992.

VILLANI, A.; ALMEIDA PACCA, J. L.; FREITAS, D. Science Teacher Education in Brazil: 1950-2000. Science \& Education, v. 18, n. 1, p. 125-148, set. 2009.

VILLELA, W. V.; DORETO, D. T. Sobre a experiência sexual dos jovens. Cad. Saúde Pública, v. 22, n. 11, p. 2467-2472, 2006.

VOGT, C.; POLINO, C. (Orgs). Percepção Pública da Ciência: resultados da pesquisa na Argentina, Brasil, Espanha e Uruguai. Campinas/São Paulo: Editora da Unicamp/FAPESP, 2003. $187 \mathrm{p}$.

WADE, S. E. Research on Importance and Interest: Implications for Curriculum Development and Future Research. Educational Psychology Review, v. 13, n. 3, p. 243-261, 2001.

YÁÑEZ, X. D.; MATURANA, H. Hacia una era post posmoderna en las comunidades educativas. Revista Iberoamericana de Educación, v. 49, p. 135-161, 2009.

ZELEZNY, L. C.; CHUA, P.-P.; ALDRICH, C. Elaborating on Gender Differences in Environmentalism. Journal of Social Issues, v. 56, n. 3, p. 443-457, 2000. 


\section{ANEXO A - Questionário ROSE Brasil completo.}

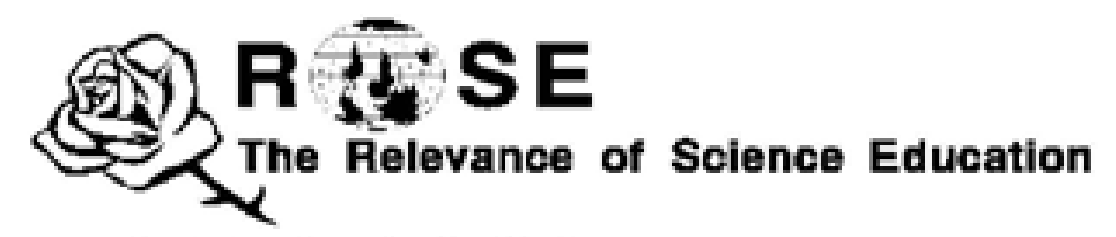

A relevância da educaçăo de ciências

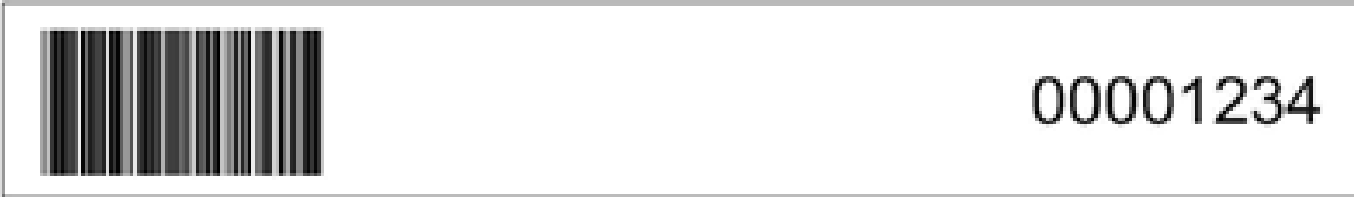

Esta pesquisa contém perguntas sobre voct, suas experiências e seus interesses, dentro e fora da escola.

Năo há respostas corretas ou erradas, apenas as que săo certas para voce.

Pense beme responda com sinceridade.

Este questionário está sendo aplicado a alunos de muitos paises, e assim algumas perguntas podem parecer estranhas. Se houver uma pergunta que năo entenda, deixe-a em branco.

O objetivo do questionário é saber o que é que os alunos de várias partes do mundo pensam da ciềncia, tanto na escola como no seu dia-a-dia. Esta informação poderá ajudar a melhorar as escolas.

Para responder as perguntas, simplesmente preencha completamente o quadradinho utilizando necessariamente caneta azul ou preta. Veja o exemplo:

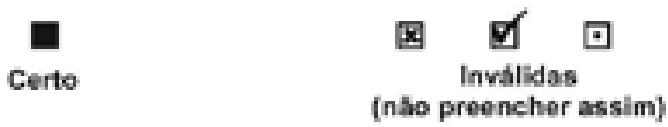

Suas respostas sāo anônimas, portanto nāo escreva seu nome no questionário.

Suas respostas văo nos ajudar muito.

MUITOOBRIGADO!

Comece aqui:

Sou

$$
\square \text { mulher }
$$

Tenho

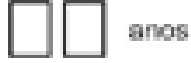

Eu moro en

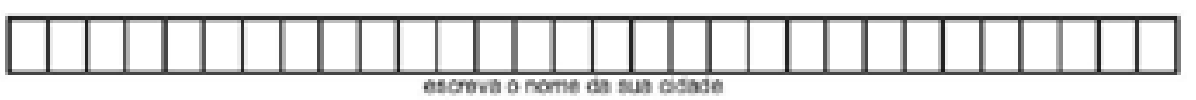

Quantos livros há na sua casa (cada metro de prateleira tem mais ou menos 40 livros)? (Assinale só uma op̧̧̃o)
$\square$ Nerhum
口 1.10 livros
11.50 livros
51-100 livros
101-250 livros
251-500 livros
$\square$ Mais que 500 livros

Quantos banheiros há na sua casa? (Assinale só uma opçăo)
$\square$ Nerhum
$\square 1$
$\square 2$
ㅁ 3
$\square 4$
$\square 5$
Mas que 5 


\section{A. O que eu quero aprender}

\section{Qual é o seu nivel de interesse em aprender os seguintes assuntos ou temas?}

(Assinale sua resposta preenchendo oquadradinhe correspondente em cada linha. Se nlo entender, deixe a linha em branco).

\begin{tabular}{|c|c|c|c|c|c|}
\hline & & 1 & 2 & 3 & 4 \\
\hline 1 & Estrelas, planetas e o Universo & $\square$ & $\square$ & $\square$ & $\square$ \\
\hline 2 & Substâncias quimicas, suas propriedades e como reagem & $\square$ & $\square$ & $\square$ & $\square$ \\
\hline 3 & O interior da Terra & $\square$ & $\square$ & $\square$ & $\square$ \\
\hline 4 & Como evoluem e se transformam as montanhas, nios e oceanos & $\square$ & $\square$ & $\square$ & $\square$ \\
\hline 5 & Nuvens, chuva e tempo & $\square$ & $\square$ & $\square$ & $\square$ \\
\hline 6 & Origem e evolugito da vida na Terra & $\square$ & $\square$ & $\square$ & $\square$ \\
\hline 7 & Como o corpo humano 6 feito e como funciona & $\square$ & $\square$ & $\square$ & $\square$ \\
\hline 8 & Hereditariedade e como os genes afetam o nosso desenvolvimento & $\square$ & $\square$ & $\square$ & $\square$ \\
\hline 9 & Sexo e reproduçäo & $\square$ & $\square$ & $\square$ & $\square$ \\
\hline 10 & Controle de natalidade e contracepçăo & $\square$ & $\square$ & $\square$ & $\square$ \\
\hline 11 & Como os bebess crescem e se desenvolvem & $\square$ & $\square$ & $\square$ & $\square$ \\
\hline 12 & Clonagem de animais & $\square$ & $\square$ & $\square$ & $\square$ \\
\hline 13 & Animais de diversas partes do mundo & $\square$ & $\square$ & $\square$ & $\square$ \\
\hline 14 & Dinossauros, como viveram e porque desapareceram & $\square$ & $\square$ & $\square$ & $\square$ \\
\hline 15 & Como as plantas crescem e se reproduzem & $\square$ & $\square$ & $\square$ & $\square$ \\
\hline 16 & Como as pessoas, animais, plantas e ambiente dependem uns dos outros & $\square$ & $\square$ & $\square$ & $\square$ \\
\hline 17 & Átomos e moléculas & $\square$ & $\square$ & $\square$ & $\square$ \\
\hline 18 & Como a radicatividade afeta o corpo humano & $\square$ & $\square$ & $\square$ & $\square$ \\
\hline 19 & A luz invisível à nossa volta (infravermelho, ultravioleta) & $\square$ & $\square$ & $\square$ & $\square$ \\
\hline 20 & Como os animais utilizam cores para se esconderem, atrairem ou assustarem & $\square$ & $\square$ & $\square$ & $\square$ \\
\hline 21 & Como diferentes instrumentos musicais produzem sons diferentes & $\square$ & $\square$ & $\square$ & $\square$ \\
\hline 22 & Buracos negros, supernovas e outros objetos do espaco & $\square$ & $\square$ & $\square$ & $\square$ \\
\hline 23 & Como meteoritos, cometas e asteróides podem causar catástrofes na Terra & $\square$ & $\square$ & $\square$ & $\square$ \\
\hline 24 & Terremotos e vulcóes & $\square$ & $\square$ & $\square$ & $\square$ \\
\hline 25 & Tomados, furaçles e ciclones & $\square$ & $\square$ & $\square$ & $\square$ \\
\hline 26 & Epidemias e doenças que causam muitas mortes & $\square$ & $\square$ & $\square$ & $\square$ \\
\hline 27 & Animais perigosos e venenosos & $\square$ & $\square$ & $\square$ & $\square$ \\
\hline 28 & Plantas tóxicas da minha regiø̄o & $\square$ & $\square$ & $\square$ & $\square$ \\
\hline
\end{tabular}




\begin{tabular}{|c|c|c|c|c|c|}
\hline & & 1 & 2 & 3 & 4 \\
\hline 29 & Venenos mortais e o que estes fazem ao corpo humano & $\square$ & $\square$ & $\square$ & $\square$ \\
\hline 30 & Como funciona a bomba atômica & $\square$ & $\square$ & $\square$ & $\square$ \\
\hline 31 & Quimicos explosivos & $\square$ & $\square$ & $\square$ & $\square$ \\
\hline 32 & Amas biológicas e químicas e o que fazem ao corpo humano & $\square$ & $\square$ & $\square$ & $\square$ \\
\hline 33 & O efelio dos choques elétricos e dos relämpagos no corpo humano & $\square$ & $\square$ & $\square$ & $\square$ \\
\hline 34 & Qual a sensaçăo de viver sem peso no espaco & $\square$ & $\square$ & $\square$ & $\square$ \\
\hline 35 & Como caminhar orientado pelas estrelas & $\square$ & $\square$ & $\square$ & 口 \\
\hline 36 & Como o olho consegue ver luz e cores & $\square$ & $\square$ & $\square$ & $\square$ \\
\hline 37 & O que comer para nos mantermos saudáveis e em boa forma fisica & $\square$ & $\square$ & $\square$ & $\square$ \\
\hline 38 & As perturbaçbes alimentares, como anorexia e bulimia & $\square$ & $\square$ & $\square$ & $\square$ \\
\hline 39 & A capacidade de loçes e cremes manterem a pele jovem & $\square$ & $\square$ & $\square$ & $\square$ \\
\hline 40 & Como manter o meu corpo forte e em boa condiçäo física & $\square$ & $\square$ & $\square$ & $\square$ \\
\hline 41 & Cirurgias plásticas e tratamentos de beleza & $\square$ & $\square$ & $\square$ & $\square$ \\
\hline 42 & Como a luz solar $e$ a dos bronzeadores artificiais afetam a pele & $\square$ & $\square$ & $\square$ & $\square$ \\
\hline 43 & Como nosso organismo consegue ouvir diferentes sons & $\square$ & $\square$ & $\square$ & $\square$ \\
\hline 44 & Foguetes, satélites e viagens espaciais & $\square$ & $\square$ & $\square$ & $\square$ \\
\hline 45 & O uso de satelites para comunicação e outros propositos & $\square$ & $\square$ & $\square$ & $\square$ \\
\hline 46 & Como o raio- $x$, o ultra-som, etc. săo usados na medicina & $\square$ & $\square$ & $\square$ & $\square$ \\
\hline 47 & Como funcionam os motores a diesel, a álcool, a gás e a gasolina & $\square$ & $\square$ & $\square$ & $\square$ \\
\hline 48 & Como funciona uma usina nuclear & $\square$ & $\square$ & $\square$ & $\square$ \\
\hline
\end{tabular}




\section{B. O meu futuro emprego}

Qualé a importância das seguintes questöes para a sua futura profissăo ou emprego?

(Assinale sua resposta preenchendo oquadradinhe correspondente em cada linha. Se nis entender, deixe a linha em branco).

\begin{tabular}{|c|c|c|c|c|c|}
\hline & & 1 & 2 & 3 & 4 \\
\hline 1 & Trabalhar com pessoas e năo com objetos & $\square$ & $\square$ & $\square$ & $\square$ \\
\hline 2 & Ajudar outras pessoas & $\square$ & $\square$ & $\square$ & $\square$ \\
\hline 3 & Trabalhar com animais & $\square$ & $\square$ & $\square$ & 口 \\
\hline 4 & Trabalhar para a protegảo do ambiente & $\square$ & $\square$ & $\square$ & $\square$ \\
\hline 5 & Trabalhar com algo fácil e năo ocmplicado & $\square$ & $\square$ & $\square$ & $\square$ \\
\hline 6 & Construir ou consertar coisas com as mãos & $\square$ & $\square$ & 口 & $\square$ \\
\hline 7 & Trabalhar com mácquinas ou ferramentas & $\square$ & $\square$ & 口 & $\square$ \\
\hline 8 & Trabalho criativo e artistico & $\square$ & $\square$ & 口 & $\square$ \\
\hline 9 & Usar os meus talentos e capacidades & $\square$ & $\square$ & $\square$ & $\square$ \\
\hline 10 & Construir, desenhar ou inventar algo & $\square$ & $\square$ & $\square$ & $\square$ \\
\hline 11 & Criar novas idélas & $\square$ & $\square$ & $\square$ & $\square$ \\
\hline 12 & Ter muito tempo para os meus amigos & $\square$ & $\square$ & $\square$ & $\square$ \\
\hline 13 & Tomar as minhas próprias decisôes & $\square$ & $\square$ & $\square$ & $\square$ \\
\hline 14 & Trabalho independente de outras pessoas & $\square$ & $\square$ & $\square$ & $\square$ \\
\hline 15 & Trabalhar com algo que considero importante e significativo & $\square$ & $\square$ & $\square$ & $\square$ \\
\hline 16 & Trabalhar com algo que coincida com os meus valores & $\square$ & $\square$ & $\square$ & $\square$ \\
\hline 17 & Ter muito tempo para a minha familia & $\square$ & $\square$ & $\square$ & $\square$ \\
\hline 18 & Trabalhar em algo que implique viajar muito & $\square$ & $\square$ & $\square$ & $\square$ \\
\hline 19 & $\begin{array}{l}\text { Trabalhar num local onde frequientemente acontecem coisas novas e } \\
\text { emocionantes }\end{array}$ & $\square$ & $\square$ & $\square$ & $\square$ \\
\hline 20 & Ganhar muito dinheiro & $\square$ & $\square$ & $\square$ & $\square$ \\
\hline 21 & Controlar outras pessoas & $\square$ & $\square$ & $\square$ & $\square$ \\
\hline 22 & Tomar-me famoso & $\square$ & $\square$ & $\square$ & $\square$ \\
\hline 23 & Ter muito tempo para os meus interesses, hobbies e atividades de lazer & $\square$ & $\square$ & $\square$ & $\square$ \\
\hline 24 & Assumir posiçăo de chefia no meu local de trabalho & $\square$ & $\square$ & $\square$ & $\square$ \\
\hline 25 & Desenmolver ou expandir as meus conhecimentos e capacidades & $\square$ & $\square$ & $\square$ & $\square$ \\
\hline 26 & Trabalhar em equipe, com muitas pessoas & $\square$ & $\square$ & 口 & $\square$ \\
\hline
\end{tabular}




\section{O que quero aprender}

Qualé o seu nivel de interesse em aprender os seguintes assuntos ou temas?

(Atsinale sua resposta preenchendo oquadradnho correspondente em cada linha. Se nlo entender, deice a linha em branco).

\begin{tabular}{|c|c|c|c|c|c|}
\hline & & 1 & 2 & 3 & 4 \\
\hline 1 & $\begin{array}{l}\text { Como o petróleo é transformado em cutros materiais como plásticos e } \\
\text { tecidos }\end{array}$ & $\square$ & $\square$ & $\square$ & $\square$ \\
\hline 2 & $\begin{array}{l}\text { Instrumentos ópticos e como funcionam (telescópio, máquina fotográfica, } \\
\text { microsoópio, elc.) }\end{array}$ & $\square$ & $\square$ & $\square$ & $\square$ \\
\hline 3 & $\begin{array}{l}\text { O uso do raio laser para efeitos técricos (gravadores de CDs, leitores de } \\
\text { códigos de barra, etc.) }\end{array}$ & $\square$ & $\square$ & $\square$ & $\square$ \\
\hline 4 & $\begin{array}{l}\text { Como fitas cassete, grawadores de CD e DVD armazenam e reproduzem } \\
\text { sons e música }\end{array}$ & $\square$ & $\square$ & $\square$ & $\square$ \\
\hline 5 & Como funcionam coisas como o rádio e a televiș̄o & $\square$ & $\square$ & 口 & $\square$ \\
\hline 6 & Como os telefones celulares enviam e recebem mensagens & $\square$ & $\square$ & $\square$ & $\square$ \\
\hline 7 & Como os computadores funcionam & $\square$ & $\square$ & $\square$ & $\square$ \\
\hline 8 & A possibilidade de vida fora do planeta Terra & $\square$ & $\square$ & 口 & $\square$ \\
\hline 9 & $\begin{array}{l}\text { Astrologia e hor } \delta s c o p o s \text { e se os planetas podem influenciar os seres } \\
\text { humanos }\end{array}$ & $\square$ & $\square$ & 口 & $\square$ \\
\hline 10 & Os mistérios do espaço ainda por resolver & $\square$ & $\square$ & $\square$ & $\square$ \\
\hline 11 & A vida, a morte e a alma humana & $\square$ & $\square$ & 口 & $\square$ \\
\hline 12 & Medicinas altemativas (acupuntura, homeopatia, ioga, etc.) e a sua eficacia & $\square$ & $\square$ & 口 & $\square$ \\
\hline 13 & Porque sonhamos e qual o significado dos nossos sonhos & $\square$ & $\square$ & $\square$ & $\square$ \\
\hline 14 & Bruxas e fantasmas, e se existem ou nåo & $\square$ & $\square$ & 口 & $\square$ \\
\hline 15 & Transmissão de pensamentos, leîura de mentes, sexto sentido, intuiç̧̄o, etc & $\square$ & $\square$ & $\square$ & $\square$ \\
\hline 16 & Porque as estrelas brilham e porque o céu é azul & $\square$ & $\square$ & $\square$ & $\square$ \\
\hline 17 & Porque conseguimos ver o arco-iris & $\square$ & $\square$ & $\square$ & $\square$ \\
\hline 18 & $\begin{array}{l}\text { As propriedados das pedras e dos cristais e como são usados para } \\
\text { embelezar }\end{array}$ & $\square$ & $\square$ & 口 & $\square$ \\
\hline
\end{tabular}




\section{Eu e os desafios ambientais}

Até que ponto você concorda com as seguintes afirmaçōes sobre os problemas do ambiente (poluiçăo de ar e de água, abuso de recursos naturais, mudanças climáticas globais, etc.)?

(Assinale sua resposta preenchendo o quadradirho conespondente en cada linha. Se nilo ertender, deive a linha em branco).

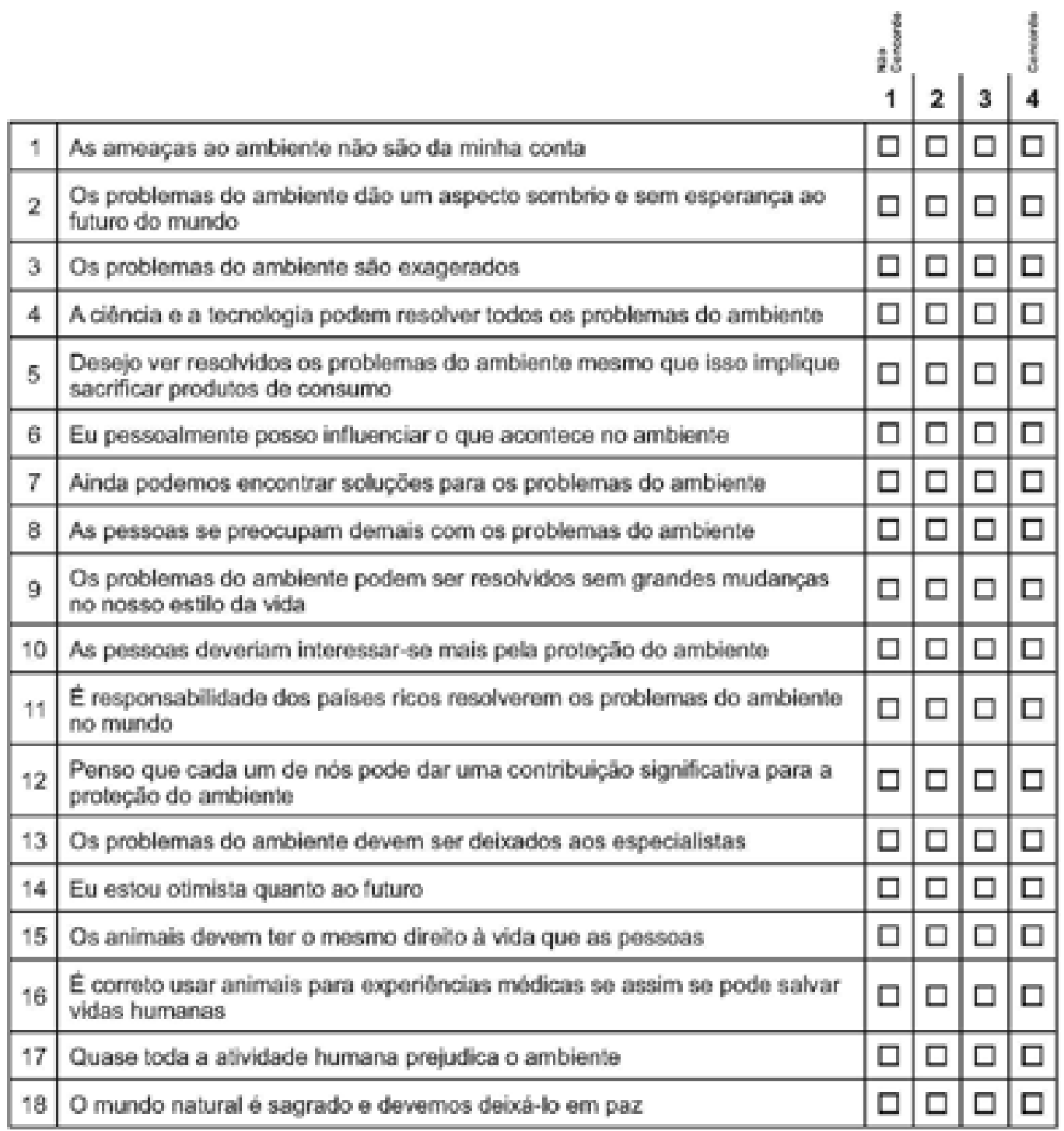




\section{E. O que quero aprender}

Qual é o seu nivel de interesse em aprender os seguintes assuntos ou temas?

(Assinale sua resposta preenchendo q quadradinho correspondente em cada linha, Se nă enlender, dejce a linha em brance).

\begin{tabular}{|c|c|c|c|c|c|}
\hline & & 1 & 2 & 3 & 4 \\
\hline 1 & Simetrias e padrōes em folhas e flores & $\square$ & $\square$ & $\square$ & $\square$ \\
\hline 2 & Como se formam no céu as cores do pör-do-sol & $\square$ & $\square$ & $\square$ & $\square$ \\
\hline 3 & A camada de ozónio e como pode ser afetada pelos seres humanos & $\square$ & $\square$ & $\square$ & $\square$ \\
\hline 4 & O efeito estufa e como pode ser modificado pelos seres humanos & $\square$ & $\square$ & $\square$ & $\square$ \\
\hline 5 & O que se pode fazer para assegurar ar limpo e água potável & $\square$ & $\square$ & $\square$ & $\square$ \\
\hline 6 & Como a tecnologia nos ajuda a tratar de residuos, lixo e esgotos & $\square$ & $\square$ & $\square$ & $\square$ \\
\hline 7 & Como controlar epidemias e doenças & $\square$ & $\square$ & $\square$ & $\square$ \\
\hline 8 & O câncer, o que sabemos e como podemos tratá-lo & $\square$ & $\square$ & $\square$ & $\square$ \\
\hline 9 & As doenças sexualmente transmissiveis e como se proteger delas & $\square$ & $\square$ & $\square$ & $\square$ \\
\hline 10 & Como prestar primeiros socorros & $\square$ & $\square$ & $\square$ & $\square$ \\
\hline 11 & O que sabemos sobre HIVIAIDS e como controlá-la & $\square$ & $\square$ & $\square$ & $\square$ \\
\hline 12 & Como o alcool e o tabaco podem afetar o corpo humano & $\square$ & $\square$ & $\square$ & $\square$ \\
\hline 13 & Como as diferentes drogas proibidas podem afetar o nosso corpo & $\square$ & 口 & $\square$ & $\square$ \\
\hline 14 & Os possíveis perigos de radiaçōes de telefones celulares e computadores & $\square$ & $\square$ & 口 & $\square$ \\
\hline 15 & Como os sons e ruidos altos podem prejudicar a minha audição & $\square$ & $\square$ & $\square$ & $\square$ \\
\hline 16 & Como proteger especies de animais ameaçados de extinçăo & $\square$ & $\square$ & $\square$ & $\square$ \\
\hline 17 & Como se melhoram as colheitas em hortas e rocas & $\square$ & $\square$ & $\square$ & $\square$ \\
\hline 18 & Uso medicinal de plantas & $\square$ & $\square$ & $\square$ & $\square$ \\
\hline 19 & A agricultura orgánica, sem uso de pesticidas e adubos artificiais & $\square$ & $\square$ & $\square$ & $\square$ \\
\hline 20 & Como a energia pode ser poupada e usada de forma mais eficaz & $\square$ & $\square$ & $\square$ & $\square$ \\
\hline 21 & Nowos recursos de energia - sol, vento, marés, cndas, etc. & $\square$ & $\square$ & $\square$ & $\square$ \\
\hline 22 & $\begin{array}{l}\text { Como săo produzidos, conservados e armazenados os diferentes tipos de } \\
\text { alimentos }\end{array}$ & $\square$ & $\square$ & $\square$ & $\square$ \\
\hline 23 & Como o meu corpo cresce e se desenvolve & $\square$ & $\square$ & $\square$ & $\square$ \\
\hline 24 & Os animais da minha regiầ & $\square$ & $\square$ & $\square$ & $\square$ \\
\hline 25 & As plantas da minha regiåo & $\square$ & $\square$ & $\square$ & $\square$ \\
\hline 26 & Os detergentes e sabóes e como funcionam & $\square$ & $\square$ & $\square$ & $\square$ \\
\hline 27 & Eletricidade, sua produçâo e uso doméstico & $\square$ & $\square$ & 口 & $\square$ \\
\hline
\end{tabular}




\begin{tabular}{|c|c|c|c|c|c|}
\hline & & 1 & 2 & 3 & 4 \\
\hline 28 & Como usilizar e consertar equipamentos elétricos e mecânicos & $\square$ & $\square$ & $\square$ & $\square$ \\
\hline 29 & A primoira viagem para a lua e a história da exploraçảo do espaço & $\square$ & $\square$ & $\square$ & $\square$ \\
\hline 30 & Como a elotricidade influenciou o desenvolvimento da nossa sociedade & $\square$ & $\square$ & $\square$ & $\square$ \\
\hline 31 & Os aspectos biologicos e humanos do aborto & $\square$ & $\square$ & 口 & $\square$ \\
\hline 32 & Como a tecnologia genética pode evitar doenças & $\square$ & $\square$ & 口 & $\square$ \\
\hline 33 & Os beneficios e os possiviveis perigos dos métodos modemos da agricultura & $\square$ & $\square$ & $\square$ & $\square$ \\
\hline 34 & Porque é que a religiâo e a ciência às vezes entram em conflito & $\square$ & $\square$ & $\square$ & $\square$ \\
\hline 35 & Os riscos e os beneficios dos aditivos alimentares & $\square$ & $\square$ & 口 & $\square$ \\
\hline 36 & Porque 6 que os cientistas às vezes discordam entre si & $\square$ & $\square$ & 口 & $\square$ \\
\hline 37 & Cientistas famosos e as suas vidas & $\square$ & $\square$ & 口 & $\square$ \\
\hline 38 & Erros e fracassos em pesquisas e invençes & $\square$ & $\square$ & $\square$ & $\square$ \\
\hline 39 & $\begin{array}{l}\text { Como as novas idèias cientificas às vezes desafiam a religiấ, a autoridade } \\
\text { e a tradiçăo }\end{array}$ & $\square$ & $\square$ & 口 & $\square$ \\
\hline 40 & Invengoles e descobrimentos que transformaram o mundo & $\square$ & $\square$ & $\square$ & $\square$ \\
\hline 41 & Invenpobes e descobrimentos recentes da ciência e da tecnologia & $\square$ & $\square$ & $\square$ & $\square$ \\
\hline 42 & Fenômenos que os ciensistas ainda năo conseguem explicar & $\square$ & $\square$ & $\square$ & $\square$ \\
\hline
\end{tabular}


F. As minhas aulas de ciências

Até que ponto vocề concorda com as seguintes afirmações sobre a ciência que já aprendeu na escola?

(Assinale sua resposta preenchendo o quadradinho correspondente em cada inha. Se nâlo entender, debe a linha em branco).

\begin{tabular}{|c|c|c|c|c|c|}
\hline & & 1 & 2 & 3 & \\
\hline 1 & A disciplina Ciências aborda conteúdos dificeis & $\square$ & $\square$ & $\square$ & $\square$ \\
\hline 2 & A disciplina Ciências é interessante & $\square$ & $\square$ & $\square$ & $\square$ \\
\hline 3 & As Ciências, para mim, são bastante fáceis de aprender & $\square$ & $\square$ & $\square$ & $\square$ \\
\hline 4 & As Ciências abriram-me os olhos para empregos novos e emocionantes & $\square$ & $\square$ & $\square$ & $\square$ \\
\hline 5 & Gosto mais de Ciências do que das outras disciplinas & $\square$ & 口 & $\square$ & $\square$ \\
\hline 6 & Penso que todos deveråo aprender Ciências & $\square$ & 口 & $\square$ & 口 \\
\hline 7 & $\begin{array}{l}\text { Os conhecimentos que adquiro em Cìncias serảo úteis na minha vida } \\
\text { cotidlana }\end{array}$ & $\square$ & $\square$ & $\square$ & 口 \\
\hline 8 & $\begin{array}{l}\text { Penso que a cilncia que eu aprendo na escola melhorara as minhas } \\
\text { oportunidades de carreira }\end{array}$ & $\square$ & $\square$ & $\square$ & 口 \\
\hline 9 & As Ciências tomaram-me mais critíco e cótico & $\square$ & $\square$ & $\square$ & $\square$ \\
\hline 10 & $\begin{array}{l}\text { As Clências estimularam a minha curiosidade acerca das coisas que ainda } \\
\text { nấo conseguimos explicar }\end{array}$ & $\square$ & $\square$ & ㅁ & $\square$ \\
\hline 11 & As Ciências aumentaram o meu gosto pela natureza & $\square$ & $\square$ & $\square$ & $\square$ \\
\hline 12 & $\begin{array}{l}\text { As Ciências mostraram-me a importancla da ciêncla para a forma como } \\
\text { vivemos }\end{array}$ & $\square$ & $\square$ & $\square$ & $\square$ \\
\hline 13 & A ciência que aprendo na escola ensina-me a cuidar melhor da minha saúde & $\square$ & $\square$ & $\square$ & $\square$ \\
\hline 14 & Gostaria de ser cientista & $\square$ & $\square$ & $\square$ & $\square$ \\
\hline 15 & Gostaria de aprender tanta ciência quanto possivel na escola & $\square$ & $\square$ & $\square$ & $\square$ \\
\hline 16 & Gostaria de ter um emprego que lide com tecnologia avançada & $\square$ & 미 & 口 & $\square$ \\
\hline
\end{tabular}


G. As minhas opiniões sobre a ciência e a tecnologia

Até que ponto você concorda com as seguintes afirmaçōes?

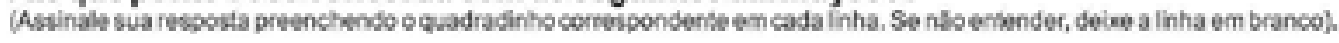

\begin{tabular}{|c|c|c|c|c|c|}
\hline & & 1 & 2 & 3 & 4 \\
\hline 1 & A ciência e a tecnologia têm grande importância para a Sociedade & $\square$ & $\square$ & $\square$ & $\square$ \\
\hline 2 & $\begin{array}{l}\text { A ciência e a tecnologia encontrarăo curas para doenças como a AIDS, o } \\
\text { câncer, elc. }\end{array}$ & 口 & $\square$ & $\square$ & $\square$ \\
\hline 3 & $\begin{array}{l}\text { Devido à ciência e à tecnologia, haverá melhores oportunidades para as } \\
\text { futuras geraçdes }\end{array}$ & $\square$ & $\square$ & $\square$ & $\square$ \\
\hline 4 & $\begin{array}{l}\text { A ciência e a tecnologia tornam as nossas vidas mais saudáveis, mais fácels } \\
\text { e mais confortáweis }\end{array}$ & $\square$ & $\square$ & $\square$ & $\square$ \\
\hline 5 & As novas fecnologias tomarâo o trabalho mais interessante & $\square$ & $\square$ & $\square$ & $\square$ \\
\hline 6 & $\begin{array}{l}\text { Os beneficios da cilncia sỉo maiores do que os efeitos negativos que possa } \\
\text { ter }\end{array}$ & $\square$ & $\square$ & $\square$ & $\square$ \\
\hline 7 & A ciência e a tecnologia ajudarl̆o a erradicar a pobreza e a fome no mundo & $\square$ & $\square$ & $\square$ & $\square$ \\
\hline 8 & A ciôncia e a tocnologia podem resolver quase todos os problemas & $\square$ & $\square$ & $\square$ & $\square$ \\
\hline 9 & A ciéncia e a tecnologia ajudam os pobres & $\square$ & $\square$ & $\square$ & $\square$ \\
\hline 10 & A ciência e a tecnologia sấo as causas dos problemas do ambiente & $\square$ & $\square$ & $\square$ & $\square$ \\
\hline 11 & Um pais precisa de ciência e de tecnologia para se desenwolver & $\square$ & $\square$ & $\square$ & $\square$ \\
\hline 12 & A cióncia e a tecnologia beneficiam principalmente os paises desenvolvidos & $\square$ & $\square$ & $\square$ & 口 \\
\hline 13 & $\begin{array}{l}\text { Os cientistas seguem o método clentifico que os leva sempre as respostas } \\
\text { corretas }\end{array}$ & $\square$ & $\square$ & $\square$ & $\square$ \\
\hline 14 & Podemos sempre confiar no que os cientistas dizem & $\square$ & $\square$ & $\square$ & $\square$ \\
\hline 15 & Os cientistas sāo neutros e objetivos & $\square$ & $\square$ & $\square$ & $\square$ \\
\hline 16 & As teorias cientificas desenvolvem-se e mudam constantemente & $\square$ & $\square$ & $\square$ & $\square$ \\
\hline
\end{tabular}




\section{H.As minhas experiências fora da escola}

\section{Quantas vezes vocể já fez estas experiências fora da escola?}

(Ass inale sua resposta preenchendo o quadradinho correspondente em onda linha. Se nlo entender, dejo a imha em branco).

Já..

\begin{tabular}{|c|c|c|c|c|c|}
\hline & & 1 & 2 & 3 & 4 \\
\hline 1 & tentei encontrar as constelaçōes no cév & $\square$ & $\square$ & $\square$ & 口 \\
\hline 2 & li o meu horoscopo (prever o futuro através dos astros) & $\square$ & $\square$ & $\square$ & $\square$ \\
\hline 3 & utilizei um mapa para me orientar & $\square$ & $\square$ & $\square$ & $\square$ \\
\hline 4 & utilizel uma bússola para determinar a direçâo & $\square$ & $\square$ & $\square$ & $\square$ \\
\hline 5 & fz coleçäo de pedras ou conchas diferentes & $\square$ & $\square$ & $\square$ & $\square$ \\
\hline 6 & vỉ um animal nascer (sem ser na televisâo) & $\square$ & $\square$ & $\square$ & 口 \\
\hline 7 & cuidei de animais numa fazenda ou sítio & $\square$ & $\square$ & $\square$ & 口 \\
\hline 8 & visitei um jardim zoologico & $\square$ & $\square$ & $\square$ & $\square$ \\
\hline 9 & visitei um centro de cillncias ou um museu de ciências & $\square$ & $\square$ & $\square$ & $\square$ \\
\hline 10 & ordenhei animais como vacas, ovelhas ou cabras & $\square$ & $\square$ & $\square$ & $\square$ \\
\hline 11 & fiz produlos com leite, como iogurtes, manteiga, queijos & $\square$ & $\square$ & $\square$ & $\square$ \\
\hline 12 & li coisas scbre a natureza ou as ciencias em livros ou revistas & $\square$ & $\square$ & $\square$ & $\square$ \\
\hline 13 & vi documentários sobre a natureza na televisăo ou no cinema & $\square$ & $\square$ & $\square$ & 口 \\
\hline 14 & apanhei frutas ou plantas comestiveis & $\square$ & $\square$ & $\square$ & $\square$ \\
\hline 15 & fui caçar & $\square$ & $\square$ & $\square$ & 口 \\
\hline 16 & fui pescar & $\square$ & $\square$ & $\square$ & $\square$ \\
\hline 17 & plantei sementes e as vi crescer & $\square$ & $\square$ & $\square$ & $\square$ \\
\hline 18 & fiz composto orgânico (adubo) com folhas ou livo & $\square$ & $\square$ & $\square$ & $\square$ \\
\hline 19 & $\begin{array}{l}\text { fiz um instrumento (como por exemplo uma flauta ou bateria) de materiais } \\
\text { naturais }\end{array}$ & $\square$ & $\square$ & $\square$ & $\square$ \\
\hline 20 & fiz crochê, triob̂ ou tapeçaria (tapetes, pulseiras, bolsas), etc. & $\square$ & $\square$ & 口 & $\square$ \\
\hline 21 & montei uma barraca (acampamento) & $\square$ & $\square$ & $\square$ & $\square$ \\
\hline 22 & fzz uma fogueira com carvâo ou lenha & $\square$ & $\square$ & $\square$ & $\square$ \\
\hline 23 & preparei comida numa fogueira ou fogareiro a gás & $\square$ & $\square$ & $\square$ & $\square$ \\
\hline 24 & separei lixo para reciclagem & $\square$ & $\square$ & $\square$ & $\square$ \\
\hline 25 & limpei e cuidei de uma ferida, machucado & $\square$ & $\square$ & $\square$ & $\square$ \\
\hline 26 & vi uma radiografia de uma parte do meu corpo & $\square$ & $\square$ & $\square$ & 口 \\
\hline 27 & tomei remedios para evitar ou tratar uma infeçalo ou outra doença & $\square$ & $\square$ & $\square$ & $\square$ \\
\hline 28 & $\begin{array}{l}\text { tomei ervas medicinais cu fiz tratamentos altemativos (acupuntura, } \\
\text { homeopatia, ioga, etc.) }\end{array}$ & $\square$ & 口 & $\square$ & 口 \\
\hline 29 & ful a um hospital como paciente & $\square$ & $\square$ & $\square$ & $\square$ \\
\hline
\end{tabular}




\begin{tabular}{|c|c|c|c|c|c|}
\hline \multicolumn{2}{|l|}{ Já... } & $\begin{array}{l}\frac{7}{2} \\
1\end{array}$ & \multicolumn{2}{|c|}{ 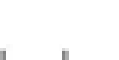 } & \\
\hline 30 & utilizei binóculos & $\square$ & $\square$ & $\square$ & $\square$ \\
\hline 31 & utilizei uma máquina fotográfica & $\square$ & $\square$ & $\square$ & $\square$ \\
\hline 32 & fiz um arco e flechas, bumerangue, etc. & $\square$ & $\square$ & $\square$ & $\square$ \\
\hline 33 & utilizei uma pis:ola/espingarda de ar comprimido & $\square$ & 口 & $\square$ & $\square$ \\
\hline 34 & utilizôi uma bomba de água ou sifão & $\square$ & 口 & 口 & $\square$ \\
\hline 35 & montei uma miniatura (modelo) de avilas, carro ou barco, etc. & $\square$ & $\square$ & $\square$ & $\square$ \\
\hline 36 & utilizei um kit de ciências (quimica, optica, eletricidade etc.) & $\square$ & $\square$ & $\square$ & $\square$ \\
\hline 37 & utilizei um moinho de vento, uma roda de água & $\square$ & $\square$ & $\square$ & $\square$ \\
\hline 38 & gravei um video, DVD, CD ou fita cassete & $\square$ & $\square$ & $\square$ & $\square$ \\
\hline 39 & troquei tampadas ou fusiveis & $\square$ & $\square$ & $\square$ & $\square$ \\
\hline 40 & liguei um aparelho elétrico a uma tomada & 口 & $\square$ & $\square$ & $\square$ \\
\hline 41 & utilizei um cronめmetro & $\square$ & $\square$ & $\square$ & $\square$ \\
\hline 42 & medi a temperatura $c 0 m$ um termbmetro & $\square$ & $\square$ & $\square$ & $\square$ \\
\hline 43 & utilizei uma regua, uma fita métrica, trena, etc. & $\square$ & 口 & $\square$ & $\square$ \\
\hline 44 & utilizei um tob/one celular & $\square$ & 口 & $\square$ & $\square$ \\
\hline 45 & enviei ou recebi uma mensagem SMS (mensagem de texto do celular) & 口 & 口 & $\square$ & $\square$ \\
\hline 46 & procurei informaçles na Internet & $\square$ & $\square$ & $\square$ & $\square$ \\
\hline 47 & joguei jogos de computador & $\square$ & $\square$ & $\square$ & $\square$ \\
\hline 48 & utilizei um dicionário, enciclopédia. etc. no computador & $\square$ & 口 & 口 & $\square$ \\
\hline 49 & gravei música da Intemet & 口 & 口 & 口 & $\square$ \\
\hline 50 & enviei ou recebi e-mail & $\square$ & $\square$ & $\square$ & $\square$ \\
\hline 51 & utilizel um processador de texto no computador (Word, etc.) & $\square$ & $\square$ & $\square$ & $\square$ \\
\hline 52 & $\begin{array}{l}\text { desmontei um aparelho (rádio, relógio, computador, telefone, exc.) para ver } \\
\text { como funcicna }\end{array}$ & 口 & $\square$ & $\square$ & $\square$ \\
\hline 53 & fiz pâlo, massa ou bolos & 口 & 口 & 口 & $\square$ \\
\hline 54 & cozinhei uma refeiçōo & $\square$ & $\square$ & $\square$ & $\square$ \\
\hline 55 & caminhei ao mesmo tempo em que equilibrava um objeto na cabeça & $\square$ & $\square$ & $\square$ & $\square$ \\
\hline 56 & utilizel um carninho de mâo (daqueles de pedreiro) & $\square$ & $\square$ & $\square$ & $\square$ \\
\hline 57 & utilizei um pé-de-cabra (alavanca para abrir portas/caixas, por exemplo) & $\square$ & $\square$ & $\square$ & $\square$ \\
\hline 58 & utilizei corda e roldana para levantar coisas pesadas & 口 & 口 & 口 & $\square$ \\
\hline 59 & consertei um pneu de biciclota & $\square$ & $\square$ & 口 & $\square$ \\
\hline 60 & utilizei ferramentas como serrote, chave de fenda ou martelo & $\square$ & 口 & $\square$ & $\square$ \\
\hline 61 & recarreguei uma bateria de carro & $\square$ & $\square$ & $\square$ & $\square$ \\
\hline
\end{tabular}



I. Qual é a sua religiāo? (Preencha o quadradinho equivalente à sua opçăo religiosa).
Caloblica
Evangelica
Oulras denominacōes protestanles
Budista
$\square$ Judaica
$\square$ islämica
Candomble
Umbanda
$\square$ Espinita Kardecista
Nenhuma
$\square$ Oulra

Qual?

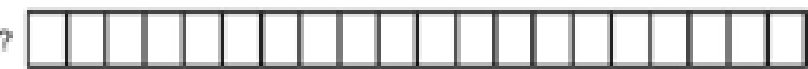

J. Quanto pratico minha religiăo.

Quantas vezes frequento o serviço religioso?

(Assinale sua resposta preenchendo o quadradirho correspondente em cada inha. Se nalo entender, deixe a linha em branco).

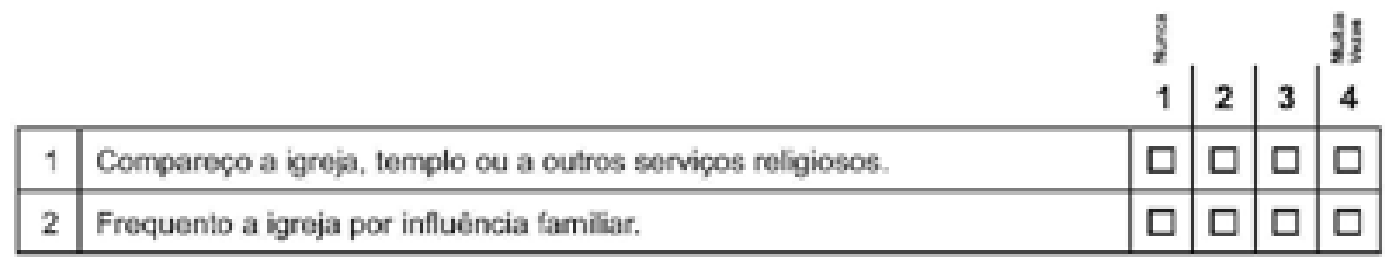

\section{O que eu concordo}

\section{Qual é o seu nivel de aceitaçăo das seguintes afirmaçŏes ?}

(Assinale sua resposta preenchendo o quadradinho correspondente en cada linha. Se nJo entender, debre a linha em branco).

\begin{tabular}{|c|c|c|c|c|c|}
\hline & & 1 & 2 & 3 & 4 \\
\hline 1 & Sou uma pessca religiosa, ou uma pessca de fé. & $\square$ & $\square$ & $\square$ & $\square$ \\
\hline 2 & Compreendo e acredito na doutrina ou nos ensinos religiosos. & $\square$ & $\square$ & $\square$ & $\square$ \\
\hline 3 & Participo com freqūência das reuniōes da minha religiåo. & $\square$ & $\square$ & $\square$ & $\square$ \\
\hline 4 & Minha religiâo me impede de acreditar na evoluçẩo biológica. & $\square$ & $\square$ & $\square$ & $\square$ \\
\hline 5 & Minha fé e/ou moral afetariam minha escolha de alguma carreira. & $\square$ & $\square$ & $\square$ & $\square$ \\
\hline 6 & Sinto que minha fé contradiz as teorias cientificas atuais. & $\square$ & $\square$ & $\square$ & $\square$ \\
\hline
\end{tabular}




\section{O que eu concordo}

Qualé o seu nivel de aceitaçăo das afirmaçōes que aparecem a seguir?

(Ausinale sua resposta preenchendo oquadradinho correspondente em cada inha. Se nlo eriander, deixe a linha em branco).

\begin{tabular}{|c|c|c|c|c|c|}
\hline & & 1 & 2 & 3 & 4 \\
\hline 1 & A formaçăo do planeta Terra se deu há cerca de 4,5 bilhđes de ancs. & $\square$ & $\square$ & $\square$ & $\square$ \\
\hline 2 & Os fósseis săo indicios de espécies que viveram no passado. & $\square$ & $\square$ & $\square$ & $\square$ \\
\hline 3 & $\begin{array}{l}\text { As espécies atuais de animais e plantas se originaram de outras especies } \\
\text { do passado. }\end{array}$ & 口 & $\square$ & $\square$ & $\square$ \\
\hline 4 & $\begin{array}{l}\text { Os individuos que têm muitos descendentes transmitem suas caracteristicas } \\
\text { vantajosas às nowas geraçōes. }\end{array}$ & $\square$ & $\square$ & $\square$ & $\square$ \\
\hline 5 & A formação de um fóssil pode demorar milhōes de anos. & $\square$ & $\square$ & 口 & $\square$ \\
\hline 6 & A evoluçäo ocorre tanto em plantas como em animais. & $\square$ & $\square$ & 口 & $\square$ \\
\hline 7 & Os humanos primitivos eram presas de dinossauros carnivoros. & $\square$ & $\square$ & $\square$ & $\square$ \\
\hline 8 & Os primeiros seres humanos viveram no ambiente africano. & $\square$ & $\square$ & $\square$ & $\square$ \\
\hline 9 & A espécie humana habita a Terra há cerca de 100.000 anos. & $\square$ & $\square$ & $\square$ & $\square$ \\
\hline 10 & Diferentes especies atuais podem ter um ancestral comum. & $\square$ & $\square$ & $\square$ & $\square$ \\
\hline 11 & $\begin{array}{l}\text { As condiphes na Terra primitiva favoreceram a ocorrencia de reap̧es } \\
\text { quimicas que transformarvam compostos inorgânicos em compostos } \\
\text { orgânicos que acabaram gerando vida. }\end{array}$ & 口 & $\square$ & $\square$ & $\square$ \\
\hline 12 & Os humanos primitivos eram caçadores de dinossauros herbívoros. & 口 & $\square$ & ㅁ & 口 \\
\hline 13 & $\begin{array}{l}\text { O ser humano se originou da mesma forma como as demais especies } \\
\text { bioḱgicas. }\end{array}$ & 口 & 口 & 口 & $\square$ \\
\hline
\end{tabular}

\section{N. Você já estudou sobre os assuntos citados acima nas aulas de ciências?}
口 N\$๊
口 Sim, poucos
Sim, a maicria
$\square \mathrm{Sim}$, locios 


\section{APÊNDICE A - Resultados obtidos junto às seções ACE "O que quero aprender" (completo).}

Tabela Apêndice A - Resultados obtidos junto às seções ACE: médias e testes Mann-Whitney para diferenças em relação ao gênero dos estudantes.

\begin{tabular}{|c|c|c|c|c|c|c|}
\hline \multirow[b]{2}{*}{ Questões ACE: “O que quero aprender?” } & \multirow{2}{*}{$\begin{array}{l}\text { Média } \\
\text { Geral }\end{array}$} & \multicolumn{2}{|c|}{ Média } & \multirow{2}{*}{$\begin{array}{c}\text { Diferença } \\
\text { (H-M) }\end{array}$} & \multirow[b]{2}{*}{ IC 95 (Dif) } & \multirow{2}{*}{$\begin{array}{c}\text { P- } \\
\text { valor }\end{array}$} \\
\hline & & Homem & Mulher & & & \\
\hline A01 - Estrelas, planetas e o Universo & 2,56 & 2,52 & 2,59 & $-0,07$ & {$[-0.16 ; 0.01]$} & 0,085 \\
\hline $\begin{array}{l}\text { A02 - Substâncias químicas, suas propriedades e } \\
\text { como reagem }\end{array}$ & 2,42 & 2,39 & 2,45 & $-0,06$ & {$[-0.15 ; 0.02]$} & 0,215 \\
\hline A03 - O interior da Terra & 2,40 & 2,42 & 2,39 & 0,03 & {$[-0.07 ; 0.11]$} & 0,586 \\
\hline $\begin{array}{l}\text { A04 - Como evoluem e se transformam as } \\
\text { montanhas, rios e oceanos }\end{array}$ & 2,37 & 2,39 & 2,37 & 0,02 & {$[-0.07 ; 0.11]$} & 0,679 \\
\hline A05 - Nuvens, chuva e tempo & 2,34 & 2,25 & 2,4 & $-0,15$ & {$[-0.23 ;-0.06]$} & 0,01 \\
\hline A06 - Origem e evolução da vida na Terra & 2,82 & 2,78 & 2,86 & $-0,08$ & {$[-0.17 ; 0.01]$} & 0,093 \\
\hline $\begin{array}{l}\text { A07 - Como o corpo humano é feito e como } \\
\text { funciona }\end{array}$ & 3,03 & 2,84 & 3,18 & $-0,34$ & {$[-0.43 ;-0.26]$} & 0,01 \\
\hline $\begin{array}{l}\text { A08 - Hereditariedade e como os genes afetam o } \\
\text { nosso desenvolvimento }\end{array}$ & 2,45 & 2,19 & 2,64 & $-0,45$ & {$[-0.54 ;-0.37]$} & 0,01 \\
\hline A09 - Sexo e reprodução & 3,1 & 3,18 & 3,05 & 0,13 & {$[0.05 ; 0.21]$} & 0,01 \\
\hline A10 - Controle de natalidade e contracepção & 2,09 & 1,92 & 2,22 & $-0,3$ & {$[-0.39 ;-0.22]$} & 0,01 \\
\hline A11 - Como os bebês crescem e se desenvolvem & 2,66 & 2,29 & 2,93 & $-0,64$ & {$[-0.72 ;-0.55]$} & 0,01 \\
\hline A12 - Clonagem de animais & 2,68 & 2,71 & 2,66 & 0,05 & {$[-0.04 ; 0.15]$} & 0,234 \\
\hline A13 - Animais de diversas partes do mundo & 2,76 & 2,81 & 2,72 & 0,09 & {$[-0.01 ; 0.17]$} & 0,075 \\
\hline $\begin{array}{l}\text { A14 - Dinossauros, como viveram e porque } \\
\text { desapareceram }\end{array}$ & 2,69 & 2,80 & 2,60 & 0,2 & {$[0.1 ; 0.29]$} & 0,01 \\
\hline A15 - Como as plantas crescem e se reproduzem & 2,29 & 2,23 & 2,33 & $-0,1$ & {$[-0.18 ;-0.02]$} & 0,026 \\
\hline $\begin{array}{l}\text { A16 - Como as pessoas, animais, plantas e } \\
\text { ambiente dependem uns dos outros }\end{array}$ & 2,69 & 2,52 & 2,82 & $-0,3$ & {$[-0.39 ;-0.22]$} & 0,01 \\
\hline A17 - Átomos e moléculas & 2,21 & 2,16 & 2,24 & $-0,08$ & {$[-0.17 ; 0.01]$} & 0,08 \\
\hline $\begin{array}{l}\text { A18 - Como a radioatividade afeta o corpo } \\
\text { humano }\end{array}$ & 2,70 & 2,64 & 2,75 & $-0,11$ & {$[-0.2 ;-0.02]$} & 0,015 \\
\hline $\begin{array}{l}\text { A19 - A luz invisível à nossa volta (infravermelho, } \\
\text { ultravioleta) }\end{array}$ & 2,65 & 2,66 & 2,64 & 0,02 & {$[-0.07 ; 0.11]$} & 0,654 \\
\hline $\begin{array}{l}\text { A20 - Como os animais utilizam cores para se } \\
\text { esconderem, atraírem ou assustarem }\end{array}$ & 2,71 & 2,66 & 2,74 & $-0,08$ & {$[-0.17 ; 0.01]$} & 0,063 \\
\hline $\begin{array}{l}\text { A21 - Como diferentes instrumentos musicais } \\
\text { produzem sons diferentes }\end{array}$ & 2,61 & 2,56 & 2,65 & $-0,09$ & {$[-0.19 ; 0]$} & 0,051 \\
\hline $\begin{array}{l}\text { A22 - Buracos negros, supernovas e outros objetos } \\
\text { do espaço }\end{array}$ & 2,65 & 2,78 & 2,56 & 0,22 & {$[0.12 ; 0.32]$} & 0,01 \\
\hline $\begin{array}{l}\text { A } 23 \text { - Como meteoritos, cometas e asteróides } \\
\text { podem causar catástrofes na Terra }\end{array}$ & 2,88 & 2,91 & 2,86 & 0,05 & {$[-0.05 ; 0.13]$} & 0,363 \\
\hline A24 - Terremotos e vulcões & 2,82 & 2,78 & 2,85 & $-0,07$ & {$[-0.16 ; 0.01]$} & 0,089 \\
\hline A25 - Tornados, furacões e ciclones & 2,83 & 2,83 & 2,84 & $-0,01$ & {$[-0.1 ; 0.07]$} & 0,644 \\
\hline $\begin{array}{l}\text { A26 - Epidemias e doenças que causam muitas } \\
\text { mortes }\end{array}$ & 2,87 & 2,60 & 3,07 & $-0,47$ & {$[-0.55 ;-0.38]$} & 0,01 \\
\hline A27 - Animais perigosos e venenosos & 2,89 & 2,88 & 2,91 & $-0,03$ & {$[-0.11 ; 0.06]$} & 0,659 \\
\hline A28 - Plantas tóxicas da minha região & 2,49 & 2,46 & 2,52 & $-0,06$ & {$[-0.15 ; 0.03]$} & 0,189 \\
\hline $\begin{array}{l}\text { A } 29 \text { - Venenos mortais e o que estes fazem ao } \\
\text { corpo humano }\end{array}$ & 2,90 & 2,79 & 2,99 & $-0,2$ & {$[-0.28 ;-0.1]$} & 0,01 \\
\hline A30 - Como funciona a bomba atômica & 2,85 & 3,07 & 2,69 & 0,38 & {$[0.29 ; 0.47]$} & 0,01 \\
\hline A31 - Químicos explosivos & 2,64 & 2,82 & 2,50 & 0,32 & {$[0.23 ; 0.41]$} & 0,01 \\
\hline $\begin{array}{l}\text { A32 - Armas biológicas e químicas e o que fazem } \\
\text { ao corpo humano }\end{array}$ & 2,67 & 2,74 & 2,62 & 0,12 & {$[0.03 ; 0.2]$} & 0,01 \\
\hline
\end{tabular}


CONTINUAÇÃO - Tabela Apêndice A - Resultados obtidos junto às seções ACE: médias e testes Mann-Whitney para diferenças em relação ao gênero dos estudantes.

\begin{tabular}{|c|c|c|c|c|c|c|}
\hline \multirow[b]{2}{*}{ Questões ACE: “O que quero aprender?” } & \multirow{2}{*}{$\begin{array}{l}\text { Média } \\
\text { Geral }\end{array}$} & \multicolumn{2}{|c|}{ Média } & \multirow{2}{*}{$\begin{array}{l}\text { Diferença } \\
\text { (H-M) }\end{array}$} & \multirow[b]{2}{*}{ IC 95 (Dif) } & \multirow{2}{*}{$\begin{array}{c}\text { P- } \\
\text { valor }\end{array}$} \\
\hline & & Homem & Mulher & & & \\
\hline $\begin{array}{l}\text { A33 - O efeito dos choques elétricos e dos } \\
\text { relâmpagos no corpo humano }\end{array}$ & 2,97 & 2,95 & 2,98 & $-0,03$ & {$[-0.11 ; 0.06]$} & 0,653 \\
\hline $\begin{array}{l}\text { A34 - Qual a sensação de viver sem peso no } \\
\text { espaço }\end{array}$ & 2,87 & 2,84 & 2,89 & $-0,05$ & {$[-0.15 ; 0.04]$} & 0,283 \\
\hline A35 - Como caminhar orientado pelas estrelas & 2,72 & 2,60 & 2,81 & $-0,21$ & {$[-0.3 ;-0.11]$} & 0,01 \\
\hline A36 - Como o olho consegue ver luz e cores & 2,95 & 2,85 & 3,03 & $-0,18$ & {$[-0.27 ;-0.1]$} & 0,01 \\
\hline $\begin{array}{l}\text { A37 - O que comer para nos mantermos saudáveis } \\
\text { e em boa forma física }\end{array}$ & 3,05 & 2,94 & 3,14 & $-0,2$ & {$[-0.29 ;-0.12]$} & 0,01 \\
\hline $\begin{array}{l}\text { A38 - As perturbações alimentares, como anorexia } \\
\text { e bulimia }\end{array}$ & 2,64 & 2,18 & 2,98 & $-0,8$ & {$[-0.89 ;-0.71]$} & 0,01 \\
\hline $\begin{array}{l}\text { A39 - A capacidade de loções e cremes manterem } \\
\text { a pele jovem }\end{array}$ & 2,66 & 2,18 & 3,02 & $-0,84$ & {$[-0.92 ;-0.75]$} & 0,01 \\
\hline $\begin{array}{l}\text { A40 - Como manter o meu corpo forte e em boa } \\
\text { condição física }\end{array}$ & 3,23 & 3,15 & 3,29 & $-0,14$ & {$[-0.22 ;-0.06]$} & 0,004 \\
\hline A41 - Cirurgias plásticas e tratamentos de beleza & 2,45 & 1,94 & 2,83 & $-0,89$ & {$[-0.98 ;-0.8]$} & 0,01 \\
\hline $\begin{array}{l}\text { A } 42 \text { - Como a luz solar e a dos bronzeadores } \\
\text { artificiais afetam a pele }\end{array}$ & 2,58 & 2,20 & 2,86 & $-0,66$ & {$[-0.74 ;-0.57]$} & 0,01 \\
\hline $\begin{array}{l}\text { A } 43 \text { - Como nosso organismo consegue ouvir } \\
\text { diferentes sons }\end{array}$ & 2,68 & 2,55 & 2,78 & $-0,23$ & {$[-0.31 ;-0.14]$} & 0,01 \\
\hline A44 - Foguetes, satélites e viagens espaciais & 2,56 & 2,73 & 2,44 & 0,29 & {$[0.2 ; 0.38]$} & 0,01 \\
\hline $\begin{array}{l}\text { A } 45 \text { - O uso de satélites para comunicação e outros } \\
\text { propósitos }\end{array}$ & 2,46 & 2,61 & 2,34 & 0,27 & {$[0.18 ; 0.36]$} & 0,01 \\
\hline $\begin{array}{l}\text { A } 46 \text { - Como o raio-x, o ultra-som, etc. são usados } \\
\text { na medicina }\end{array}$ & 2,8 & 2,63 & 2,93 & $-0,3$ & {$[-0.39 ;-0.21]$} & 0,01 \\
\hline $\begin{array}{l}\text { A47 - Como funcionam os motores a diesel, a } \\
\text { álcool, a gás e a gasolina }\end{array}$ & 2,44 & 2,74 & 2,22 & 0,52 & {$[0.43 ; 0.61]$} & 0,01 \\
\hline A48 - Como funciona uma usina nuclear & 2,75 & 2,94 & 2,61 & 0,33 & {$[0.25 ; 0.43]$} & 0,01 \\
\hline $\begin{array}{l}\text { C01 - Como o petróleo é transformado em outros } \\
\text { materiais como plásticos e tecidos }\end{array}$ & 2,49 & 2,54 & 2,46 & 0,08 & {$[-0.01 ; 0.18]$} & 0,071 \\
\hline $\begin{array}{l}\text { C02 - Instrumentos ópticos e como funcionam } \\
\text { (telescópio, máquina fotográfica, microscópio, } \\
\text { etc.) }\end{array}$ & 2,69 & 2,64 & 2,72 & $-0,08$ & {$[-0.17 ; 0.01]$} & 0,085 \\
\hline $\begin{array}{l}\text { C03 - O uso do raio laser para efeitos técnicos } \\
\text { (gravadores de CDs, leitores de códigos de barra, } \\
\text { etc.) }\end{array}$ & 2,66 & 2,82 & 2,54 & 0,28 & {$[0.19 ; 0.37]$} & 0,01 \\
\hline $\begin{array}{l}\text { C04 - Como fitas cassete, gravadores de CD e } \\
\text { DVD armazenam e reproduzem sons e música }\end{array}$ & 2,74 & 2,83 & 2,67 & 0,16 & {$[0.06 ; 0.24]$} & 0,001 \\
\hline $\begin{array}{l}\text { C05 - Como funcionam coisas como o rádio e a } \\
\text { televisão }\end{array}$ & 2,74 & 2,81 & 2,68 & 0,13 & {$[0.05 ; 0.23]$} & 0,003 \\
\hline $\begin{array}{l}\text { C06 - Como os telefones celulares enviam e } \\
\text { recebem mensagens }\end{array}$ & 2,89 & 2,83 & 2,94 & $-0,11$ & {$[-0.2 ;-0.02]$} & 0,01 \\
\hline C07 - Como os computadores funcionam & 3,11 & 3,17 & 3,07 & 0,1 & {$[0.02 ; 0.19]$} & 0,006 \\
\hline $\begin{array}{l}\text { C08 - A possibilidade de vida fora do planeta } \\
\text { Terra }\end{array}$ & 3,04 & 3,03 & 3,05 & $-0,02$ & {$[-0.11 ; 0.07]$} & 0,773 \\
\hline $\begin{array}{l}\text { C09 - Astrologia e horóscopos e se os planetas } \\
\text { podem influenciar os seres humanos }\end{array}$ & 2,44 & 2,26 & 2,58 & $-0,32$ & {$[-0.41 ;-0.23]$} & 0,01 \\
\hline C10 - Os mistérios do espaço ainda por resolver & 2,60 & 2,62 & 2,58 & 0,04 & {$[-0.05 ; 0.14]$} & 0,386 \\
\hline C11 - A vida, a morte e a alma humana & 2,93 & 2,76 & 3,05 & $-0,29$ & {$[-0.39 ;-0.2]$} & 0,01 \\
\hline $\begin{array}{l}\text { C12 - Medicinas alternativas (acupuntura, } \\
\text { homeopatia, ioga, etc.) e a sua eficácia }\end{array}$ & 2,49 & 2,21 & 2,70 & $-0,49$ & {$[-0.58 ;-0.39]$} & 0,01 \\
\hline $\begin{array}{l}\text { C13 - Porque sonhamos e qual o significado dos } \\
\text { nossos sonhos }\end{array}$ & 3,17 & 2,93 & 3,34 & $-0,41$ & {$[-0.5 ;-0.33]$} & 0,01 \\
\hline
\end{tabular}


CONTINUAÇÃO - Tabela Apêndice A - Resultados obtidos junto às seções ACE: médias e testes Mann-Whitney para diferenças em relação ao gênero dos estudantes.

\begin{tabular}{|c|c|c|c|c|c|c|}
\hline \multirow{2}{*}{ Questões ACE: “O que quero aprender?" } & \multirow{2}{*}{$\begin{array}{l}\text { Média } \\
\text { Geral }\end{array}$} & \multicolumn{2}{|c|}{ Média } & \multirow{2}{*}{$\begin{array}{l}\text { Diferença } \\
\text { (H-M) }\end{array}$} & \multirow{2}{*}{ IC 95 (Dif) } & \multirow{2}{*}{$\begin{array}{c}\text { P- } \\
\text { valor }\end{array}$} \\
\hline & & Homem & Mulher & & & \\
\hline C14 - Bruxas e fantasmas, e se existem ou não. & 2,20 & 2,13 & 2,26 & $-0,13$ & {$[-0.23 ;-0.02]$} & 0,016 \\
\hline $\begin{array}{l}\text { C15 - Transmissão de pensamentos, leitura de } \\
\text { mentes, sexto sentido, intuição, etc. }\end{array}$ & 2,67 & 2,51 & 2,79 & $-0,28$ & {$[-0.38 ;-0.19]$} & 0,01 \\
\hline $\begin{array}{l}\text { C16 - Porque as estrelas brilham e porque o céu é } \\
\text { azul }\end{array}$ & 2,75 & 2,67 & 2,82 & $-0,15$ & {$[-0.25 ;-0.06]$} & 0,001 \\
\hline C17 - Porque conseguimos ver o arco-íris & 2,61 & 2,49 & 2,7 & $-0,21$ & {$[-0.31 ;-0.13]$} & 0,01 \\
\hline $\begin{array}{l}\text { C18 - As propriedades das pedras e dos cristais e } \\
\text { como são usados para embelezar }\end{array}$ & 2,42 & 2,25 & 2,55 & $-0,3$ & {$[-0.39 ;-0.21]$} & 0,01 \\
\hline E01 - Simetrias e padrões em folhas e flores & 1,75 & 1,76 & 1,75 & 0,01 & {$[-0.06 ; 0.1]$} & 0,95 \\
\hline $\begin{array}{l}\text { E02 - Como se formam no céu as cores do pôr-do- } \\
\text { sol }\end{array}$ & 2,55 & 2,45 & 2,63 & $-0,18$ & {$[-0.27 ;-0.09]$} & 0,01 \\
\hline $\begin{array}{l}\text { E03 - A camada de ozônio e como pode ser afetada } \\
\text { pelos seres humanos }\end{array}$ & 2,66 & 2,64 & 2,67 & $-0,03$ & {$[-0.11 ; 0.07]$} & 0,607 \\
\hline $\begin{array}{l}\text { E04 - O efeito estufa e como pode ser modificado } \\
\text { pelos seres humanos }\end{array}$ & 2,74 & 2,75 & 2,72 & 0,03 & {$[-0.06 ; 0.12]$} & 0,384 \\
\hline $\begin{array}{l}\text { E05 - O que se pode fazer para assegurar ar limpo } \\
\text { e água potável }\end{array}$ & 3,06 & 3,00 & 3,10 & $-0,1$ & {$[-0.19 ;-0.02]$} & 0,032 \\
\hline $\begin{array}{l}\text { E06 - Como a tecnologia nos ajuda a tratar de } \\
\text { resíduos, lixo e esgotos }\end{array}$ & 2,81 & 2,80 & 2,82 & $-0,02$ & {$[-0.1 ; 0.07]$} & 0,886 \\
\hline E07 - Como controlar epidemias e doenças & 3,01 & 2,80 & 3,18 & $-0,38$ & {$[-0.46 ;-0.29]$} & 0,01 \\
\hline $\begin{array}{l}\text { E08 - O câncer, o que sabemos e como podemos } \\
\text { tratá-lo }\end{array}$ & 3,24 & 3,01 & 3,40 & $-0,39$ & {$[-0.46 ;-0.3]$} & 0,01 \\
\hline $\begin{array}{l}\text { E09 - As doenças sexualmente transmissíveis e } \\
\text { como se proteger delas }\end{array}$ & 3,22 & 3,06 & 3,33 & $-0,27$ & {$[-0.36 ;-0.2]$} & 0,01 \\
\hline E10 - Como prestar primeiros socorros & 3,33 & 3,17 & 3,45 & $-0,28$ & {$[-0.35 ;-0.2]$} & 0,01 \\
\hline $\begin{array}{l}\text { E11 - O que sabemos sobre HIV/AIDS e como } \\
\text { controlá-la }\end{array}$ & 3,18 & 2,99 & 3,31 & $-0,32$ & {$[-0.4 ;-0.24]$} & 0,01 \\
\hline $\begin{array}{l}\text { E12 - Como o álcool e o tabaco podem afetar o } \\
\text { corpo humano }\end{array}$ & 3,00 & 2,85 & 3,11 & $-0,26$ & {$[-0.35 ;-0.18]$} & 0,01 \\
\hline $\begin{array}{l}\text { E13 - Como as diferentes drogas proibidas podem } \\
\text { afetar o nosso corpo }\end{array}$ & 3,04 & 2,84 & 3,19 & $-0,35$ & {$[-0.44 ;-0.27]$} & 0,01 \\
\hline $\begin{array}{l}\text { E14 - Os possíveis perigos de radiações de } \\
\text { telefones celulares e computadores }\end{array}$ & 2,83 & 2,82 & 2,83 & $-0,01$ & {$[-0.1 ; 0.08]$} & 0,977 \\
\hline $\begin{array}{l}\text { E15 - Como os sons e ruídos altos podem } \\
\text { prejudicar a minha audição }\end{array}$ & 2,79 & 2,74 & 2,82 & $-0,08$ & {$[-0.17 ; 0]$} & 0,086 \\
\hline $\begin{array}{l}\text { E16 - Como proteger espécies de animais } \\
\text { ameaçados de extinção }\end{array}$ & 2,99 & 2,98 & 3,00 & $-0,02$ & {$[-0.11 ; 0.06]$} & 0,989 \\
\hline $\begin{array}{l}\text { E17 - Como se melhoram as colheitas em hortas e } \\
\text { roças }\end{array}$ & 2,29 & 2,35 & 2,24 & 0,11 & {$[0.03 ; 0.21]$} & 0,012 \\
\hline E18 - Uso medicinal de plantas & 2,63 & 2,51 & 2,72 & $-0,21$ & {$[-0.3 ;-0.12]$} & 0,01 \\
\hline $\begin{array}{l}\text { E19 - A agricultura orgânica, sem uso de } \\
\text { pesticidas e adubos artificiais }\end{array}$ & 2,28 & 2,32 & 2,25 & 0,07 & {$[-0.02 ; 0.16]$} & 0,107 \\
\hline $\begin{array}{l}\text { E20 - Como a energia pode ser poupada e usada de } \\
\text { forma mais eficaz }\end{array}$ & 2,77 & 2,83 & 2,73 & 0,1 & {$[0.01 ; 0.18]$} & 0,026 \\
\hline $\begin{array}{l}\text { E21 - Novos recursos de energia - sol, vento, } \\
\text { marés, ondas, etc. }\end{array}$ & 2,77 & 2,88 & 2,69 & 0,19 & {$[0.1 ; 0.27]$} & 0,01 \\
\hline $\begin{array}{l}\text { E22 - Como são produzidos, conservados e } \\
\text { armazenados os diferentes tipos de alimentos }\end{array}$ & 2,50 & 2,48 & 2,52 & $-0,04$ & {$[-0.13 ; 0.05]$} & 0,382 \\
\hline E23 - Como o meu corpo cresce e se desenvolve & 3,04 & 2,86 & 3,17 & $-0,31$ & {$[-0.39 ;-0.22]$} & 0,01 \\
\hline E24 - Os animais da minha região & 2,47 & 2,55 & 2,41 & 0,14 & {$[0.05 ; 0.23]$} & 0,002 \\
\hline E25 - As plantas da minha região & 2,29 & 2,35 & 2,24 & 0,11 & {$[0.03 ; 0.2]$} & 0,008 \\
\hline E26 - Os detergentes e sabões e como funcionam & 2,07 & 2,10 & 2,05 & 0,05 & {$[-0.04 ; 0.14]$} & 0,319 \\
\hline
\end{tabular}


CONCLUSÃO - Tabela Apêndice A - Resultados obtidos junto às seções ACE: médias e testes

Mann-Whitney para diferenças em relação ao gênero dos estudantes.

\begin{tabular}{|c|c|c|c|c|c|c|}
\hline \multirow[b]{2}{*}{ Questões ACE: “O que quero aprender?” } & \multirow{2}{*}{$\begin{array}{l}\text { Média } \\
\text { Geral }\end{array}$} & \multicolumn{2}{|c|}{ Média } & \multirow{2}{*}{$\begin{array}{c}\text { Diferença } \\
\text { (H-M) }\end{array}$} & \multirow[b]{2}{*}{ IC 95 (Dif) } & \multirow{2}{*}{$\begin{array}{c}\mathbf{P}- \\
\text { valor }\end{array}$} \\
\hline & & Homem & Mulher & & & \\
\hline E27 - Eletricidade, sua produção e uso doméstico & 2,50 & 2,62 & 2,41 & 0,21 & {$[0.12 ; 0.3]$} & 0,01 \\
\hline $\begin{array}{l}\text { E28 - Como utilizar e consertar equipamentos } \\
\text { elétricos e mecânicos }\end{array}$ & 2,42 & 2,86 & 2,09 & 0,77 & {$[0.67 ; 0.86]$} & 0,01 \\
\hline $\begin{array}{l}\text { E29 - A primeira viagem para a lua e a história da } \\
\text { exploração do espaço }\end{array}$ & 2,51 & 2,56 & 2,47 & 0,09 & {$[0 ; 0.19]$} & 0,051 \\
\hline $\begin{array}{l}\text { E30 - Como a eletricidade influenciou o } \\
\text { desenvolvimento da nossa sociedade }\end{array}$ & 2,53 & 2,67 & 2,42 & 0,25 & {$[0.17 ; 0.34]$} & 0,01 \\
\hline E31 - Os aspectos biológicos e humanos do aborto & 2,79 & 2,44 & 3,05 & $-0,61$ & {$[-0.69 ;-0.52]$} & 0,01 \\
\hline $\begin{array}{l}\text { E32 - Como a tecnologia genética pode evitar } \\
\text { doenças }\end{array}$ & 2,92 & 2,74 & 3,05 & $-0,31$ & {$[-0.4 ;-0.22]$} & 0,01 \\
\hline $\begin{array}{l}\text { E33 - Os benefícios e os possíveis perigos dos } \\
\text { métodos modernos da agricultura }\end{array}$ & 2,26 & 2,33 & 2,2 & 0,13 & {$[0.04 ; 0.22]$} & 0,005 \\
\hline $\begin{array}{l}\text { E34 - Porque é que a religião e a ciência às vezes } \\
\text { entram em conflito }\end{array}$ & 2,77 & 2,66 & 2,85 & $-0,19$ & {$[-0.28 ;-0.1]$} & 0,01 \\
\hline $\begin{array}{l}\text { E35 - Os riscos e os benefícios dos aditivos } \\
\text { alimentares }\end{array}$ & 2,47 & 2,45 & 2,50 & $-0,05$ & {$[-0.14 ; 0.04]$} & 0,256 \\
\hline $\begin{array}{l}\text { E36 - Porque é que os cientistas às vezes } \\
\text { discordam entre si }\end{array}$ & 2,43 & 2,43 & 2,43 & 0 & {$[-0.09 ; 0.09]$} & 0,977 \\
\hline E37 - Cientistas famosos e as suas vidas & 2,04 & 2,07 & 2,01 & 0,06 & {$[-0.03 ; 0.15]$} & 0,208 \\
\hline E38 - Erros e fracassos em pesquisas e invenções & 2,35 & 2,40 & 2,31 & 0,09 & {$[0 ; 0.19]$} & 0,035 \\
\hline $\begin{array}{l}\text { E39 - Como as novas idéias científicas às vezes } \\
\text { desafiam a religião, a autoridade e a tradição }\end{array}$ & 2,45 & 2,39 & 2,5 & $-0,11$ & {$[-0.2 ;-0.01]$} & 0,037 \\
\hline $\begin{array}{l}\text { E40 - Invenções e descobrimentos que } \\
\text { transformaram o mundo }\end{array}$ & 2,83 & 2,87 & 2,81 & 0,06 & {$[-0.03 ; 0.15]$} & 0,204 \\
\hline $\begin{array}{l}\text { E41 - Invenções e descobrimentos recentes da } \\
\text { ciência e da tecnologia }\end{array}$ & 2,74 & 2,82 & 2,68 & 0,14 & {$[0.05 ; 0.23]$} & 0,001 \\
\hline $\begin{array}{l}\text { E42 - Fenômenos que os cientistas ainda não } \\
\text { conseguem explicar }\end{array}$ & 2,95 & 2,99 & 2,93 & 0,06 & {$[-0.03 ; 0.15]$} & 0,192 \\
\hline
\end{tabular}




\section{APÊNDICE B - Resultados obtidos junto à seção B "Meu futuro emprego".}

Tabela Apêndice B - Resultados obtidos junto à seção B: médias e testes Mann-Whitney para diferenças em relação ao gênero dos estudantes.

\begin{tabular}{|c|c|c|c|c|c|c|}
\hline \multirow{2}{*}{ Questões seção B: "Meu futuro emprego" } & \multirow{2}{*}{$\begin{array}{l}\text { Média } \\
\text { Geral }\end{array}$} & \multicolumn{2}{|c|}{ Média } & \multirow{2}{*}{$\begin{array}{l}\text { Diferença } \\
(\mathbf{H}-\mathbf{M})\end{array}$} & \multirow{2}{*}{ IC 95 (Dif) } & \multirow{2}{*}{$\begin{array}{c}\text { P- } \\
\text { valor }\end{array}$} \\
\hline & & Homem & Mulher & & & \\
\hline B01 - Trabalhar com pessoas e não com objetos & 2,77 & 2,61 & 2,9 & $-0,29$ & {$[-0.37 ;-0.2]$} & 0,010 \\
\hline B02 - Ajudar outras pessoas & 3,29 & 3,1 & 3,44 & $-0,34$ & {$[-0.42 ;-0.27]$} & 0,010 \\
\hline B03 - Trabalhar com animais & 2,24 & 2,21 & 2,26 & $-0,05$ & {$[-0.14 ; 0.05]$} & 0,304 \\
\hline B04 - Trabalhar para a proteção do ambiente & 2,74 & 2,69 & 2,77 & $-0,08$ & {$[-0.18 ; 0]$} & 0,070 \\
\hline $\begin{array}{l}\text { B05 - Trabalhar com algo fácil e não } \\
\text { complicado }\end{array}$ & 2,49 & 2,59 & 2,41 & 0,18 & {$[0.09 ; 0.28]$} & 0,010 \\
\hline $\begin{array}{l}\text { B06 - Construir ou consertar coisas com as } \\
\text { mãos }\end{array}$ & 2,16 & 2,51 & 1,9 & 0,61 & {$[0.52 ; 0.7]$} & 0,010 \\
\hline B07 - Trabalhar com máquinas ou ferramentas & 2,19 & 2,57 & 1,91 & 0,66 & {$[0.57 ; 0.75]$} & 0,010 \\
\hline B08 - Trabalho criativo e artístico & 2,55 & 2,46 & 2,62 & $-0,16$ & {$[-0.25 ;-0.06]$} & 0,001 \\
\hline B09 - Usar os meus talentos e capacidades & 3,35 & 3,29 & 3,39 & $-0,1$ & {$[-0.18 ;-0.02]$} & 0,003 \\
\hline B10 - Construir, desenhar ou inventar algo & 2,66 & 2,81 & 2,55 & 0,26 & {$[0.17 ; 0.36]$} & 0,01 \\
\hline B11 - Criar novas idéias & 3,04 & 3,01 & 3,06 & $-0,05$ & {$[-0.13 ; 0.04]$} & 0,082 \\
\hline B12 - Ter muito tempo para os meus amigos & 2,89 & 2,85 & 2,93 & $-0,08$ & {$[-0.17 ;-0.01]$} & 0,047 \\
\hline B13 - Tomar as minhas próprias decisões & 3,43 & 3,29 & 3,52 & $-0,23$ & {$[-0.3 ;-0.16]$} & 0,01 \\
\hline B14 - Trabalho independente de outras pessoas & 2,83 & 2,77 & 2,87 & $-0,1$ & {$[-0.19 ;-0.01]$} & 0,016 \\
\hline $\begin{array}{l}\text { B15 - Trabalhar com algo que considero } \\
\text { importante e significativo }\end{array}$ & 3,61 & 3,48 & 3,71 & $-0,23$ & {$[-0.3 ;-0.17]$} & 0,01 \\
\hline $\begin{array}{l}\text { B16 - Trabalhar com algo que coincida com os } \\
\text { meus valores }\end{array}$ & 3,4 & 3,25 & 3,51 & $-0,26$ & {$[-0.33 ;-0.19]$} & 0,01 \\
\hline B17 - Ter muito tempo para a minha família & 3,36 & 3,35 & 3,36 & $-0,01$ & {$[-0.08 ; 0.06]$} & 0,835 \\
\hline $\begin{array}{l}\text { B18 - Trabalhar em algo que implique viajar } \\
\text { muito }\end{array}$ & 2,63 & 2,63 & 2,63 & 0 & {$[-0.09 ; 0.09]$} & 0,937 \\
\hline $\begin{array}{l}\text { B19 - Trabalhar num local onde } \\
\text { freqüentemente acontecem coisas novas e } \\
\text { emocionantes }\end{array}$ & 3,16 & 3,03 & 3,26 & $-0,23$ & {$[-0.31 ;-0.14]$} & 0,01 \\
\hline B20 - Ganhar muito dinheiro & 3,5 & 3,51 & 3,49 & 0,02 & {$[-0.05 ; 0.08]$} & 0,491 \\
\hline B21 - Controlar outras pessoas & 2,21 & 2,38 & 2,07 & 0,31 & {$[0.22 ; 0.4]$} & 0,01 \\
\hline B22 - Tornar-me famoso & 2,51 & 2,65 & 2,41 & 0,24 & {$[0.14 ; 0.33]$} & 0,01 \\
\hline $\begin{array}{l}\text { B23 - Ter muito tempo para os meus interesses, } \\
\text { hobbies e atividades de lazer }\end{array}$ & 3,02 & 3,04 & 3,01 & 0,03 & {$[-0.05 ; 0.11]$} & 0,503 \\
\hline $\begin{array}{l}\text { B24 - Assumir posição de chefia no meu local } \\
\text { de trabalho }\end{array}$ & 3,2 & 3,18 & 3,22 & $-0,04$ & {$[-0.12 ; 0.04]$} & 0,372 \\
\hline $\begin{array}{l}\text { B25 - Desenvolver ou expandir os meus } \\
\text { conhecimentos e capacidades }\end{array}$ & 3,54 & 3,45 & 3,61 & $-0,16$ & {$[-0.22 ;-0.1]$} & 0,01 \\
\hline B26 - Trabalhar em equipe, com muitas pessoas & 3,24 & 3,18 & 3,27 & $-0,09$ & {$[-0.17 ;-0.01]$} & 0,034 \\
\hline
\end{tabular}




\section{APÊNDICE C - Resultados obtidos junto à seção $H$ "As minhas experiências fora da escola".}

Tabela Apêndice C1 - Resultados obtidos junto à seção H: médias e testes Mann-Whitney para diferenças em relação ao gênero dos estudantes.

\begin{tabular}{|c|c|c|c|c|c|c|}
\hline \multirow{2}{*}{$\begin{array}{c}\text { Questões da seção "As minhas experiências fora } \\
\text { da escola" }\end{array}$} & \multirow{2}{*}{$\begin{array}{l}\text { Média } \\
\text { Geral }\end{array}$} & \multicolumn{2}{|c|}{ Média } & \multirow{2}{*}{$\begin{array}{l}\text { Diferença } \\
\text { (H-M) }\end{array}$} & \multirow{2}{*}{ IC 95 (Dif) } & \multirow{2}{*}{$\begin{array}{c}\text { P- } \\
\text { valor }\end{array}$} \\
\hline & & Homem & Mulher & & & \\
\hline H01 - tentei encontrar as constelações no céu & 2,12 & 2,09 & 2,14 & $-0,05$ & {$[-0.15 ; 0.05]$} & 0,544 \\
\hline $\begin{array}{l}\text { H02 - li o meu horóscopo (prever o futuro através } \\
\text { dos astros) }\end{array}$ & 2,65 & 2,13 & 3,02 & $-0,89$ & {$[-0.98 ;-0.79]$} & 0,010 \\
\hline H03 - utilizei um mapa para me orientar & 2,18 & 2,25 & 2,13 & 0,12 & {$[0.03 ; 0.22]$} & 0,010 \\
\hline $\begin{array}{l}\text { H04 - utilizei uma bússola para determinar a } \\
\text { direção }\end{array}$ & 1,67 & 1,87 & 1,53 & 0,34 & {$[0.26 ; 0.43]$} & 0,010 \\
\hline H05 - fiz coleção de pedras ou conchas diferentes & 2,09 & 1,96 & 2,19 & $-0,23$ & {$[-0.34 ;-0.14]$} & 0,010 \\
\hline H06 - vi um animal nascer (sem ser na televisão) & 2,43 & 2,47 & 2,39 & 0,08 & {$[-0.03 ; 0.18]$} & 0,136 \\
\hline H07 - cuidei de animais numa fazenda ou sítio & 2,25 & 2,27 & 2,24 & 0,03 & {$[-0.07 ; 0.14]$} & 0,391 \\
\hline H08 - visitei um jardim zoológico & 2,37 & 2,37 & 2,37 & 0 & {$[-0.09 ; 0.11]$} & 0,731 \\
\hline $\begin{array}{l}\text { H09 - visitei um centro de ciências ou um museu } \\
\text { de ciências }\end{array}$ & 1,96 & 1,96 & 1,96 & 0 & {$[-0.1 ; 0.09]$} & 0,576 \\
\hline $\begin{array}{l}\text { H10 - ordenhei animais como vacas, ovelhas ou } \\
\text { cabras }\end{array}$ & 1,78 & 1,93 & 1,67 & 0,26 & {$[0.16 ; 0.35]$} & 0,010 \\
\hline $\begin{array}{l}\text { H11 - fiz produtos com leite, como iogurtes, } \\
\text { manteiga, queijos }\end{array}$ & 1,73 & 1,71 & 1,75 & $-0,04$ & {$[-0.13 ; 0.05]$} & 0,622 \\
\hline $\begin{array}{l}\text { H12 - li coisas sobre a natureza ou as ciências em } \\
\text { livros ou revistas }\end{array}$ & 2,95 & 2,79 & 3,07 & $-0,28$ & {$[-0.37 ;-0.19]$} & 0,010 \\
\hline $\begin{array}{l}\text { H13 - vi documentários sobre a natureza na } \\
\text { televisão ou no cinema }\end{array}$ & 3,04 & 2,91 & 3,13 & $-0,22$ & {$[-0.3 ;-0.13]$} & 0,010 \\
\hline H14 - apanhei frutas ou plantas comestíveis & 3,19 & 3,06 & 3,28 & $-0,22$ & {$[-0.31 ;-0.13]$} & 0,010 \\
\hline H15 - fui caçar & 1,76 & 2,18 & 1,45 & 0,73 & {$[0.64 ; 0.82]$} & 0,010 \\
\hline H16 - fui pescar & 2,66 & 2,88 & 2,51 & 0,37 & {$[0.27 ; 0.47]$} & 0,010 \\
\hline H17 - plantei sementes e as vi crescer & 2,63 & 2,62 & 2,64 & $-0,02$ & {$[-0.12 ; 0.08]$} & 0,663 \\
\hline $\begin{array}{l}\text { H18 - fiz composto orgânico (adubo) com folhas } \\
\text { ou lixo }\end{array}$ & 1,85 & 1,98 & 1,75 & 0,23 & {$[0.14 ; 0.32]$} & 0,010 \\
\hline $\begin{array}{l}\text { H19 - fiz um instrumento (como por exemplo uma } \\
\text { flauta ou bateria) de materiais naturais }\end{array}$ & 1,59 & 1,77 & 1,46 & 0,31 & {$[0.23 ; 0.4]$} & 0,010 \\
\hline $\begin{array}{l}\text { H20 - fiz crochê, tricô ou tapeçaria (tapetes, } \\
\text { pulseiras, bolsas), etc. }\end{array}$ & 2,03 & 1,56 & 2,37 & $-0,81$ & {$[-0.9 ;-0.73]$} & 0,010 \\
\hline H21 - montei uma barraca (acampamento) & 2,14 & 2,24 & 2,07 & 0,17 & {$[0.07 ; 0.27]$} & 0,010 \\
\hline H22 - fiz uma fogueira com carvão ou lenha & 2,63 & 2,8 & 2,51 & 0,29 & {$[0.19 ; 0.39]$} & 0,010 \\
\hline $\begin{array}{l}\text { H23 - preparei comida numa fogueira ou fogareiro } \\
\text { a gás }\end{array}$ & 2,55 & 2,55 & 2,56 & $-0,01$ & {$[-0.12 ; 0.09]$} & 0,789 \\
\hline H24 - separei lixo para reciclagem & 2,36 & 2,3 & 2,41 & $-0,11$ & {$[-0.2 ;-0.02]$} & 0,023 \\
\hline H25 - limpei e cuidei de uma ferida, machucado & 3,15 & 3,04 & 3,22 & $-0,18$ & {$[-0.27 ;-0.1]$} & 0,010 \\
\hline $\begin{array}{l}\text { H26 - vi uma radiografia de uma parte do meu } \\
\text { corpo }\end{array}$ & 2,63 & 2,6 & 2,66 & $-0,06$ & {$[-0.16 ; 0.04]$} & 0,219 \\
\hline $\begin{array}{l}\text { H27 - tomei remédios para evitar ou tratar uma } \\
\text { infecção ou outra doença }\end{array}$ & 3,11 & 3 & 3,2 & $-0,2$ & {$[-0.29 ;-0.11]$} & 0,01 \\
\hline $\begin{array}{l}\mathrm{H} 28 \text { - tomei ervas medicinais ou fiz tratamentos } \\
\text { alternativos (acupuntura, homeopatia, ioga, etc.) }\end{array}$ & 1,98 & 2,03 & 1,95 & 0,08 & {$[-0.01 ; 0.18]$} & 0,047 \\
\hline H29 - fui a um hospital como paciente & 3,24 & 3,1 & 3,34 & $-0,24$ & {$[-0.32 ;-0.16]$} & 0,01 \\
\hline H30 - utilizei binóculos & 2,46 & 2,6 & 2,36 & 0,24 & {$[0.15 ; 0.34]$} & 0,01 \\
\hline
\end{tabular}

CONTINUA 
CONCLUSÃO Tabela Apêndice C1 - Resultados obtidos junto à seção H: médias e testes

Mann-Whitney para diferenças em relação ao gênero dos estudantes.

\begin{tabular}{|c|c|c|c|c|c|c|}
\hline \multirow{2}{*}{$\begin{array}{c}\text { Questões da seção "As minhas experiências fora } \\
\text { da escola" }\end{array}$} & \multirow{2}{*}{$\begin{array}{l}\text { Média } \\
\text { Geral }\end{array}$} & \multicolumn{2}{|c|}{ Média } & \multirow{2}{*}{$\begin{array}{l}\text { Diferença } \\
\text { (H-M) }\end{array}$} & \multirow{2}{*}{ IC 95 (Dif) } & \multirow{2}{*}{$\begin{array}{c}\text { P- } \\
\text { valor }\end{array}$} \\
\hline & & Homem & Mulher & & & \\
\hline H31 - utilizei uma máquina fotográfica & 3,57 & 3,37 & 3,71 & $-0,34$ & {$[-0.41 ;-0.27]$} & 0,01 \\
\hline H32 - fiz um arco e flechas, bumerangue, etc. & 1,89 & 2,24 & 1,65 & 0,59 & {$[0.5 ; 0.68]$} & 0,01 \\
\hline $\begin{array}{l}\text { H33 - utilizei uma pistola/espingarda de ar } \\
\text { comprimido }\end{array}$ & 1,8 & 2,24 & 1,47 & 0,77 & {$[0.68 ; 0.86]$} & 0,01 \\
\hline H34 - utilizei uma bomba de água ou sifão & 1,74 & 2,01 & 1,54 & 0,47 & {$[0.38 ; 0.56]$} & 0,01 \\
\hline $\begin{array}{l}\text { H35 - montei uma miniatura (modelo) de avião, } \\
\text { carro ou barco, etc. }\end{array}$ & 1,92 & 2,14 & 1,76 & 0,38 & {$[0.29 ; 0.47]$} & 0,01 \\
\hline $\begin{array}{l}\text { H36 - utilizei um kit de ciências (química, óptica, } \\
\text { eletricidade, etc.) }\end{array}$ & 1,58 & 1,72 & 1,48 & 0,24 & {$[0.16 ; 0.32]$} & 0,01 \\
\hline $\begin{array}{l}\text { H37 - utilizei um moinho de vento, uma roda de } \\
\text { água }\end{array}$ & 1,56 & 1,71 & 1,45 & 0,26 & {$[0.18 ; 0.34]$} & 0,01 \\
\hline H38 - gravei um vídeo, DVD, CD ou fita cassete & 2,85 & 2,86 & 2,85 & 0,01 & {$[-0.09 ; 0.11]$} & 0,872 \\
\hline H39 - troquei lâmpadas ou fusíveis & 2,62 & 3,01 & 2,34 & 0,67 & {$[0.58 ; 0.77]$} & 0,01 \\
\hline H40 - liguei um aparelho elétrico a uma tomada & 3,62 & 3,55 & 3,68 & $-0,13$ & {$[-0.21 ;-0.07]$} & 0,01 \\
\hline H41 - utilizei um cronômetro & 3,09 & 3,25 & 2,98 & 0,27 & {$[0.18 ; 0.36]$} & 0,01 \\
\hline H42 - medi a temperatura com um termômetro & 2,93 & 2,83 & 2,99 & $-0,16$ & {$[-0.26 ;-0.07]$} & 0,01 \\
\hline $\begin{array}{l}\text { H43 - utilizei uma régua, uma fita métrica, trena, } \\
\text { etc. }\end{array}$ & 3,47 & 3,39 & 3,52 & $-0,13$ & {$[-0.2 ;-0.05]$} & 0,01 \\
\hline H44 - utilizei um telefone celular & 3,71 & 3,59 & 3,81 & $-0,22$ & {$[-0.29 ;-0.16]$} & 0,01 \\
\hline $\begin{array}{l}\text { H45 - enviei ou recebi uma mensagem SMS } \\
\text { (mensagem de texto do celular) }\end{array}$ & 3,63 & 3,46 & 3,76 & $-0,3$ & {$[-0.37 ;-0.23]$} & 0,01 \\
\hline H46 - procurei informações na Internet & 3,66 & 3,51 & 3,77 & $-0,26$ & {$[-0.32 ;-0.19]$} & 0,01 \\
\hline H47 - joguei jogos de computador & 3,5 & 3,49 & 3,51 & $-0,02$ & {$[-0.1 ; 0.05]$} & 0,581 \\
\hline $\begin{array}{l}\text { H48 - utilizei um dicionário, enciclopédia, etc. no } \\
\text { computador }\end{array}$ & 3,3 & 3,16 & 3,4 & $-0,24$ & {$[-0.33 ;-0.15]$} & 0,01 \\
\hline H49 - gravei música da Internet & 3,16 & 3,12 & 3,18 & $-0,06$ & {$[-0.15 ; 0.04]$} & 0,03 \\
\hline H50 - enviei ou recebi e-mail & 3,36 & 3,27 & 3,43 & $-0,16$ & {$[-0.25 ;-0.08]$} & 0,01 \\
\hline $\begin{array}{l}\text { H51 - utilizei um processador de texto no } \\
\text { computador (Word, etc.) }\end{array}$ & 3,27 & 3,21 & 3,32 & $-0,11$ & {$[-0.2 ;-0.02]$} & 0,004 \\
\hline $\begin{array}{l}\text { H52 - desmontei um aparelho (rádio, relógio, } \\
\text { computador, telefone, etc.) para ver como funciona }\end{array}$ & 2,67 & 2,98 & 2,44 & 0,54 & {$[0.44 ; 0.64]$} & 0,01 \\
\hline H53 - fiz pão, massa ou bolos & 2,84 & 2,38 & 3,17 & $-0,79$ & {$[-0.89 ;-0.7]$} & 0,01 \\
\hline H54 - cozinhei uma refeição & 3,21 & 2,85 & 3,46 & $-0,61$ & {$[-0.7 ;-0.52]$} & 0,01 \\
\hline $\begin{array}{l}\text { H55 - caminhei ao mesmo tempo em que } \\
\text { equilibrava um objeto na cabeça }\end{array}$ & 2,28 & 2,15 & 2,37 & $-0,22$ & {$[-0.32 ;-0.12]$} & 0,01 \\
\hline $\begin{array}{l}\text { H56 - utilizei um carrinho de mão (daqueles de } \\
\text { pedreiro) }\end{array}$ & 2,66 & 2,89 & 2,5 & 0,39 & {$[0.29 ; 0.48]$} & 0,01 \\
\hline $\begin{array}{l}\text { H57 - utilizei um pé-de-cabra (alavanca para abrir } \\
\text { portas/caixas, por exemplo) }\end{array}$ & 1,82 & 2,16 & 1,56 & 0,6 & {$[0.51 ; 0.69]$} & 0,01 \\
\hline $\begin{array}{l}\text { H58 - utilizei corda e roldana para levantar coisas } \\
\text { pesadas }\end{array}$ & 2,01 & 2,44 & 1,71 & 0,73 & {$[0.64 ; 0.83]$} & 0,01 \\
\hline H59 - consertei um pneu de bicicleta & 1,96 & 2,49 & 1,58 & 0,91 & {$[0.82 ; 1.01]$} & 0,01 \\
\hline $\begin{array}{l}\text { H60 - utilizei ferramentas como serrote, chave de } \\
\text { fenda ou martelo }\end{array}$ & 2,89 & 3,15 & 2,7 & 0,45 & {$[0.35 ; 0.54]$} & 0,01 \\
\hline H61 - recarreguei uma bateria de carro & 1,6 & 1,95 & 1,34 & 0,61 & {$[0.52 ; 0.7]$} & 0,01 \\
\hline
\end{tabular}


Tabela Apêndice C2 - Médias e testes de Mann-Whitney para diferença em relação ao gênero dos estudantes para as categorias do grupo de questões $\mathrm{H}$ (elaboradas pela autora).

\begin{tabular}{|c|c|c|c|c|c|c|}
\hline \multirow{2}{*}{ Categorias para as questões da Seção H } & \multirow{2}{*}{ Média } & \multicolumn{2}{|c|}{ Média } & \multirow{2}{*}{$\begin{array}{c}\text { Diferen } \\
\text { ça } \\
\text { (H-M) }\end{array}$} & \multirow{2}{*}{$\begin{array}{c}\text { IC 95\% } \\
\text { (Diferença) }\end{array}$} & \multirow{2}{*}{$\begin{array}{c}\text { P- } \\
\text { valor }\end{array}$} \\
\hline & & Homens & Mulheres & & & \\
\hline $\begin{array}{l}\text { Tive contato físico com a natureza e os } \\
\text { animais }\end{array}$ & 2,33 & 2,39 & 2,29 & 0,1 & {$[0.05 ; 0.15]$} & 0 \\
\hline $\begin{array}{l}\text { Utilizei ferramentas e/ou objetos (objetos } \\
\text { de medição, localização, etc.) }\end{array}$ & 2,37 & 2,53 & 2,24 & 0,29 & {$[0.24 ; 0.34]$} & 0 \\
\hline $\begin{array}{l}\text { Tive contato com tecnologia de informação } \\
\text { (computadores) e comunicação ( Internet e } \\
\text { celulares) }\end{array}$ & 3,47 & 3,37 & 3,54 & $-0,17$ & {$[-0.23 ;-0.11]$} & 0 \\
\hline Fiz materiais, produtos, comidas. & 2,12 & 2,06 & 2,17 & $-0,1$ & {$[-0.16 ;-0.05]$} & 0 \\
\hline $\begin{array}{l}\text { Participei ativamente de atividades em } \\
\text { acampamentos }\end{array}$ & 2,40 & 2,43 & 2,38 & 0,05 & {$[-0.02 ; 0.12]$} & 0,158 \\
\hline $\begin{array}{l}\text { Busquei conhecimentos sobre a natureza } \\
\text { através de leituras, TV e centros de } \\
\text { ciências }\end{array}$ & 2,65 & 2,55 & 2,72 & $-0,17$ & {$[-0.23 ;-0.11]$} & 0 \\
\hline Cuidados com saúde & 2,83 & 2,76 & 2,88 & $-0,12$ & {$[-0.18 ;-0.06]$} & 0 \\
\hline Fiz tarefas, reparos e consertos domésticos & 2,53 & 2,74 & 2,38 & 0,36 & {$[0.31 ; 0.41]$} & 0 \\
\hline Li meu horóscopo & 2,65 & 2,13 & 3,02 & $-0,89$ & {$[-0.98 ;-0.79]$} & 0 \\
\hline
\end{tabular}




\title{
APÊNDICE D - Carta de instruções para as escolas participantes do projeto ROSE.
}

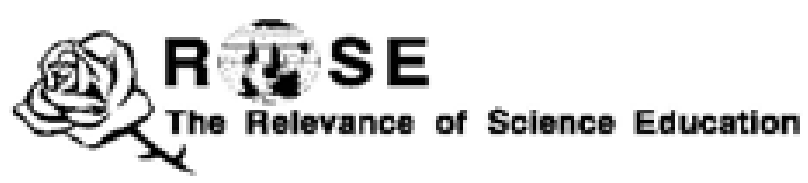

A relevância da educação de ciências

\section{INSTRUÇÕES PARA OS PARTICIPANTES DO PROJETO ROSE BRASIL}

\author{
Caro(a) aplicador(a),
}

O projeto "A relevância da educação de ciências" (ROSE) tem como objetivo averiguar o interesse que estudantes de cerca de 15 anos têm pela ciência, suas aulas de ciências e sua futura profissão. Ele não avalia o conhecimento (proficiência) que o aluno tem sobre temas das ciências, por isso, qualquer aluno, independentemente de seu desempenho escolar, pode participar do projeto.

Não há respostas certas ou erradas no questionário ROSE. As respostas revelam apenas o grau de interesse que os jovens têm pela ciência e suas aulas de ciências, numa escala de 1 a 4.

O questionário está organizado em 13 seções:

- Seções A, C e E: "O que eu quero aprender". Essas seções compreendem 108 tópicos nas quais o aluno é convidado a expressar suas respostas como "Desinteressado" (opção 1) a "Muito Interessado" (opção 4), com dois níveis intermediários (opções 2 e 3).

- Seção B: "O meu futuro emprego". Essa seção possui 26 itens na qual o aluno deve expressar suas respostas como "Nada importante" (opção 1) a "Muito importante" (opção 4), com dois níveis intermediários (opções 2 e 3).

- Seção D: "Eu e os desafios ambientais". Seção composta por 18 itens na qual o aluno deve responder de "Não concordo" (opção 1) a "Concordo" (opção 4), com dois níveis intermediários (opções 2 e 3).

- Seção F: "As minhas aulas de ciências". Seção composta por 16 itens na qual o aluno deve responder de "Não concordo" (opção 1) a "Concordo" (opção 4), com dois níveis intermediários (opções 2 e 3).

- Seção G: "As minhas opiniões sobre a ciência e a tecnologia". Seção composta por 16 itens na qual o aluno deve responder "Não concordo" (opção 1) a "Concordo" (opção 4), com dois níveis intermediários (opções 2 e 3 ). 
- Seção H: "As minhas experiências fora da escola". Seção constituída por 61 itens na qual o aluno é convidado a responder quantas vezes vivenciou determinadas circunstâncias, assinalando uma escala entre "Nunca" (opção 1) e "Muitas vezes" (opção 4), com dois níveis intermediários (opções 2 e 3 ).

- Seções I, J, L, M e N. Seções que procuram estabelecer relações entre a opção religiosa do aluno e o ensino de evolução. Na seção I o aluno é convidado a responder qual é sua opção religiosa; na seção $J$ sua freqüência a serviços religiosos; nas seções $L$ e $M$ seu nível de aceitação a afirmações sobre religião e evolução; e na Seção $\mathrm{N}$ se ele já estudou determinados assuntos nas aulas de ciências.

As informações acerca da aplicação do questionário e seu retorno seguem abaixo:

\section{SOBRE A TURMA PARTICIPANTE}

\begin{tabular}{|l|l|}
\hline Série de Aplicação & $1^{\circ}$ ano do Ensino Médio \\
\hline Número de turmas & 1 \\
\hline Grupo alvo & Turma com mais alunos com 15 anos de idade \\
\hline Tamanho da turma & 25 (mínimo) a 30 (máximo) alunos \\
\hline Distribuição de gênero & Se possível, número equivalente de meninos e meninas. \\
\hline
\end{tabular}

SOBRE O PERÍODO DE APLICAÇÃO

\begin{tabular}{|l|l|}
\hline Data & $\begin{array}{l}\text { Pedimos a gentileza de aplicar o questionário do mês de junho } \\
\text { de 2011. }\end{array}$ \\
\hline
\end{tabular}

SOBRE O PREENCHIMENTO DO QUESTIONÁRIO

\begin{tabular}{|l|l|}
\hline $\begin{array}{l}\text { Instrumento } \\
\text { preenchimento }\end{array}$ & $\begin{array}{l}\text { Caneta azul ou preta } \\
\text { aluno. Não deve ser colocado x ou qualquer outro tipo de } \\
\text { marcação. }\end{array}$ \\
\hline $\begin{array}{l}\text { Instruções da 1ª página } \\
\text { Certo }\end{array}$ \\
$\begin{array}{l}\text { Tempálidas } \\
\text { (não preencher assim) } \\
\text { questionário }\end{array}$
\end{tabular}

\section{TERMO DE LIVRE CONSENTIMENTO}

\begin{tabular}{|l|l|}
\hline O que é & $\begin{array}{l}\text { É um termo que deve ser datado e assinado pelo diretor(a) } \\
\text { escolar, no qual ele(a) autoriza a realização da pesquisa. Deve } \\
\text { ser devolvido com os questionários preenchidos. }\end{array}$ \\
\hline
\end{tabular}


SOBRE A EQUIPE ESCOLAR QUE PARTICIPOU DA PESQUISA

\begin{tabular}{|l|l|}
\hline $\begin{array}{l}\text { Diretor(a), professores } \\
\text { e/ou funcionários }\end{array}$ & $\begin{array}{l}\text { Todos aqueles da equipe escolar que participaram da aplicação } \\
\text { do projeto ROSE em sua instituição e que queiram receber uma } \\
\text { declaração de participação devem enviar seus dados, listados } \\
\text { nas instruções acerca da devolução dos questionários. }\end{array}$ \\
\hline $\begin{array}{l}\text { Declaração de } \\
\text { participação }\end{array}$ & $\begin{array}{l}\text { Todas as escolas que enviarem os questionários preenchidos } \\
\text { pelos alunos à equipe do Projeto ROSE, e que desejarem, } \\
\text { receberão uma declaração de participação da Faculdade de } \\
\text { Educação da Universidade de São Paulo. }\end{array}$ \\
\hline
\end{tabular}

SOBRE A DEVOLUÇÃO DOS QUESTIONÁRIOS

\begin{tabular}{|c|c|}
\hline Meio & $\begin{array}{l}\text { Dentro do envelope enviado à escola há } 4 \text { envelopes vazios, } \\
\text { devidamente etiquetados e selados, onde devem ser } \\
\text { colocados: } \\
\text { 1) Os questionários preenchidos: } \\
\text { 2) O termo de livre consentimento assinado pelo diretor(a) } \\
\text { da escola } \\
\text { 3) Nome, RG, cargo ocupado na escola e função junto ao } \\
\text { projeto ROSE da equipe participante que queira receber o } \\
\text { atestado de participação. } \\
\text { Pedimos a gentileza de colocar os envelopes no correio, de } \\
\text { forma que cada um contenha no máximo } 9 \text { questionários. }\end{array}$ \\
\hline Data & $\begin{array}{l}\text { Pedimos a gentileza da escola retornar os envelopes até julho } \\
\text { de } 2011 \text {. }\end{array}$ \\
\hline
\end{tabular}




\title{
APÊNDICE E - Carta de apresentação do projeto ROSE enviada às escolas.
}

\author{
São Paulo, _ de ___ de 201_. \\ IImo(a). Sr(a). \\ Diretor(a) da Escola \\ Prezado(a) Senhor(a),
}

Somos um grupo de pesquisa da Universidade de São Paulo que faz parte de um projeto articulado com diversos países chamado "Relevância da educação de ciências" (ROSE). Estamos convidando sua escola a participar desse projeto, que é sediado na Universidade de Oslo (Noruega) e visa averiguar o interesse de estudantes de 14-15 anos pela ciência, suas aulas de ciências e sua futura profissão.

Até o momento mais de 40 países já participaram do ROSE, que durante o ano de 2010 será implementado no Brasil com o apoio do Conselho Nacional de Desenvolvimento Científico e Tecnológico (CNPq), órgão do Ministério da Ciência e Tecnologia.

Cerca de 120 escolas participantes do projeto PISA em 2009 foram selecionadas para participar do projeto ROSE em 2010. Sua escola é uma delas e poderá representar o estado de São Paulo, mediante sua aprovação.

Diferentemente de outros projetos, não se verifica o desempenho acadêmico dos alunos, ou seja, não há questões sobre o conteúdo de ciências. Não há respostas certas ou erradas e não haverá ranqueamento de escolas em nenhum sentido. Os nomes das escolas selecionadas, bem como as respostas colhidas, permanecerão sob sigilo, e serão divulgados apenas os resultados globais.

Diante de sua permissão, enviaremos através do correio o questionário ROSE, que é composto por uma série de afirmações acerca de diversos temas da ciência, onde o aluno é convidado a assinalar qual é o seu nível de interesse sobre esses temas. Cada escola selecionará uma turma do $1^{\circ}$ ano do Ensino Médio para responder o questionário. As instruções de aplicação estarão dentro do envelope, junto com um telefone para contato em caso de dúvidas.

Caso sua escola decida não participar, pedimos que nos encaminhe um e-mail para o coordenador do projeto o quanto antes. Em todo caso, diante da premência de prazos que enfrentamos, enviaremos 
um envelope por correio para as escolas que não manifestarem objeção. Caso sua escola decida não participar, o envelope poderá ser simplesmente devolvido ao remetente e assim entenderemos sua manifestação.

Temos certeza que a comunidade educacional brasileira se beneficiará com os resultados deste estudo internacional, com dados que nos permitirão entender melhor quais são os reais interesses e aspirações dos estudantes brasileiros e em que medida eles se assemelham aos de outros países.

A participação da equipe da escola será devidamente atestada pela nossa instituição, que procura continuamente estreitar laços de parceria com as escolas dos sistemas de ensino, buscando um aperfeiçoamento mútuo e contínuo.

Desde já agradecemos sua atenção.

Atenciosamente,

Prof. Dr Nelio Bizzo

Coordenador da Equipe ROSE - Brasil

Faculdade de Educação

Universidade de São Paulo

e-mail: bizzo@usp.br tel (011) 3091-3099

e-mail do projeto: projetorose2010@gmail.com 


\section{APÊNDICE F - Termo de Consentimento Livre e Esclarecido enviado para as escolas participantes da pesquisa.}

TERMO DE CONSENTIMENTO LIVRE E ESCLARECIDO

Eu compreendo os direitos dos participantes da pesquisa intitulada "Projeto ROSE - O estudo da relevância do ensino da ciência e tecnologia para os jovens brasileiros", orientada pelo Prof. Dr. Nelio Bizzo, e que tem como pesquisadores Ana Maria Santos Gouw e Helenadja Mota Rios Pereira, da Faculdade de Educação da Universidade de São Paulo, que podem ser contatados pelo e-mail projetorose2010@gmail.com ou pelo telefone 11 3091-3099. E autorizo a participação dos alunos da escola

na qualidade de respon-

sável por esta instituição. Compreendo como e porquê este estudo está sendo feito. Os responsáveis pela pesquisa garantem o sigilo que assegure a privacidade dos sujeitos quanto aos dados envolvidos na pesquisa. Receberei uma cópia assinada deste formulário de consentimento.

Nome:

Cargo: de de 201_.

(município) 